UNIVERSIDAD POLITÉCNICA DE MADRID ESCUELA TÉCNICA SUPERIOR DE INGENIERÍA AGRONÓMICA, ALIMENTARIA Y DE BIOSISTEMAS

\title{
EFECTO DE ARTHROSPIRA PLATENSIS SOBRE EL COMPORTAMIENTO Y FLORA INTESTINAL DE OREOCHROMIS NILOTICUS
}

TESIS DOCTORAL

AUTOR:

IGNACIO PLAZA GORDO

INGENIERO AGRONOMO SUPERIOR 
ESCUELA TÉCNICA SUPERIOR DE INGENIERÍA

AGRONÓMICA, ALIMENTARIA Y DE BIOSISTEMAS
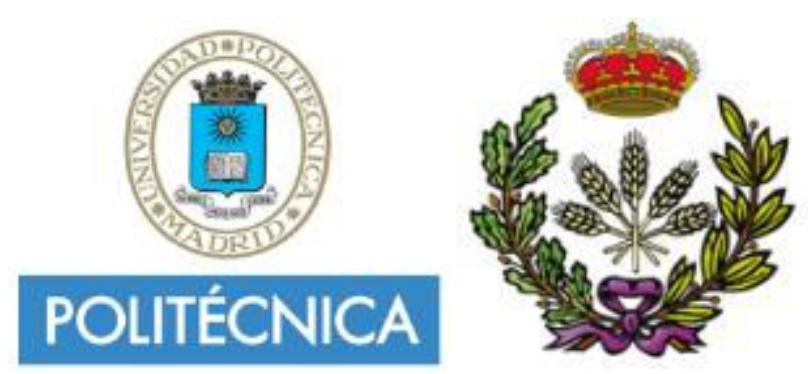

\title{
EFECTO DE ARTHROSPIRA PLATENSIS SOBRE EL COMPORTAMIENTO Y FLORA INTESTINAL DE OREOCHROMIS NILOTICUS
}

\author{
AUTOR: \\ IGNACIO PLAZA GORDO \\ Ingeniero Agrónomo Superior \\ DIRECTORES: \\ MORRIS VILLARROEL ROBINSON \\ Doctor en Biología \\ JOSE LUIS GARCÍA LÓPEZ \\ Doctor en Química y Bioquímica
}

DEPARTAMENTEO DE PRODUCCION AGRARIA 
D. Morris Villarroel, Profesor Titular del Departamento de Producción Agraria de la Escuela Técnica Superior de Ingeniería Agronómica, Alimentaria y de Biosistemas de la Universidad Politécnica de Madrid.

D. José Luis García López, Profesor de Investigación de la Agencia Estatal Consejo Superior de Investigaciones Científicas del Departamento de Biotecnología Microbiana y de Plantas del Centro de Investigaciones Biológicas (CSIC) de Madrid.

Certifican: Que la presente Memoria de Tesis Doctoral titulada: "Efecto de Arthrospira platensis sobre el comportamiento y flora intestinal de Oreochromis niloticus", del que es autor el Ingeniero Agrónomo Superior Ignacio Plaza Gordo, ha sido realizada bajo nuestra dirección conjunta, y cumple las condiciones exigidas para optar al grado de Doctor en el programa Tecnología Agroambiental para una Agricultura Sostenible.

Para que conste, firman los presentes en Madrid, septiembre, 2018.

Fdo.: D. Morris Villarroel

Fdo.: D. José Luis García López 


\section{AGRADECIMIENTOS}




\section{AGRADECIMIENTOS}

En primer lugar, quiero agradecérselo a mis padres y abuelos, mis mecenas, que han trabajado duro para que yo pudiera dedicarme a mis estudios.

A todos aquellos que se preocuparon de mi educación, en especial en estos últimos meses, a mis tutores y amigos, José Luis García, Beatriz Galán y Morris Villarroel.

A la colaboración de la escuela en la E.T.S.I. Montes por prestarme su tiempo y conocimientos También agradecer al doctor y compañero de tesis Rubén Bermejo-Poza, que sin su inestimable ayuda y espíritu no hubiera llegado al final de esta tesis.

A mi novia por aguantarme estos meses sin parar de hablar de algas, peces, sensores y cosas por el estilo, y no sólo por escucharme si no por aportar su granito de arena a este trabajo.

Y a mis hermanos, sin vuestra colaboración esto no hubiera sido posible.

Este trabajo se realizó dentro del proyecto INSPIRA1 (Ref. S2013 / ABI2783) financiado por la Comunidad de Madrid y cofinanciado por Fondos Estructurales de la Unión Europea FEDER 


\section{INDICE}




\section{INDICE GENERAL}

LISTA DE TABLAS ............................................................................................ VIII

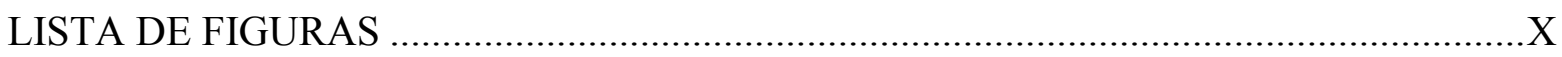

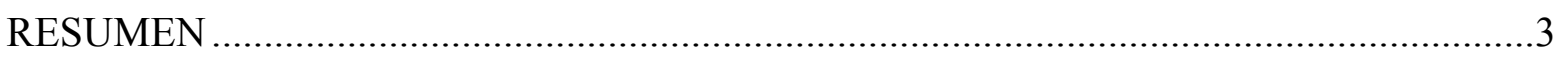

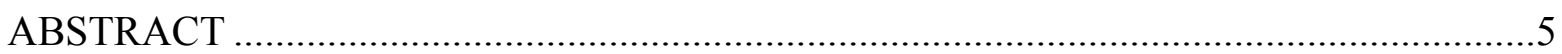

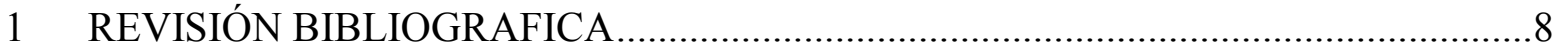

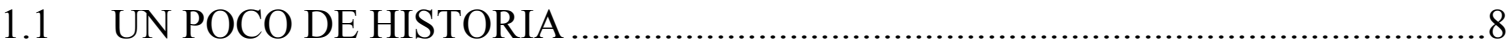

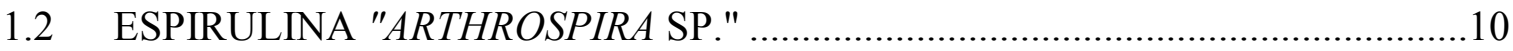

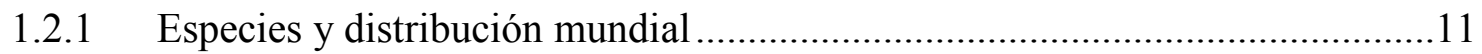

1.2.2 Producción mundial de la Arthrospira sp......................................................11

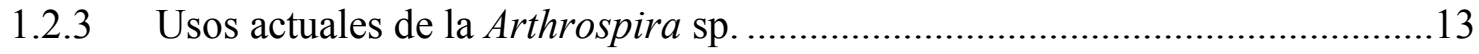

1.2.4 Características nutricionales de la Arthrospira sp.......................................14

1.2.5 Aplicación de Arthrospira sp. en animales ...............................................19

1.3 TILAPIA DEL NILO "OREOCHROMIS NILOTICUS SP." .................................22

1.3.1 Producción mundial de Oreochromis niloticus ...........................................24

1.3.2 Características nutricionales de Oreochromis niloticus ................................25

1.4 EFECTO DE ARTHOSPIRA PLATENIS EN OREOCROMIS NILOTICUS...........28

1.4.1 Supervivencia, crecimiento, y calidad de la carne.......................................28

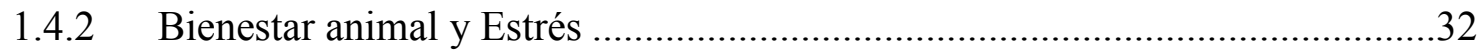

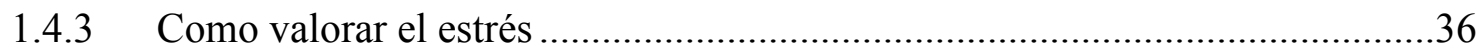

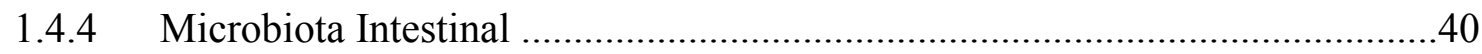

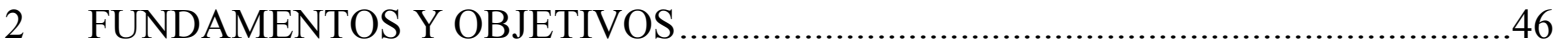

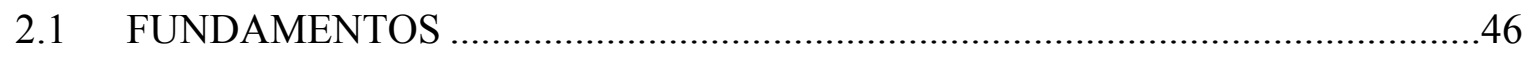

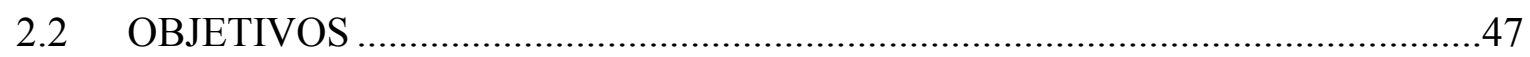

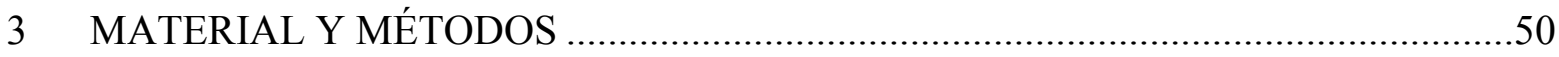

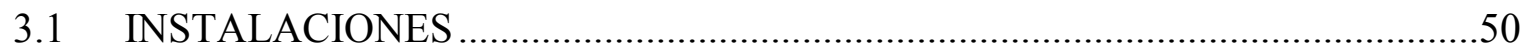




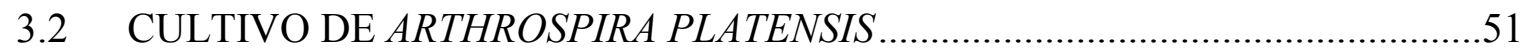

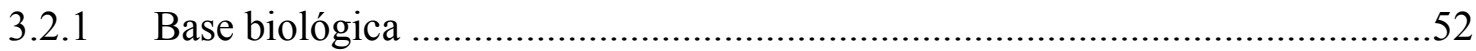

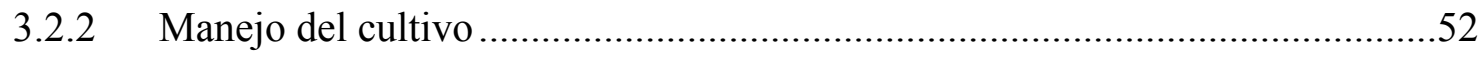

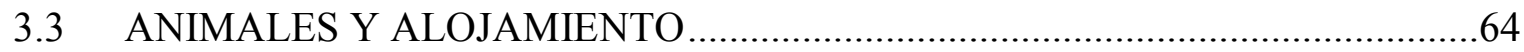

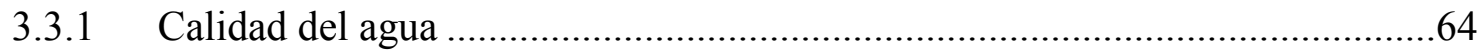

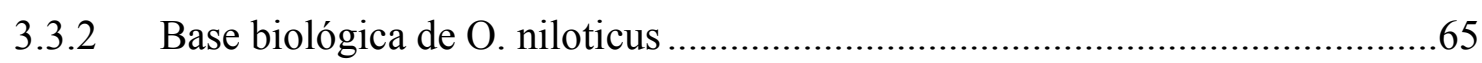

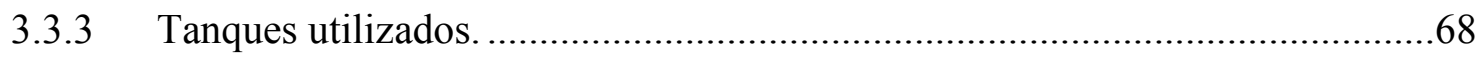

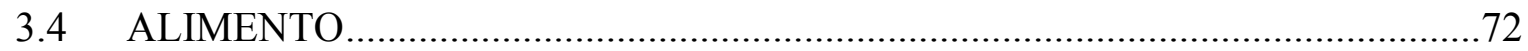

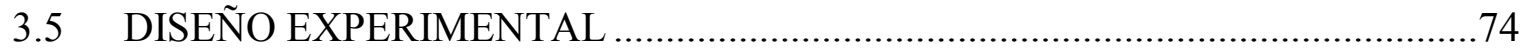

3.5.1 Consideraciones de bienestar animal al sacrificio ......................................74

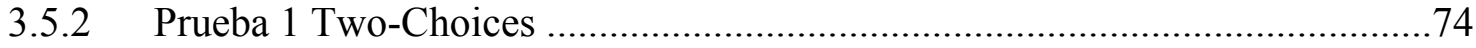

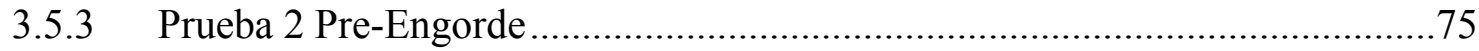

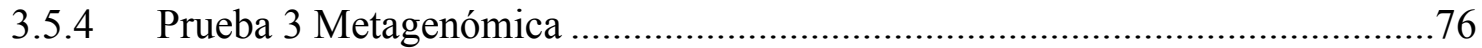

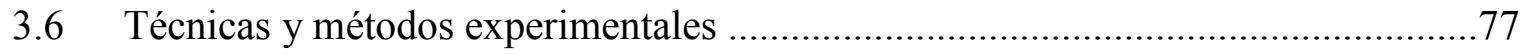

3.6.1 Crecimiento de los peces y supervivencia de los alevines .............................77

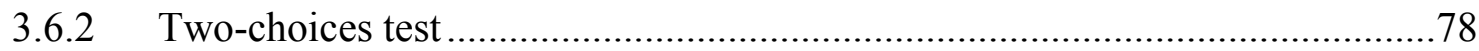

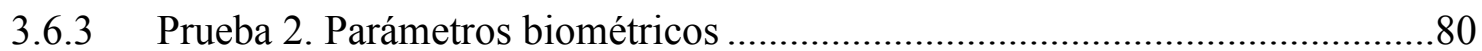

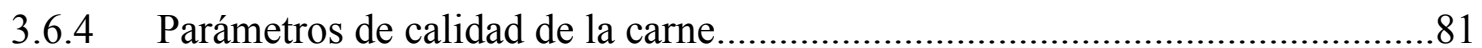

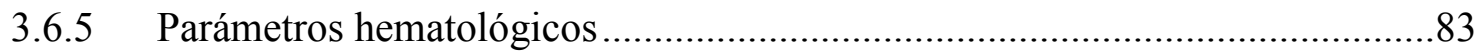

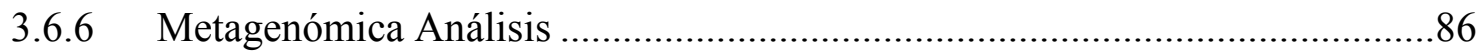

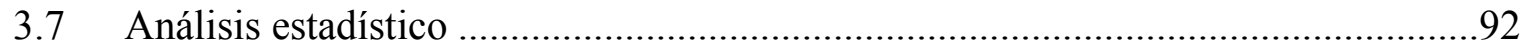

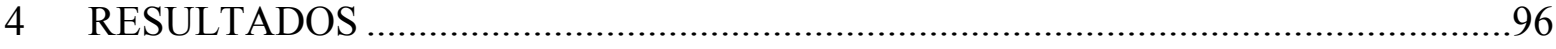

4.1 Experimentos con alevines de tilapia “Two-Choices" "........................................96

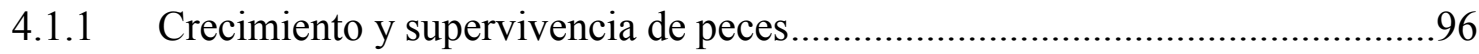

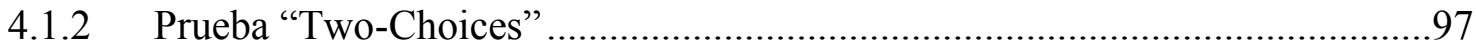

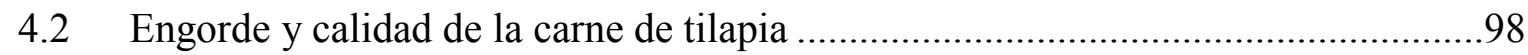

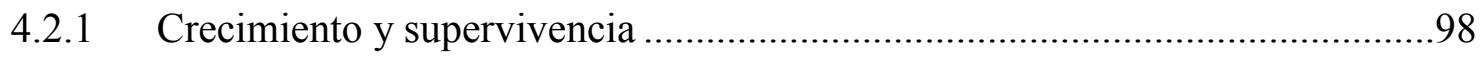




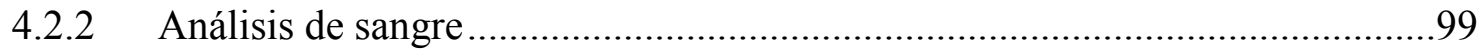

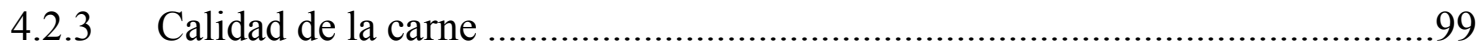

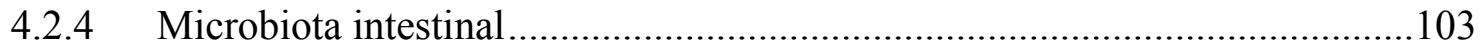

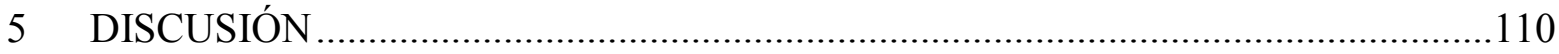

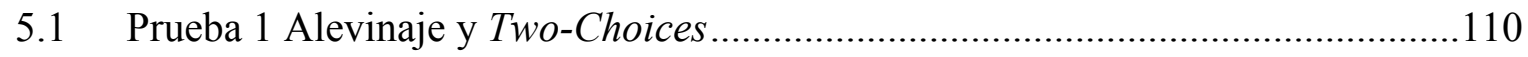

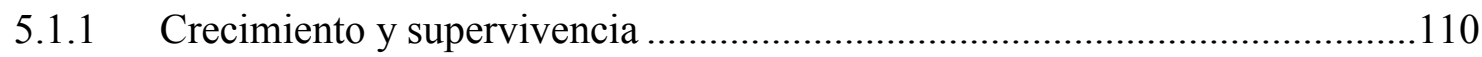

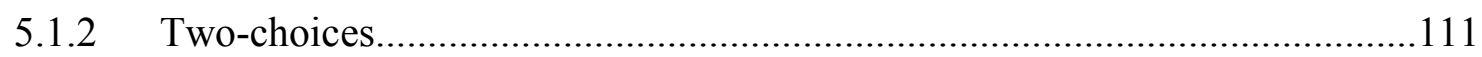

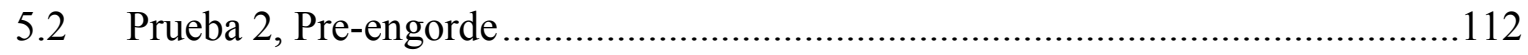

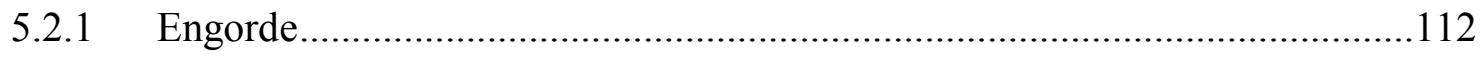

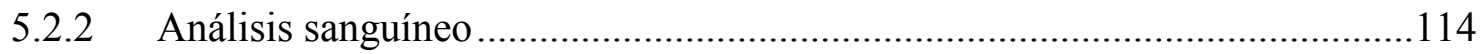

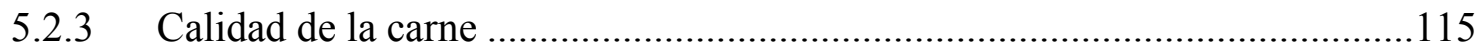

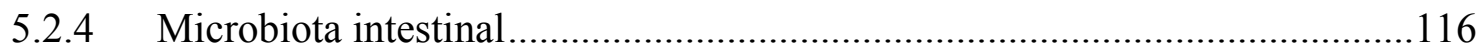

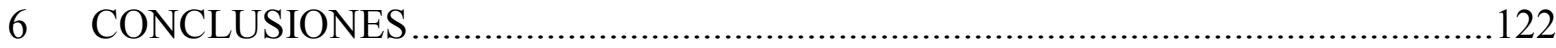

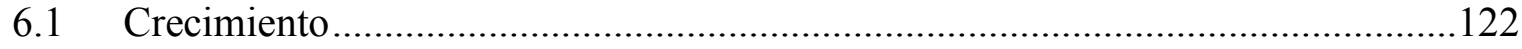

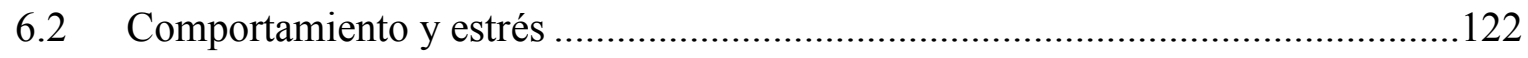

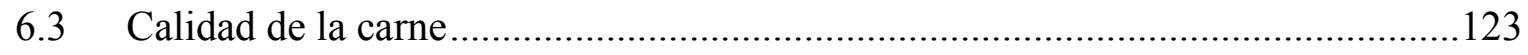

6.4 Efecto del suplemento de espirulina sobre el microbiota intestinal de la tilapia. .123

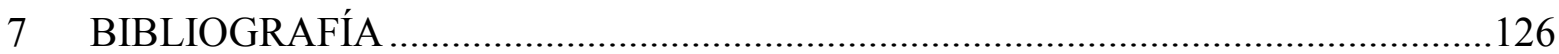

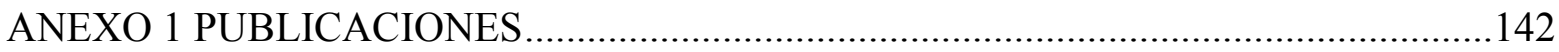

Effect of spirulina (Arthrospira platensis) supplementation on tilapia (Oreochromis niloticus) growth and stress responsiveness under hypoxia

Effect of Arthrospira supplementation on Oreochromis niloticus gut microbiota and flesh quality 156

ANEXO 2 KRONA 182

ANEXO 3 ARDUINO. 192 


\section{LISTA DE TABLAS}

Tabla 1.1 Resumen de la producción de Arthrospira sp. (en toneladas) en los principales países productores desde el año 2010 (FAO FishStats 2017).

Tabla 1.2 Composición bioquímica de Arthrospira sp. (100 g) Datos de USDA 2017 ........14

Tabla 1.3 Composición en aminoácidos esenciales (g/100g) tipo aportados por Arthrospira sp. (IIMSAM, 2012; Herickson, 1989) vs. Recomendaciones de necesidades para humanos (FAO), tilapia (Fitzsimmons, 1997), y las contenidas en Chlorella sp. y huevo (Quevedo, 1999).

Tabla 1.4 Cuadro resumen de la cantidad y calidad de la proteína (UNP, utilización neta proteica) en alimentos comunes, incluyendo a Arthrospira sp. y algunas algas comunes. Datos de Quevedo (1999), y Henrikson (1989).

Tabla 1.5 Composición en lípidos principales en Arthrospira sp. en \% de ácidos grasos y lípidos totales (según Maza et al., 2011).

Tabla 1.6 Composición en carbohidratos de Arthrospira sp. (\% de Carbohidratos), según Pignolet et al. (2012) y Cohen et al. (2014).

Tabla 1.7 Composición pigmento-vitamínica de Arthrospira sp. (mg/kg MS). Datos de IISAM 2012, USDA 2017.Necesidades en la dieta de Tilapia (Fitzsimmons, 1997).

Tabla 1.8 Composición mineral de tipo de Arthrospira sp. (mg/kg MS). IISAM (2012) y USDA (2017). Necesidades en la dieta de Tilapia (Fitzsimmons, 1997).

Tabla 1.9 Estadística pesquera de $O$. niloticus en los países de máxima captura. Datos en toneladas (FAO Stast, 2017)

Tabla 1.10 Producción mundial de tilapia cultivada en toneladas en el periodo comprendido entre el 2010 y el 2014. Datos obtenidos de FAO Fish-Stats (2017).

Tabla 1.11 Composición bioquímica de la O. niloticus (100 g) según Dale et al. (2004)...25

Tabla 1.12 Composición en aminoácidos de la O. niloticus (g/100g) de Dale et al. (2004) vs, patrón nutricional FAO (2011).

Tabla 1.13 Composición en ácidos grasos de la O. niloticus (g/100g). Dale et al. (2004). ..26

Tabla 1.14 Composición en minerales de la O. niloticus (g/100 g). Dale et al. 2004. .27

Tabla 1.15 Cambios en algunos parámetros de la tilapia del Nilo (O. niloticus) después de 24 h de exposición a hipoxia, sobrepoblación y hambre (EL-Khaldi, 2010).

Tabla 1.16 Eficiencia de asimilación (EA) de las microalgas por la O. niloticus en \% según Moriarty y Moriarty (1973). 
Tabla 1. 17 Cuadro resumen de la metagenómica aplicada en microbiota intestinal de peces.

Tabla 3.1 Observaciones en el cultivo de A. platensis según Xarxa espirulina (2016) y

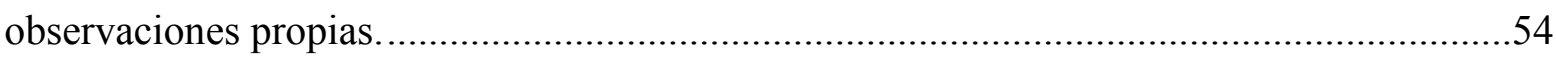

Tabla 3.2 Composición mineral del medio de cultivo de Arthrospira sp. Zarrouk (1966)...56

Tabla 3.3 Calendario de trabajo en el cultivo de $A$. platensis en el invernadero. . .60

Tabla 3.4 Indicadores fisiológicos basales de la calidad de agua según Branson (2000). ...64

Tabla 4.1 Composición aproximada de dietas experimentales (materia seca, cenizas, proteína bruta $\mathrm{PB}$, extracto de éter de éter EE, fibra detergente neutro FDN, fibra detergente ácida $\mathrm{ADF}$, lignina de detergente ácido ADL y energía bruta). . .73 


\section{LISTA DE FIGURAS}

Figura 1.1. Mujeres recolectado Díhe (Arthrospira platensis) de manera tradicional, en el lago Chad (Republica del Chad, África Central). Fuente: Marzot (2004).

Figura 1.2. Uno de los más antiguos bajo relieves egipcios de 4000 años que muestra la tilapia criada en estanques (Gigal, 2012).

Figura 1.3.Arthrospira sp. Imagen de microscopia óptica (Fuente: PELLAGOFIO no $33\left(2^{\mathrm{a}}\right.$ época, julio/agosto 2015).

Figura 1.4 Distribución mundial de los afloramientos naturales de Arthrospira sp. Datos IIMSAM 2012.

Figura 1.5 Producción mundial de Arthrospira sp. en toneladas (verde) y 1000 USD (rojo). Datos de FAO FishStats (2017).

Figura 1.6 Diversos productos que se pueden encontrar en el mercado que contienen Arthrospira sp. a) en polvo "Natur Green, b) crema corporal "Ella Baché", c) pasta (tallarines) "DXN", d) infusiones "Kona Green" y e) jabón " Flor de Lis".

Figura 1.7 Estructura química de la ficobilina presente en la ficocianina. Zheng et al., 2013.

Figura 1.8 Distribución geográfica de las poblaciones originarias de O. niloticus y sus subespecies (Beveridge y Baird, 2000; FAO, 2017).

Figura 1.9 Diferencia de coloración de O. niloticus linnaeus, 1758 (Cichlidae). Arriba se puede ver los colores pardo-grisáceos normales de la tilapia salvaje. Debajo se puede observar los colores verde-rojizos y negros correspondientes a la librea de apareamiento. .23

Figura 1.10 Pesca, producción y valor en USD, de tilapia del Nilo desde 1950. Datos obtenidos de FAO Fish-Stats (2017).

Figura 1.11 Procesos bioquímicos en peces durante la fase post-mortem y principales indicadores de calidad de la carne (adaptado de Poli et al. (2005)).

Figura 1.12 Esquema de adaptación al estrés según la bibliografía existente.

Figura 1.13 Esquema de la respuesta al estrés eje CRH-ACTH-Cortisol. Según la bibliografía existente. .35

Figura 1.14 Molécula de cortisol. (11ß)-11,17, 21-trihidroxipregn-4-eno-3,20-diona 37

Figura 3.1 Invernaderos de la Escuela Técnica Superior de Ingenieros Agrónomos de Madrid situados a $40.446353 \mathrm{~N}-3.738341 \mathrm{E}$ 
Figura 3.2 Instalaciones de Acuicultura de la Escuela Técnica Superior de Ingenieros de Montes de Madrid, situadas a 40.450806 N, -3.721382 E. .50

Figura 3.3 A. platensis PCC9018. Imagen de microscopia óptica, del cultivo utilizado durante los experimentos realizados en 2016. 52

Figura 3.4 Fases de arranque de cultivo de $A$. platensis. 53

Figura 3.5 Algas que son posibles contaminantes del cultivo de A. platensis como Chlorella sp. (A), Anabaena sp. (B), Anabaenopsis sp. (C), y Microcystis sp. (D). .53

Figura 3.6 Cultivo de $A$. platensis en bio-reactores tubulares en el invernadero de la ETSIAAB. Se puede observar la diferencia de densidad entre el cultivo de la izquierda (recién cosechado) y el de la derecha (esperando a ser cosechado).

Figura 3.7 Dimensiones de los FBR de plástico utilizados para el cultivo de A. platensis...58 Figura 3.8 Sensor de turbidez desarrollado con Arduino Leonardo, el sensor de color OPT 101 (Burr-Brown) y piezas de Lego®. .59

Figura 3.9 Foto realizada durante la fase de calibrado del sensor de turbidez. .59

Figura 3.10 Curva de crecimiento de la Arthrospira expresado en g/L en peso seco. Los puntos representan las medidas de concentración obtenidas, y la línea verde es la curva obtenida, mediante ajuste logístico del tipo [a / (1+exp $(b-c * t(d))]$.

Figura 3.11 Izquierda, Foto realizada durante un día de cosecha de A. platensis con maya de $46 \mu \mathrm{m}$. Derecha, esquema del FBR, así como las indicaciones cosecha y alimentación.......61

Figura 3. 12 Diferenciación sexual en $O$. niloticus. ............................................................66

Figura 3. 13 Esquema de la técnica para la obtención de Supermachos

Figura 3.14 Tanques troncocónicos utilizados, dimensiones, y flujo de agua con el desagüe en la parte inferior y salida al filtro a $1 / 4$ de la base.

Figura 3.15 Filtros EHEIM classic; Mod 2217 con su conformación para el experimento..69 Figura 3.16 Race-ways utilizados en la prueba de pre-engorde y metagenómica. Dimensiones, y flujo de agua.

Figura 3. 17 Piensos utilizados en las distintas pruebas. A) piensos en granulo de 0,1 - 0,2 Ø $\mathrm{cm}$ para la prueba de alevines, B) pienso peletizado a $0,5-0,7 \varnothing \mathrm{cm}$ para la prueba de preengorde y metagenómica.

Figura 3.18 Fotografía de la entrada del pez E9B6. Cada pez fue identificado individualmente con un microchip (i-Tag 162,2x12 mm) colocado bajo la aleta dorsal, medido, fotografiado y asignado a uno de los tratamientos.

Figura 3.19 Fotografía utilizada para poder medir y contar los alevines a la entrada a los tanques. 
Figura 3.20 Fotografía de los tanques durante los ensayos del experimento "Two-Choices", en los invernaderos de los campos de prácticas de Agrónomos, UPM. .79

Figura 3.21 Esquema y medidas de los tanques utilizados para la realización de la prueba de "Two-Choices". .80

Figura 3.22 Trabajos de aturdimiento, pesado y medición en la prueba de pre-engorde......81

Figura 3. 23 Evolución y medición del rigor mortis. Método Cuttinger (Korhenen et al., 1990). 82

Figura 3.24 Fotografía de la medición de $\mathrm{pH}$ y la $\mathrm{T}^{\mathrm{a}}$ durante uno de los ensayos. .82

Figura 3.25 Modelo CIELAB. 83

Figura 3. 26 Puesta a punto del protocolo de secuenciación de los genes marcadores del microbiota del intestino de O. niloticus. (A) Toma de muestras del intestino, (B) extracción, limpieza y extracción del contenido bacteriano del intestino, (C) lisis y extracción de ADN y amplificación del gen 16S-ARNr, (D) Ligación 16S-pGEM-T® Vector, (E) transformación E. coli, (F) cultivo de E. coli en LB+ampicilina y selección de colonias blancas (recombinantes), $(\mathrm{G}+\mathrm{H})$ extracción de plásmidos mediante el kit high pure plasmid isolation miniprep de Roche ${ }^{\circledR}$; (Y) secuenciación de los insertos con los 16S-ARNr clonados; (J) revisión de las secuencias en la biblioteca on-line (NCIB); (K) identificación de los genes encontrados.

Figura 3.27 Mapa del plásmido p-GEM $\mathbb{R}-\mathrm{T}$ Easy Vector. .88

Figura 3.28 Esquema del protocolo de extracción del ADN de la microbiota intestinal de $O$. niloticus utilizado durante la tesis: (A) toma de muestras del intestino; (B) extracción, limpieza y extracción del contenido bacteriano del intestino; (C) lisis y extracción del ADN total; (D) amplificación del 16S-ARNr; (E) secuenciación en MiSeq de los amplicones 16S-ARNr; (F) ensamblaje de secuencias e identificación computacional con los programas Silva y QIIME.

Figura 3.29 Esquema del procedimiento de extracción de ADN del Stool Mini Kit de QIAamp. .90

Figura 4.1 Tiempo de salida ( $\mathrm{min}$ ) de los primeros cinco peces por tratamiento, diferenciando entre los controles $(\mathbf{O})$ y los suplementados con A. platensis $(\mathbf{\Delta})$. La línea azul claro es la concentración de $\mathrm{O}_{2}$ en ppm en el Tanque A. La línea azul oscuro es la curva de regresión obtenida con los datos de oxigeno medios durante la prueba, para conocer a qué nivel de $\mathrm{O}_{2}$ respondió cada pez, $\left(\mathrm{O}_{2}(\mathrm{ppm})=1,78+6,19 \cdot 0,94^{\mathrm{t}(\mathrm{min})}\right)(\mathrm{r}=0,98)$. 
Figura 4.2 Curvas de espectro reflectancia de la carne de O. niloticus sp. a 0 h y $24 \mathrm{~h}$ tras el sacrificio. Para dos tratamientos distintos, control (CRT) y suplementada al $3 \%$ de $A$. platensis (SPR). Las barras marcan los rangos donde se encontró diferencia significativa en la reflectancia (\%) entre tratamientos a las $24 \mathrm{~h}$.

Figura 4.3 Grafica jerárquica en Krona, nivel de especie, de uno de los individuos de la prueba. Identificados con las siglas del tratamiento SPR (suplementados con A. platensis) y con los cuatro dígitos de su chip. 103

Figura 4.4 Abundancia relativa, nivel phyla, de bacterias encontradas en el intestino de 16 individuos $O$. niloticus en dos tratamientos alimentados diferentes, 8 individuos con dieta control (CTR) y 8 individuos suplementados con A. platensis (SPR), incluyendo medias por tratamiento y media total.

Figura 4.5 Abundancia media relativa, nivel género, de bacterias encontradas en el intestino de 16 individuos $O$. niloticus en dos tratamientos alimentados diferentes, 8 individuos con dieta control (CTR) y 8 individuos suplementados con A. platensis (SPR). 106

Figura 5.1 Análisis de similitud de grupos de bacterias intestinales de diferentes estudios en Oreochromis usando la prueba de Bray-Curtis. Utilizando los datos medios de los contribuidos por el control de peces de los diversos estudios realizados por los autores. ...117 


\section{LISTA DE ABREVIATURAS}

a.C. Antes De Cristo

ACTH Hormona Adrenocorticótropa

ADF Fibra Acido Detergente

ADL Lignina de Detergente Ácido

ADN Ácido Desoxirribonucleico

ADP Adenosín-5'-difosfato

ANOVA Análisis de Varianza

ARN Ácido Ribonucleico

ATP Adenosín-5'-trifosfato

CIB Centro de Investigaciones Biológicas

CIE Internacionale Comisión De l'Eclairage

CRH Hormona Liberadora de Corticotropina

CSIC Consejo Superior de Investigaciones Científicas

CTR Grupo Control

dNTPs Deoxinucleósido Trifosfato

ECOSOC Permanent Observer with the United Nations Economic and Social Council

EE. Extracto Etéreo

ELISA Enzimo-Inmunoanálisis Competitivo

ETSIAAB Escuela Técnica Superior de Ingeniería Agronómica, Alimentaria y de Biosistemas

ETSIM Escuela Técnica Superior De Ingenieros De Montes

FAO Food and Agriculture Organization

FAWC Farm Animal Welfare Committee

FBR Foto-Bio-Reactor

GMD Ganancia Media Diaria

GMT Ganancia Media Del Tanque

GOD Enzima Glucosa Oxidasa

HPI Eje Hipotálamo-Pituitaria-Intrarrenal

HRPO Cortisol Conjugado Por La Peroxidasa De Rábano Picante

IC Índice de Conversión

IIMSAM Intergovernmental Institution for the use of Micro-Algae against Malnutrition

LDH Lactato Deshidrogenasa

LO Lactato Oxidasa

MS Materia Seca

NADH Nicotinamida Adenina Dinucleótido

NAT Nitrógeno Amoniacal Total

NCIB National Center For Biotechnology Information

NDF Fibra Neutro Detergente

PB Proteína Bruta

PBS Solución Salina Tamponada Con Fosfato

PCR Polymerase Chain Reaction

PIT Peso Inicial Del Tanque

PM Peso Húmedo

POD Defectos de Oxidación de Piruvato

PS Peso Seco

PUFAs Ácidos Grasos Altamente Poli-Insaturados

RAS Recirculation Aquaculture System 
S. Siglo

SBS Sequencing by Synthesis

SPR Grupo Arthrospira platensis

Srv Supervivencia

TAG Triacilglicéridos

UNP Unidad Neta Proteica

UPM Universidad Politécnica De Madrid

USD United States Dollars

USDA United States Department of Agriculture 


\section{RESUMEN}




\section{RESUMEN}

Estudios recientes han demostrado que la suplementación de alimentos con Arthrospira sp. tiene un efecto beneficioso sobre la salud y el crecimiento de los peces, pero se sabe poco acerca de sus posibles efectos sobre la capacidad de respuesta al estrés, o cómo la administración de suplementos afecta al microbiota intestinal o la calidad de la carne.

En el primer estudio, se administró alimento suplementado con Arthrospira platensis (CP 9108) al $0 \%$ y al $1 \%$ en alevines de Oreochromis niloticus, de aproximadamente $10 \mathrm{mg}$ de peso vivo al inicio del período experimental. Estos se dividieron en dos tratamientos $(\mathrm{n}=16$ tanques, 8 tanques / tratamiento, 25 alevines / tanque). Ambas dietas fueron isocalóricas e isonitrogenadas (5,00 / 4,98 kcal / g MS y 44,6 / 44,8 CP\% MS, respectivamente). La tasa de alimentación fue del 6\% de peso vivo con cuatro comidas al día durante 50 días. Los tanques usados funcionaban bajo un sistema de recirculación. El aumento de peso por tanque, la tasa de crecimiento específica y la tasa de conversión alimenticia fueron similares entre los tratamientos, pero la suplementación con A. platensis aumentó significativamente la supervivencia $(\mathrm{p}<0.05)$.

Tras el tratamiento se midió la respuesta al estrés en todos los peces de 12 de los tanques. Mediante una prueba no invasiva de "two-choice" (dos opciones). Para ello se necesitan dos tanques unidos por un canal, donde se presentan diferentes estímulos, y se observa la respuesta de los alevines a la situación. La prueba inicia colocando todos los peces de un mismo tanque ( $n=6$ por tratamiento), en el tanque A sombreado (situación favorable), mientras que el otro tanque B es iluminado (estresante). Seguidamente, se fue disminuyendo lentamente la concentración de $\mathrm{O}_{2}$ en el tanque A. Los peces alimentados con A. platensis se mantuvieron significativamente $(P=0,001)$ más tiempo en el tanque $A(30,20 \mathrm{~min} \pm 13,22)$ que los controles $(17,35 \mathrm{~min} \pm 8,32)$, lo que sugiere una menor capacidad de respuesta al estrés y una mayor tolerancia a la hipoxia.

En el segundo estudio, se administró alimento suplementado con A. platensis (CP 9108) al $3 \%$ a juveniles de en torno a $109 \mathrm{~g}$ de $O$. niloticus durante un período de 50 días, y se comparó parámetros sanguíneos y de calidad de carne con los controles. Los niveles de triglicéridos y cortisol fueron mayores en los peces suplementados, aunque dentro de los parámetros normales aceptados para la especie. El crecimiento diario promedio fue mayor en los peces suplementados $(\mathrm{P}<0,05)$. El rigor mortis se resolvió antes en peces suplementados $(\mathrm{P}<0,05)$ indicando una posible vida útil más corta del producto. Todos estos datos sugieren un aumento 
del metabolismo de los peces suplementados con A. platensis. Por otro lado, el color de la carne de los peces suplementados, fue más intenso a las $24 \mathrm{~h}$ post-mortem en el rango de 470 $500 \mathrm{~nm}$ y $620-660 \mathrm{~nm}$, lo que corresponde con un perfil de aumento de $\beta$-caroteno y ficocianina en los peces alimentados con A. platensis.

Finalmente, se tomaron 16 muestras ( $\mathrm{n}=8$ por tratamiento) de intestino de los peces utilizados en la segunda prueba para realizar su microbiota intestinal. Se obtuvieron un total de 5.470.272 lecturas de las 16 muestras, una diversidad gamma de 1563 especies. No se encontraron diferencias significativas entre los tratamientos; Los patrones de diversidad alfa fueron similares (media $\pm \mathrm{SE}$, Simpson 0,80 \pm 0,08, Shannon 2,68 $\pm 0,53$, Margalef 38,07 \pm $8,65$, Caos 560,9 $\pm 113,3)$. El patrón del microbiota en el nivel de phylum observado se compone de 36,58\% de Proteobacterias, y 32,85\% de Fusobacterias, seguido de 9,24\% de Actinobacterias. Esto sugiere que la suplementación con un 3\% de A. platensis no afecta al microbiota intestinal de $O$. niloticus. 


\section{ABSTRACT}

Several recent studies have shown that adding Arthrospira sp. to feed can have beneficial effects on the health and growth of fish, but less is known about its possible effects on the ability to respond to stress, or how supplementation affects gut microbiota or the quality of the meat.

In the first trial, feed was supplemented with $0 \%$ or $1 \%$ Arthrospira platensis (CP 9108) and fed to Oreochromis niloticus fry, of approximately $10 \mathrm{mg}$ live weight. in two treatments ( $\mathrm{n}=$ 16 tanks, 8 tanks / treatment, 25 fry / tank). Both diets were isocaloric and isonitrogenous (5.00 / $4.98 \mathrm{kcal} / \mathrm{g}$ MS and 44.6 / 44.8 CP\% MS, respectively). The feeding rate was $6 \%$ live weight, four meals a day for 50 days. Fish were kept in tanks in a recirculating system. The increase in weight per tank, the specific growth rate and the feed conversion rate were similar between treatments, but supplementation with $A$. platensis significantly increased survival $(\mathrm{p}<0.05)$.

At the end of the trial, the stress response was measured in all the fish from 12 tanks. using a non-invasive "two-choice" test, where two tanks were joined by a tunnel, and different stimuli were presented, and the response of the fry was observed. The test started by placing all the fish in tank A ( $n=6$ per treatment) which was shaded (favourable situation), while the other tank $\mathrm{B}$ was lit (stressful). Then, the concentration of $\mathrm{O}_{2}$ in the shaded tank was slowly decreased, forcing the fish to choose between stressful situations It was observed that the fish fed with $A$. platensis stayed significantly $(\mathrm{P}=0,001)$ longer in tank A $(30.20 \mathrm{~min} \pm 13.22)$ than the controls (17.35 $\mathrm{min} \pm 8.32)$, which suggests a lower capacity to respond to stress and a greater tolerance to hypoxia.

During the second trial, feed supplemented with $A$. platensis (CP 9108) at 3\% was administered to juveniles of around $109 \mathrm{~g}$ of $O$. niloticus during a period of 50 days, and blood and meat quality parameters were compared with controls. Significant differences were obtained in blood triglyceride and cortisol levels, which were higher in A. platensis fish, although within the normal parameters accepted for the species. The average daily growth was higher in the supplemented fish $(\mathrm{P}<0.05)$. Rigor mortis was resolved earlier in A. platensis fish $(\mathrm{P}<0.05)$ indicating a possible shorter shelf life of the product. All these data suggest an increase in the metabolism of fish supplemented with A. platensis. On the other hand, the meat colour of the supplemented fish was more intense at $24 \mathrm{~h}$ post-mortem was higher in the range 
of 470-500 nm and $620-660 \mathrm{~nm}$, which corresponds to an increase profile of $\beta$-carotene and phycocyanin in fish fed A. platensis.

Finally, 16 samples $(n=8$ per treatment) were taken from the intestine of the fish used in the second test, to perform a gut microbiota test. A total of 5,470,272 readings were obtained from the 16 samples, a gamma diversity of 1563 species. No significant differences were found between the treatments; The alpha diversity patterns were similar (mean $\pm \mathrm{SE}$, Simpson 0.80 \pm 0.08 , Shannon 2.68 \pm 0.53 , Margalef 38.07 \pm 8.65 , Chaos 560.9 \pm 113.3 ). The microflora pattern at the level of phylum observed is composed of $36.58 \%$ of Proteobacteria, and $32.85 \%$ of Fusobacteria, followed by $9.24 \%$ of Actinobacteria. This shows that supplementation with $3 \%$ of $A$. platensis does not affect the intestinal microbiota of $O$. niloticus. 


\section{REVISIÓN BIBLIOGRÁFICA}




\section{REVISIÓN BIBLIOGRAFICA}

\subsection{UN POCO DE HISTORIA}

A lo largo de la historia las algas y microalgas han sido utilizadas por los humanos con diferentes propósitos. En China, se han encontrado referencias que se remontan al 2000 a.C., que dan constancia del uso del alga Nostoc en la alimentación humana. En Japón se tienen datos del consumo de algas desde el año 274 años a.C. En Europa las algas ya se vienen utilizando en las regiones costeras, regiones "pobres y desfavorecidas", para alimentar animales, tal y como también se dio en Europa en las zonas costeras del Atlántico en Francia durante la Primera Guerra Mundial debido a la escasez de avena y forraje (Bacha, 2015).

Centrando la vista en el género de cianobacterias (coloquialmente mal consideradas como microalgas), del que va a tratar esta tesis doctoral, la primera referencia histórica sobre Arthrospira sp. la podemos encontrar en las crónicas de los Conquistadores españoles. En la Crónica de Francisco Hernández y la de Fray Toribio de Benavente siglo XVI se puede leer que habitantes de Tenochtitlán, hoy Ciudad de México, recolectaban mediante cuerdas y paños una especie de fango de color azul que denominaban "Tecuitlatl", en náhuatl "excremento de piedra". Mas tarde, ya en el S.XX, en los años 40 la revista de la Sociedad Linneana de Burdeos publicó la investigación de un ficólogo francés, Dangeard, que mencionaba el dihé, una sustancia consumida por el pueblo de Kanem (Henrikson, 1989; Abdulqader et al., 2000). Veinticinco años más tarde al botánico Léonard, miembro de la expedición belga que recorrió el Sahara desde el Atlántico hasta el Mar Rojo, demostró que contenía esencialmente una microalga, la cianobacteria Arthrospira platensis (PaniaguaMichael et al., 2004). 


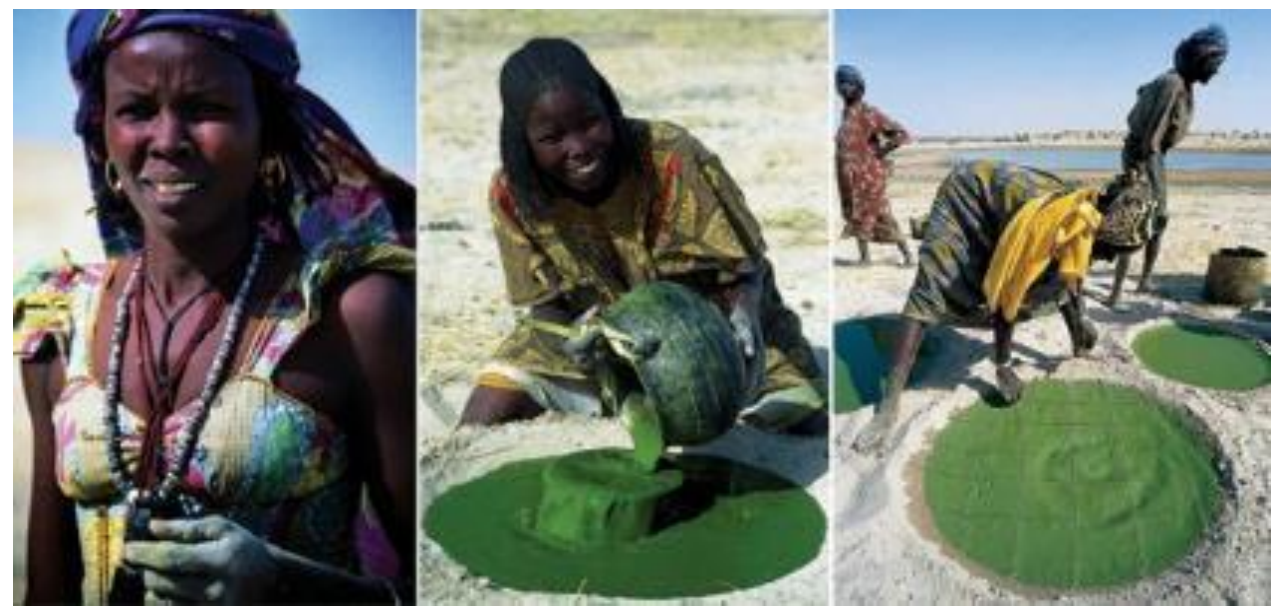

Figura 1.1. Mujeres recolectado Díhe (Arthrospira platensis) de manera tradicional, en el lago Chad (Republica del Chad, África Central). Fuente: Marzot (2004).

Las primeras menciones que encontramos de acuicultura se remontan al antiguo Egipto. Donde en bajo-relieves de una tumba egipcia de la época predinástica, que data de hace más de 4000 años puede verse como los egipcios cultivaban en tanques ejemplares de genero Tilapia (Oreochromis sp.), genero objetivo de este estudio. La tilapia del Nilo ( $O$. niloticus) fue conocido por los egipcios con el nombre de inet, simbolizó el renacimiento, la vida y la fertilidad. Aparece con mucha frecuencia en las paletas de época predinástica (Nagada II) e incluso se encuentra representada en etiquetas de marfil del período tinita. Quizá el hecho de que los egipcios se fijaran en este animal fue porque este pez era del color del sol (rojizo) y además tenía una forma ovalada, es decir, reunía los requisitos idóneos para relacionarlo con Atum-Ra.

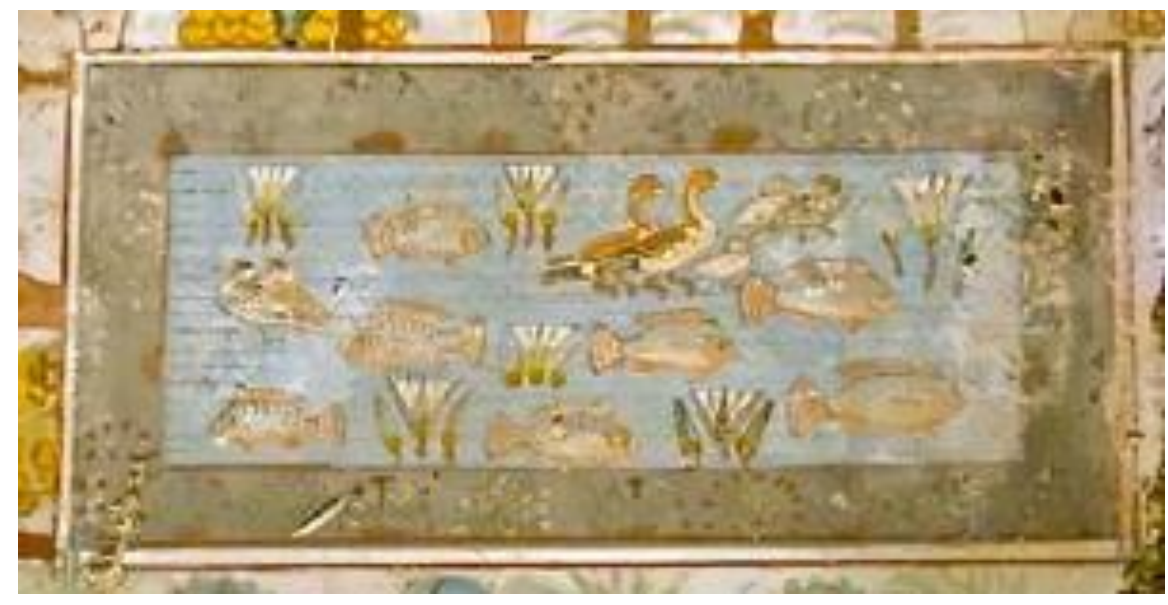

Figura 1.2. Uno de los más antiguos bajo relieves egipcios de 4000 años que muestra la tilapia criada en estanques (Gigal, 2012). 


\subsection{ESPIRULINA "ARTHROSPIRA SP."}

La cianobacteria comúnmente conocida como Espirulina (Arthrospira sp.) es descendiente de las primeras formas de vida fotosintética. No siendo realmente una microalga, debido a algunas similitudes compartidas con las mismas, las cianobacterias se suelen englobar incorrectamente en el término microalgas. El género cianobacteria surgió hace más de 3500 millones de años y engloba a las bacterias responsables de crear la atmosfera actual (Henrikson, 1989). La Arthrospira sp. pertenece al orden de los Oscillatoriales (Figura 1.3), que flotan libremente en lagos tropicales y subtropicales alcalinos ricos en carbonato y bicarbonato. Se trata de un organismo multicelular foto-autótrofo que se agrupa formando tricomas o formas filamentosas, enrolladas en hélice levógira. La forma helicoidal es característica del género, pero la longitud y la dimensión de la hélice varia con la especie, incluso dentro de la misma especie. Estas diferencias parecen tener que ver con las condiciones ambientales de crecimiento y temperatura (Ciferri, 1983). El diámetro de las células se sitúa entre los 3-12 $\mu \mathrm{m}$, mientras que el diámetro de la hélice varía entre los 50-80 $\mu \mathrm{m}$. La forma helicoidal se mantiene en medio líquido, pero cuando se seca se forma una autentica espiral (Ciferri, 1983).

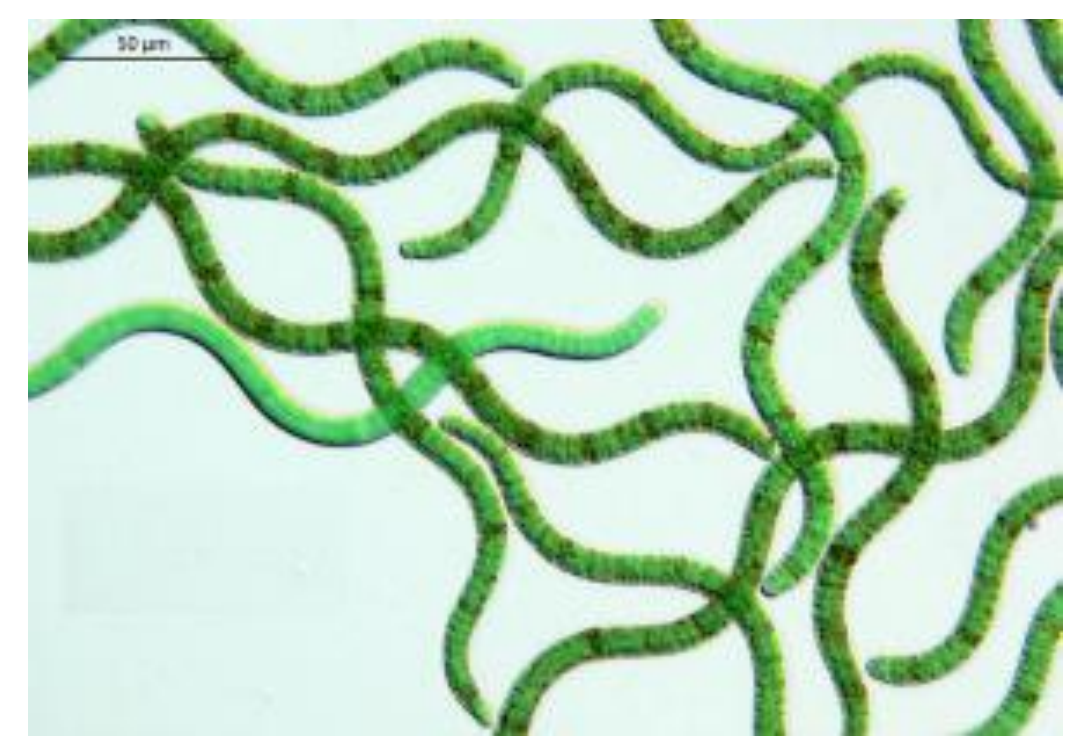

Figura 1.3. Arthrospira sp. Imagen de microscopia óptica (Fuente: PELLAGOFIO no 33 (2 época, julio/agosto 2015). 


\subsubsection{Especies y distribución mundial}

De este género se conocen multitud de sub-especies. Las más relevantes son Arthrospira platensis que es originaria de África y Asia, seguida de Arthrospira maxima que es exclusiva de América Central y Sudamérica, y Arthrospira pacifica, endémica de Hawái. Su distribución a lo largo del globo la podemos observar en la Figura 1.4.

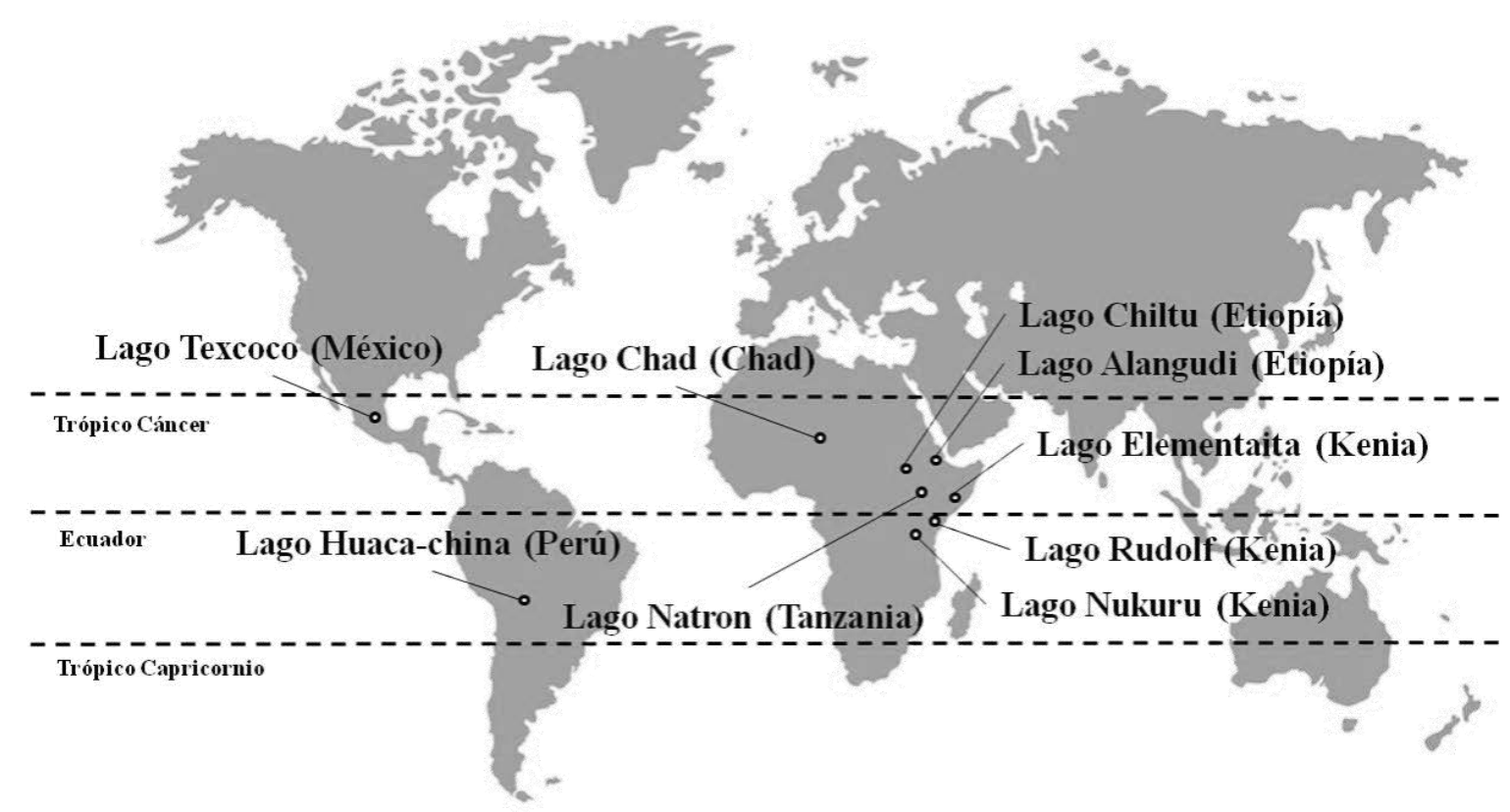

Figura 1.4 Distribución mundial de los afloramientos naturales de Arthrospira sp. Datos IIMSAM 2012.

A nivel nacional, Arthrospira sp. puede encontrarse de forma salvaje en el Parque Nacional de Doñana (Huelva). No siendo original de la Península, se cree que llego trasportada por las aves durante sus migraciones, como el flamenco rosa (Phoenicopterus roseus), provenientes de las lagunas volcánicas africanas anteriormente mencionadas, donde si son oriundas.

\subsubsection{Producción mundial de la Arthrospira sp.}

Las principales compañías productoras de Arthrospira sp. se localizan en el continente asiático, donde su cultivo se lleva a cabo de manera intensiva dentro de estanques artificiales. Según los datos de la FAO, su producción viene oscilando entre 60 y 100 TM de biomasa por año a nivel mundial. La Arthrospira sp. se deshidrata y pulveriza para fabricar comprimidos o capsulas que se venden como suplementos alimenticios (Vonshak, 1997). La producción mundial se estima que posee un valor de unos 40000000 USD/anuales según datos de la FAO (Figura 1.5). 


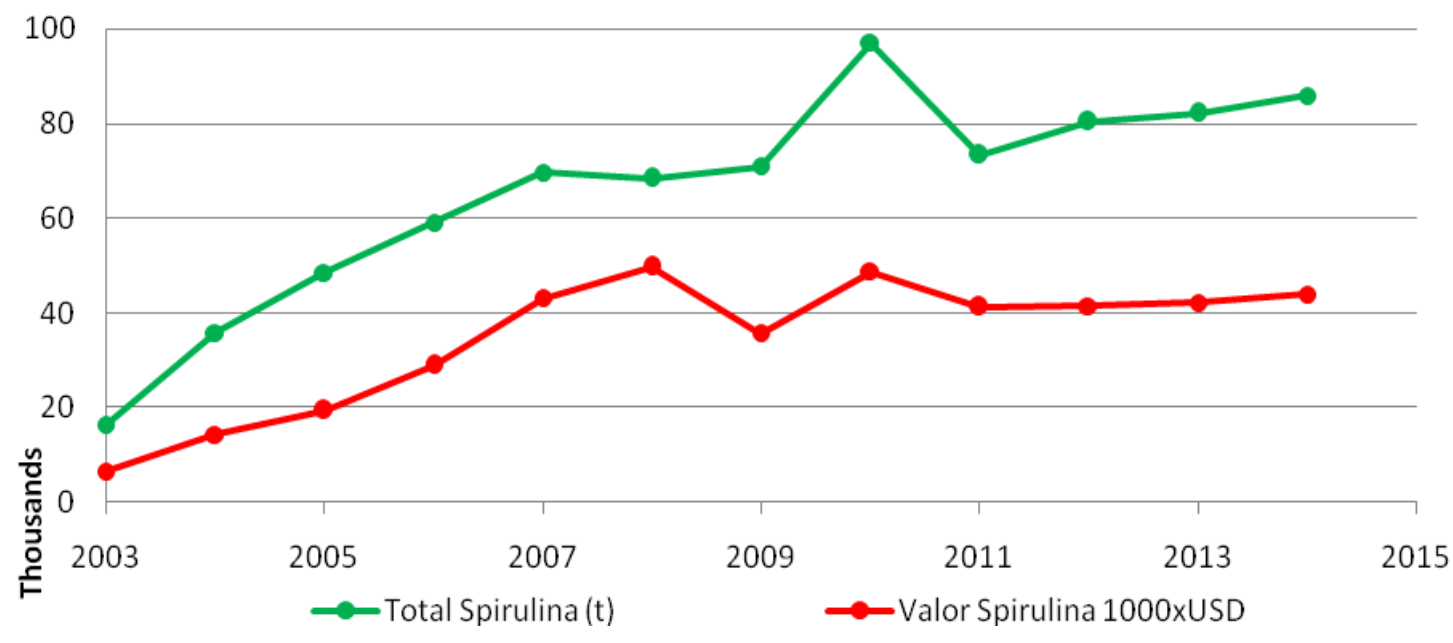

Figura 1.5 Producción mundial de Arthrospira sp. en toneladas (verde) y 1000 USD (rojo). Datos de FAO FishStats (2017).

Teniendo en cuenta los datos de la FAO de 2014, el principal productor mundial de Arthrospira sp. es China, que produce más del 99\%. Excluyendo a China, aparecen países como Grecia que ocupa el segundo lugar, con un clima similar al español. Posteriormente aparecen países como Burkina Faso, República Centroafricana, México o Senegal (Tabla 1.1).

Tabla 1.1 Resumen de la producción de Arthrospira sp. (en toneladas) en los principales países productores desde el año 2010 (FAO FishStats 2017).

\begin{tabular}{lrrrrr} 
País (País) & $\mathbf{2 0 1 0}$ & $\mathbf{2 0 1 1}$ & $\mathbf{2 0 1 2}$ & $\mathbf{2 0 1 3}$ & $\mathbf{2 0 1 4}$ \\
\hline China & 96910 & 72820 & 80050 & 81890 & 85530 \\
Grecia & $\ldots$ & 198 & 174 & 93 & 126 \\
Burkina Faso & 70 & 100 & 100 & 120 & 100 \\
República Centroafricana & 30 & 30 & 42 & 40 & 40 \\
México & $\ldots$ & $\ldots$ & $\ldots$ & $\ldots$ & 5.76 \\
Senegal & 1.6 & 0.06 & $\ldots$ & 1.8 & 3 \\
\hline Total & 97016.6 & 73368.1 & 80366 & 82157.1 & 85804.8
\end{tabular}

A pesar de que la venta de Arthrospira sp. se encuentra en un mercado totalmente desarrollado, en España la producción y comercialización de esta cianobacteria es escasa, pudiéndose encontrar tan sólo en puntos de ventas especializados o a través de internet. Una de las empresas pioneras productoras nivel nacional se encuentra en el parque natural de Sierra Espuña (Murcia) donde existe una explotación familiar llamada ASN-Leader. 


\subsubsection{Usos actuales de la Arthrospira sp.}

El principal interés de Arthrospira sp. radica en el consumo humano debido a los macronutrientes y micronutrientes que contiene, algunos de los llamados esenciales como los ácidos grasos omega-3, los solo pueden ser sintetizados en baja proporción por el organismo humano a partir de algunos precursores. También es interesante por otras propiedades que se le atribuyen, tales como incrementar los niveles de energía, reducir el estrés premenstrual, incrementar el rendimiento de atletas, mejorar el apetito y ofrecer protección antioxidante (Ramírez-Moreno et al., 2006).

Arthrospira sp. se comercializa por sus atribuidas propiedades terapéuticas. En roedores y humanos parece tener efectos sobre la inmuno-regulación, así como ejercer otros efectos como antioxidante, como anti-cancerígeno, como antiviral, y ser activo contra la hiperlipidemia y la hiperglicemia (Belay \& Gershwin2006; Liu et al., 2000). Varias de las propiedades antes mencionadas se deben a algunos de los constituyentes de Arthrospira sp., entre los que destacan los ácidos grasos poli-insaturados (PUFA) omega-3y omega-6, el $\beta$-caroteno, el $\alpha$ tocoferol, la ficocianina, los compuestos fenólicos y un complejo aislado recientemente, el denominado Ca-Spirulan (Ca-SP) que tiene actividad antiviral (Chamorro et al., 2002).

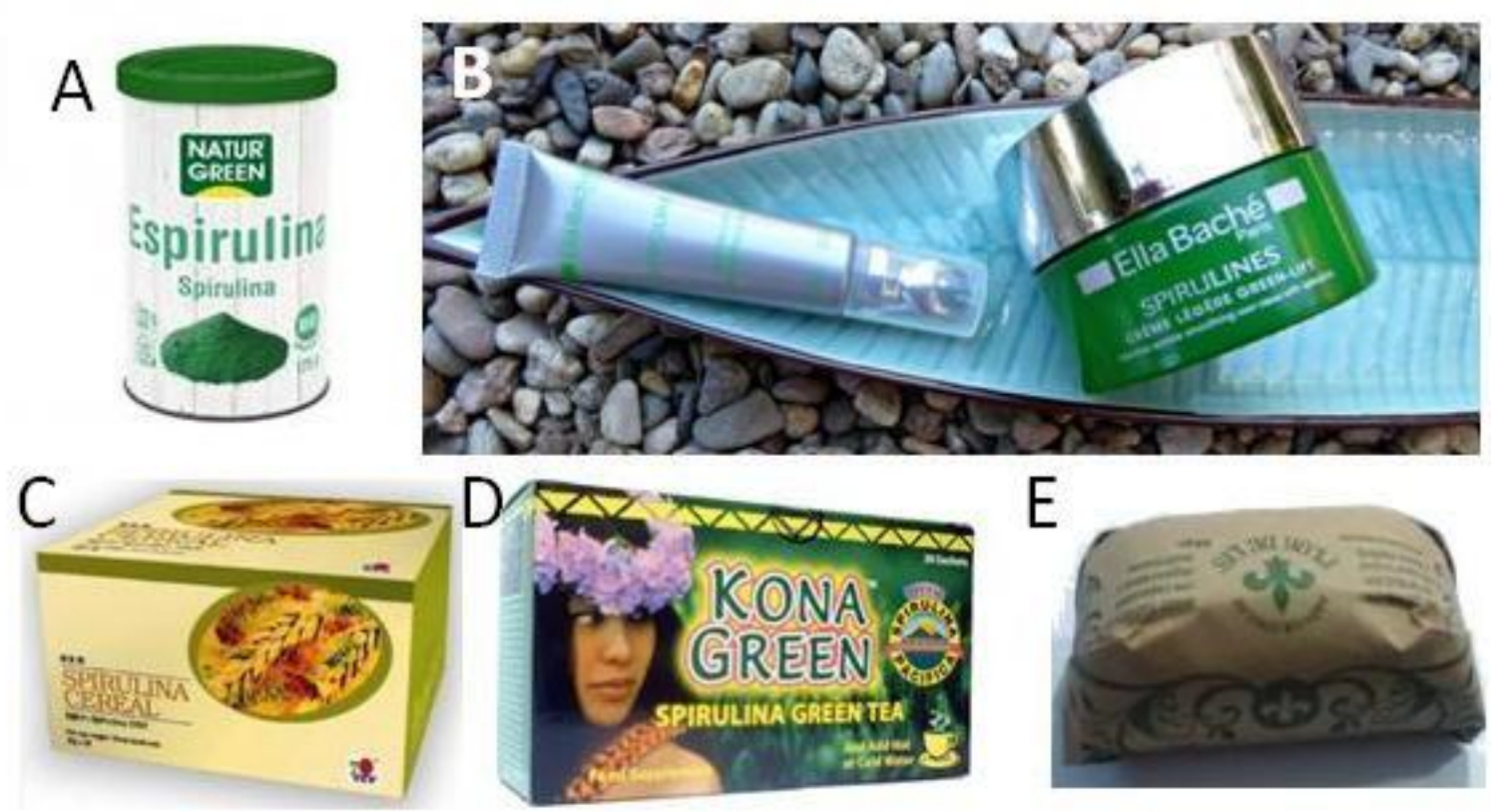

Figura 1.6 Diversos productos que se pueden encontrar en el mercado que contienen Arthrospira sp. a) en polvo "Natur Green, b) crema corporal "Ella Baché", c) pasta (tallarines) "DXN", d) infusiones "Kona Green" y e) jabón " Flor de Lis". 


\subsubsection{Características nutricionales de la Arthrospira sp.}

Esta cianobacteria es una fuente de alimentación rica en proteínas, aminoácidos, vitaminas, minerales y otros nutrientes (Tabla 1.2). Uno de sus principales usos es como suplemento alimenticio, ya sea en polvo, encapsulada, en tabletas, como sustituto de harina, en pastas para sopa, salsas, barras de granola, golosinas o bebidas instantáneas de frutas o vegetales (Sasson, 1997). El IIMSAM (The Intergovernmental Institution for the Use of Micro-algae Against Malnutrition), trabaja en multitud de países donde promociona el uso de Arthrospira sp. como solución para la malnutrición severa.

Tabla 1.2 Composición bioquímica de Arthrospira sp. (100g) Datos de USDA 2017

\begin{tabular}{lr} 
Composición de Arthrospira sp. & en $\mathbf{1 0 0 ~ g}$ \\
\hline Energía & $290 \mathrm{kcal}$ \\
Carbohidratos & $23,90 \mathrm{~g}$ \\
Grasas & $5,38 \mathrm{~g}$ \\
$\quad$ Saturadas & $2,65 \mathrm{~g}$ \\
$\quad$ Mono-insaturadas & $0,68 \mathrm{~g}$ \\
$\quad$ Poli-insaturadas & $2,08 \mathrm{~g}$ \\
Proteínas & $57,47 \mathrm{~g}$ \\
Agua & $4,68 \mathrm{~g}$
\end{tabular}

Arthrospira sp. está reconocida mundialmente por el Permanent Observer with the United Nations Economic and Social Council (ECOSOC), y está sujeta a la resolución E/2003/212, de 5 de marzo del 2003. Arthrospirasp.representa una alternativa a la malnutrición, no solo por sus propiedades nutritivas sino porque su cultivo y recolección son sencillas. Los estudios de toxicidad revelan que es inocua pudiéndose utilizar como suplemento alimenticio en animales y humanos (Chamorro y Salazar-Jacobo, 1995; Chamorro et al., 1996).

\subsubsection{Proteínas}

Arthrospira sp. tiene un contenido en proteína total inusualmente alto, en torno al $65 \%$ en peso seco (Phang et al., 2000). En la Tabla 1.3 se resume su composición de aminoácidos. Contiene todos los aminoácidos esenciales y en cantidades muy balanceadas, teniendo en cuenta las necesidades nutricionales del ser humano y los estándares FAO. 
Tabla 1.3 Composición en aminoácidos esenciales (g/100g) tipo aportados por Arthrospira sp. (IIMSAM, 2012; Herickson, 1989) vs. Recomendaciones de necesidades para humanos (FAO), tilapia (Fitzsimmons, 1997), y las contenidas en Chlorella sp. y huevo (Quevedo, 1999).

\begin{tabular}{lcccccc} 
Aminoácido & $\begin{array}{c}\text { Arthrospira } \\
\text { sp.2012 }\end{array}$ & $\begin{array}{c}\text { Arthrospira } \\
\text { sp.1989 }\end{array}$ & $\begin{array}{c}\text { Patrón } \\
\text { Humano }\end{array}$ & Nec.Tilapias & Chlorella sp. & Huevo \\
\hline Isoleucina & 6,40 & 3,50 & 3,20 & 4,30 & 4,82 & 5,80 \\
Leucina & 10,40 & 5,40 & 6,60 & 7,00 & 10,78 & 9,00 \\
Histidina & 4,50 & 2,90 & 2,00 & 5,00 & 7,70 & 6,70 \\
Metionina & 2,20 & 2,00 & $3,10^{1}$ & 1,70 & 1,55 & 3,00 \\
Fenilalanina & 5,40 & 5,80 & $5,90^{2}$ & 4,50 & 6,02 & 5,30 \\
Treonina & 5,40 & 3,20 & 3,10 & 3,60 & 5,60 & 5,30 \\
Triptófano & 1,50 & 0,90 & 0,85 & 1,00 & 1,70 & 1,50 \\
Valina & 7,50 & 4,00 & 4,30 & 5,80 & 7,86 & 7,20 \\
& & & & & & \\
\end{tabular}

No obstante, se ha de tener en cuenta un factor muy importanteque es la digestibilidad de la proteína puesto que no toda la proteína que se ingiere es digerida por el organismo. La digestibilidad de la proteína del género Arthrospira sp. se encuentra en torno al $62 \%$ (Henrikson, 1989), un porcentaje de digestibilidad similar a las proteínas de origen vegetal como el trigo (63\%) o el tofu (65\%), e inferior a las de origen animal como el pescado $(80 \%)$ o el huevo (94\%).

Tabla 1.4 Cuadro resumen de la cantidad y calidad de la proteína (UNP, utilización neta proteica) en alimentos comunes, incluyendo a Arthrospira sp. y algunas algas comunes. Datos de Quevedo (1999), y Henrikson (1989).

\begin{tabular}{lccc} 
Alimento & Proteína (\%) & UNP (\%) & Proteína útil (\%) \\
\hline Arthrospira sp. & 65 & 62 & 40,30 \\
Huevo seco & 47 & 94 & 44,18 \\
Levadura de cerveza & 45 & 50 & 22,50 \\
Chlorella sp. & 40 & 62 & 24,80 \\
Harina de soja integral & 37 & 61 & 22,57 \\
Leche en polvo desnatada & 36 & 82 & 29,52 \\
Queso parmesano & 36 & 70 & 25,20 \\
Germen de trigo & 27 & 67 & 18,09 \\
Cacahuetes & 26 & 38 & 9,88 \\
Pollo & 24 & 67 & 16,08 \\
Pescado & 22 & 80 & 17,60 \\
Carne de buey & 22 & 67 & 14,74 \\
Semillas de sésamo & 19 & 60 & 11,40 \\
Harina de avena integral & 15 & 66 & 9,90 \\
Harina de trigo integral & 14 & 63 & 8,82 \\
Harina Ulva sp. & 11 & 86 & 9,07 \\
Harina Laurencia johnstonii & 10 & 83 & 8,63 \\
Harina Sargassum sinicola & 9 & 91 & 8,47 \\
Tofu húmedo & 8 & 65 & 5,20 \\
Arroz integral & 8 & 60 & 4,80
\end{tabular}


Para obtener el porcentaje de proteína útil de un alimento se ha de multiplicar el porcentaje de proteína que contiene por el porcentaje de digestibilidad de la proteína. Desde este punto de vista, la Arthrospira sp. se acerca a los valores nutricionales del huevo, por encima de alimentos como la leche o la carne (Tabla 1.4).

\subsubsection{Lípidos}

El contenido en lípidos en Arthrospira sp. es de aproximadamente un 6\% en peso seco, del cual el 1-2\% son ácidos grasos altamente poli-insaturados (PUFAs). En particular esta cianobacteria es rica en ácido $\gamma$-linoleico (Macera et al., 2005). Se ha de tener en cuenta que tanto su cantidad como composición varía en función de las condiciones de cultivo, principalmente de la iluminación recibida y de la concentración de nitrógeno del cultivo. Cuando la iluminación es escasa, aumenta el contenido de lípidos en el interior de las células, como reserva de energía.

Tabla 1.5 Composición en lípidos principales en Arthrospira sp. en \% de ácidos grasos y lípidos totales (según Maza et al., 2011).

\begin{tabular}{|c|c|c|c|}
\hline Lípidos & $\mathrm{N}^{0} \mathrm{C}$ & Fórmula & $\%$ \\
\hline Saturados & $\mathrm{N}: 0$ & & 52,725 \\
\hline \multirow{2}{*}{ Ácido Mirístico } & 14:0 & $\mathrm{CH}_{3}\left(\mathrm{CH}_{2}\right)_{12} \mathrm{COOH}$ & 0,724 \\
\hline & $15: 0$ & $\mathrm{CH}_{3}\left(\mathrm{CH}_{2}\right)_{13} \mathrm{COOH}$ & 0,454 \\
\hline Ácido Palmítico & $16: 0$ & $\mathrm{CH}_{3}\left(\mathrm{CH}_{2}\right)_{14} \mathrm{COOH}$ & 46,784 \\
\hline Ácido Margárico & $17: 0$ & $\mathrm{CH}_{3}\left(\mathrm{CH}_{2}\right)_{14} \mathrm{COOH}$ & 0,487 \\
\hline \multirow[t]{2}{*}{ Ácido Esteárico } & 18:0 & $\mathrm{CH}_{3}\left(\mathrm{CH}_{2}\right)_{15} \mathrm{COOH}$ & 1,154 \\
\hline & 19:0 & $\mathrm{CH}_{3}\left(\mathrm{CH}_{2}\right)_{16} \mathrm{COOH}$ & 0,473 \\
\hline Ácido Araquínoico & 20:0 & $\mathrm{CH}_{3}\left(\mathrm{CH}_{2}\right)_{17} \mathrm{COOH}$ & 1,301 \\
\hline Ácido Behénico & 22:0 & $\mathrm{CH}_{3}\left(\mathrm{CH}_{2}\right)_{19} \mathrm{COOH}$ & 1,340 \\
\hline Monoinsaturados & $\mathrm{N}: 1$ & & 16,662 \\
\hline Ácido Sapiénico & $16: 1$ & $\mathrm{CH}_{3}\left(\mathrm{CH}_{2}\right)_{8} \mathrm{CH}=\mathrm{CH}\left(\mathrm{CH}_{2}\right)_{4} \mathrm{COOH}$ & 1,630 \\
\hline Ácido Palmitoleico & $16: 1$ & $\mathrm{CH}_{3}\left(\mathrm{CH}_{2}\right)_{5} \mathrm{CH}=\mathrm{CH}\left(\mathrm{CH}_{2}\right)_{7} \mathrm{COOH}$ & 3,497 \\
\hline Ácido Oleico & 18:1 & $\mathrm{CH}_{3}\left(\mathrm{CH}_{2}\right)_{7} \mathrm{CH}=\mathrm{CH}\left(\mathrm{CH}_{2}\right)_{7} \mathrm{COOH}$ & 7,210 \\
\hline Ácido Eláico & 18:1 & $\mathrm{CH}_{3}\left(\mathrm{CH}_{2}\right)_{7} \mathrm{CH}=\mathrm{CH}\left(\mathrm{CH}_{2}\right)_{7} \mathrm{COOH}$ & 0,210 \\
\hline Poli-insaturados & N:n & & 34,613 \\
\hline Ácido Linoleico & 18:2 & $\mathrm{CH}_{3}\left(\mathrm{CH}_{2}\right)_{4} \mathrm{CH}=\mathrm{CHCH}_{2} \mathrm{CH}=\mathrm{CH}\left(\mathrm{CH}_{2}\right)_{7} \mathrm{COOH}$ & 16,007 \\
\hline Ácido $\alpha$-Linolénico & $18: 3$ & $\mathrm{CH}_{3} \mathrm{CH}_{2} \mathrm{CH}=\mathrm{CHCH}_{2} \mathrm{CH}=\mathrm{CHCH}_{2} \mathrm{CH}=\mathrm{CH}\left(\mathrm{CH}_{2}\right)_{7} \mathrm{COOH}$ & 17,028 \\
\hline Ác, 11,14 Eicosanocio & 20:2 & $\mathrm{CH}_{3}\left(\mathrm{CH}_{2}\right)_{9} \mathrm{CH}=\mathrm{CHCH}_{2} \mathrm{CH}=\mathrm{CH}\left(\mathrm{CH}_{2}\right)_{4} \mathrm{COOH}$ & 0,077 \\
\hline Ácido Araquidónico & $20: 4$ & $\mathrm{CH}_{3}\left(\mathrm{CH}_{2}\right)_{4} \mathrm{CH}=\mathrm{CHCH}_{2} \mathrm{CH}=\mathrm{CHCH}_{2} \mathrm{CH}=\mathrm{CHCH}_{2} \mathrm{CH}=\mathrm{CH}\left(\mathrm{CH}_{2}\right)_{3} \mathrm{COOH}$ & 1,501 \\
\hline
\end{tabular}




\subsubsection{Glúcidos}

Arthrospira sp. tiene un contenido en azúcares de 8-14\% del peso seco principalmente en forma de polisacáridos de los que sus monómeros mayoritarios son glucosa, galactosa, manosa y ribosa (Tabla 1.6).

Tabla 1.6 Composición en carbohidratos de Arthrospira sp. (\% de Carbohidratos), según Pignolet et al. (2012) y Cohen B. (2014).

\begin{tabular}{lrr} 
Carbohidratos & Pignolet 2012 & Cohen $\mathbf{1 9 9 7}$ \\
\hline Galactosa & 14,9 & 8,2 \\
Xilosa & 14,3 & 4,5 \\
Glucosa & 13,2 & 7,5 \\
Fructosa & 13,2 & 3,3 \\
Ramosa & 3,7 & 17,1 \\
Arabinosa & 1,0 & $\ldots$ \\
Manosa & 0,3 & 1,9 \\
Ac. Galacturónico y Glucurónico & 13,5 & $\ldots$. \\
Glicerol & $\ldots$. & 7,4 \\
Metil-hexosa & $\ldots$. & 8,1 \\
Ribosa & $\ldots$. & 8,1
\end{tabular}

Pigmentos y vitaminas: al tratarse de un organismo foto-autótrofo la Arthrospira sp. contiene elevadas concentraciones de pigmentos. Los pigmentos ayudan a sintetizar muchas encimas necesarias para regular el metabolismo, y son importantes antioxidantes. Arthrospira sp, contiene carotenoides $(0,37 \%$ en peso), así como clorofila, y ficocianina (Figura 1.7). Este último pigmento es un complejo proteico que forma hasta un $20 \%$ del peso. Este compuesto solo se encuentra en las denominadas algas verde-azuladas (Henrikson, 1989). Arthrospira sp. contiene vitaminas: $\mathrm{B}_{1}$ (tiamina), $\mathrm{B}_{2}$ (riboflavina), $\mathrm{B}_{3}$ (niacina), $\mathrm{B}_{6}$ (piridoxina), $\mathrm{B}_{12}$ (cianocobalamina), C y E, entre otras.

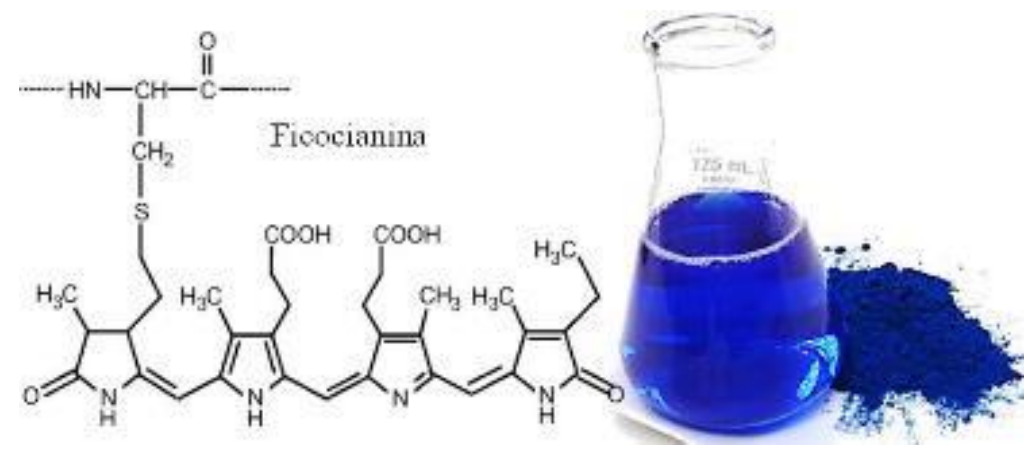

Figura 1.7 Estructura química de la ficobilina presente en la ficocianina. Zheng et al., 2013. 
Tabla 1.7 Composición pigmento-vitamínica de Arthrospira sp. (mg/kg MS). Datos de IISAM 2012, USDA 2017.Necesidades en la dieta de Tilapia (Fitzsimmons, 1997).

$\begin{array}{lrrr}\text { Vitaminas de la } & \text { IIMSAM 2012 } & \text { USDA 2017 } \\ \text { Arthrospira sp. (MS) } & (\ldots / \mathrm{kg}) & \begin{array}{r}\text { Fitzsimmons } \\ (\ldots / \mathrm{kg})\end{array} & \begin{array}{r}\text { 1997Nec.Tilapia(.../kg) } \\ \hline \text { Vitamina A (retinol) }\end{array} \\ \text { Vitamina B1 (tiamina) } & \ldots 5 & 290 \mu \mathrm{mg} & 4000-\mathrm{UI} \\ \text { Vitamina B2 (riboflavina) } & 40 \mathrm{mg} & 23,8 \mathrm{mg} & 11 \mathrm{mg} \\ \text { Vitamina B3 (niacina) } & \ldots . & 128,2 \mathrm{mg} & 20 \mathrm{mg} \\ \text { Vitamina B5 (ácido pantoténico) } & 11 \mathrm{mg} & 34,8 \mathrm{mg} & \ldots \\ \text { Vitamina B6 (piridoxina) } & 3 \mathrm{mg} & 6,4 \mathrm{mg} & 35 \mathrm{mg} \\ \text { Vitamina B12 (Cianocobalamina) } & 2 \mathrm{mg} & \ldots . & 11 \mathrm{mg} \\ \text { Vitamina C (ácido ascórbico) } & \ldots . & 101 \mathrm{mg} & 0.01 \mathrm{mg} \\ \text { Vitamina E ( } \alpha \text {-tocoferol) } & 190 \mathrm{mg} & 5 \mathrm{mg} & 375 \mathrm{mg} \\ \text { Vitamina K (fitomenadiona) } & \ldots . . & 255 \mathrm{mg} & 66-\mathrm{UI} \\ \text { Inositol } & 350 \mathrm{mg} & \ldots . & 4,4 \mathrm{mg} \\ \beta \text {-caroteno } & 1.700 \mathrm{mg} & 342 \mu \mathrm{g} & \ldots \\ \alpha \text {-caroteno } & \text { Trazas } & \ldots . & \ldots \\ \text { Biotina (H) } & 0,4 \mathrm{mg} & \ldots . . & \ldots \\ \text { Ácido Fólico } & 0,5 \mathrm{mg} & \ldots . . & 5 \mathrm{mg}\end{array}$

Minerales: Durante su desarrollo las microalgas absorben y "quelan" de forma natural muchos oligoelementos (Henrikson, 1989). De esta forma los minerales son mejor asimilados por el organismo humano. Evidentemente el contenido mineral de Arthrospira sp. varía según el medio de cultivo (Tabla 1.8), siendo una fuente de hierro de calidad y fácilmente asimilable. Es de uso aconsejable en dietas vegetarianas y veganas.

Tabla 1.8 Composición mineral de tipo de Arthrospira sp. (mg/kg MS). IISAM (2012) y USDA (2017). Necesidades en la dieta de Tilapia (Fitzsimmons, 1997).

\begin{tabular}{lrrr}
$\begin{array}{l}\text { Minerales de la } \\
\text { Arthrospira sp. (MS). }\end{array}$ & $\begin{array}{r}\text { IIMSAM 2012 } \\
(\mathrm{mg} / \mathrm{kg})\end{array}$ & $\begin{array}{r}\text { USDA 2017 } \\
(\mathrm{mg} / \mathrm{kg})\end{array}$ & $\begin{array}{r}\text { Fitzsimmons 1997 } \\
\text { Nec.Tilapias (mg/kg) }\end{array}$ \\
\hline Calcio & $1.045-1.315$ & 1.200 & $\ldots$ \\
Hierro & $475-580$ & 285 & 150 \\
Magnesio & $1.410-1.915$ & 1.950 & 500 \\
Manganeso & $18-25$ & 19 & 13 \\
Fósforo & $7.617-8.942$ & 1.180 & 7000 \\
Potasio & $13.305-15.400$ & 13.630 & $\ldots$ \\
Sodio & $275-412$ & 10.480 & $\ldots$ \\
Zinc & $27-39$ & 20 & 20
\end{tabular}

Su contenido en ácidos nucleicos puede ser un problema para los pacientes con propensión a sufrir gota. 


\subsubsection{Aplicación de Arthrospira sp. en animales}

Uno de los problemas principales en el uso de microalgas en la producción animal lo encontramos en los costes de producción, sobre todo si los comparamos con otras fuentes de alimentación animal. Esto hace que su uso sea poco práctico en muchas operaciones de producción animal a gran escala (Becker, 2007). Sin embargo, el coste de Arthrospira sp. se puede reducir con la mejora y evolución de los medios de producción (Shimamatsu, 2004; Raoof et al., 2006; Peiretti y Meineri, 2011). Además, cabe destacar que la investigación de la utilización de Arthrospira sp. en la producción animal y su impacto en la calidad del producto nos permite comprender cada vez más los aspectos prácticos de su uso.

\subsubsection{Avicultura}

En avicultura algunos investigadores han demostrado una mejora en la salud de los pollos cuando se incluye en la dieta Arthrospira sp. en niveles del 1\%, observando mayor resistencia a las enfermedades (Venkataraman et al., 1994; Qureshi et al., 1996; Al-Batshan et al., 2001). Estos estudios también evidencian, que Arthrospira sp. mejora la calidad de los productos derivados de la producción avícola.

En gallinas ponedoras encontramos referencias de un aumento en el color de la yema de huevo (naranja) (Ross y Dominy, 1990; Sujatha y Narahari, 2011; Saxena et al., 1983). Hallazgos similares se han encontrado en ensayos con codornices japonesas (Ross et al., 1994). El efecto de Arthrospira sp. sobre el color de la yema es el resultado de su alto contenido de zeaxantina, xantofilas y otros pigmentos carotenoides, particularmente el $\beta$-caroteno, que se acumula dentro de la yema (Anderson et al., 1991; Takashi, 2003). Se ha encontrado que estos mismos compuestos también se acumulan en el tejido muscular de los pollos.

\subsubsection{Porcino}

En porcino, si analizamos la relación que tiene la suplementación con Arthrospira sp. en los reproductores, Granaci (2007) encontró que los verracos que recibían un extracto de Arthrospira sp. tenían una mayor calidad de esperma en general que sus contrapartes no suplementadas en términos de aumento del volumen de esperma en un $11 \%$, y motilidad y viabilidad posterior al almacenamiento en un $5 \%$.

\subsubsection{Rumiantes}

El rumen de los rumiantes les hace especialmente adecuado para la utilización de algas en la dieta. Arthrospira sp. se puede usar en rumiantes en niveles de hasta un $20 \%$ del alimento total, niveles superiores a los recomendados para otras microalgas como Chlorella o 
Scenedesmus obliguggs (Gouveia et al., 2008). Algunos estudios muestran que Arthrospira sp. aumenta la producción de proteína cruda microbiana y reduce su tiempo de retención dentro del rumen (Quigley y Poppi, 2009). Además, aproximadamente un 20\% de Arthrospira sp. suministrada no es degradada por el rumen y puede ser digerida directamente por el abomaso (Quigley y Poppi, 2009; Panjaitan et al., 2010; Zhang et al., 2010). Otro dato interesante es que se puede administrar en rumiantes en suspensión acuosa de la microalga, siendo aceptada por estos (Panjaitan et al., 2010), lo que reduce uno de los factores más costosos de su producción, el secado.

En recientes investigaciones, se atribuye a la suplementación con algas la capacidad de seleccionar la población de protozoos ruminales, influyendo de esta forma en la proporción de ácidos grasos de cadena corta (Boeckaert et al., 2008). Shimkiene et al. (2010) han demostrado que los corderos de ovejas gestantes que reciben Arthrospira sp. nacen con más peso (hasta 4,07\% más). En corderos, Bezerra et al. (2010) encontraron que los corderos que reciben Arthrospira sp. tienen pesos vivos y ganancias medidas diarias (GMD) más altas que otros corderos que no reciben.

\subsubsection{Ganado Lechero}

Arthrospira sp. tiene resultados positivos en la productividad en ganado lechero. Estudios como los de Kulpys et al. (2009) muestran que las vacas que recibían Arthrospira sp. en la dieta tenían un aumento de hasta un $21 \%$ en la producción de leche. Además, Simkus et al. $(2007,2008)$ reflejaron un aumento en la grasa láctea (entre 17.6\% y 25.0\%), proteína de la leche (hasta 9.7\%) y lactosa (hasta 11.7\%). El contenido de ácidos grasos saturados de la leche disminuyó y los ácidos grasos monoinsaturados y PUFA's aumentaron cuando las vacas recibieron Arthrospira sp. (Christaki et al., 2012). El consumo de Arthrospira sp. también se ha asociado con disminuciones significativas en el recuento de células somáticas de la leche (Simkus et al., 2007), mejorando así el valor de la misma. Además, se ha encontrado que las vacas lecheras que reciben Arthrospira sp. tienen una mejor condición corporal (8.5-11\%) (Kulpys et al., 2009).

\subsubsection{Acuicultura}

Las algas son parte de la dieta básica de los ecosistemas acuáticos. En acuicultura las microalgas se usan muy habitualmente, principalmente para la producción de larvas y juveniles y peces, así como para elevar el zooplancton requerido para la alimentación de animales juveniles. Arthrospira sp. se usa en cantidades sustanciales (más de $100 \mathrm{t}$ anuales) 
como alimentación de peces y camarones, e incluso se pueden proyectar mercados más grandes si los costos de producción pudieran reducirse. Aunque, del efecto y rendimiento de A. platensis en acuicultura se retomará en más en profundidad en posteriores capítulos de la tesis, se puede mencionar a priori algunos ejemplos.

Varios estudios han considerado los efectos de la suplementación con A. platensis (menos del $10 \%$ de la dieta) en los peces. En peces de cola de espada roja (Xiphophorus helleri) a los que se les administró $8 \%$ de $A$. platensis, aumentó el consumo de alimento, el peso corporal, la longitud, el peso de las gónadas y el número de crías (James et al., 2006). En gourami de tres puntos (Trichopodus trichopterus), Khanzadeh et al. (2016) encontraron que 5\% de A. platensis (reemplazo de la harina de pescado) mejora el consumo de alimento, la tasa de conversión alimentación (FCR) y el índice gonadosomático. Truchasarcoíris (Oncorhynchus mykiss) suplementadas con un $10 \%$ de A. platensis (una fuente de pigmento natural) deposita más carotenoides en el tejido muscular (Teimouri et al., 2013). La adición de A. platensis a la alimentación de guppies (Poecilia reticulata) mejora su tolerancia a una toxina (rojo de metilo), que se manifiesta por una reducción notable de los efectos citotóxicos en los glóbulos rojos (Sharma et al., 2005).

\subsection{Arthrospira sp. en Oreochromis sp.}

En $O$. niloticus, cuando se agrega $0,5-1-2 \%$ de $A$. platensis al alimento se mejora su sistema inmunitario (Abdel-Tawwab y Ahmad, 2009), tiene efectos antioxidantes y promueve el crecimiento (Takeuchi et al., 2002; Belal y El-Hais, 2012), probablemente debido a su alto contenido en xilosa, fructosa, galacturónico y ácido glucurónico (todos los cuales se consideran prebióticos) y otros compuestos como los ácidos grasos $\omega 3$ y $\omega 6$, el $\beta$-caroteno o la ficocianina (Pingnolet et al., 2012), que tienen actividad antiviral (Chamorro et al., 2002). Se han utilizado diferentes estrategias para modificar el microbiota intestinal utilizando prebióticos en Oreochromis sp. (Haygood y Jha, 2016).

Según Belay et al. (1996), desde el punto de vista de la relación coste-efectividad, la aplicación más prometedora puede ser sus efectos de mejora inmunitaria y, a través de esto, sus propiedades antivirales y antibacterianas, ya que estos efectos se presentan a concentraciones suplementarias muy bajas en los alimentos. Los animales jóvenes a menudo tienen un sistema inmune deficiente durante las primeras semanas de vida. 


\subsection{TILAPIA DEL NILO "OREOCHROMIS NILOTICUS SP."}

Con el nombre de Tilapia se conoce a un grupo de peces originarios de regiones tropicales y subtropicales de África (Figura 1.8), en las que se dan las condiciones favorables para su reproducción y crecimiento. Prefiere aguas someras y cálidas de entre 28 y $36^{\circ} \mathrm{C}$, siendo su límite de temperatura inferior de $11-12^{\circ} \mathrm{C}$ y superior de $42^{\circ} \mathrm{C}$. Es un pez omnívoro que se alimenta de fitoplancton, plantas acuáticas, pequeños invertebrados, fauna béntica, desechos y capas bacterianas asociadas al detritus (Beveridge y Baird, 2000). La tilapia ha sido catalogada como uno de los cultivos acuícolas más prometedores y de mayor futuro para la acuicultura, debido principalmente a altísima adaptabilidad y a su velocidad de crecimiento (Gramados et al., 2002; Green, 1995).

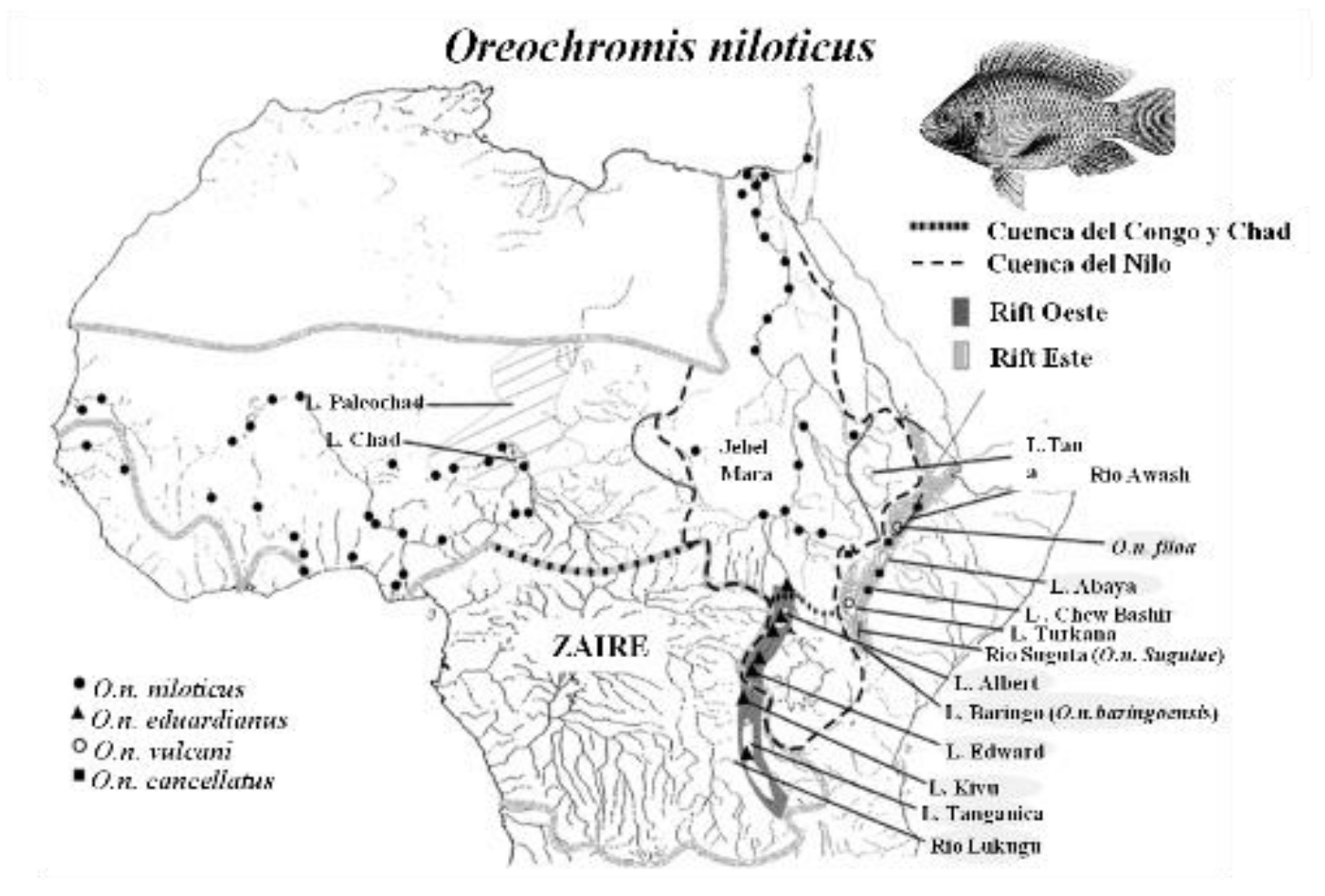

Figura 1.8 Distribución geográfica de las poblaciones originarias de O. niloticus y sus sub-especies (Beveridge y Baird, 2000; FAO, 2017).

Según la descripción de la FAO, O. niloticus se describe como un pez de cuerpo comprimido dónde la profundidad del pedúnculo caudal es igual a su longitud. Durante la época de desove, las aletas pectoral, dorsal y caudal adquieren una coloración rojiza y la aleta dorsal unas tonalidades más oscuras con líneas negras (Figura 1.9). 

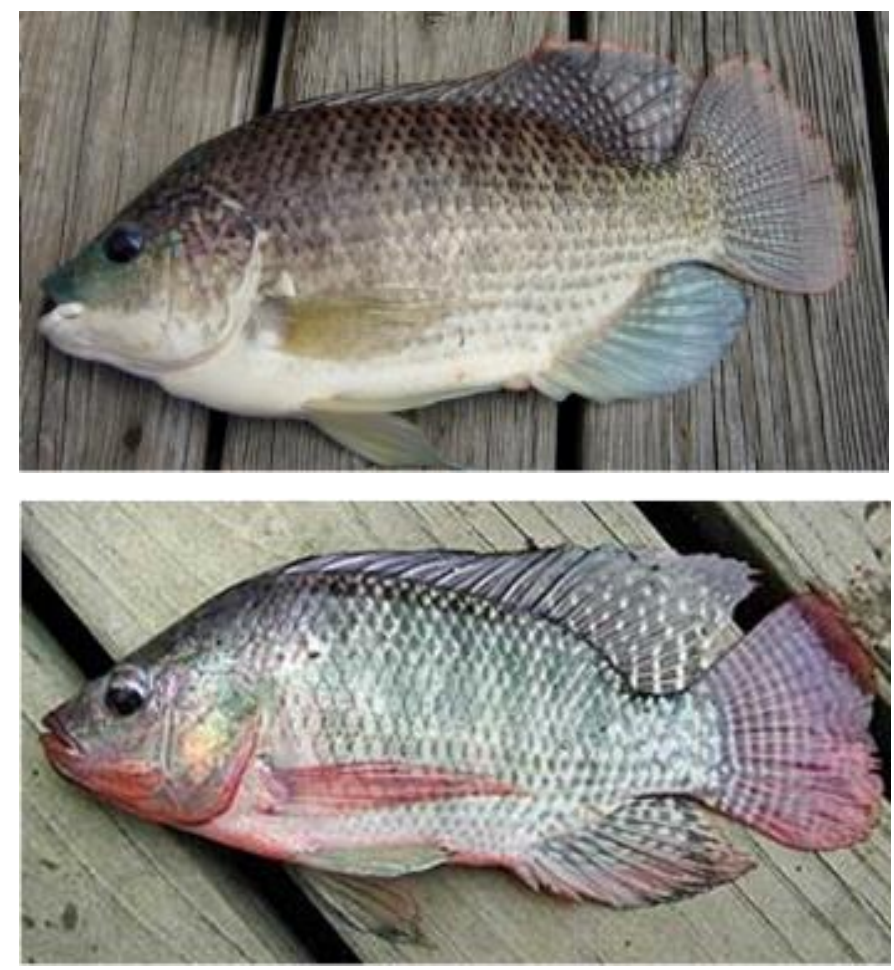

Figura 1.9 Diferencia de coloración de O. niloticus linnaeus, 1758 (Cichlidae). Arriba se puede ver los colores pardo-grisáceos normales de la tilapia salvaje. Debajo se puede observar los colores verderojizos y negros correspondientes a la librea de apareamiento.

El género Oreochromis sp. ha sido introducido en aguas naturales de un gran número de países tropicales y subtropicales de América central, Sudamérica y Asia. La distribución geográfica actual se puede inferir observando los datos oficiales de su pesca (Tabla 1.9), que predomina en los países de origen, como Egipto, Kenia o Sudan, seguido por países tropicales donde su implantación temprana y la climatología favorecen su crecimiento, como Indonesia, Tailandia, Kenia o Malí.

Tabla 1.9 Estadística pesquera de O. niloticus en los países de máxima captura. Datos en toneladas (FAO Stast, 2017).

\begin{tabular}{lrrrrr} 
País & $\mathbf{2 0 1 0}$ & $\mathbf{2 0 1 1}$ & $\mathbf{2 0 1 2}$ & $\mathbf{2 0 1 3}$ & $\mathbf{2 0 1 4}$ \\
\hline Egipto & 130.330 & 120.220 & 102.186 & 102.802 & 107.956 \\
Indonesia & 17.345 & 22.534 & 28.484 & 27.332 & 28.480 \\
Tailandia & 32.645 & 35.203 & 33.491 & 19.982 & 28.100 \\
Kenia & 24.572 & 38.153 & 25.261 & 25.071 & 25.999 \\
Malí & 30.000 & 32.400 & 21.342 & 29.826 & 22.415 \\
Sudán & 0 & 0 & 18.000 & 18.000 & 18.000 \\
Ruanda & 443 & 938 & 1.377 & 1.173 & 2.002 \\
El Salvador & 0 & 0 & 850 & 790 & 831 \\
Burundi & 41 & 24 & 44 & 28 & 15 \\
Rep. Djibuti & 5 & 6 & 10 & 10 & 10 \\
Ecuador & 22 & 43 & 5 & 7 & 3
\end{tabular}




\subsubsection{Producción mundial de Oreochromis niloticus}

Según los informes de la FAO (FAO Stats, 2017) la producción mundial de tilapia sigue el ritmo ascendente (Figura 1.10), con China en la cabeza en 2014 con 1278483 t, mientras que Egipto, el país de origen, reportó una producción cercana a las 760000 t en ese mismo año. Por otro lado, Indonesia supero la producción de Egipto alcanzando casi el millón de toneladas. Tailandia y Filipinas oscilan entre las 200000 t y 150000 t, respectivamente. España se sitúa en un modesto puesto $66^{\circ}$, con una producción que ronda las $10 \mathrm{t}$ anuales (Tabla 1.10).

Tabla 1.10 Producción mundial de tilapia cultivada en toneladas en el periodo comprendido entre el 2010 y el 2014. Datos obtenidos de FAO Fish-Stats (2017).

\begin{tabular}{lrrrrr} 
País (País) & $\mathbf{2 0 1 0}$ & $\mathbf{2 0 1 1}$ & $\mathbf{2 0 1 2}$ & $\mathbf{2 0 1 3}$ & $\mathbf{2 0 1 4}$ \\
\hline China & 998.890 & 1.080 .800 & 1.164 .733 & 1.243 .317 & 1.278 .483 \\
Indonesia & 429.053 & 567.077 & 695.063 & 914.168 & 999.694 \\
Egipto & 557.049 & 610.617 & 768.752 & 635.843 & 759.601 \\
Tailandia & 179.240 & 155.544 & 203.029 & 197.595 & 188.907 \\
Filipinas & 168.399 & 166.429 & 164.582 & 168.872 & 169.467 \\
Uganda & 31.500 & 28.101 & 52.303 & 47.841 & 53.093 \\
Ghana & 9.424 & 18.200 & 26.400 & 30.900 & 36.900 \\
Honduras & 16.455 & 20.000 & 20.500 & 22.600 & 29.750 \\
Rep. Dem. Pop. Lao & 20.580 & 24.000 & 25.500 & 27.000 & 27.000 \\
Ecuador & 47.733 & 48.000 & 39.818 & 23.920 & 23.900 \\
España $\left(66^{\circ}\right)$ & 0 & 0 & 0 & 9,1 & 10,38 \\
Total & 2.537 .491 & 2.809 .773 & 3.261 .192 & 3.425 .121 & 3.670 .259
\end{tabular}

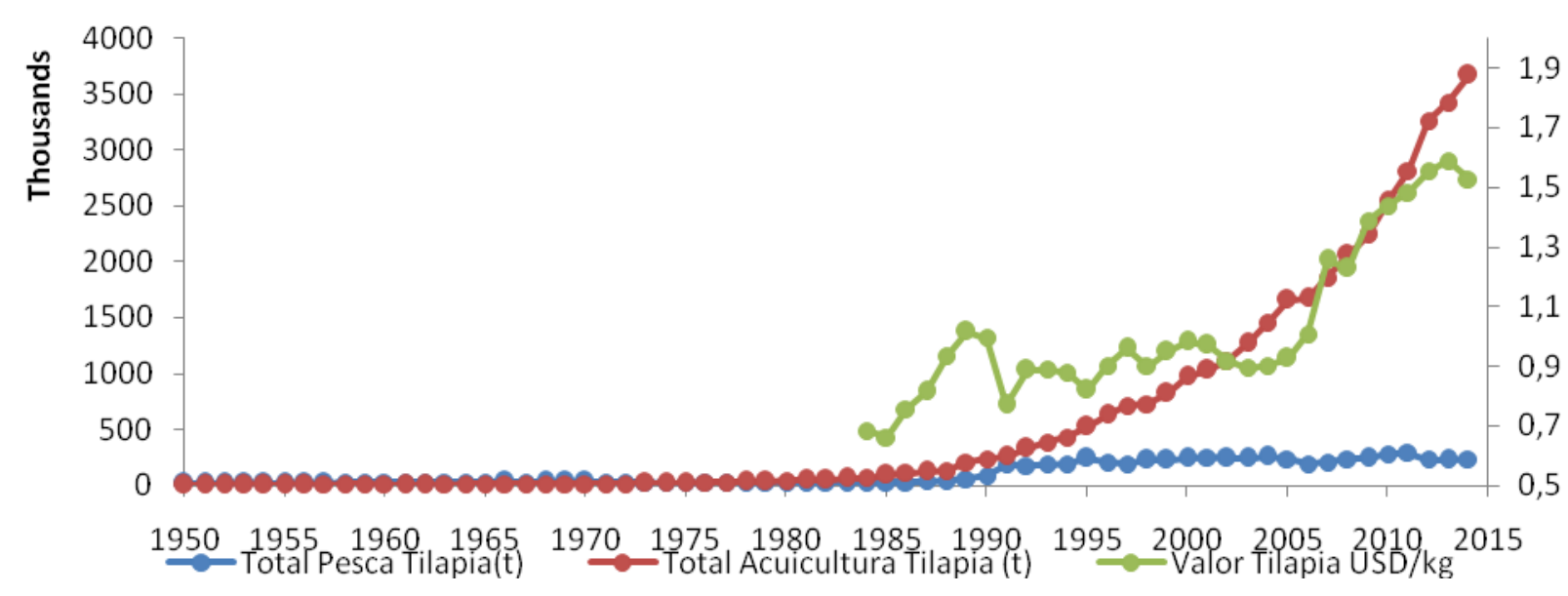

Figura 1.10 Pesca, producción y valor en USD, de tilapia del Nilo desde 1950. Datos obtenidos de FAO Fish-Stats (2017). 
Estados Unidos es un gran importador de esta especie, siendo el tercer producto acuícola más importado por ese país, después del camarón y el salmón del Atlántico. En China, la mayoría de la producción se destina a consumo interno. Un pequeño porcentaje se exporta a Estados Unidos y en menor medida, a otros destinos. Ha demostrado ser un producto de gran acogida en el mercado latinoamericano, siendo uno de los pescados más consumidos en El Salvador y Colombia.

En España su consumo y comercialización aun es baja, pero poco a poco aparece en los menús de escuelas, hospitales y universidades. Los principales productores del país se encuentran en el sur y la costa levantina, donde los rangos estacionales de temperatura son buenos para su producción. Las empresas más importantes en España son Valaqua (Valencia), Tilamur (Murcia) y Bravía (Córdoba).

\subsubsection{Características nutricionales de Oreochromis niloticus}

La composición química de los peces varía considerablemente entre especies, individuos, así como del sexo, la edad, época del año y nivel de alimentación. Los principales constituyentes de la carne de tilapia en término medio se expresan en la tabla siguiente (Tabla1.11).

Tabla 1.11 Composición bioquímica de la O. niloticus (100 g) según Dale et al. (2004).

Composición Tilapia

Energía

Carbohidratos

Grasas

Saturadas

Mono-insaturadas

Polinsaturadas

Proteínas

Agua

\section{En 100 g MS} 290 Kcal

$0 \mathrm{~g}$

$11,74 \mathrm{~g}$

$4,49 \mathrm{~g}$

$5,33 \mathrm{~g}$

$1,91 \mathrm{~g}$

$54,80 \mathrm{~g}$

$7,40 \mathrm{~g}$

Las proteínas del pescado contienen todos los aminoácidos esenciales y de la misma manera que las proteínas de la leche, los huevos y la carne de mamíferos, tienen un valor biológico muy alto (Tabla 1.12). 
Tabla 1.12 Composición en aminoácidos de la O. niloticus (g/100g) de Dale et al. (2004) vs, patrón nutricional FAO (2011).

\begin{tabular}{lrr} 
Aminoácidos & FAO 2011 & Promedio (g/100 g) \pm SD \\
\hline Isoleucina & 3,20 & $1,72 \pm 0,12$ \\
Leucina & 5,90 & $3,18 \pm 0,12$ \\
Lisina & 4,50 & $3,37 \pm 0,13$ \\
Metionina & $3,10^{1}$ & $1,18 \pm 0,09$ \\
Arginina & $5,90^{2}$ & $3,67 \pm 0,13$ \\
Treonina & 3,10 & $2,03 \pm 0,08$ \\
Triptófano & 0,85 & $0,39 \pm 0,03$ \\
Valina & 4,30 & $2,19 \pm 0,15$ \\
Cisteína & $\ldots$ & $0,36 \pm 0,03$ \\
Histidina & 2,00 & $1,07 \pm 0,06$ \\
& & Incluye cisteína $^{1}$, incluye tirosina $^{2}$.
\end{tabular}

Los lípidos presentes en las especies de peces óseos pueden ser divididos en dos grandes grupos: los fosfolípidos y los triglicéridos. Algunos peces contienen ceras esterificadas como parte de sus depósitos de grasa (Tabla 1.13).

Tabla 1.13 Composición en ácidos grasos de la O. niloticus (g/100g). Dale et al. (2004).

\begin{tabular}{|c|c|c|c|}
\hline $\begin{array}{l}\text { Lípidos } \\
\text { (Principales) }\end{array}$ & $\mathbf{N}^{0} \mathbf{C}$ & Fórmula & g MS \\
\hline Saturados & $\mathrm{N}: 0$ & & 10,6 \\
\hline Ácido Mirístico & 14:0 & $\mathrm{CH}_{3}\left(\mathrm{CH}_{2}\right)_{12} \mathrm{COOH}$ & 3,1 \\
\hline Ácido Esteárico & 18:0 & $\mathrm{CH}_{3}\left(\mathrm{CH}_{2}\right)_{15} \mathrm{COOH}$ & 7,5 \\
\hline Monoinsaturados & $\mathrm{N}: 1$ & & 41,5 \\
\hline $\begin{array}{l}\text { Ácido } \\
\text { Palmitoleico }\end{array}$ & $16: 1$ & $\mathrm{CH}_{3}\left(\mathrm{CH}_{2}\right)_{5} \mathrm{CH}=\mathrm{CH}\left(\mathrm{CH}_{2}\right)_{7} \mathrm{COOH}$ & 6,1 \\
\hline Ácido Oleico & $18: 1$ & $\mathrm{CH}_{3}\left(\mathrm{CH}_{2}\right)_{7} \mathrm{CH}=\mathrm{CH}\left(\mathrm{CH}_{2}\right)_{7} \mathrm{COOH}$ & 35,4 \\
\hline Polinsaturados & $\mathbf{N}: \mathbf{n}$ & & \\
\hline Ácido Palmítico & $16: 2$ & $\mathrm{CH}_{3}\left(\mathrm{CH}_{2}\right)_{4} \mathrm{CH}=\mathrm{CHCH}_{2} \mathrm{CH}=\mathrm{CH}\left(\mathrm{CH}_{2}\right)_{7} \mathrm{COOH}$ & 25,7 \\
\hline Ácido Linoleico & $18: 2$ & $\mathrm{COOH}-\left(\mathrm{CH}_{2}\right)_{7}-\mathrm{CH}=\mathrm{CH}-\mathrm{CH}_{2}-\mathrm{CH}=\mathrm{CH}-\left(\mathrm{CH}_{2}\right)_{4}-\mathrm{CH}_{3}$ & 11,9 \\
\hline $\begin{array}{l}\text { Ácido } \\
\text { Araquidónico }\end{array}$ & $20: 4$ & $\mathrm{CH}_{3}\left(\mathrm{CH}_{2}\right)_{4} \mathrm{CH}=\mathrm{CHCH}_{2} \mathrm{CH}=\mathrm{CHCH}_{2} \mathrm{CH}=\mathrm{CHCH}_{2} \mathrm{CH}=\mathrm{CH}\left(\mathrm{CH}_{2}\right)_{3} \mathrm{COOH}$ & 2,0 \\
\hline Omega 3 totales & $\mathrm{N}: 3$ & $\ldots$ & 3,7 \\
\hline
\end{tabular}

Respecto a los minerales, la carne de pescado se considera una fuente particularmente valiosa de calcio y fósforo, así como también de hierro y cobre. Los peces de mar tienen un alto contenido de yodo (Tabla 1.14). 
Tabla 1.14 Composición en minerales de la O. niloticus (g/100 g). Dale et al. 2004.

\begin{tabular}{lc} 
Minerales & $\%$ \\
\hline Calcio & 8,4 \\
Sodio & 0,38 \\
Magnesio & 0,15 \\
Fósforo & 4,1 \\
Potasio & 0,38 \\
& $\mathrm{ppm}$ \\
\hline Cobre & 9,0 \\
Zinc & 67,5 \\
Manganeso & 13,9 \\
Hierro & 187,0
\end{tabular}




\subsection{EFECTO DE ARTHOSPIRA PLATENIS EN OREOCROMIS NILOTICUS}

En su hábitat natural $O$. niloticus se alimenta principalmente de algas (incluyendo cianobacterias) e invertebrados. A. platensis es rica en vitamina B12 y $\beta$-caroteno (20 veces más que las zanahorias) y tiene una alta concentración de aminoácidos esenciales, ácidos grasos ( $\omega 3$ y $\omega 6)$ y minerales (Takeuchi et al., 2002; James et al., 2006), una gran cantidad de proteína (aproximadamente 68\% en peso seco, Phang et al., 2000), así como propiedades antioxidantes. Por todas estas razones es comúnmente utilizado como un suplemento natural en alimentos para animales, incluyendo alimentos para peces (McCarthy, 2007).

\subsubsection{Supervivencia, crecimiento, y calidad de la carne}

El principal cometido de la acuicultura es proveer de proteína de gran calidad, al menor coste posible. Además, como cualquier tipo de producción el control y mejora del crecimiento y la calidad es un concepto fundamental.

\subsubsection{Supervivencia}

El proceso de alevinaje es un momento delicado y sensible en cualquier producción piscícola124 Una vez que los peces superan la fase de juvenil la mortalidad desciende por debajo del 10\% (Meyer, 2004). Esto se debe en parte a que durante las fases tempranas son más sensibles a los parásitos (coccidos, trichodíonidos ó trematodos), a las enfermedades bacterianas (Aeromonas hydrophila, Flavobacterium culumnaris ó Edwarsiella tarda), así como a los cambios ambientales. Además de esto, se ha de tener en cuenta que los ritmos de crecimiento entre individuos son distintos. Se establecen jerarquías, y pueden darse episodios de canibalismo, reduciendo la supervivencia de los alevines más débiles (Berrios y Snow, 1983). Todo esto produce un alto número de bajas durante esta fase crucial.

Estudios suplementando $A$. platensis en la alimentación de peces han demostrado que $A$. platensis actúa como inmunoestimulante, aumentando la resistencia de los peces expuestos al patógenos como Aeromonas hydrophila (Watanuki et al., 2006). Disminuir este número de bajas significa incrementar la eficiencia de las producciones y la inclusión de algas como la A. platensis puede resultar beneficiosa como complemento vitamínico y proteico. Estos nutrientes pueden mejorar la condición de los peces más débiles, mejorando su respuesta al estrés. 


\subsubsection{Crecimiento}

El crecimiento de los peces depende de varios factores como la temperatura, densidad, tipo y tasa de alimentación, y calidad del agua (Villarroel et al., 2011; Xie et al., 2011; Meyer, 1999). En O. niloticus, la mayor tasa de crecimiento la presentan los machos de 6 a 8 meses, el crecimiento promedio de estos es de 18 a $25 \mathrm{~cm}$, con un peso de 150 a $300 \mathrm{~g}$, con unas tasas de crecimiento de 7,66 g/semanales (García et al., 2012).

Para estimar el crecimiento se cuenta con varios parámetros productivos. Los más utilizados son la ganancia media diaria, el factor de condición corporal o el índice de condición alimenticia. Algunos estudios con Arthrospira sp. como suplemento en peces encontraron que A. platensis actúa como promotor del crecimiento (Nandeesha et al., 2001; Takeuchi et al., 2002; Abdel-Tawwab y Ahmad, 2009; Gómes et al., 2012).

\subsubsection{Calidad de la carne}

Según la FAO (2017), la calidad de la carne se define generalmente en función de su calidad composicional (coeficiente magro-graso) y de factores de palatabilidad tales como su aspecto, olor, firmeza, jugosidad, ternura y sabor. La calidad nutritiva de la carne es objetiva, mientras que la calidad "como producto comestible", tal y como es percibida por el consumidor, es altamente subjetiva.

La calidad de la carne está influida por varios aspectos, en el que el más importante es la dieta. Pero también, está influido por el manejo y las características ambientales. Algunos investigadores como Takeuchi et al. (2002) o Abdel-Tawwab y Ahmad (2009) mostraron que los peces alimentados con A. platensis tenían un mayor contenido de proteína, un mayor contenido de lípidos polares y un menor contenido de cenizas que los peces alimentados con la dieta comercial.

La calidad de la carne se puede valorar desde un punto de vista distinto a la composición bioquímica. Para ello se cuenta con una serie de parámetros que están interrelacionados entre sí, y que afectan al proceso de carnificación, o de maduración de la carne. En la figura (1.11) se presentan los principales procesos bioquímicos que se dan durante la fase post-morten, así como los indicadores de respuesta al estrés asociados a la calidad de la carne. 


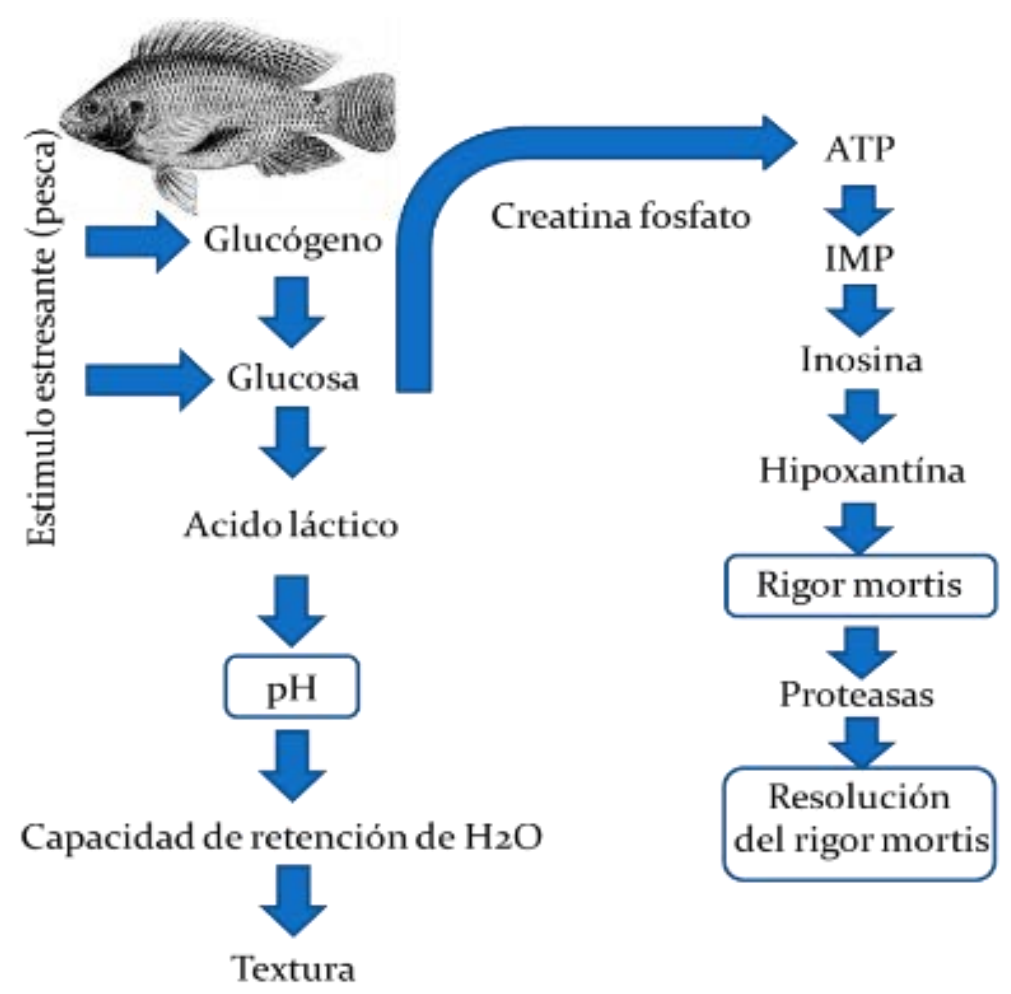

Figura 1.11. Procesos bioquímicos en peces durante la fase post-mortem y principales indicadores de calidad de la carne (adaptado de Poli et al. (2005)).

La energía necesaria para la actividad muscular de un animal vivo se obtiene de los glúcidos, principalmente glucógeno, presentes en el músculo. En un animal en buen estado y relajado, el nivel de glucógeno muscular es elevado. Tras el sacrificio, este glucógeno se transforma en ácido láctico por la respiración anaerobia del musculo. Esto provoca que la canal y el musculo se vuelvan rígidos, apareciendo el fenómeno denominado "rigor mortis". Los niveles adecuados de ácido láctico son necesarios para producir carne de buena calidad, tierna, con buen color, sabor y textura. Cuando el animal es estresado antes del sacrificio, se consume parte o todo el glucógeno disponible en el musculo, lo que reduce la producción de ácido láctico.

Si tiene lugar una gran acumulación previa al sacrificio de lactato en el musculo, principalmente debida a una respuesta del estrés, el $\mathrm{pH}$ de la carne descenderá rápidamente tras el sacrificio. Si el musculo sufre esta rápida caída de $\mathrm{pH}$ la acumulación de ácido láctico es más rápida y establecimiento del rigor mortis sucede antes (1-4 h post-mortem).

De forma contraria, si el animal presenta un agotamiento de sus reservas de glucógeno previo al sacrificio, el $\mathrm{pH}$ no va a descender lo suficientemente rápido tras el sacrificio porque no habrá una suficiente producción de ácido láctico. 
En un animal tranquilo, que no está sometido a una situación de estrés, la creatina fosfato va a ayudar a regenerar los niveles de ATP en el musculo. Sin embargo, cuando el animal ha sido expuesto a un estímulo estresante previo al sacrificio, la creatina fosfato va a ser consumida, presentando niveles inferiores o ningunos de creatina fosfato en el musculo tras sacrificio. Debido a esta situación el ATP va a tener que ser generado desde otra fuente. Esta nueva fuente va a ser principalmente glucógeno, ya que es el mayor depósito de energía en el musculo, que va a ser metabolizado para suplir la falta de ATP y en consecuencia mantener los músculos en un estado de pre-rigor.

\subsection{Rigor mortis}

El rigor mortis es un proceso por el cual se produce una reducción de flexibilidad del musculo, tras la muerte que se corresponden a los procesos bioquímicos explicados anteriormente. Inmediatamente tras la muerte los músculos son blandos y muy flexibles, prerigor mortis. Con el trascurso del tiempo, al cabo de unas horas (1-6h), los músculos comienzan a endurecerse y ya no son capaces de moverse. Transcurridas unas cuantas horas más, comienza el proceso de carnificación. Las proteasas del musculo son liberadas y comienzan a digerir las fibras musculares devolviendo la flexibilidad a los músculos que pierden esta rigidez (post-rigor). Este proceso depende de varios factores, entre los que se encuentra, la especie, el tamaño del pez, el manejo pre-sacrificio, la temperatura de conservación o la alimentación. Las microalgas y sus componentes pueden mejorar la composición bioquímica de la carne de pescado, y por lo tanto interferir en este proceso.

En Oreochromis sp. alimentado con Arthrospira sp. varios estudios han analizado los cambios en la textura de la carne, la composición de las proteínas y los ácidos grasos (Lu et al., 2003; El-Sheekh et al., 2014). Pero se sabe menos sobre el efecto de esta cianobacteria sobre la evolución del rigor mortis.

\subsubsection{2 pH muscular}

Inmediatamente después del cese de la circulación de la sangre en el organismo, el glucógeno almacenado es degradado anaeróbicamente y se acumula ácido láctico en el musculo (Grigorakis et al., 2003), lo que provoca un descenso de pH muscular. A mayor concentración de glucógeno muscular pre-sacrificio, más bajo será el pH y viceversa (Bermejo-Poza et al., 2015). El estado nutricional del pez, así como el nivel de respuesta al estrés, tienen una gran influencia sobre este parámetro de calidad. 


\subsection{Color de la carne}

La industria de la acuicultura, especialmente en las producciones de trucha arcoíris (Oncorhynchus mykiss) y el salmón (Salmo salar), el color de la canal es un importante indicador de calidad para el consumidor. El color de la carne puede modificarse a través de la alimentación. La Unión Europea está preocupada por el uso de ciertos pigmentos utilizados en la acuicultura (Penninks et al., 2017). Las microalgas se muestran como una alternativa viable utilizada en diferentes especies. En O. mykiss y $S$. salar el uso de pigmentos, astaxantina, procedentes de microalgas (Haematococcus pluvialis) se usan habitualmente en la formulación de piensos, para intensificar el color asalmonado en carne de estos peces (Sommer et al., 1991, 1992; Baker et al., 2002).

En este mismo sentido, A. platensis e utiliza en la cría de las mascotas para avivar los colores de aves exóticas y peces de acuario. Pero se sabe menos acerca del efecto que esta cianobacteria y sus pigmentes pueden tener en el color de la canal, de los peces y animales de abasto.

\subsubsection{Bienestar animal y Estrés}

El concepto de bienestar animal incluye tres elementos importantes que tener en consideración. El primer punto es el correcto funcionamiento del organismo, lo que entre otras cosas supone que los animales estén sanos y bien alimentados. En segundo lugar, el estado emocional del animal, incluyendo la ausencia de emociones negativas tales como el dolor y el miedo crónico, y la posibilidad de expresar algunas conductas normales propias de la especie (Fraser et al., 1997). Estos tres principios no son necesariamente contradictorios, sino que en muchas ocasiones son complementarios (Mendl, 2001). Cuando se cumplen estos requisitos el animal está en armonía con el ambiente que lo rodea (Broom, 1986; Mancera y del Rio, 2005). Aunque las condiciones de bienestar pueden variar entre individuos y en el tiempo, ya que un animal no se encuentra en el mismo estado de bienestar todo el tiempo (Curtis, 1985).

Según Ellis et al. (2004) se respeta el bienestar cuando se cumplen las "cinco Libertades" propuestas por la Unión Europea para asuntos sobre el bienestar animal. (FAWC, 1996). 
- Libres de hambre y sed: mediante acceso a agua fresca y comida que garantice la cría de unos animales saludables y vigorosos.

- Libres de agresiones térmicas y físicas: aportándoles un alojamiento apropiado, incluyendo protección y un área de descanso confortable.

- Libres de dolor, lesiones y enfermedades: mediante la prevención, rápido diagnóstico y tratamiento.

- Libres para expresar su comportamiento normal: apretándoles el suficiente espacio, condiciones adecuadas, y en compañía de animales de su misma especie, edad y condición.

- Libres de temores y angustias: asegurando unas condiciones que eviten el sufrimiento mental, que les pueda producir un estrés que altere su bienestar.

Estas libertades forman la base para la legislación y regulación del bienestar animal en la cría de animales. Estas leyes y regulaciones van tomando forma según la ciencia va proporcionando más información sobre las respuestas y necesidades etológicas de las respectivas especies en producción.

En acuicultura se deben desarrollar prácticas de manejo que reduzcan el estrés y sus efectos potencialmente dañinos para el pez, ya que las técnicas de producción son cada vez más intensas (restricción de espacio, alteración de factores ambientales, densidad de siembra, entre otros), lo que puede producir efectos no deseados en los animales, causados por el estrés, enfermedades y mermas en la producción. Estas prácticas deben incluir un control continuo tanto del medioambiente de los animales acuáticos como de la condición física de los mismos.

\subsubsection{Respuesta al estrés de los teleósteos}

El estrés puede ser definido como una situación en la cual el equilibrio dinámico de un organismo (estado homeostático) es modificado como consecuencia de la acción de un estímulo intrínseco o extrínseco al animal, denominado agente estresante (Mancera y del Rio, 2005). Estos estímulos pueden ser factores físicos, fisiológicos, conductuales o psicólogos (Dantzer y Mormède, 1983). Según Huntingford et al. (2006), los peces pueden sentir el dolor puesto que tienen las vías sensibles para procesar dichos estímulos y mecanismos cerebrales que procesan dicha información y generan respuestas comportamentales que sugieren negativas experiencias subjetivas. En el caso concreto de los peces, fueron los primeros vertebrados en desarrollar una respuesta al estrés, que incluye, interrelaciones entre los ejes relacionados con el sistema nervioso y el sistema endocrino (Barandica y Tort, 2008). 
Al ser los peces poiquilotermos y totalmente acuáticos, dependen de la calidad y constancia del medio, requieren una calidad y una temperatura constante, ya que una variación por fuera del rango de confort aceptable dará lugar a estrés, enfermedad y mortalidad, al afectar negativamente a su sistema inmune (Conte, 2004). Aunque el estrés es inherente a la vida, el objetivo del buen manejo es mantener el nivel por debajo del umbral de la manifestación patológica. Las características del agua en el cultivo de peces están afectadas por factores como el tipo de sistema de producción empleado, el entorno medioambiental externo, la densidad animal, y la cantidad y calidad del alimento. En los sistemas de recirculación de agua (RAS) la temperatura del agua y los parámetros como el oxígeno, el dióxido de carbono, la alcalinidad, la dureza y el contenido de los residuos del amoniaco, están contralados mecánicamente o biológicamente para mantener la homeostasis del medio (Masser et al., 2000).

La respuesta al estrés viene dada por una respuesta adaptativa (capacita al individuo a enfrentarse a la situación adversa) y una respuesta no adaptativa (los mecanismos se fuerzan más allá a de sus límites, empeorando su salud; Barton e Iwama (1991)). Cuando el agente estresante es puntual, se produce una respuesta aguda, pero si este persiste se produce una respuesta crónica (Pickering, 1998) (Figura 1.12).

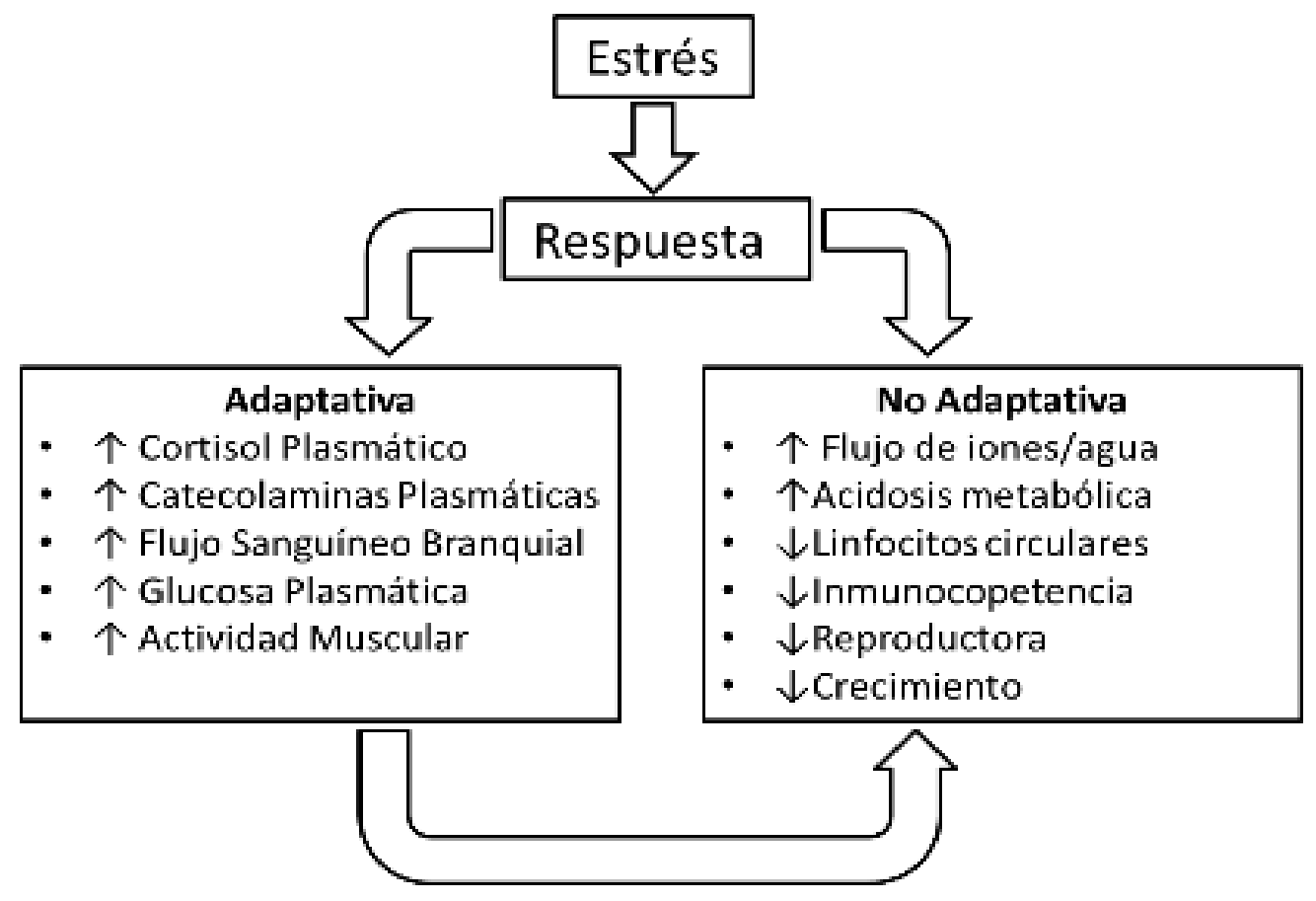

Figura 1.12Esquema de adaptación al estrés según la bibliografía existente. 
En los teleósteos podemos diferenciar tres etapas relacionadas con el estrés (Wedemyer, 1996). Se inicia con una respuesta primara, relacionada con una serie de cambios endocrinos consecuencia del estímulo del estrés (Figura 1.13). En este punto se liberan catecolaminas (adrenalina y noradrenalina). Estas en la práctica son difíciles de medir y de determinar y su presencia en el torrente sanguíneo es muy baja (Wendelaar, 1997).

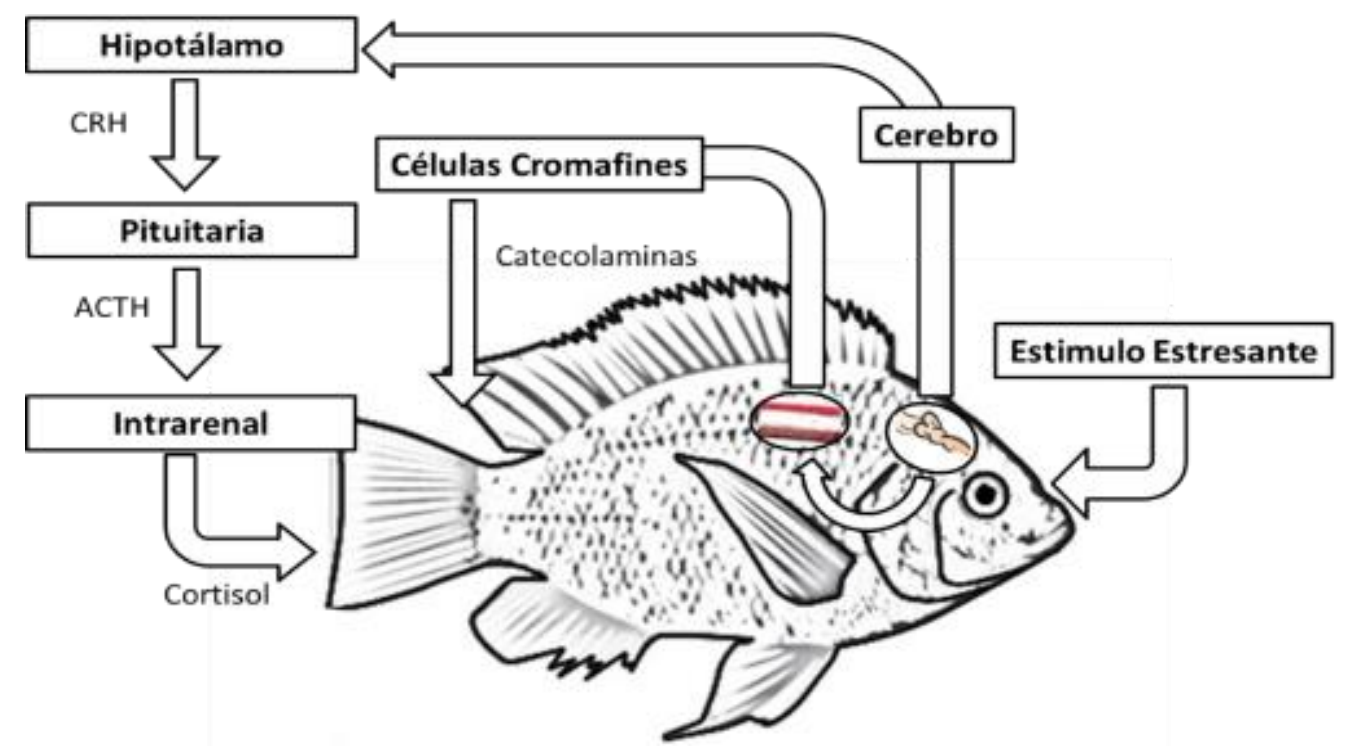

Figura 1.13 Esquema de la respuesta al estrés eje CRH-ACTH-Cortisol. Según la bibliografía existente.

Tras la producción de catecolaminas, se estimula el eje hipotálamo-pituitaria-intrarrenal o HPI (Sumpter, 1997). Este comienza con la activación de neurotransmisores cerebrales provocando la liberación de la hormona liberadora de corticotropina $(\mathrm{CRH})$ por parte de las neuronas del hipotálamo. Estas hormonas son trasportadas hacia la glándula pituitaria, donde se activará la hormona adrenocorticótropa $(\mathrm{ACTH})$, que finalmente estimula la producción de cortisol (Sumpter, 1997) en el tejido intrarrenal, equivalente a la corteza renal en mamíferos.

Durante la fase secundaria se producen una serie de cambios consecuencia de la liberación hormonal de la primera fase. Estos cambios se producen a nivel metabólico, fisiológico y tisular, incluyendo por ejemplo el aumento del ritmo cardiaco, por una mayor demanda de oxígeno, una movilización de reservas, y un incremento de la gluconeogénesis.

Posteriormente y como consecuencia de las anteriores, aparece la tercera fase de la respuesta, dando lugar a una disminución del crecimiento y de la resistencia a enfermedades, así como alteraciones en la capacidad reproductora. También se reduce la capacidad de hacer frente a 
otras situaciones estresantes adicionales (Wedemeyer, 1996; Wendelaar 1997; Barry et al., 1993; Pickering y Pottinger, 1995).

En un estudio sobre el bienestar en dorada (Sparus aurata L.), se mostró que los indicadores de estrés se reducían al suplementar a estas con vitaminas C y E (Ortuño et al., 2003). A. platensis es rica en inmunoestimulantes, como las vitaminas $\mathrm{C}$ y E. Estos inmunoestimulantes pueden interferir con los ejes responsables del estrés (CRH-ACTH), reduciendo el estrés a lo largo de su respuesta primaria (Fletcher, 1997; Montero et al., 2001).

\subsubsection{Como valorar el estrés}

\subsubsection{Parámetros hematológicos}

Los parámetros hematológicos han sido ampliamente utilizados como indicadores de estrés en distintas especies animales (Barton, 2011), así como en O. niloticus (Tabla 1.15). La existencia de niveles altos de cortisol, glucosa y lactato plasmáticos son utilizadas con frecuencia como indicadores de respuesta de estrés (Mommsen et al., 1999). Estos parámetros están afectados también por la alimentación. Estudios con inclusión de $A$. platensis en la dieta de esturiones (Huso huso) (Adel et al., 2016) y en trucha arcoíris (Oncorhynchus mykiss) (Teimouri et al., 2013) mostraron una disminución en los niveles de cortisol y triacilglicéridos en sangre de los individuos suplementados.

Tabla 1.15 Cambios en algunos parámetros de la tilapia del Nilo (O. niloticus) después de $24 \mathrm{~h}$ de exposición a hipoxia, sobrepoblación y hambre (EL-Khaldi, 2010).

\begin{tabular}{lcccr} 
& \multicolumn{1}{c}{$\begin{array}{c}\text { Cortisol } \\
(\mathbf{n g} / \mathbf{m l})\end{array}$} & $\begin{array}{c}\text { Glucosa } \\
(\mathbf{m g} / \mathbf{1 0 0} \mathbf{~ m l})\end{array}$ & \multicolumn{1}{c}{$\begin{array}{c}\text { LDH } \\
(\mathbf{u} / \mathbf{l})\end{array}$} & \multicolumn{1}{c}{ CPK } \\
& $13,41 \pm 1,20$ & $105,72 \pm 1,18$ & $1971,91 \pm 1,38$ & $490,50 \pm 1,25$ \\
\hline Control & $149,27 \pm 1,08$ & $111,00 \pm 0,26$ & $2325,20 \pm 1,44$ & $260,18 \pm 1,72$ \\
Hipoxia & $154,12 \pm 0,90$ & $124,70 \pm 0,33$ & $892,16 \pm 1,09$ & $630,00 \pm 1,26$ \\
Sobrepoblación & $136,18 \pm 1,04$ & $98,14 \pm 0,42$ & $788,62 \pm 1,38$ & $680,12 \pm 1,45$
\end{tabular}

\subsection{Cortisol}

El cortisol (cortisol, Figura 1.14) es una hormona esteroide, producida por la glándula suprarrenal. Es el principal corticosteroide de los peces teleósteos y sus concentraciones se incrementan significativamente a consecuencia a situaciones de estrés (Barton e Iwama, 1991). Su función principal es la de incrementar los niveles de azúcar en sangre, y ayudar al metabolismo de carbohidratos, grasas y proteínas. 


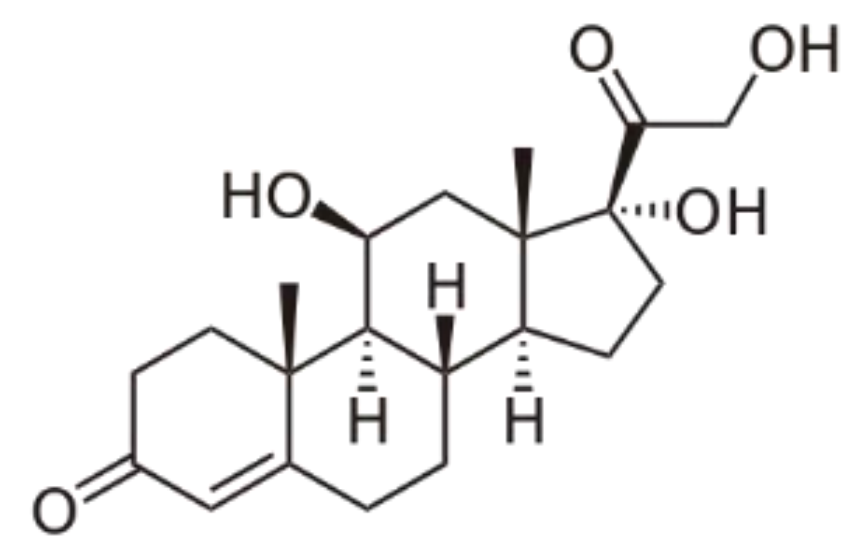

Figura 1.14 Molécula de cortisol. (11ß)-11,17, 21-trihidroxipregn-4-eno-3,20-diona

El cortisol disminuye la formación ósea y reduce la respuesta del sistema inmunitario. En estado de estrés crónico puede elevar la concentración a más de $100 \mathrm{ng} / \mathrm{ml}$, para después retornar a niveles normales próximos a 10-20 ng/ml, aunque la causa de la elevación persista (Pickering y Christie, 1981), generalmente antes de 6 a 8 h. Por otro lado, el cortisol está relacionado con el metabolismo lipidico. El cortisol aumenta la lipolisis a nivel de tejido adiposo, musculo rojo e hígado, lo que genera un incremento de los ácidos grasos libres en plasma.

\subsection{Glucosa}

Una de las respuestas endocrinas al estrés, y como consecuencia de la liberación de cortisol, es el aumento de la glucosa plasmática. Esta puede ser usado como un parámetro alternativo para evaluar la respuesta al estrés puesta que su respuesta es paralela a la del cortisol, aunque normalmente más lenta en el tiempo (Mommsen et al., 1999).Por otro lado, la concentración plasmática está íntimamente relacionado con la dieta y el estado nutricional, por lo que se debe medir en combinación con otros indicadores, según diferentes autores los niveles medios de glucosa se encuentran entorno a los $95 \mathrm{mg} / 100 \mathrm{ml}$ (El-Khaldi, 2010; Sandoval-Gioet al., 2013).

\subsection{Lactato}

El lactato es un producto de la degradación del ácido pirúvico, obtenido del proceso de glucolisis. La concentración del lactato en el músculo puede subir súbitamente en situaciones de esfuerzo por la actividad anaeróbica (alta actividad muscular). El lactato puede ser utilizado como un indicador de lucha o de huida y puede estar relacionado con el desarrollo de jerarquías. 


\subsection{Triglicéridos}

La concentración plasmática de triglicéridos también puede ser de utilidad como indicador de respuesta al estrés (Bennettet al., 2007), ya que incrementa su concentración bajo condiciones estresantes cuando el cuerpo necesita energía, encontrándose sus niveles medios en O. niloticus en torno a $150 \mathrm{mg} / 100 \mathrm{ml}$ (Husáinet al., 1995).

\subsection{Actividad enzimática del lactato deshidrogenasa (LDH)}

La lactato deshidrogenasa o LDH es una enzima catalizadora de la reacción redox en la que el piruvato es reducido a lactato gracias a la oxidación de NADH a NAD ${ }^{+}$. Esta enzima participa en el metabolismo energético anaerobio, reduciendo el piruvato (procedente de la glucólisis) para regenerar el $\mathrm{NAD}^{+}$, que en presencia de glucosa es el sustrato limitante de la vía glucolítica. Niveles elevados de estas enzimas en plasma reflejan un estrés a nivel hepático, renal o muscular (Banaee et al., 2011).

\subsection{Creatin fosfoquinasa (CPK)}

La enzima CPK cataliza la producción de fosfocreatina a través de la fosforilación de una molécula de creatina, consumiendo una molécula de ATP en el proceso. En la miofibrilla, al inicio de la contracción muscular, la concentración de ADP aumenta a medida que disminuye los niveles de ATP. En esta situación la enzima cataliza la reacción inversa, transfiriendo un radical fosforilo al ADP, restaurando rápidamente la concentración de ATP. Así, la fosfocreatina, por intermedio del ATP, constituye una reserva energética rápidamente utilizable por el músculo esquelético y otros tejidos. Un aumento de esta enzima en sangre expresa un daño muscular por gran actividad, o por algún proceso anormal.

\subsubsection{Alternativas no invasivas para medir el estrés}

Los métodos anteriormente citados para medir el estrés se basan en mediciones costosas, basadas en test de laboratorio, que en ocasiones necesitan el sacrificio del animal, como es en el caso de peces pequeños (alevines benjamines y juveniles). Todos estos métodos a menudo no están rigurosamente vinculados a los resultados de la condición física. Una alternativa es observar la alteración refleja como un signo directo de estrés que puede medirse fácil y rápidamente en natación libre o en peces restringidos que responden a estímulos como la gravedad, la luz, el sonido y el tacto (Davis, 2010). 


\subsection{Estrés por Luz}

Maximino et al. (2007) demostró que tanto machos como hembras de O. niloticus prefieren la oscuridad que la luz. Un trabajo realizado por Fortes-Silva et al (2010), concluye que la tilapia del Nilo prefiere salir a alimentarse durante la noche. De manera refleja los peces evitan exponerse a la luz intensa, donde se sienten vulnerable al ataque de un depredador, prefiriendo esconderse en penumbra. Un estudio realizado por Carvalho et al (2013) concluye que la intensidad de luz aumentada tiene un efecto acumulativo que aumenta la agresividad y la actividad de la tilapia del Nilo. Algunos estudios demuestran que el color de la luz a la que son expuestos puede producir diferentes reacciones de estrés. Volpato y Barreto (2001) demostraron que la luz azul (250 lux) en $O$. niloticus es preferible a la luz verde o blanca.

\subsection{Estrés por hipoxia}

El oxígeno disuelto $\left(\mathrm{O}_{2}\right)$ es un factor fundamental para la vida de los organismos acuáticos. En la naturaleza los peces suelen estar expuestos a cambios en la concentración de oxígeno debido a muchos factores, saltos de agua, temperatura del agua, actividad de microorganismos, densidad de individuos, etc. El oxígeno es un factor importante en el proceso de respiración y el metabolismo de los animales. En los peces de cultivo es común que ellos sean expuestos a cortos periodos de hipoxia o anoxia a causa de fallos en las rutinas de manejo (Valenzuela et al., 2002).

La hipoxia crónica puede influir sobre el sistema inmune (Henrique et al., 2002), haciendo a los peces más susceptibles a infecciones, enfermedades y si esta persiste, causa la muerte. Los bajos niveles de oxígeno también pueden afectar al consumo de alimentos, y a la eficiencia alimentaria, lo que evidentemente afecta a las tasas de crecimiento (Vatsos y Angelidis, 2010).

Los peces tienen distintos mecanismos para enfrentarse a la hipoxia. En truchas expuestas a hipoxia se observó una disminución del consumo de oxígeno y un incremento del número de eritrocitos en circulación (Valenzuela et al., 2002). En general los peces pueden tener tres tipos de respuesta a hipoxia, que están asociadas con el tiempo de exposición. Una inmediata (minutos), produciendo ajustes a nivel fisiológico, como la reducción de la frecuencia cardiaca; una respuesta secundaria (horas), con una respuesta a nivel celular, con un ajuste de los niveles hematológicos relacionados con la captación de oxigeno (Powers, 1980); y una tercera (días), donde se ajustan los mecanismos de homeostasis respiratoria con el proceso de captación de energía, comportamiento y reproducción. Todo este proceso está controlado por el eje hipotálamo-pituitaria-interrenal. 


\subsubsection{Microbiota Intestinal}

El sistema digestivo en el género Oreochromis sp. es largo, típico de las especies herbívoras y omnívoras. Comienza en la boca, que presenta en su interior dientes mandibulares, continúa con esófago corto y el estómago. El intestino tiene forma de tubo que se adelgaza tras el píloro, diferenciándose en dos partes; una anterior, corta, que corresponde al duodeno, y una posterior más larga, aunque de menor diámetro. El intestino es entre 7-13 veces más largo que la longitud total del cuerpo, característica que predomina en las especies herbívoras. Presenta dos glándulas importantes asociadas con el tracto digestivo: el hígado, que es un órgano grande y de estructura alargada y el páncreas, en forma de pequeños fragmentos redondos y difíciles de observar por estar incluidos en la grasa que rodea a los ciegos pilóricos (Trewavas, 1983).

Tabla 1.16 Eficiencia de asimilación (EA) de las microalgas por la $O$. niloticus en \% según Moriarty y Moriarty (1973).

\begin{tabular}{lr} 
Alga & AE \% \\
\hline Microcystis sp. & 70 \\
Anabaena & 75 \\
Nitzschia & 79 \\
Chlorella & 49
\end{tabular}

La eficiencia de digestión de las células de cianobacterias en O. niloticus se encuentra en torno al 75\% (Tabla 1.16), mayor que el de otros tipos de microalgas como es el caso de Chlorella sp. Esto se debe a que las cianobacterias no contienen una pared de celulosa que proteja el interior de la célula, lo que las hace más digestibles. La digestión y la asimilación de los nutrientes en las tilapias han sido muy estudiadas. Este proceso se realiza en dos etapas, la primera en el estómago donde la acción de las enzimas junto con los ácidos intestinales (disminuye $\mathrm{pH}$ estomacal $<1$ ), se encargan de romper la estructura de las células eucariotas y procariotas ingeridas (Moriarty y Moriarty, 1973). La segunda fase ocurre en el intestino donde el $\mathrm{pH}$ se mantiene en torno 6,8-8,8 y la actividad de la tripsina, quimo-tripsina, amilasa y esterasas se intensifica. En $O$. niloticus la digestión de las proteínas se completa en el primer cuarto del intestino.

Para regular la flora interna patógena, durante años ha estado utilizando diferentes tipos de antibióticos, pero su uso está prohibido para la ganadería en Europa desde 2003, (EC) N. ${ }^{\circ}$ 1831/2003 (European Commission, 2003). Actualmente se intenta afronta el problema desde 
otra perspectiva. En un esfuerzo por reducir el uso de antibióticos en la producción animal intensiva, los investigadores han estado buscando alternativas (El-Haroun et al., 2006), tales como los prebióticos (Mosenthin y Bauer, 2000; Patterson y Burkholder, 2003; Gaggìa et al., 2010), que estimulan la actividad del microbiota beneficioso en el intestino, mejorando al mismo tiempo la salud y el crecimiento. El uso de prebióticos es más extendido en animales terrestres que en peces y mariscos, pero varios estudios han demostrado los efectos beneficiosos del uso de prebióticos en la acuicultura (Ringø et al., 2010). Los prebióticos utilizados en los peces incluyen ácidos grasos de cadena corta (Zhou et al., 2009), oligosacáridos no digeribles (fructosa, galactosa, xilosa y glucosa, Grisdale-Helland et al. (2008)) y fibra dietética (inulina, oligofructosa o celulosa, Cerezuela et al. (2008)). Estos tipos de compuestos se pueden encontrar en microalgas y cianobacterias (O'Sullivan et al., 2010; Evans y Critchley, 2014; De Jesus Raposo et al., 2016; Leal et al., 2017; Lyons et al., 2017).

\subsubsection{Metagenómica}

La aparición de nuevas técnicas de metagenómica supone un punto de inflexión a la hora de entender la colonización y la biodiversidad bacteriana que podemos estudiar en distintos sectores, especialmente en el ámbito intestinal. Anteriormente, el estudio de la flora bacteriana intestinal dependía de los medios de cultivo, lo cual nos daba una visión muy sesgada de la realidad. Esto es debido, entre otros factores, al desconocimiento de los requerimientos nutricionales de determinados grupos y subgrupos de bacterias.

El termino metagenómica puede definirse como el estudio del material genético de una muestra tomada directamente de un nicho, y por tanto eliminando la necesidad de aislamiento del cultivo. La ventaja de estas técnicas de secuenciación es la forma de abordar el problema. Estas técnicas son independientes de medios de cultivos, obteniéndose la colección de todo el material genético, dando una versión más global y detallada de las comunidades bacterianas y su abundancia relativa.

La técnica más común consta de la extracción del material genético de una muestra biológica, y la amplificación de la secuencia gen del RNA ribosomal 16S por PCR. Este gen común en todas las bacterias y tiene partes variables y constantes, lo que permiten la clasificación taxonómica precisa de las bacterias de cualquier comunidad. Con la ayuda de las nuevas herramientas de secuenciación masiva, como el sistema Illumina SBS, permiten conocer y describir en profundidad la composición de la flora bacteriana de cualquier nicho. 
En peces estas técnicas han facilitado el estudio del microbiota intestinal. Recientemente, Gajardo et al. (2016) han construido un mapa de alta resolución del microbiota intestinal en Salmo salar (salmón del atlántico), utilizando Fluorometria Qubit 2.0. Dehler et al. (2017) estudiaron los factores ambientales y fisiológicos que influyen en el microbiota intestinal de juveniles de S. salar. En O. niloticus Giatsis et al. (2015), usando pirosecuenciación, estudió el impacto del entorno de crianza sobre el desarrollo del microbiota intestinal (Tabla 1.17).

En peces, varios estudios basados en técnicas metagenómicas han encontrado que diferentes tratamientos afectan el microbiota intestinal. Recientemente, Lyon et al. (2016) encontraron que $O$. mykiss suplementado con $5 \%$ de microalgas presentaba un microbiota intestinal más diversa que los controles. En O. niloticus, Koh et al. (2014) encontraron que los peces alimentados con ácidos orgánicos frente a la oxitetraciclina tenían un crecimiento y una resistencia similares al patógeno Streptococcus agalactiae, pero las unidades formadoras de colonias eran significativamente más bajas usando ácidos orgánicos. Pedrotti et al. (2015) estudiaron en O. niloticus el efecto de los carbohidratos en la dieta en el microbiota, pero no se encontraron diferencias significativas. Sin embargo, se ha estudiado poco el efecto de $A$. platensis sobre el microbiota intestinal de $O$. niloticus. 
Tabla 1. 17 Cuadro resumen de la metagenómica aplicada en microbiota intestinal de peces.

\begin{tabular}{|c|c|c|c|c|c|c|c|c|c|}
\hline Referencia & Especie & País/sistema & Kit aislamiento & Cebado & $-R\left(5^{\prime}-3 '\right)$ & Amplificación & Tax. Programa & $\begin{array}{l}\text { Bacterias } \\
\text { principales }\end{array}$ & $\pm \%$ \\
\hline Fan et al., 2013 & $\begin{array}{l}\text { Oreochromis } \\
\text { niloticus }\end{array}$ & $\begin{array}{l}\text { Wuxi, China } \\
\text { /Ponds }\end{array}$ & $\begin{array}{l}\text { PowerSoil DNA Kit } \\
\text { (MO BIO, Carlsbad, } \\
\text { CA, USA) }\end{array}$ & $\begin{array}{l}27 \mathrm{~F} \\
338 \mathrm{RI} \\
388 \mathrm{RII} \\
\end{array}$ & $\begin{array}{l}\text { 5'-GAG TTT GAT CMT GGC TCA G-3' } \\
\text { 5'-GCW GCC TCC CGT AGG AGT-3' } \\
\text { 5'-GCW GCC ACC CGT AGG TGT-3' } \\
\end{array}$ & $\begin{array}{l}\text { QuantiFluor TM-ST } \\
\text { fluorometer }\end{array}$ & QIIME & $\begin{array}{l}\text { Fusobacteria } \\
\text { Protobacteria } \\
\text { Firmicutes } \\
\end{array}$ & $\begin{array}{l}26.0 \\
25.6 \\
19.4 \\
\end{array}$ \\
\hline $\begin{array}{l}\text { Zhai et al., } \\
2016\end{array}$ & $\begin{array}{l}\text { Oreochromis } \\
\text { niloticus }\end{array}$ & $\begin{array}{l}\text { Wuxi, China } \\
\text { /Tanks }\end{array}$ & $\begin{array}{l}\text { E.Z.N.A DNA kit } \\
\text { (Omega Bio-tek, } \\
\text { Norcross, GA, US) } \\
\end{array}$ & $\begin{array}{l}515 \mathrm{~F} \\
907 \mathrm{R}\end{array}$ & $\begin{array}{l}\text { 5'-BCode-GTG CCA GCM GC CGC GG-3' } \\
\text { 5'-CCG TCA ATT CMT TTR AGT TT-3' }\end{array}$ & Illumina MiSeq & QIIME & $\begin{array}{l}\text { Fusobacteria } \\
\text { Potobacteria } \\
\text { Bacterioidetes } \\
\end{array}$ & $\begin{array}{l}57.9 \\
30.7 \\
11.8 \\
\end{array}$ \\
\hline $\begin{array}{l}\text { Giatsis et al., } \\
2015\end{array}$ & $\begin{array}{l}\text { Oreochromis } \\
\text { niloticus }\end{array}$ & $\begin{array}{l}\text { Velden, } \\
\text { Netherlands } \\
/ \text { recirculation } \\
\text { aquaculture system } \\
y \text { active suspension } \\
\end{array}$ & $\begin{array}{lr}\text { DNeasy Blood } y & \text { Tissue Kit } \\
\text { (Qiagen, } & \text { Venlo, } \\
\text { Netherlands) }\end{array}$ & $\begin{array}{l}27 \mathrm{~F} \\
338 \mathrm{RI} \\
388 \mathrm{RII}\end{array}$ & $\begin{array}{l}\text { 5'-GAG TTT GAT CMT GGC TCA G-3' } \\
\text { 5'-GCW GCC TCC CGT AGG AGT-3' } \\
\text { 5'-GCW GCC ACC CGT AGG TGT-3' }\end{array}$ & 454 pyrosequencing & QIIME & $\begin{array}{l}\text { Actinobacteria } \\
\text { Protobacteria } \\
\text { Planctomycetes }\end{array}$ & $\begin{array}{l}43.2 \\
21.7 \\
16.6\end{array}$ \\
\hline Ran et al., 2015 & $\begin{array}{l}\text { Oreochromis } \\
\text { niloticus }\end{array}$ & $\begin{array}{l}\text { Beijing, China } \\
\text { /Tanks }\end{array}$ & NGS toolkits & $\begin{array}{l}349 \mathrm{~F} \\
806 \mathrm{R}\end{array}$ & $\begin{array}{l}\text { 5'-GYG CAS CAG KCG MGA AW-3' } \\
\text { 5'-GGA CTA CHV HHH TWT CTA AT-3' }\end{array}$ & Illumina Hiseq2500 & $\begin{array}{l}\text { UCLUST } \\
\mathrm{v} 1.2 .22\end{array}$ & $\begin{array}{l}\text { Fusobacteria } \\
\text { Potobacteria }\end{array}$ & $\begin{array}{l}54.0 \\
34.0 \\
\end{array}$ \\
\hline $\begin{array}{l}\text { Gaikwad et al., } \\
2017\end{array}$ & $\begin{array}{l}\text { Oreochromis } \\
\text { mossambicus }\end{array}$ & $\begin{array}{l}\text { Maharashtra, India } \\
\text { River, Mula }\end{array}$ & $\begin{array}{l}\text { Stool Mini Kit } \\
\text { (Qiagen, Venlo, } \\
\text { Netherlands) } \\
\end{array}$ & $\begin{array}{l}27 \mathrm{~F} \\
519 \mathrm{R}\end{array}$ & $\begin{array}{l}\text { 5'-AGR GTT TGA TCM TGG CTC AG-3' } \\
\text { 5'-GWA TTA CCG CGG CKG CTG-3' }\end{array}$ & Illumina Miseq & QIIME & $\begin{array}{l}\text { Fusobacteria } \\
\text { Protobacteria } \\
\text { Firmicutes } \\
\end{array}$ & $\begin{array}{l}53.2 \\
26.8 \\
6.9 \\
\end{array}$ \\
\hline $\begin{array}{l}\text { Gaikwad et al., } \\
2017\end{array}$ & $\begin{array}{l}\text { Oreochromis } \\
\text { mossambicus }\end{array}$ & $\begin{array}{l}\text { Maharashtra, India } \\
\text { Lake, Talegaon } \\
\text { Dabhade }\end{array}$ & $\begin{array}{l}\text { Stool Mini Kit } \\
\text { (Qiagen, Venlo, } \\
\text { Netherlands) }\end{array}$ & $\begin{array}{l}27 \mathrm{~F} \\
519 \mathrm{R}\end{array}$ & $\begin{array}{l}\text { 5'-AGR GTT TGA TCM TGG CTC AG-3' } \\
\text { 5'-GWA TTA CCG CGG CKG CTG-3' }\end{array}$ & Illumina Miseq & QIIME & $\begin{array}{l}\text { Fusobacteria } \\
\text { Protobacteria } \\
\text { Actinobacteria }\end{array}$ & $\begin{array}{l}36.8 \\
23.6 \\
15.0 \\
\end{array}$ \\
\hline Ye et al., 2014 & $\begin{array}{l}\text { Gizzard } \\
\text { shad }\end{array}$ & $\begin{array}{l}\text { Illinois, EEUU } \\
\text { river }\end{array}$ & FastDNA spin kit & $\begin{array}{l}515 \mathrm{~F} \\
909 \mathrm{R}\end{array}$ & $\begin{array}{l}\text { 5'-GTG CCA GCM GCC GCG GTA A-3' } \\
\text { 5'-TAA TGG ATC CAG TGG CGA GCC } \\
\text { CTC AGA TCC TGC AT-3' } \\
\end{array}$ & Fluorometria Qubit 2.1 & QIIME & $\begin{array}{l}\text { Cyanobacteria } \\
\text { Firmicutes } \\
\text { Fusobacteria } \\
\end{array}$ & $\begin{array}{l}27.4 \\
20.8 \\
11.1 \\
\end{array}$ \\
\hline Ye et al., 2014 & $\begin{array}{l}\text { Hypophthalmichthys } \\
\text { molitrix }\end{array}$ & $\begin{array}{l}\text { Illinois, EEUU } \\
\text { river }\end{array}$ & FastDNA spin kit & $\begin{array}{l}515 \mathrm{~F} \\
909 \mathrm{R}\end{array}$ & $\begin{array}{l}\text { 5'-GTG CCA GCM GCC GCG GTA A-3' } \\
\text { 5'-TAA TGG ATC CAG TGG CGA } \\
\text { GCC CTC AGA TCC TGC AT-3' } \\
\end{array}$ & Fluorometria Qubit 2.1 & QIIME & $\begin{array}{l}\text { Cyanobacteria } \\
\text { Protobacteria } \\
\text { Firmicutes } \\
\end{array}$ & $\begin{array}{l}23.2 \\
19.4 \\
11.4 \\
\end{array}$ \\
\hline $\begin{array}{l}\text { Gajardo et al., } \\
2016\end{array}$ & $\begin{array}{l}\text { Salmo } \\
\text { salar }\end{array}$ & $\begin{array}{l}\text { Sunndalsøra } \\
\text { (Norway) RAS }\end{array}$ & $\begin{array}{l}\text { Stool Mini Kit } \\
\text { (Qiagen, Venlo, } \\
\text { Netherlands) } \\
\end{array}$ & $\begin{array}{l}27 \mathrm{~F} \\
338 \mathrm{RI} \\
388 \mathrm{RII} \\
\end{array}$ & $\begin{array}{l}\text { 5'-GAG TTT GAT CMT GGC TCA G-3' } \\
\text { 5'-GCW GCC TCC CGT AGG AGT-3' } \\
\text { 5'-GCW GCC ACC CGT AGG TGT-3' } \\
\end{array}$ & Fluorometria Qubit 2.0 & QIIME & $\begin{array}{l}\text { Protobacteria } \\
\text { Firmicutes } \\
\text { Actinobacteria } \\
\end{array}$ & $\begin{array}{l}63.0 \\
20.1 \\
5.3 \\
\end{array}$ \\
\hline $\begin{array}{l}\text { Dehler et } \\
\text { al.,2017 }\end{array}$ & $\begin{array}{l}\text { Salmo } \\
\text { salar parr }\end{array}$ & $\begin{array}{l}\text { West coast Scotlan } \\
\text { freshwater } \\
\text { commercial cages }\end{array}$ & $\begin{array}{l}\text { Stool Mini Kit } \\
\text { (Qiagen, Venlo, } \\
\text { Netherlands) }\end{array}$ & & $\begin{array}{l}\text { 5'-CCT ACG GGN GGC WGC AG-3' } \\
\text { 5'-GAC TAC HVG GGT ATC TAA TCC-3' }\end{array}$ & Illumina MiSeq & QIIME & $\begin{array}{l}\text { Firmicutes } \\
\text { Protobacteria } \\
\text { Actinobacteria }\end{array}$ & $\begin{array}{l}50.0 \\
23.2 \\
7.1\end{array}$ \\
\hline $\begin{array}{l}\text { Torrecillas et } \\
\text { al., } 2017\end{array}$ & $\begin{array}{l}\text { Dicentrachus } \\
\text { labraz }\end{array}$ & $\begin{array}{l}\text { Gran } \quad \text { Canarias } \\
\text { (spain) } \\
\text { /Tanks }\end{array}$ & $\begin{array}{l}\text { Stool Mini Kit } \\
\text { (Qiagen, Venlo, } \\
\text { Netherlands) }\end{array}$ & $\begin{array}{l}338 \mathrm{~F} \\
518 \mathrm{R} \\
\end{array}$ & $\begin{array}{l}\text { 5'-CGC CCG CCG CGC GCG GCG GGC } \\
\text { GGG GCG GGG GCA CGG GGG GCC } \\
\text { TAC GGG AGG CAG CAG-3' } \\
\text { 5'-ATT ACC GCG GCT GTC GG-3' } \\
\end{array}$ & $\begin{array}{l}\text { LIGHTrum services } \\
\text { GATC Biotech AG } \\
\text { (Konstanz, Germany) }\end{array}$ & $\begin{array}{l}\text { Squence Scanner v1.0 } \\
\text { applied Biosystems }{ }^{\circledR} \text {, } \\
\text { CA, USA }\end{array}$ & $\begin{array}{l}\text { Actinobacteria } \\
\text { Firmicutes } \\
\text { Protobacteria }\end{array}$ & $\begin{array}{l}27.6 \\
14.4 \\
8.5\end{array}$ \\
\hline $\begin{array}{l}\text { Huyben et al., } \\
2017\end{array}$ & $\begin{array}{l}\text { Oncorhynchus } \\
\text { mykiss }\end{array}$ & $\begin{array}{l}\text { Kälarne, Suecia } \\
\text { /Tanks }\end{array}$ & $\begin{array}{l}\text { Stool Mini Kit } \\
\text { (Qiagen, Venlo, } \\
\text { Netherlands) }\end{array}$ & $\begin{array}{r}515 \mathrm{~F} \\
805 \mathrm{R}\end{array}$ & $\begin{array}{l}\text { 5'- GTG CCA GCM GCC GCGG TAA-3' } \\
\text { 5'- GAC TAC HVG GGT ATC TAA TCC- } \\
\text { 3' }\end{array}$ & $\begin{array}{l}\text { Illumina MiSeq } \\
\text { SciLifeLab AB } \\
\text { (Estocolmo, Suecia) }\end{array}$ & QIIME & $\begin{array}{l}\text { Firmicutes } \\
\text { Protobacteria } \\
\text { Actinobacteria } \\
\end{array}$ & $\begin{array}{l}75.3 \\
18.8 \\
2.4 \\
\end{array}$ \\
\hline $\begin{array}{l}\text { Michl et al., } \\
2017\end{array}$ & $\begin{array}{l}\text { Oncorhynchus } \\
\text { mykiss }\end{array}$ & $\begin{array}{l}\text { Büsum, } \\
\text { Germany/acuaria }\end{array}$ & $\begin{array}{l}\text { DNeasy Blood } y \text { Tissue Kit } \\
\text { (Qiagen, Venlo, } \\
\text { Netherlands) }\end{array}$ & $\begin{array}{l}969 \mathrm{~F} \\
1406 \mathrm{R}\end{array}$ & $\begin{array}{l}\text { 5'-ACG CGH NRA ACC TTA CC-3' } \\
\text { 5'-ACG GGC RGT GWG TRC AA-3' }\end{array}$ & $\begin{array}{l}\text { Illumina MiSeq } \\
\text { SciLifeLab AB } \\
\text { (Estocolmo, Suecia) }\end{array}$ & QIIME & $\begin{array}{l}\text { Protobacteria } \\
\text { Firmicutes } \\
\text { Bacterioidetes }\end{array}$ & $\begin{array}{l}52.7 \\
20.7 \\
17.2\end{array}$ \\
\hline
\end{tabular}




\section{FUNDAMETOS Y OBJETIVOS}




\section{FUNDAMENTOS Y OBJETIVOS}

\subsection{FUNDAMENTOS}

El objetivo principal de la nutrición animal, más en concreto en acuicultura, es proporcionar una mezcla equilibrada de ingredientes para respaldar las funciones vitales a un costo aceptable. Siguiendo esta línea de pensamiento, por el momento no sería rentable utilizar A. platensis $(\approx 40 € / \mathrm{kg})$ como sustituto de la proteína, pero puede ser útil como suplemento nutricional, ya que mejora la eficiencia de la alimentación, la canal calidad y respuesta fisiológica al estrés en varias especies de peces (Takechi et al., 2002; AbdelTawwab et al., 2009; Velasquez et al., 2016), contribuyendo estas mejoras a un aumento de la calidad de producto y a la consecución de otros beneficios en la producción que pueden rentabilizarse.

Otro aspecto fundamental que se desea abordar en la nutrición animal es reducir el uso de antibióticos, probióticos y colorantes artificiales utilizados en producción animal intensiva, buscando alternativas en productos naturales como las microalgas, en concreto en $A$. platensis. 


\subsection{OBJETIVOS}

El objetivo general de este trabajo es analizar el efecto de suplementos de $A$. platensis (espirulina) sobre el crecimiento y bienestar de O. niloticus (tilapia). Dentro del objetivo general se abordarán cuatro objetivos más específicos,

1. Determinar el efecto del suplemento de espirulina en el crecimiento y el comportamiento de tilapia juvenil.

2. Determinar el efecto del suplemento de espirulina sobre los parámetros plasmáticos indicadores de estrés en tilapia adulta.

3. Determinar el efecto del suplemento de espirulina en la calidad de la carne de la tilapia.

4. Determinar el efecto del suplemento de espirulina sobre el microbiota intestinal de la tilapia. 


\section{MATERIAL Y MÉTODOS}

\subsection{INSTALACIONES}

Para la realización de los experimentos se contó con la colaboración de varias instituciones, que cedieron las instalaciones para el proyecto. En primer lugar, los invernaderos de la ETSIAAB (Figura3.1) situados en el Campo de prácticas. En estos invernaderos se cultivaron tanto los alevines de $O$. niloticus como la A. platensis necesaria para la realización del estudio. En estas instalaciones también se mantuvieron los peces durante la época invernal, y en ellas se realizaron la prueba de alevines y two-choices.

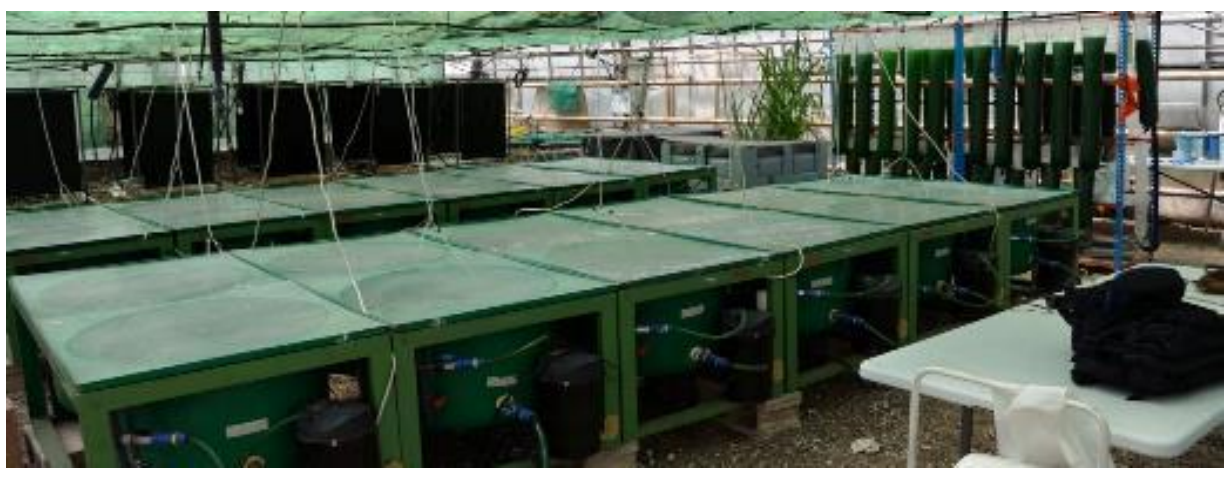

Figura 3.1 Invernaderos de la Escuela Técnica Superior de Ingenieros Agrónomos de Madrid situados a $40.446353 \mathrm{~N}-3.738341 \mathrm{E}$.

En segundo lugar, se encuentra las instalaciones de acuicultura (Figura 3.2) de la ETSIM donde se realizaron los experimentos de pre-engorde, y los peces pasaban la época estival. Finalmente, en los laboratorios del CIB (Centro de Investigaciones Biológicas) del CSIC (Consejo Superior de Investigaciones Científicas), situadas en la Ciudad Universitaria de Madrid, se llevó a cabo las pruebas de metagenómica.

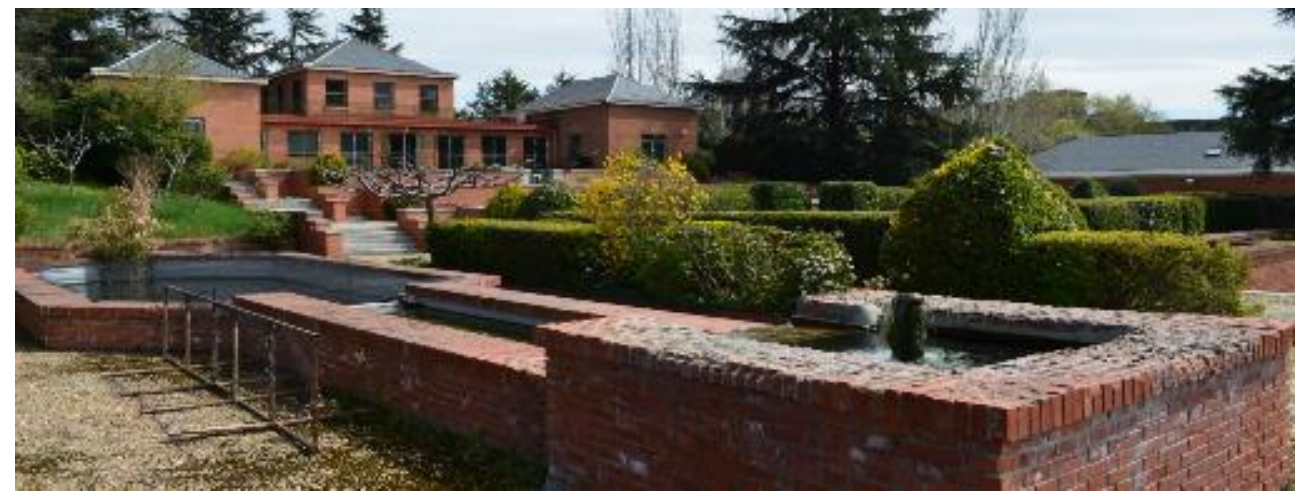

Figura 3.2 Instalaciones de Acuicultura de la Escuela Técnica Superior de Ingenieros de Montes de Madrid, situadas a 40.450806 N, -3.721382 E. 


\subsection{CULTIVO DE ARTHROSPIRA PLATENSIS}

La producción de Arthrospira sp. es la base común de todas las pruebas, por lo que se comienza con la metodología usada en su producción. Arthrospira sp. puede crecer bajo tres regímenes de alimentación, autótrofa, heterótrofa o mixotrófa, siendo un organismo extremófilo que se desarrolla en condiciones muy alcalinas $(\mathrm{pH}>9,5)$ y en presencia de altas concentraciones de sal $\left(\mathrm{NaHCO}_{3}>16 \mathrm{~g} / \mathrm{L}\right)$.

A la hora de cultivar un alga, o en el caso de una cianobacteria bajo un régimen autótrofo o mixotrófo, es importante un buen diseño del Foto-Bio-Reactor (FBR). Este debe seguir unos criterios de diseño, apuntando a una alta productividad, una eficiente conversión de energía, y al mismo tiempo brindar una fiabilidad y estabilidad. Además, debe ajustarse a los medios y los recursos y herramientas que disponibles. Dentro de estos parámetros se debe diseñar de forma adecuada al cultivo, y no de forma generalista.

En el caso de $A$. platensis, hay varios factores cruciales que se deben tener en cuenta, entre ellos la alta alcalinidad ( $\mathrm{pH}>9$ ) y salinidad (5-45 g/L) del medio de cultivo (Jourdan, 1999). Esto obliga a utilizar materiales resistentes a la corrosión, evitando materiales metálicos. La iluminación es indispensable para el crecimiento de Arthrospira, pero no es recomendable mantener la iluminación de forma continua, ya que un filamento individual de Arthrospira no puede soportar una exposición prolongada a la iluminación. Una luz fuerte (pleno sol) puede ser contraproducente en los siguientes casos:

- Cultivo frio, bajo temperaturas inferiores a $\operatorname{los} 15^{\circ} \mathrm{C}$.

- Bajo un exceso de calor, el medio de cultivo puede elevar en exceso la temperatura, si supera en algún momento el rango de tolerancia, el cultivo puede caerse.

- En un cultivo diluido, pues las fibras individuales de Arthrospira, pueden estar demasiado tiempo expuestas al sol, sin la protección del sombreado que le proporcionan otros filamentos.

- En un cultivo en condiciones de estrés de cualquier tipo. 


\subsubsection{Base biológica}

Tras considerar distintas especies de Arthrospira para el cultivo, finalmente se tomó la decisión de utilizar la cepa A. platensis PCC9108 (Imagen 3.3) obtenida de la colección del Instituto Pasteur (Paris, Francia), procedente de China. La decisión se fundamentó en el conocimiento experimental contenido en la literatura que se posee de esta cepa, y por ser la cepa que mejor se adaptó a las condiciones ambientales de laboratorio y de los invernaderos de la ETSIAAB.

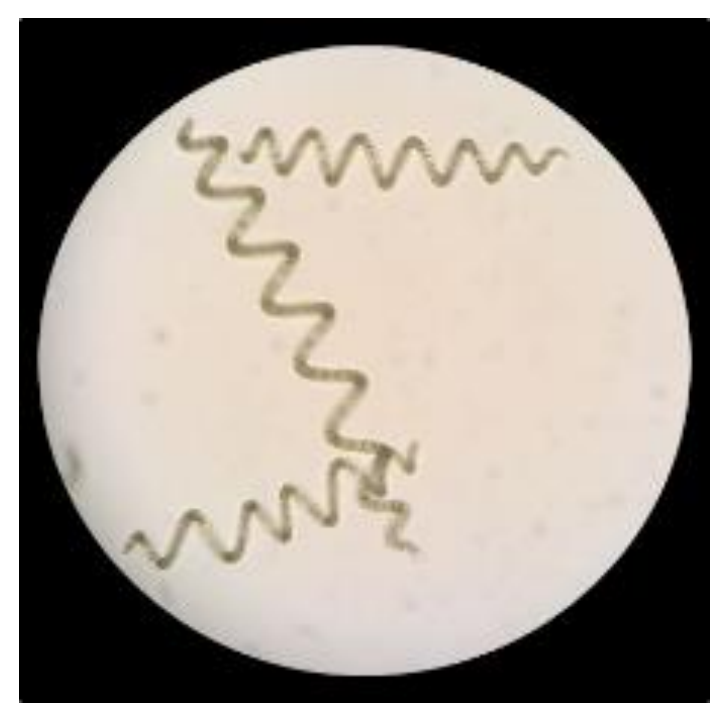

Figura 3.3 A. platensis PCC9018. Imagen de microscopia óptica, del cultivo utilizado durante los experimentos realizados en 2016.

\subsubsection{Manejo del cultivo}

El proyecto se inició con un cultivo axénico de $A$. platensis, obtenido a partir de una siembra en agar. Para iniciar el cultivo líquido, de la bacteria cultiva en agar, se transfirió inicialmente a un tubo de ensayo a $10 \mathrm{ml}$. Posteriormente, el volumen de cultivo se fue aumentando progresivamente hasta alcanzar $1 \mathrm{~L}$ (Figura 3.4). Esta fase del cultivo se realizó en el laboratorio. El medio utilizado como el instrumental usado durante esta primera fase, fue esterilizado en autoclave. Con ello, se evita cualquier tipo de contaminación inicial. Para la iluminación en el laboratorio, se utilizó unos tubos fluorescentes que emitían 1000 lux, con ciclos de luz de 16L/8N. Esta decisión fue tomada considerando las recomendaciones de la literatura (Vonshak, 1984; Gitelson, 1996; Jourdan, 1999), que estiman unas necesidades para el cultivo de entre 2000-5000 lux. 
El cultivo en fase estacionaria de $1 \mathrm{~L}$ se traspasó a un volumen de $5 \mathrm{~L}$. Manteniendo un medio estéril, cuando el cultivo se encuentra a una densidad de $3 \mathrm{~g} / \mathrm{L}$ en peso húmedo $(\mathrm{PH})$, se siembra en los bio-reactores (BR). En este momento, se consideró el cultivo afianzado, las nuevas adiciones de medio ya no se esterilizaron por autoclave, aunque se seguían tomando medidas para evitar una posible contaminación.

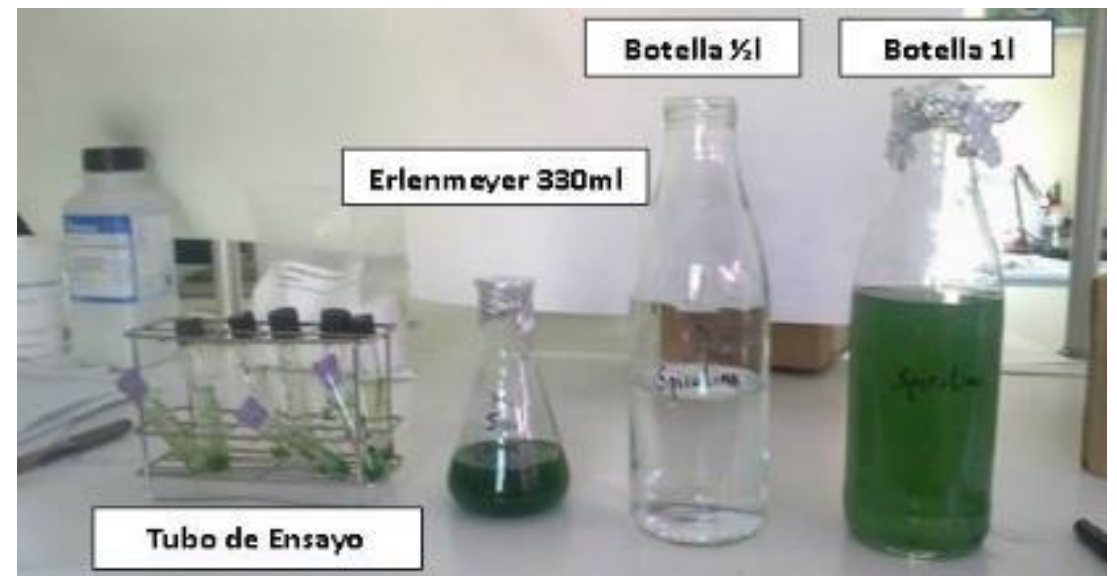

Figura 3.4 Fases de arranque de cultivo de $A$. platensis.

Una vez en el invernadero, para mantener el cultivo sano, semanalmente se llevaron muestras tomadas de los FBR al laboratorio para su control. Un cultivo en que la salinidad o la concentración de Arthrospira son muy bajas, puede ser invadido por microalgas como Chorella sp. (Figura 3.5) u otras cianobacterias. Las cianobacterias tóxicas como Anabaena sp., Anabaenopsis arnoldii y Microcystis sp., raramente se desarrollan en un cultivo de Arthrospira bien cuidado. Con un $\mathrm{pH}$ adecuado $(\mathrm{pH} 10,20)$ y con alta densidad Arthrospira domina el cultivo, evitando el desarrollo de otras especies.

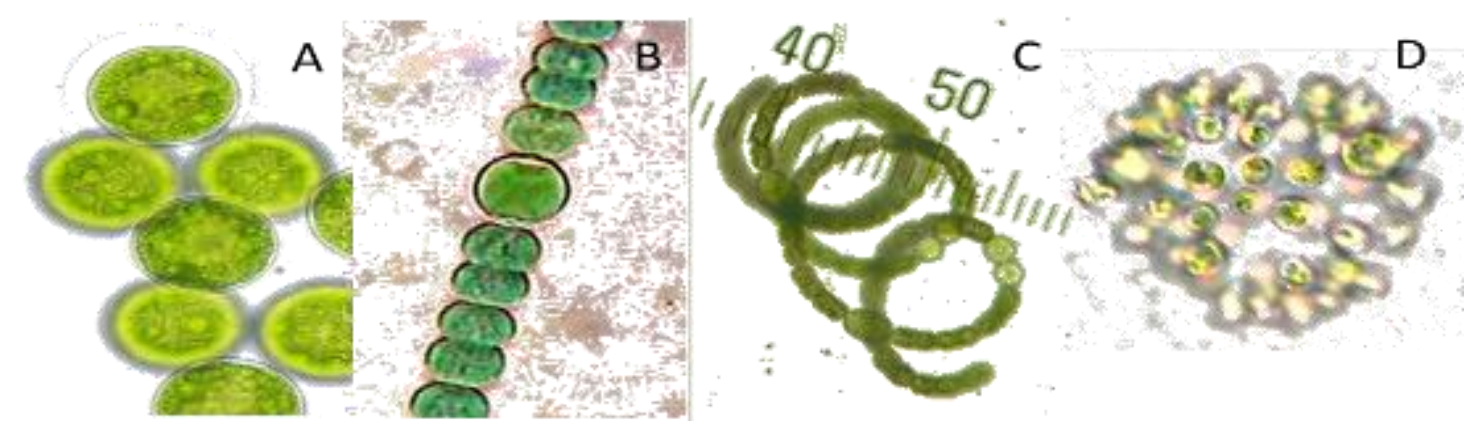

Figura 3. 5 Algas que son posibles contaminantes del cultivo de A. platensis como Chlorella sp. (A), Anabaena sp. (B), Anabaenopsis sp. (C), y Microcystis sp. (D). 
Mediante este control, no solo se mantiene el cultivo sano, si no que del cultivo se extrae mucha información. El color, olor, textura del cultivo y sus combinaciones indican el estado y salud del cultivo. La tabla adjunta (Tabla 3.1) fue realizada por la organización Xarxa espirulina (2016) y corroborada por la experiencia adquirida durante el desarrollo de la tesis.

Tabla 3.1 Observaciones en el cultivo de A. platensis según Xarxa espirulina (2016) y observaciones propias.

\begin{tabular}{lll} 
Aspecto general del cultivo & Situación del cultivo & Actuación \\
\hline A. platensis en grumos u ovillos & Diluido o estrés lumínico & $\begin{array}{l}\text { Sombrear } \\
\text { Agitar }\end{array}$ \\
\hline Capas compactas espesas & Temperatura baja & Revisar la temperatura \\
\hline Espuma blanca en superficie & Falta de nitratos & Agitar, sombrear y añadir \\
& nitratos \\
& Ruptura de filamentos. & Vigilar agitación, \\
\hline Ovillos pardos & Depósitos de sales & Revisar las sales del $\mathrm{H}_{2} \mathrm{O}$ \\
& y cultivo muerto & Purgar eliminar células \\
muertas
\end{tabular}

\begin{tabular}{lll} 
Olor & Situación del cultivo & Actuación \\
\hline Agradable & Buena salud & no tocar \\
\hline Amoniacal & Exceso de nitrógeno & Reducir el aporte de nitrato \\
\hline Sulfuroso & Fermentación & Purgar \\
\hline Fuerte a cadáver, pescado podrido & Cultivo en mal estado & $\begin{array}{l}\text { Purgar, sombrear, revisar } \\
\text { cultivo }\end{array}$ \\
Observación al microscopio & Situación del cultivo & Actuación \\
\hline $\mathrm{N}^{\mathbf{0}}$ espiras $>10$ & Falta de hierro & Añadir hierro \\
\hline Trozos pequeños $<3$ espiras & Falta de potasio & $\begin{array}{l}\text { Añadir potasio } \\
\text { Revisar la agitación }\end{array}$
\end{tabular}




\begin{tabular}{|c|c|c|}
\hline Color & Situación del cultivo & Actuación \\
\hline Verde-azulado Oscuro & Salud excelente & $\begin{array}{l}\text { Se puede reducir el } \\
\text { sombreado }\end{array}$ \\
\hline Oliva & Buena salud & No tocar \\
\hline \multirow[t]{3}{*}{ Verde claro amarillento } & Fotolisis & Aumentar el sombreo \\
\hline & Falta de nitrógeno & $\begin{array}{l}\text { Añadir medio de cultivo } \\
\text { (Nitrato) }\end{array}$ \\
\hline & Posible contaminación & $\begin{array}{l}\text { Revisar cultivo al } \\
\text { microscopio }\end{array}$ \\
\hline Verde amarillento + olor amoniaco & Exceso de nitrógeno & Reducir el aporte de Nitrato \\
\hline \multirow[t]{3}{*}{ Amarillo + espuma blanca } & Ruptura de filamentos & Vigilar el $\mathrm{pH}$ \\
\hline & & Sombrear \\
\hline & & Añadir nitrato potasio \\
\hline \multirow[t]{3}{*}{ Verde caqui } & Falta de nitrógeno & $\begin{array}{l}\text { Añadir medio de cultivo } \\
\text { (Nitrato) }\end{array}$ \\
\hline & Falta de carbono & Sombrear \\
\hline & Falta de hierro & Añadir hierro \\
\hline \multirow[t]{3}{*}{ Manchas blancas y azules oleosas } & Descomposición superficial & Retirar cultivo enfermo \\
\hline & Exceso de Insolación & Sombrear \\
\hline & & Mejorar Agitación \\
\hline Incoloro o pardo amarillento & Cultivo caído/muerto & $\begin{array}{l}\text { Revisar cultivo al } \\
\text { microscopio }\end{array}$ \\
\hline
\end{tabular}

\subsubsection{Medio de cultivo}

Las cianobacterias pueden cultivar en muchos medios tales como: BG11, ASM-1, Z8, DOBLEGA, BBM, AA, KMC, Kn Cg-10, o D (Whitton, 1992), siendo los más idóneos para la Arthrospira el medio Zarrouk y el SSM (Gitelson, 1996). Durante la tesis se ha utilizado agua destilada y agua corriente directamente obtenida del Canal de Isabel II en los FBR de producción en los invernaderos. En el caso del agua del Canal, fue previamente des clorada y esterilizada para eliminar contaminaciones no deseadas. El medio de cultivo utilizado se basa en el medio Zarrouk (Zarrouk,1966), que se compone de tres soluciones (Tabla 3.2), la primera con los macronutrientes, y las otras dos con los micronutrientes, que han de ser preparadas con anterioridad, para añadirlas al medio final a razón de $1 \mathrm{ml} / \mathrm{L}$. 
Tabla 3.2 Composición mineral del medio de cultivo de Arthrospira sp. Zarrouk (1966).

\begin{tabular}{lr} 
Macronutrientes & g/L \\
\hline $\mathrm{NaCl}$ & 1,00 \\
$\mathrm{CaCL}_{2}$ & 0,04 \\
$\mathrm{NaNO}_{3}$ & 2,50 \\
$\mathrm{FeSO}_{4} 7 \mathrm{H}_{2} \mathrm{O}$ & 0,01 \\
$\mathrm{Na}_{2} \mathrm{EDTA}$ & 0,08 \\
$\mathrm{~K}_{2} \mathrm{SO}_{4}$ & 1,00 \\
$\mathrm{MgSO}_{4} 7 \mathrm{H}_{2} \mathrm{O}$ & 0,20 \\
$\mathrm{NaHCO}_{3}$ & 16,50 \\
$\mathrm{~K}_{2} \mathrm{HPO}_{4}$ & 0,50
\end{tabular}

Micronutrientes (ml/L)

\begin{tabular}{lr}
\hline Solución $\mathbf{A 5}$ & $\mathrm{g} / \mathrm{L}$ \\
$\mathrm{ZnSO}_{4} 7 \mathrm{H}_{2} \mathrm{O}$ & 0,222 \\
$\mathrm{CuSO}_{4} \mathrm{H}_{2} \mathrm{O}$ & 0,079 \\
$\mathrm{MoO}_{3}$ & 0,015 \\
$\mathrm{H}_{3} \mathrm{BO}_{3}$ & 2,860 \\
$\mathrm{MnCl}_{2} 4 \mathrm{H}_{2} \mathrm{O}$ & 1,810 \\
$\mathrm{Solución}^{\mathrm{B} 6}$ & $\mathrm{~g} / \mathrm{L}$ \\
\hline $\mathrm{NH}_{4} \mathrm{VO}_{3}$ & 0,023 \\
$\mathrm{KCr}_{2}\left(\mathrm{SO}_{4}\right)_{2} 12 \mathrm{H}_{2} \mathrm{O}$ & 0,096 \\
$\mathrm{NiSO}_{4} 7 \mathrm{H}_{2} \mathrm{O}$ & 0,048 \\
$\mathrm{Na}_{2} \mathrm{WO}_{4} 2 \mathrm{H}_{2} \mathrm{O}$ & 0,018 \\
$\mathrm{Ti}_{2}\left(\mathrm{SO}_{4}\right)_{3}$ & 0,040 \\
$\mathrm{Co}_{2}\left(\mathrm{NO}_{2}\right)_{2} 6 \mathrm{H}_{2} \mathrm{O}$ & 0,044
\end{tabular}

\subsubsection{FBR utilizados}

Se realizaron cultivos a media escala $(<20$ L) para obtener la biomasa de Arthrospira necesaria para las pruebas. Para ello se diseñó un FBR teniendo en cuenta las necesidades del cultivo. Es decir, necesidades de iluminación, agitación y limpieza, así como las labores de manejo. Para ello, se diseñó un FBR sencillo y económico que permitió el cultivo de A. platensis en volúmenes de 12 L. Este FBR consta de una funda tubular de plástico, de polietileno de la marca Rajapack, de calidad alimentaria, de 1,2 m de longitud y de $12 \mathrm{~cm}$ de diámetro. La bolsa se mantiene termo-sellada por la parte superior, dejando 
una entrada para la alimentación y para un tubo de aireación. La parte inferior se termoselló dejando espacio para colocar una espita de plástico, de las usadas en fertiirrigación, que permitía cosechar y purgar el cultivo (i.e., extraer las células muertas y residuos que se generan).

Para obtener la Arthrospira necesaria para las pruebas, se utilizaron 20 FBR en paralelo, y 4 FBR madres (Figura 3.6). Los cultivos madre fueron renovados mensualmente con cultivo aséptico obtenido en condiciones de laboratorio. Esto se realizó para renovar periódicamente el resto de los cultivos, manteniendo así el cultivo lo más sano y puro posible.

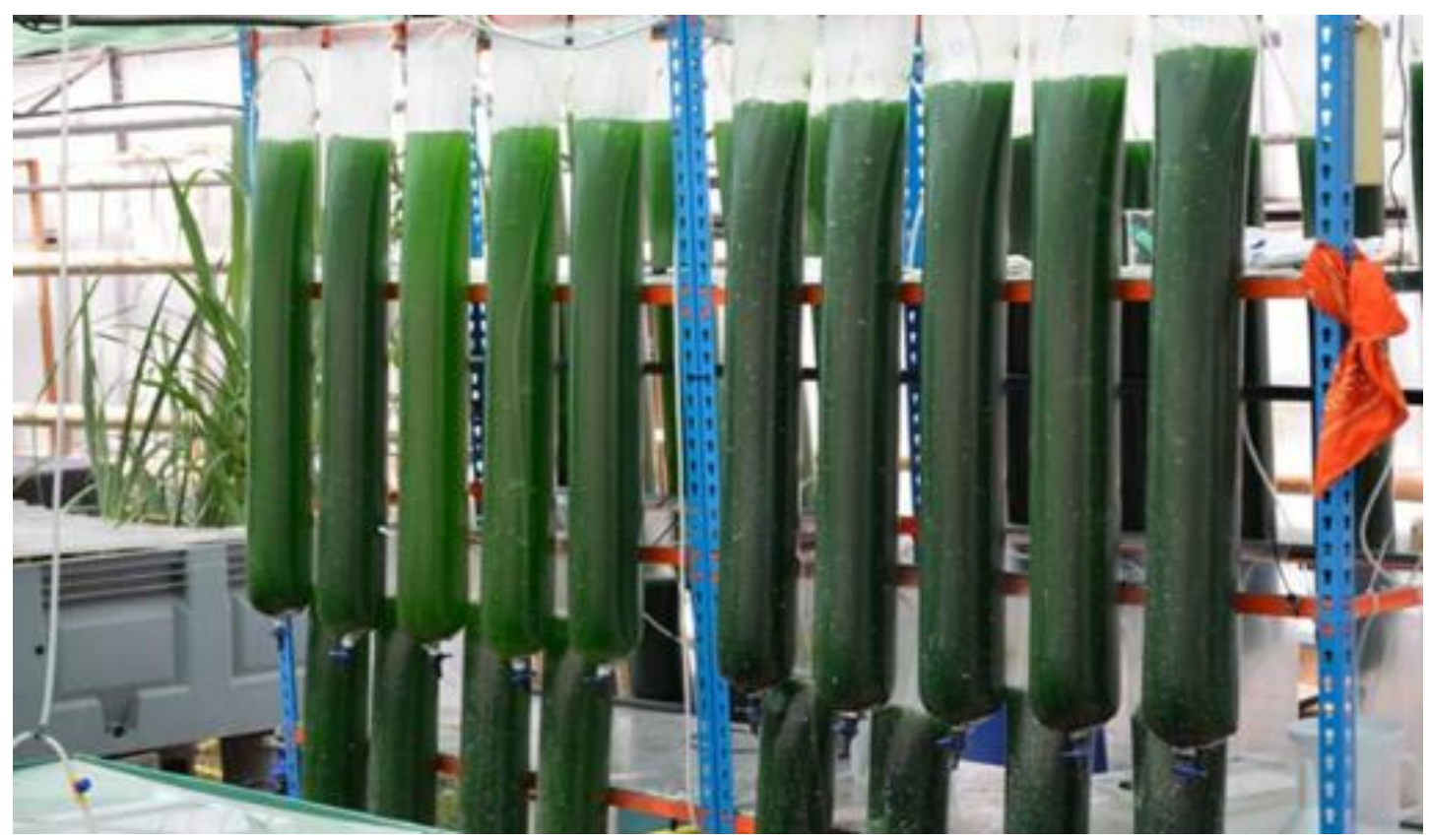

Figura 3.6 Cultivo de $A$. platensis en bio-reactores tubulares en el invernadero de la ETSIAAB. Se puede observar la diferencia de densidad entre el cultivo de la izquierda (recién cosechado) y el de la derecha (esperando a ser cosechado).

Se eligió esta forma tubular por razones técnicas. Esta forma es más eficiente energéticamente, ya que permite que el bombeo de aire necesario para el cultivo y la homogenización, y la agitación, y el enriquecimiento en $\mathrm{CO}_{2}$ necesario para el crecimiento de Arthrospira. El burbujeo debe partir desde el fondo de la bolsa, de manera que el propio burbujeo también nos sirva como método de agitación del sistema. Para ello se colocó una pieza de plomo en el extremo del tubo de aireación para que este se mantuviese fijo en el fondo de la bolsa. Para airear y agitar el cultivo se usó una bomba de aire SPAS de 0,4kW. 
Para purgar el cultivo, se paró la bomba durante unos minutos para dejar reposar el cultivo y que todas las células muertas y residuos se depositen en el fondo del FBR. Seguidamente, se procedía a abrir la espita inferior dejando salir una parte del cultivo que arrastra consigo las sales y células muertas acumuladas en el fondo del FBR, manteniendo así limpio y sano el cultivo. Tras la purga del medio se monitorizaba el crecimiento de la Arthrospira para confirmar que el crecimiento es normal. Por otro lado, se tuvo cuidado de no sellar el fondo de los tanques en ángulo recto. De haberlo hecho el fondo del FBR no se podría limpiar bien, creando una capa de células muertas y residuos en las esquinas, reduciendo así la eficiencia del purgado.

Las dimensiones elegidas favorecen distintos objetivos (Figura 3.7). Con un diámetro de $12 \mathrm{~cm}$ se consigue que la luz atraviese todo el cultivo y favorece que el burbujeo realice una buena acción de agitación-homogenización. La longitud de 1,2 m facilita el manejo de los FBR y que la bomba trabaje a menor presión, reduciendo los costes energéticos. A longitudes superiores el peso y el volumen de los tanques se incrementa de forma exponencial, lo que conlleva el uso de plásticos más resistentes, aumentando su grosor (más opacos) y el coste del material. Otra dificultad es la necesidad de utilizar una bomba más potente, que trabaje a una mayor presión. Estas dimensiones permiten la producción de unos $12 \mathrm{~L}$ de cultivo por FBR, llenos hasta 1,1 m de longitud.

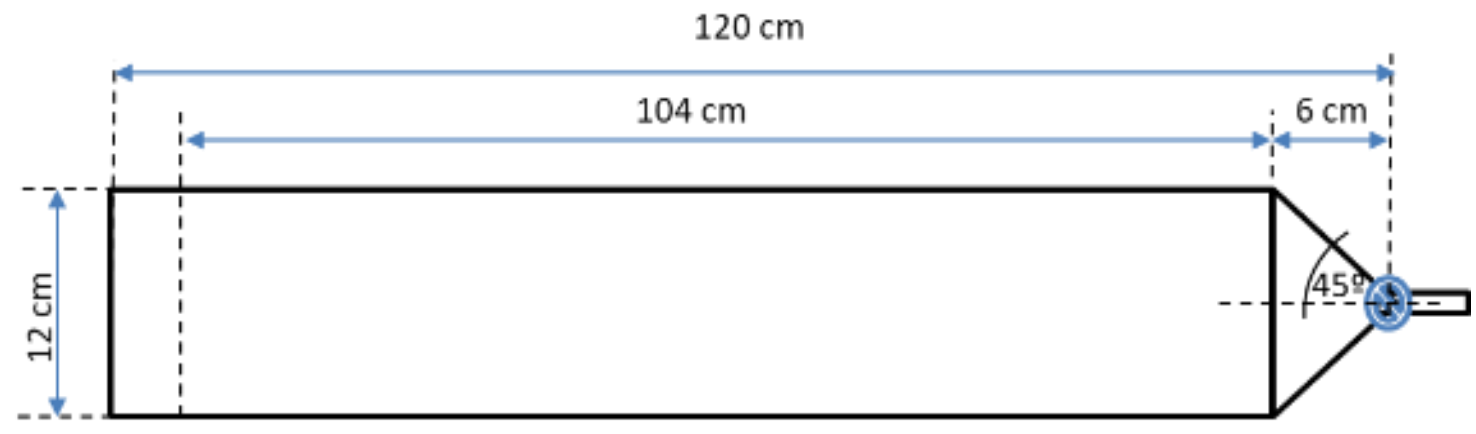

Volumen $(110 \mathrm{~cm})=6 \mathrm{~cm}^{2} \pi * 104 \mathrm{~cm}+\frac{6 \mathrm{~cm}^{2} \pi * 6 \mathrm{~cm}}{3}=11.988,32 \mathrm{cc} \simeq 12 \mathrm{~L}$

Figura 3.7 Dimensiones de los FBR de plástico utilizados para el cultivo de A. platensis 
Para trabajar con bolsas en paralelo, hubo que resolver el problema de las diferencias de presión entre bolsas, que se producen durante las fases de cosechado y alimentado. Para resolver el problema se utilizaron espitas individuales para controlar la presión de aire en cada uno de los FBR.

El manejo eficiente de un cultivo conlleva un conocimiento de sus curvas de crecimiento. Estas curvas dependen de muchos factores, entre los que se encuentra la temperatura, la exposición a la luz (tiempo e intensidad), inoculo inicial, insumos $\left(\mathrm{CO}_{2}\right.$, medio de cultivo) $\mathrm{y}$ otros factores. Con el fin de conocer las curvas de crecimiento, y poder manejar correctamente el cultivo en el invernadero, se desarrolló con Arduino un sensor de turbidez (Figura 3.8) que fue calibrado para el cultivo de Arthrospira.

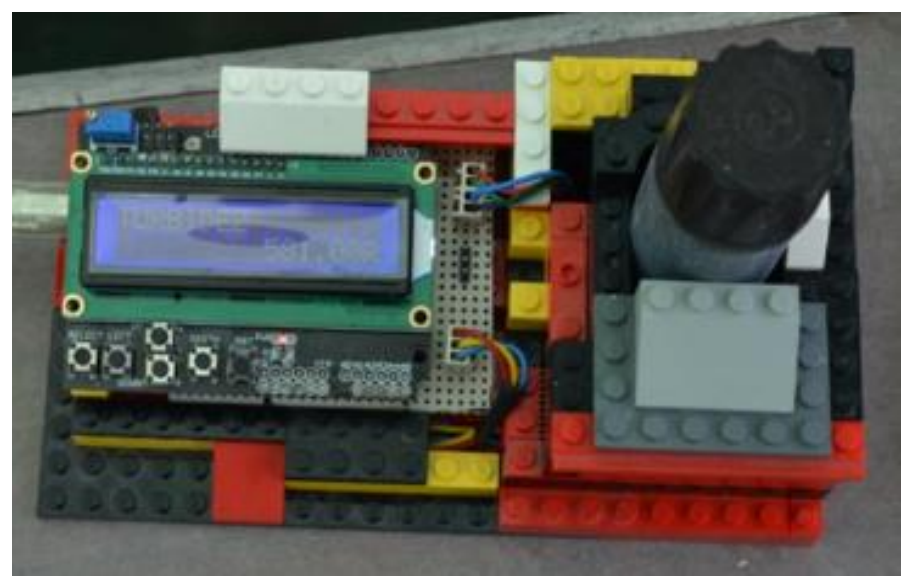

Figura 3.8 Sensor de turbidez desarrollado con Arduino Leonardo, el sensor de color OPT 101 (Burr-Brown) y piezas de Lego®.

Para el calibrado se usó diferentes concentraciones de Arthrospira (Figura 3.9) conocidas, y tres longitudes de onda 700-635 nm (rojo), 650-490 nm (verde) y 490-450 nm (azul). Una vez calibrado, se tomaron medidas diariamente, durante un mes, obteniendo las curvas de crecimiento de los FBR usados bajo nuestras condiciones de cultivo, en invernadero.

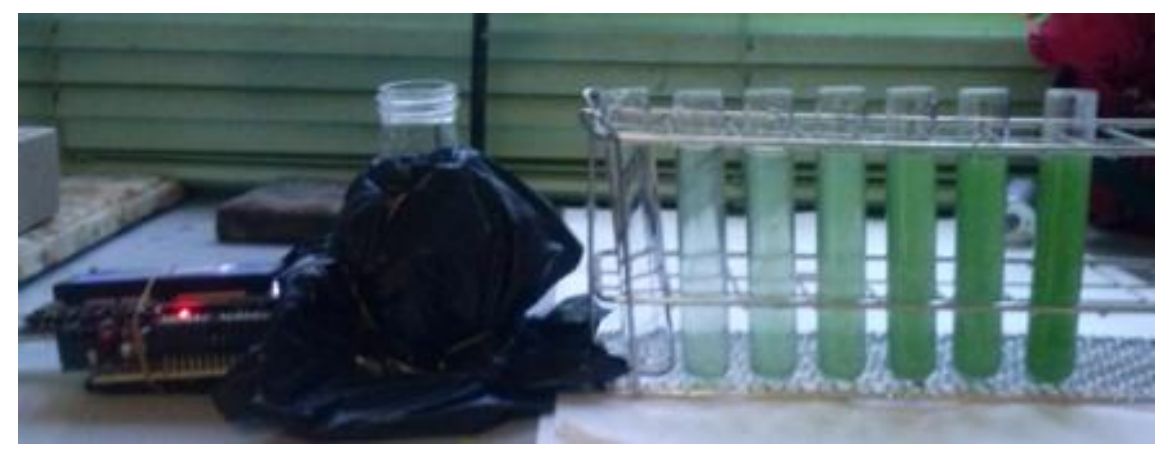

Figura 3.9 Foto realizada durante la fase de calibrado del sensor de turbidez. 
Con este objetivo se estudió el crecimiento del cultivo en condiciones controladas midiendo diariamente la concentración celular en cuatro bolsas. Estas bolsas se inocularon a una concentración inicial de $0,05 \mathrm{mg} / \mathrm{L}$ de Arthrospira y se cultivaron con un fotoperiodo de $14 \mathrm{~L} / 10 \mathrm{~N}$, normal durante el mes de mayo en Madrid, y una temperatura de $28^{\circ} \mathrm{C}$. Durante los 18 días comprendidos entre el 12 y el 30 de mayo del 2015 se obtuvo una curva de cultivo como la que se muestra en la Figura 3.10.

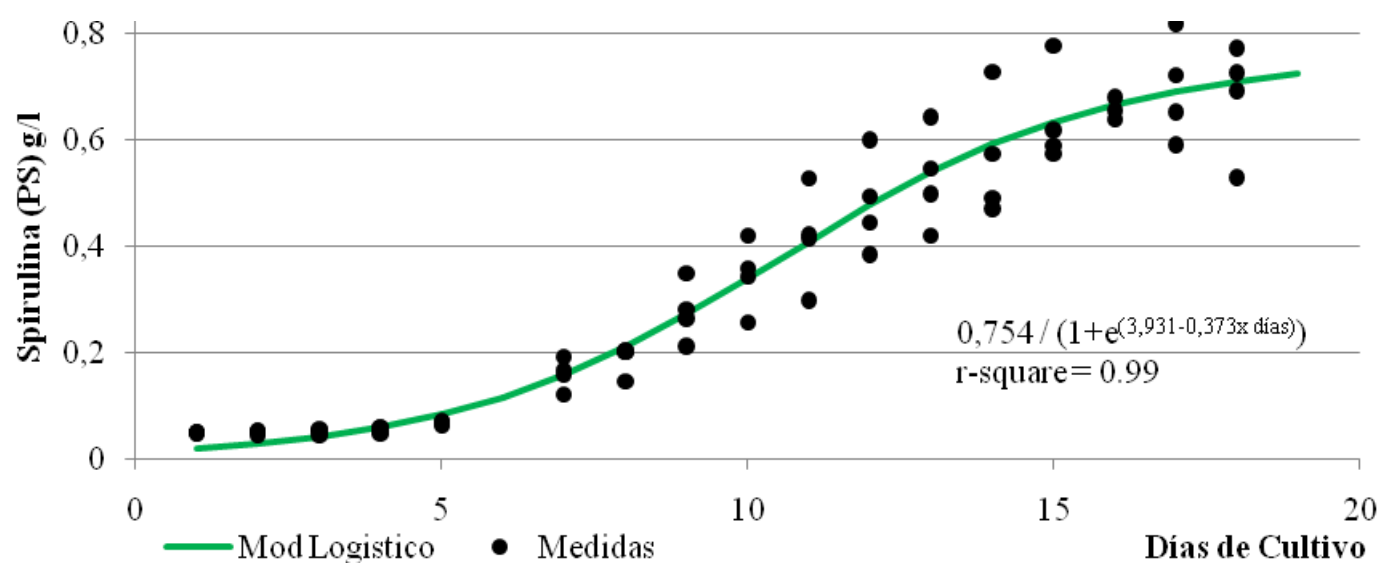

Figura 3.10 Curva de crecimiento de la Arthrospira expresado en g/L en peso seco. Los puntos representan las medidas de concentración obtenidas, y la línea verde es la curva obtenida, mediante ajuste logístico del tipo [a / $(1+\exp (\mathrm{b}-\mathrm{c} * \mathrm{t}(\mathrm{d}))]$.

Teniendo en cuenta la curva promedio obtenida, se decidió, trabajar en la zona lineal de crecimiento constante, cosechando el cultivo en el momento que alcanzaba los 0,6 g/L de Arthrospira peso seco (PS). Para mantenerse en ese intervalo, se cosecharon 2/3 del cultivo, dejando el cultivo a $0,23 \mathrm{~g} / \mathrm{L}$, aún en la fase lineal de crecimiento con una recuperación teórica de $7 \mathrm{~d}$, aproximadamente. Tras lo cual, se diseñó un calendario de trabajo del cultivo de Arthrospira semanal, que se ajustara a las curvas de crecimiento (Tabla 3.5).

Tabla 3.3: Calendario de trabajo en el cultivo de A. platensis en el invernadero.

\begin{tabular}{r|rrrrr}
\multicolumn{2}{r}{ Lunes } & Martes & Miércoles & Jueves & Viernes \\
\hline \multirow{2}{*}{ Semana } & Purgar & Cosechar & Purgar & 2/2 Alimentar & Purgar \\
& hacer medio & Secar & $1 / 2$ Alimentar & & Control madres
\end{tabular}


Los 40 BR de 12 L; 36 en producción y 4 como cultivos madres, permitió un ritmo de cultivo constante superior a los $150 \mathrm{~g}$ semanales, obteniéndose una media de 691,2 g en PS de Arthrospira al mes. Para la renovación del medio de cultivo se dispuso de una cuba de $150 \mathrm{~L}$ que se utilizó para desclorar el agua del canal y preparar el medio de cultivo enriquecido.

36 tanques $\cdot \frac{12 L}{\text { tanque }} \cdot \frac{2}{\mathbf{3}} \cdot \frac{0,6 g(P S)}{L} \cdot \frac{\mathbf{4}}{\text { mes }}=691,2 \frac{g(P S)}{\text { mes }}$ Athrospira sp.

La cosecha se efectuó a primera hora de la mañana, como recomienda Jourdan (1999). Durante la noche, Arthrospira consume parte del azúcar y grasas, y como consecuencia la concentración de proteínas es más elevada por la mañana. Para realizar la cosecha, se dispuso de una tela filtro de entre $46 \mu \mathrm{m}$ de poro, y un cubo limpio para rescatar el medio.

Tras purgar el fondo del FBR, se dejó escapar los primeros ml de cultivo, evitando tomar cultivo muerto o en fermentación que pueda estropear el secado. Se filtraban $2 / 3$ del cultivo, dejando el FBR a $1 / 3$ de capacidad. Tras la cosecha se renovaba el medio, añadiendo $1 / 3$ del medio cosechado rescatado y $1 / 3$ de alimento o medio nuevo enriquecido (Figura 3.11). Es importante que el medio de cultivo nuevo se encuentre a la misma temperatura que el medio de cultivo antiguo, para no crear choque térmico que pueda ocasionar problemas, como la caída del cultivo.
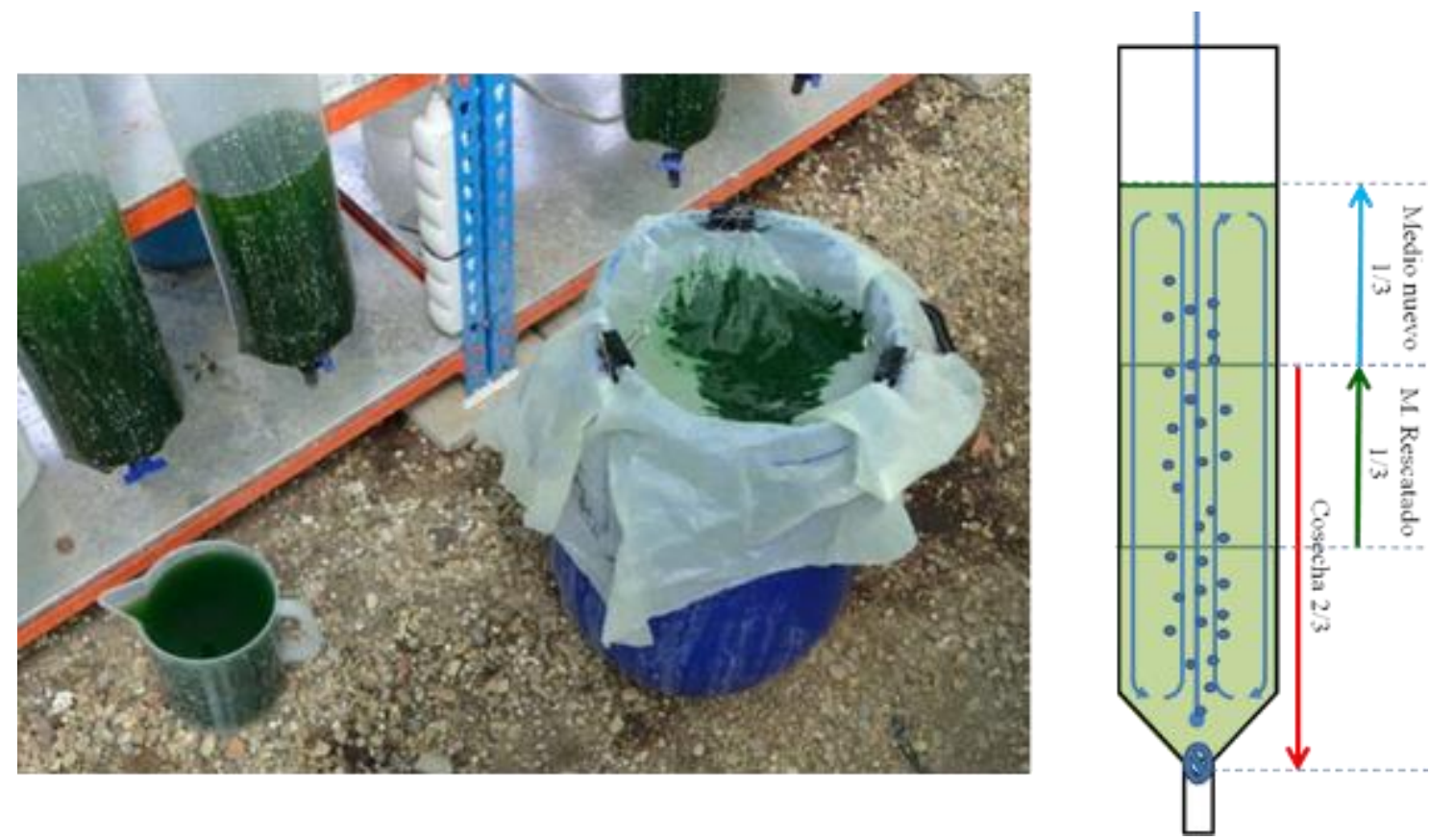

Figura 3.11 Izquierda, Foto realizada durante un día de cosecha de A. platensis con maya de 46 $\mu \mathrm{m}$. Derecha, esquema del FBR, así como las indicaciones cosecha y alimentación. 
Antes del secado, se limpiaba el cultivo cosechado con agua limpia procedente del canal, durante un tiempo estimado de unos 5-6 min, con la intención de extraer el exceso de sales. El secado de la Arthrospira se realizó en dos fases. En la primera fase o fase de concentración se elimina el $90 \%$ de la humedad y exceso de agua retenido en el cultivo. El cultivo fue escurriendo en el paño de forma mecánica, compactando a una presión de aproximadamente de $0,2 \mathrm{~kg} / \mathrm{cm}^{2}$. Tras lo cual, entraba en la segunda fase o de secado por aire. En este segundo paso, se vertía $0,5 \mathrm{~cm}$ del alga concentrada en bandejas de plástico de calidad alimentaria de $1,5 \mathrm{~cm}$ de profundidad, para posteriormente secarse en oscuridad, en un sistema de secado por corriente de aire horizontal. Para ello se usó una corriente de aire caliente, producida por una turbina de aire industrial $(32 \mathrm{~kW})$ a una temperatura controlada de entre $35-40^{\circ} \mathrm{C}$. El secado debe hacerse en oscuridad y con temperaturas no muy elevadas para evitar la degradación de proteínas, vitaminas y otros compuestos, que son de vital importancia para el desarrollo de la investigación (Jourdan, 1999). Finalmente, para conservar la Arthrospira, se empaquetó en bolsas de auto cierre, etiquetadas con día y fecha del cultivo. Las bolsas se conservaron en oscuridad en una caja de aluminio a $4^{\circ} \mathrm{C}$, para su posterior utilización. 


\subsection{ANIMALES Y ALOJAMIENTO}

Para criar en cautividad cualquier animal, concretamente O. niloticus, se ha de conocer y tener en cuenta sus necesidades biológicas, tanto de ambientales como comportamentales.

\subsubsection{Calidad del agua}

Los peces del género Oreochromis sp. son muy robustos y toleran altas densidades de cría y bajas calidades de agua, entre otros factores estresantes. Según distintos autores, existen varios indicadores que reflejan la calidad del agua y que se pueden medir desde el punto de vista del comportamiento, de la morfología o de la producción (Tabla 3.4).

Tabla 3.4 Indicadores fisiológicos basales de la calidad de agua según Branson (2000).

Categoría

Comportamiento Agregación cerca de la superficie

Incremento en tasa de respiración

Disminución consumo

Híper-excitabilidad

Nado errático

Perdida de equilibrio

Letargo, desorientación, moribundo
Problema de calidad de agua

$\downarrow$ OD.

$\uparrow \mathrm{H}_{4} \mathrm{~N}^{+} ; \downarrow \mathrm{OD} ; \uparrow \mathrm{CO}_{2}$.

$\uparrow \mathrm{H}_{4} \mathrm{~N}^{+}$.

$\uparrow \mathrm{H}_{4} \mathrm{~N}^{+}$.

$\uparrow \mathrm{H}_{4} \mathrm{~N}^{+}$.

$\uparrow \mathrm{H}_{4} \mathrm{~N}^{+}$.

$\uparrow \mathrm{H}_{4} \mathrm{~N}^{+} ; \uparrow \mathrm{CO}_{2}$

Morfología

Lamelas de las branquias rojo-brillante, $\uparrow^{-\mathrm{CO}_{2}}$.

Daño en las branquias

$\uparrow \mathrm{H}_{4} \mathrm{~N}^{+} ; \downarrow \mathrm{OD} ; \uparrow \mathrm{NO}_{2} ; \uparrow$ Sólidos en Suspensión.

Sangre marrón

$\uparrow \mathrm{NO}_{2}^{-}$.

Daños en timo

$\uparrow \mathrm{NO}_{2}^{-}$.

Desarrollo anormalidades

$\uparrow \mathrm{NO}_{3}^{-} ; \mathrm{T}^{\mathrm{a}}$.

Nefro-calcinosis

$\uparrow \mathrm{CO}_{2}$.

Enfermedades de burbujas

$\uparrow \uparrow \mathrm{O}_{2}$.

Producción

Disminución de crecimiento

$\uparrow \mathrm{H}_{4} \mathrm{~N}^{+} ; \downarrow \mathrm{OD}$.

Incremento del consumo

$\uparrow \mathrm{H}_{4} \mathrm{~N}^{+} ; \downarrow \mathrm{OD}$.

Mortalidad

Nivel letal de algún parámetro.

OD: Oxígeno Disuelto 
La calidad del agua es un factor importante para el bienestar de los peces. La información sobre las condiciones del agua se obtiene a través de métodos que van desde medición in situ con equipos para monitorear el agua hasta sofisticados sistemas de control por ordenador.

Durante la primera prueba (two-choices), las mediciones de la calidad del agua se tomaron dos veces por semana en todos los tanques. Los días elegidos fueron los lunes y jueves después de la primera comida (9:30 a 10:00 h). Las mediciones incluyeron oxígeno disuelto $\left(\mathrm{DO}_{2}\right)$, conductividad eléctrica $(\mathrm{EC})$ y niveles de amoníaco, nitritos y nitratos (Hanna HI83203). Los parámetros de calidad del agua se mantuvieron dentro de los valores normales para el crecimiento de $O$. niloticus (media \pm SE; temperatura $27,3 \pm 0,25{ }^{\circ} \mathrm{C} ; \mathrm{pH}$ $7,36 \pm 0,33 ; \mathrm{EC} 0,60 \pm 0.07 \mathrm{dS} ; \mathrm{O}_{2} 7,19 \pm 0,17 \mathrm{ppm} ; \mathrm{H}_{4} \mathrm{~N}^{+} 0,01 \pm 0,02 \mathrm{ppm} ; \mathrm{NO}_{2}{ }^{-} 0,01 \pm$ $\left.0,02 \mathrm{ppm} ; \mathrm{NO}_{3}{ }^{-} 13,48 \pm 5,78 \mathrm{ppm}\right)$, y no fueron significativamente diferentes entre los tratamientos.

En la prueba 2 y 3 (pre-engorde y metagenómica), se tomaron también medidas dos veces a la semana, cada lunes y jueves. Las mediciones se tomaron en las salidas de race-ways después de la primera comida (9:30 a 10:00 h). La temperatura de los race-ways fue controlada cada 5 min por sensores de temperatura Hobo con sonda sub-acúatica. Los parámetros de calidad del agua estuvieron dentro de los rangos normales para la tilapia (temperatura $27,3 \pm 0,3^{\circ} \mathrm{C}, \mathrm{pH} 8,38 \pm 0,15, \mathrm{EC} 0,50 \pm 0,01 \mathrm{dSm}, \mathrm{O}_{2} 7,12 \pm 0,05 \mathrm{ppm}, \mathrm{H}_{4} \mathrm{~N}^{+}$ $0,43 \pm 0,29 \mathrm{ppm})$ y no fueron significativamente diferentes entre los tratamientos, ya que compartían la misma agua. La temperatura media durante la fase de adaptación fue de 23,0 ${ }^{\circ} \mathrm{C}(\mathrm{SD} \pm 1,82)$ con un máximo de $26,7^{\circ} \mathrm{C}$ y un mínimo de $17,8^{\circ} \mathrm{C}$. El promedio de temperatura de ensayo fue de $24,4{ }^{\circ} \mathrm{C}(\mathrm{SD} \pm 1,0)$ con un máximo de $26^{\circ} \mathrm{C}$ y un mínimo de $21,3^{\circ} \mathrm{C}$.

\subsubsection{Base biológica de O. niloticus}

Los peces utilizados tuvieron dos lugares de procedencia. Los alevines de $O$. niloticus de la primera prueba (two-choices) fueron originalmente adquiridos de Valenciana de Acuicultura (Puçol, Valencia) descendencia de tilapias denominadas genetically male tilapia o GMET®, provenientes de una población de supermachos (YY) 
y hembras (XX) de la empresa Fishgen SL (Sawansee, Reino Unido), lo cual origina una prole homogénea masculinizada de alevines machos (XY).

Para la prueba de pre-engorde y de metagenómica, se adquirieron 12 reproductores directamente de la empresa fisguen SL (Sawansee, Reino Unido) reproductores YY y XX. De los cuales se seleccionan machos (2) y las hembras más grandes (6), para la criar alevines machos (XY) para la experimentación. Se alojaron en uno de los invernaderos anteriormente mencionados, y durante los meses de verano en las instalaciones de Acuicultura de la ETSIM. La diferenciación temprana entre sexos se debe realizar cuando los peces sobrepasan los $100 \mathrm{~g}$, y se basa en que el macho presenta dos orificios en el vientre el ano y orificio urogenital, mientras que las hembras poseen tres, ano, poro genital y el orificio urinario (Figura 3.12).

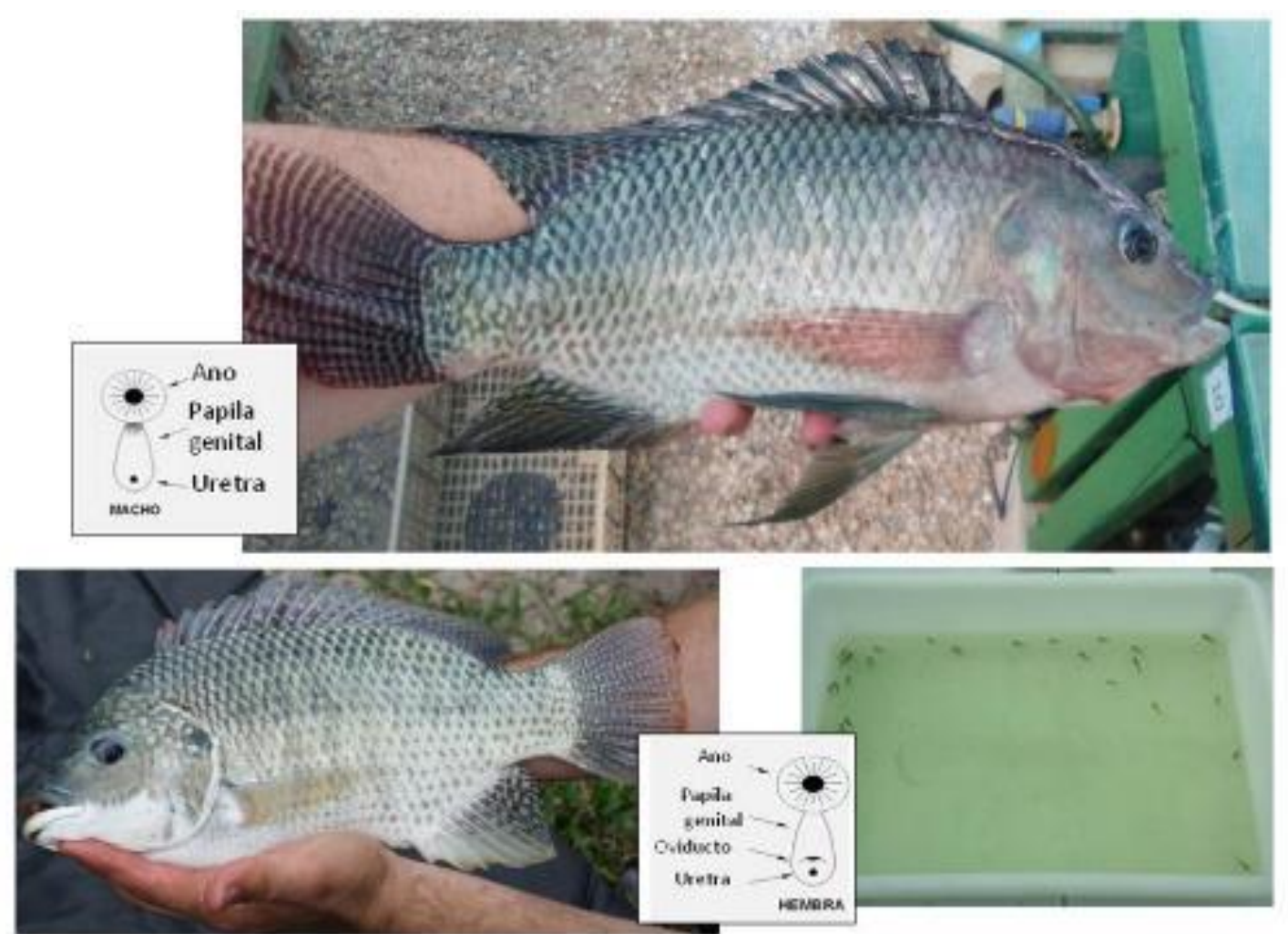

Figura 3.12 Diferenciación sexual en $O$. niloticus. 


\subsubsection{SUPERMACHOS GMET®}

Los "supermachos" son machos que presentan un genotipo YY, con dos cromosomas que determinan el sexo masculino en lugar de uno, como el genotipo masculino que se produce de forma natural (XY).

La técnica para la obtención de "supermachos" sigue los siguientes pasos (Figura 3.13): Seleccionar los mejores peces con las características óptimas de peso y talla deseadas y se hacen criar. A una parte de la generación obtenida (machos y hembras), se les suministra hormonas femeninas, lo que consigue convertir a cierto porcentaje de machos en hembras funcionales. Tendremos de esta manera un tanto por ciento de hembras XX y otro tanto por ciento de hembras XY, aunque genéticamente son XY, fenotípicamente son hembras con capacidad reproductora. Estas hembras (XY) se cruzan ahora con machos normales, también XY. Entre su descendencia habrá hembras (XX), machos normales (XY) y los supermachos (YY). Para identificar los supermachos, entre el conjunto de machos, se cruzan con hembras normales (XX) y se observa la descendencia.

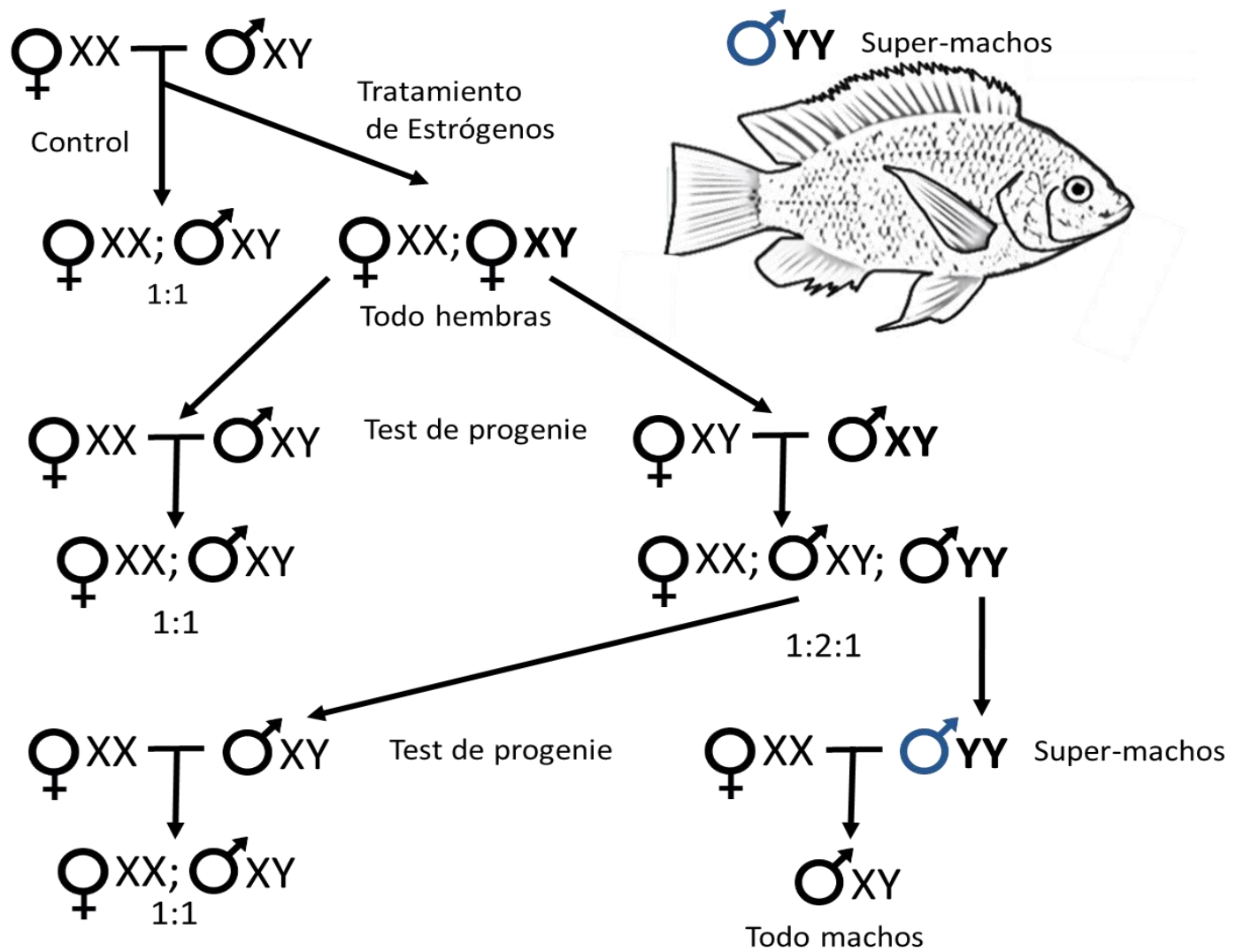

Figura 3. 13 Esquema de la técnica para la obtención de Supermachos 


\subsubsection{Tanques utilizados.}

\subsubsection{Tanques de recirculación de Agua (RAS)}

La prueba 1 (two-choices) con alevines se realizó en el invernadero usando 16 tanques de fibra de vidrio verde con un volumen de $120 \mathrm{~L}$ (Figura 3.14), de 0,46 m de altura y $0,64 \mathrm{~m}$ de diámetro en la parte superior, terminado en cono en la inferior, lo que facilita su limpieza. Todos los tanques cuentan con una tapadera transparente para evitar que los peces salten fuera del tanque o a otro tanque adyacente.

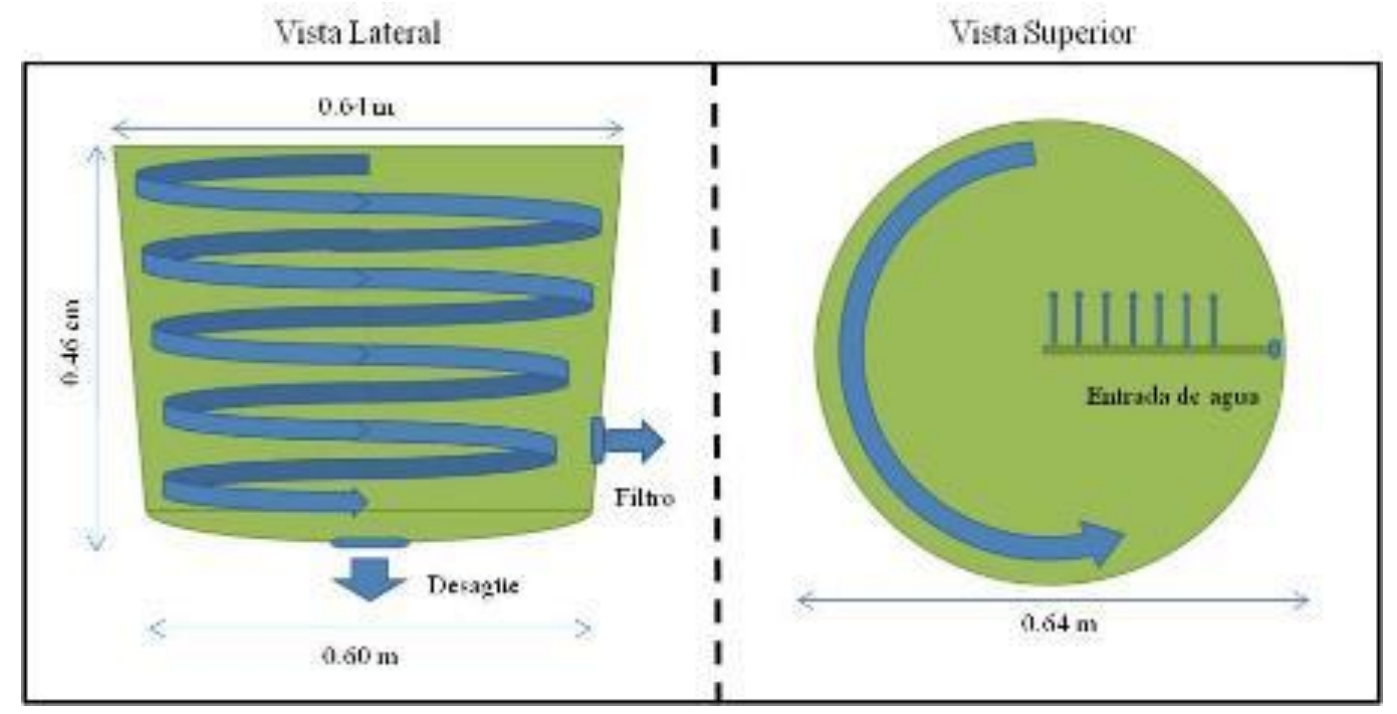

Figura 3.14 Tanques troncocónicos utilizados, dimensiones, y flujo de agua con el desagüe en la parte inferior y salida al filtro a $1 / 4$ de la base.

Uno de los factores más importantes en un sistema RAS es el reciclaje de los residuos producidos por los peces. Este se lleva a cabo gracias a un desagüé colocado en el fondo del tanque, por el que se eliminar la mayor parte de los residuos sólidos mediante purgado, y mediante una salida al filtro colocado a $1 / 4$ de altura del fondo. Los filtros realizan los ciclos de degradación del nitrógeno, el fosforo y otros elementos. Los compuestos nitrogenados son contaminantes habituales en los sistemas de acuicultura, ya que los peces producen y excretan varios productos nitrogenados de desecho, en su mayor parte como amoniaco, y deben ser mantenidos dentro de concentraciones aceptables. Los nitritos son especialmente tóxicos para los peces, oxidan la hemoglobina transformándola en metahemoglobina, que tiene muy poca capacidad de transportar oxígeno (Lewis y Morris, 1986). 
Durante los experimentos, un filtro (EHEIM classic; Mod 2217, Figura 3.15) de 6 L capacidad, $20 \mathrm{~W}$ y un flujo de agua de $1000 \mathrm{~L} \mathrm{~h}^{-1}$ se conectó a cada tanque. La toma de agua al filtro se toma a 1/4 de la altura de la base del tanque, para evitar la entrada de partículas gruesas, y restos de alimentos, que podría disminuir la eficiencia de los filtros. Estas partículas gruesas se extraen mediante purgado de los tanques 2 veces a la semana. El agua no se cambió en ningún momento durante los experimentos. Únicamente se repuso el agua perdida por evaporación, y por las purgas. Para este rellenado, siempre se usó agua del Canal previamente desclorada. Aunque los Filtros EHEIM de acuario no son los más comunes en la producción de alto rendimiento para la acuicultura, se usaron para poder aumentar el número de réplicas y para controlar la calidad de agua en cada tanque individualmente. Los filtros se rellenaron como se indica en la Figura 3.12, con $1150 \mathrm{~g}$ de canutillos EHFIMECH, dos almohadillas de esponja, $1200 \mathrm{~g}$ de piedras porosas EHFIMECH, una esponja blanca de algodón y una de fina negra de carbón activo.

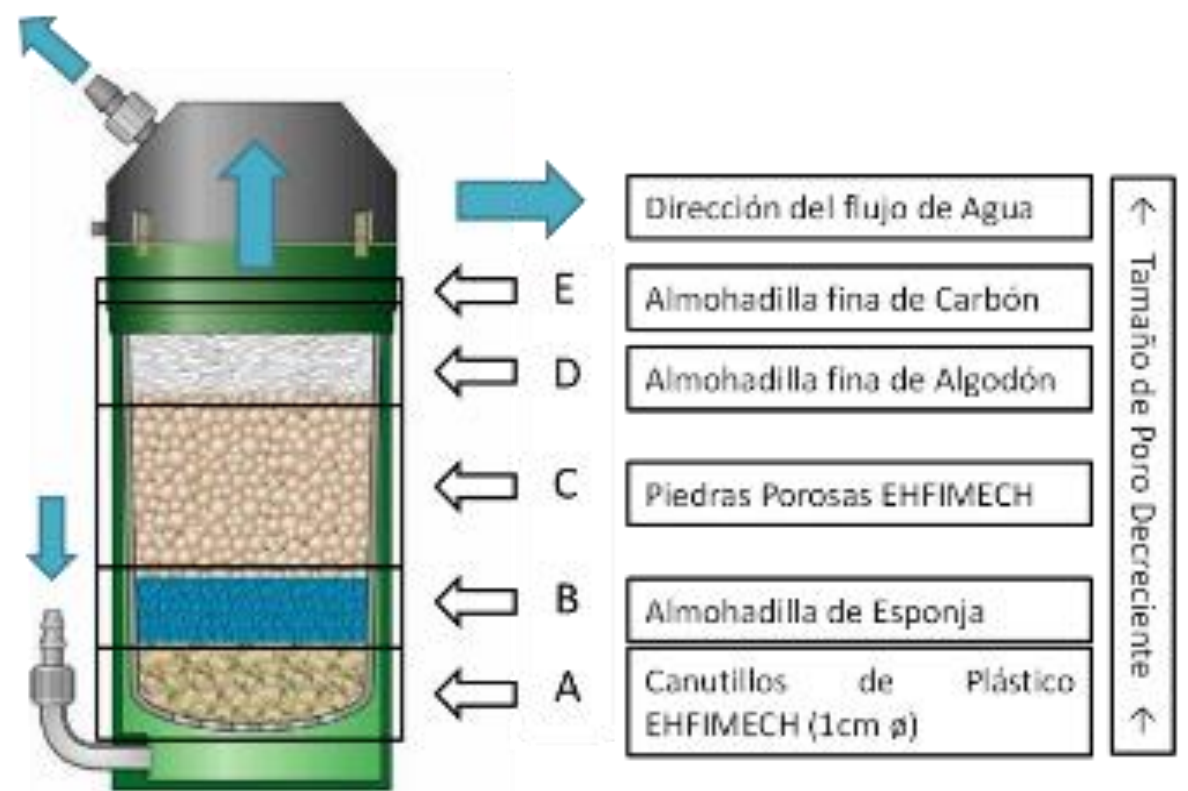

Figura 3.15 Filtros EHEIM classic; Mod 2217 con su conformación para el experimento.

Los filtros se prepararon inoculando bacterias nitrificantes (EHEIM water care), utilizando las indicaciones del proveedor. Se estimó la cantidad de nitrógeno amoniacal total (NAT) que iban a producir los peces basándose en la tasa de alimentación según Timmons et al. (2009). Se añadió el amoniaco estimado diariamente, probando la actividad microbiana, y la evolución de los compuestos nitrogenados, hasta que fue satisfactoria, lo que ocurrió transcurridas aproximadamente 3 semanas. 


$$
\begin{aligned}
& \text { NAT }=\frac{F \cdot P C \cdot 0.092 \text { Alevines } 3 g \cdot 38 \% \cdot 0.092}{t}=0.105 \mathrm{~g} \\
& 1 \text { día } \\
& \text { NATppmportanque }\left(120 \mathrm{~L} \text { )ydía }=\frac{105 \frac{\mathrm{mgNAT}}{\text { día }}}{120 \mathrm{~L}}=0.875 \mathrm{ppm}\right.
\end{aligned}
$$

F, (feed) Alimentación en peso.

$\mathrm{PC}, \%$ proteína cruda en pienso.

$\mathrm{t}$, tiempo.

0.092, constante en la ecuación de nitrógeno amoniacal total (NAT) que se basa en una aproximación de estimaciones.

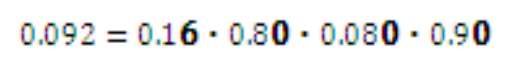

$16 \%$, nitrógeno en la proteína.

$80 \%$ nitrógeno asimilado por el pez.

$80 \%$ nitrógeno asimilado que es excretado.

$90 \%$ del nitrógeno es excretado como NAT.

El sistema de aireación para los tanques se resuelve con una bomba Million Air-MA 200 de $4 \mathrm{~W}$ de potencia, que proporciona el aire necesario a los tanques por medio de un tubo de silicona insertado dentro de cada uno de los tanques. Se utilizaron calentadores de agua de $150 \mathrm{~W}$ (ATAMAN N2867; 50-60 Hz; 20-34 ${ }^{\circ} \mathrm{C}$ ), graduados a $28{ }^{\circ} \mathrm{C}$ para mantener la temperatura constante durante el experimento. El fotoperiodo fue natural.

Para la Prueba 2 se llevaron los peces a la piscifactoría de ETSIAM (Figura 3.16). Esta se encuentra construida en una pequeña pendiente dividida en terrazas. El sistema consta de un canal interior que distribuye agua entre los race-ways laterales donde se situaran los peces. Estos tanques laterales tienen una capacidad estimada de $5,16 \mathrm{~m}^{3}$, que, a su vez, están divididos en 5 partes, mediante rejas metálicas, creando espacios de $1 \mathrm{~m}^{3}$. Los canales tienen un flujo de agua dulce constante que proviene de un pozo subterráneo $(0,2 \mathrm{~L} / \mathrm{s})$. Los tanques se encuentran al aire libre, por lo que los peces están sometidos a una temperatura $\mathrm{y}$ fotoperiodo natural. 


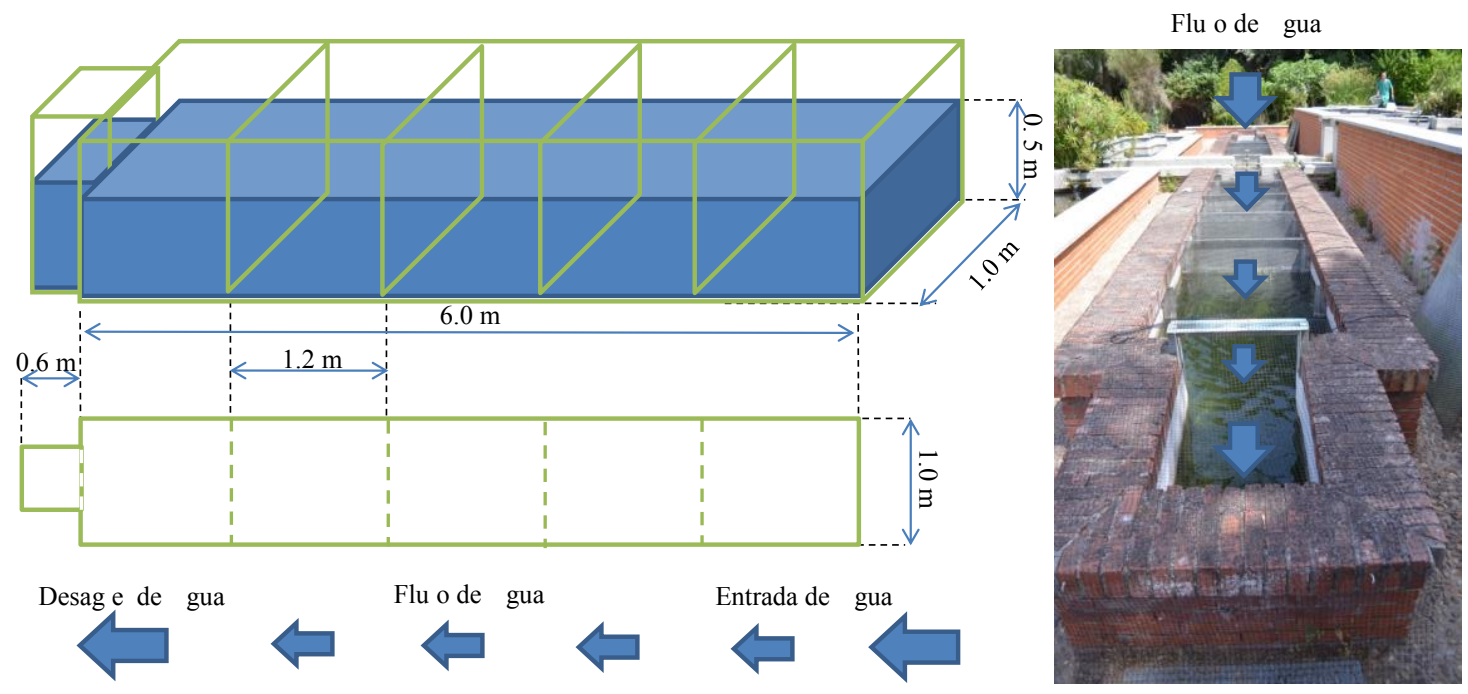

Figura 3.16 Race-ways utilizados en la prueba de pre-engorde y metagenómica. Dimensiones, y flujo de agua. 


\subsection{ALIMENTO}

Durante la fase de aclimatación todos los peces fueron alimentados con pienso comercial (T3 Skretting), que también fue la base de los piensos para las pruebas que se suplementaron con A. platensis. Para la preparación de los piensos se ha de tener en cuenta que el tamaño de partícula de la alimentación debe ser ajustado a la boca del pez. Para la prueba con los alevines de Oreochromis sp. (1 a $5 \mathrm{~cm}$ ) el tamaño de los gránulos estaba comprendido entre 0,1-0,2 cm. Por lo tanto, la alimentación de base (T3 Skretting) se trituró y se peletizó a 0,1 a $0,2 \mathrm{~cm}$. Para las alimentaciones del tratamiento con algas, el pienso tamizado se mezcló con $10 \mathrm{~g}$ de A. platensis por kg de alimento, y se peletizó al mismo tamaño $(0,2-0,1 \mathrm{~cm})$. Para los animales de pre-engorde se realizó el mismo tratamiento solo que se peletizó a un tamaño mayor de $0,5-0,7 \mathrm{~cm}$. El pienso se mantuvo a $4^{\circ} \mathrm{C}$ hasta su utilización.

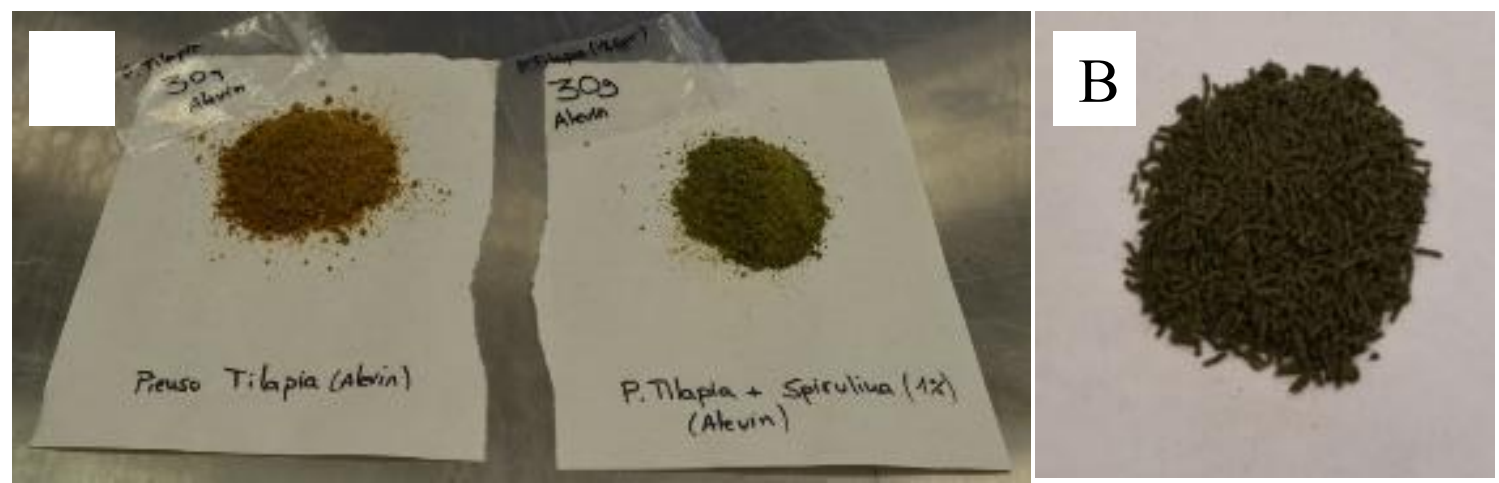

Figura 3. 17 Piensos utilizados en las distintas pruebas. A) piensos en granulo de $0,1-0,2 \varnothing \mathrm{cm}$ para la prueba de alevines, B) pienso peletizado a $0,5-0,7 \varnothing \mathrm{cm}$ para la prueba de pre-engorde y metagenómica.

Los alevines se alimentaron a un 6\% de peso vivo usando un autoalimentado (EHEIM 3581). En el caso de pre-engorde y metagenómica, en los race-ways se utilizaron los comederos de cinta, que distribuye el pienso a lo largo del día a una tasa de $3 \%$ del peso vivo.

Las dietas experimentales, el control (CTR) y la dieta conteniendo A. platensis (SPR), fueron analizadas por el laboratorio de nutrición de la ETSIAAB. Para analizar la composición proximal de la alimentación se tomaron cinco muestras por tratamiento y el porcentaje de materia seca se obtuvo por secado en horno a $105^{\circ} \mathrm{C}$, hasta peso constante, 
y el contenido de cenizas por incineración $550^{\circ} \mathrm{C}$. El contenido de proteína se midió mediante análisis de Kjeldahl y el extracto de éter por hidrólisis. El contenido de fibra se obtuvo mediante el método de Van Soest (1991) y finalmente la energía se calculó usando un calorímetro de bomba. Ambas alimentaciones fueron isocalóricas (energía bruta) e isoproteicas (proteína bruta), 5,02/4,98 kcal/g MS y 44,6/44,8 CP\% MS (Tabla 4.2).

Tabla 4.1 Composición aproximada de dietas experimentales (materia seca, cenizas, proteína bruta $\mathrm{PB}$, extracto de éter de éter EE, fibra detergente neutro FDN, fibra detergente ácida ADF, lignina de detergente ácido ADL y energía bruta).

\begin{tabular}{lrrr}
\hline & Control & A. platensis & Unidades \\
\hline Materia Seca & 92,60 & 9260 & $\%$ \\
Cenizas & 7,39 & 7,37 & $\%$ \\
PB & 44,59 & 44,3 & $\% / \mathrm{MS}$ \\
EE. & 6,39 & 6,44 & $\% / \mathrm{MS}$ \\
NDF & 26,4 & 26,23 & $\% / \mathrm{MS}$ \\
DF & 4,9 & 5,05 & $\% / \mathrm{MS}$ \\
DL & 0,6 & 0,7 & $\% / \mathrm{MS}$ \\
Energía Bruta & 5,00 & 4,9 & $\mathrm{kcal} / \mathrm{g} \mathrm{MS}$ \\
\hline
\end{tabular}




\subsection{DISEÑO EXPERIMENTAL}

\subsubsection{Consideraciones de bienestar animal al sacrificio}

Todos los animales se trataron de acuerdo a las consideraciones de bienestar animal siguiendo la normativa del departamento y aprobado en el comité de ética de la ETISAAB, según el Real Decreto 53/2013 de bienestar animal (BOE, 2013). En todas las pruebas y ensayos en los que hubo que sacrificar un animal, estos fueron anestesiados previamente usando eugenol a una concentración de $100 \mathrm{mg} / \mathrm{L}$ (Delbon y Paiva, 2012) durante $2 \mathrm{~min}$ y sacrificados cortando la espina dorsal detrás del opérculo (Lopez-Luna et al., 2016).

\subsubsection{Prueba 1 Two-Choices}

Esta prueba tiene como objetivo verificar si el suplemento alimenticio al $1 \%$ de $A$. platensis modifica la respuesta conductual al estrés, mediante una prueba no invasiva, así como las variables de producción básica en la producción de alevines como crecimiento, supervivencia y calidad del agua. Para ello se utilizaron los tanques troncocónicos especificados en la sección anterior. Tras preparar los filtros se introdujeron 25 alevines al azar por tanque, y se dejaron durante un período de aclimatación de dos semanas, bajo un mismo nivel de alimentación. Después de este período todos los peces de cada tanque fueron pesados en grupo y su longitud medida individualmente. El peso medio inicial por tanque fue de 2,64 g $(\mathrm{n}=25)$ con una desviación $\mathrm{SD} \pm 0,45 \mathrm{~g}$. La longitud inicial de los peces fue de $1,17 \mathrm{~cm}$ con una desviación del $\mathrm{SD} \pm 0,10 \mathrm{~cm}$, sin diferencias por tratamientos.

Los alevines se alimentaron a razón de $6 \%$ de peso vivo usando un dispensador automático (EHEIM 3581) que proporcionó cuatro comidas al día (7:00 h, 12:00 h, 17:00 h y 22:00 h), comenzando la prueba desde el 04-08-2015 hasta el 24-09-2015, por un total de 50 días (7 semanas). Los filtros se apagaron durante 20 min después de cada comida para evitar la pérdida de alimento. Durante este periodo de siete semanas se revisaba diariamente las bajas y se tomaran datos de crecimiento de los peces y su supervivencia. Tras finalizar este periodo se llevó a cabo el test two-choices. Se realizaron 12 pruebas de two-choices, utilizando seis tanques por tratamiento, descartando los tanques con menos de 20 alevines. En el caso de los alevines que recibieron A. platensis, todos los tanques tenían más de 20 
peces, por lo que los tanques usados para la prueba de two-choices fueron elegidos aleatoriamente lanzando un dado de 8 caras.

La prueba de two-choices comenzó con la introducción de 20 peces tomados al azar desde un mismo tanque. Se dejaron en el Tanque A para aclimatarse durante un periodo de 30 min. Trascurrido el periodo de adaptación, se abrió la compuerta que daba paso al segundo tanque (Tanque B), y se comenzó a burbujear el Tanque A con nitrógeno, para disminuir los niveles de oxígeno (a una velocidad de $1 \mathrm{ppm}$ por $10 \mathrm{~min}$ ) y el Tanque B se mantuvo con niveles normales de oxígeno (aproximadamente $7 \mathrm{ppm}$ ). El nivel de oxígeno disuelto en los tanques se monitorizó cada 10 min. Cada prueba se registró con una cámara de vídeo (Nikon 3500) para no afectar a los peces por presencia humana. Se observaron y anotaron los tiempos en que cualquier pez abandona el Tanque A para entrar en el B. La prueba se dio por terminada cuando los primeros cinco peces habían dejado el Tanque A o transcurrida una hora de prueba (si menos de cinco alevines dejaron el Tanque A). Después de este periodo se midieron, mediante técnica fotográfica, los peces que cruzaron al Tanque $\mathrm{B}$, como anteriormente se midieron todos los peces mediante la misma técnica, se puede extrapolar el tamaño de los peces que permanecieron en el tanque A.

\subsubsection{Prueba 2 Pre-Engorde}

Para esta prueba, 250 alevines de O. niloticus fueron criados usando los reproductores originarios de Sawansee (Reino Unido) y sometidos a un proceso de masculinización y criados con pienso comercial (T3 Skretting) en el mismo sistema RAS (ubicado en Madrid, $40^{\circ} 27^{\prime} 03.0$ "N $3^{\circ}$ 43'16.9" W) hasta alcanzar los 90,2 \pm 2,6 g (M \pm $\mathrm{SE}$ ). Posteriormente, se seleccionaron 100 peces de tamaño más homogéneo para la prueba. Cada pez fue identificado individualmente con un microchip (i-Tag 162,2x12 mm) colocado bajo la aleta dorsal, medido, fotografiado (Imagen 3.18) y asignado a uno de los dos tratamientos. Los peces se trasladaron a las instalaciones de la ETSIM, donde se distribuyeron en uno de los tanques de $1 \mathrm{~m}^{3}$ de un race-way. 


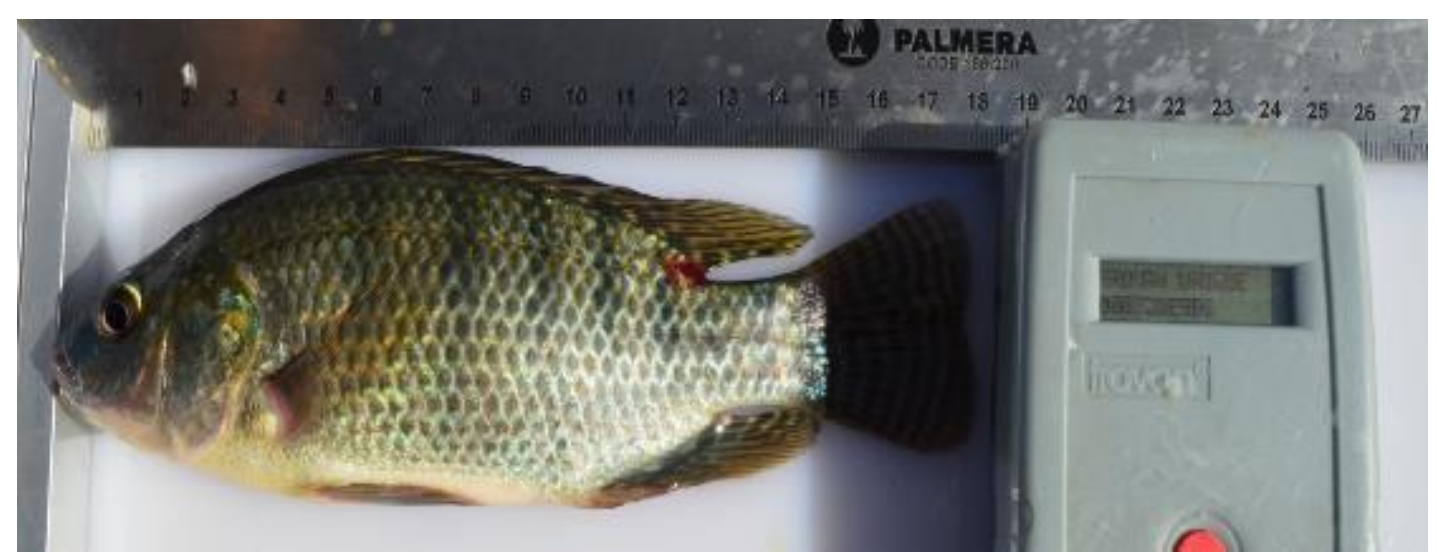

Figura 3.18 Fotografía de la entrada del pez E9B6. Cada pez fue identificado individualmente con un microchip (i-Tag 162,2x12 mm) colocado bajo la aleta dorsal, medido, fotografiado y asignado a uno de los tratamientos.

Se usaron dos secciones por tratamiento, 25 peces por tanque, para simular concentraciones comerciales de $3 \mathrm{~kg} / \mathrm{m}^{3}$. Los peces tuvieron un período de aclimatación de aproximadamente 3 semanas (-22 d a -1), durante el cual se alimentaron con alimento control (CTR), al inicio del 3\% de peso vivo, antes de que el ensayo comenzara con los diferentes alimentos. Para distribuir el alimento se utilizaron comederos de cinta, que distribuyen la comida de forma homogénea a lo largo del día. La alimentación experimental se suministró durante 7 semanas al 3,5\% de peso vivo durante el ensayo. Transcurridas las 7 semanas, se tomaron muestras de sangre de los peces y se analizaron los parámetros de crecimiento y de calidad de la carne.

\subsubsection{Prueba 3 Metagenómica}

En la prueba 3 se analizó el microbiota existente en el intestino de los peces y el efecto de la suplementación con A. platensis. Para ello se tomaron 16 peces de la prueba 2 (pre-engorde), 8 por tratamiento. Estos individuos fueron criados bajo condiciones ambientales idénticas y controladas, tanto en su cría como durante la prueba de preengorde. Esta consideración es importante pues varios estudios realizados en $O$. niloticus muestran que el microbiota ambiental puede afectar a la composición del microbiota intestinal (Giatsis et al., 2015; Giatsis et al., 2014). 


\subsection{Técnicas y métodos experimentales}

\subsubsection{Crecimiento de los peces y supervivencia de los alevines}

Los peces fueron contados, pesados en grupo a 0 y 30 días, y contados, pesados individualmente, y medidos a 50 días (Figura 3.19). Para poder realizar el contado y la medición de los peces a esta temprana edad sin causar daños se utilizó una técnica fotográfica. Los peces se recogían y se depositaban en una bandeja con un centímetro de agua. Se realizó una fotografía con una cámara digital (Nikon 3500), incluyendo una regla dentro de la bandeja para tener una referencia de la medida. Estas fotos se revisaron, contando los individuos e interpolando las medidas, por duplicado, obteniendo las medidas totales de cada uno de los peces.

Es conocido que durante la fase de alevinaje las bajas suelen ser frecuentes. En este estudio, queríamos comprobar si la suplementación con A. platensis pudo mejorar la supervivencia de los alevines. Para estudiar esto, los tanques se revisaban diariamente; las bajas se registraban y se eliminaban. Posteriormente tanto en el día 30 del experimento como en el día 50, durante la realización de los controles de peso y longitud, se pudo comprobar el número de peces que permanecieron vivos y se verificó que algunas de las bajas fueron devoradas por sus congéneres y no fueron contabilizadas durante en el control diario.

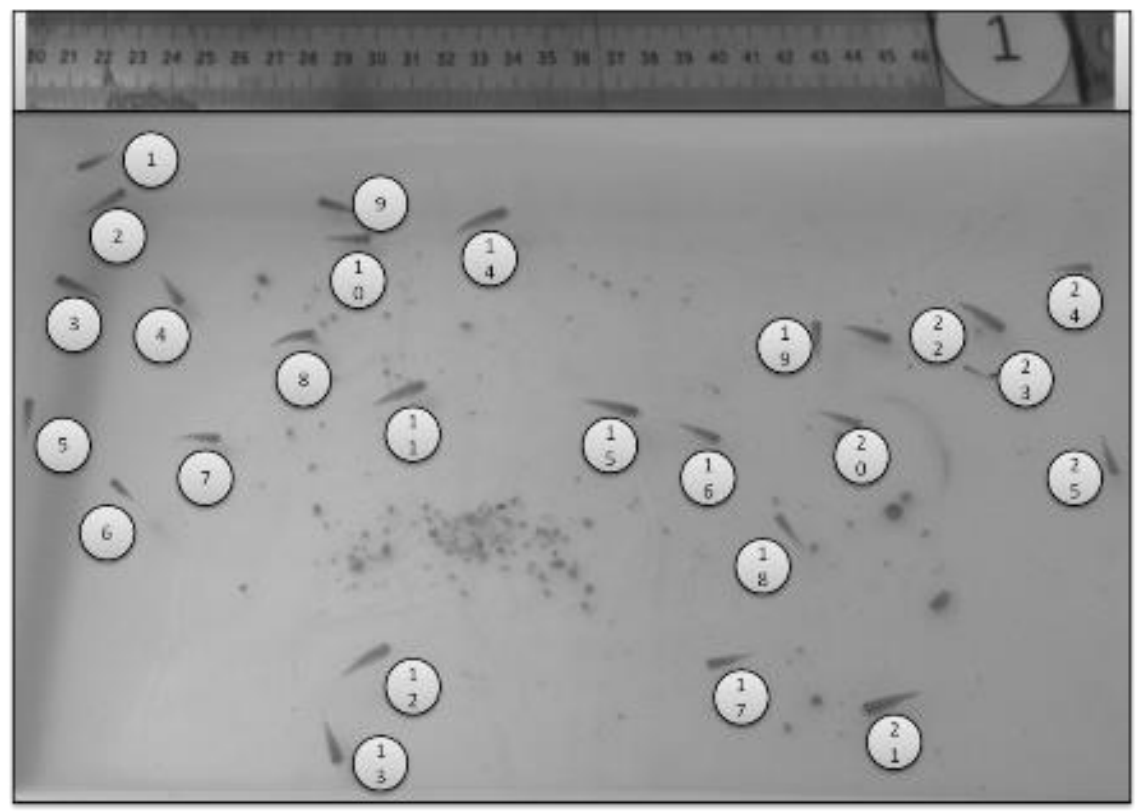

Figura 3.19 Fotografía utilizada para poder medir y contar los alevines a la entrada a los tanques. 


\subsubsection{Two-choices test}

\subsubsection{Prueba de comportamiento no invasiva "Two-Choices"}

La ética y el bienestar de los animales tiene cada vez más importancia tanto en la investigación como a los sistemas de producción animal. En la última década se han realizado muchos estudios sobre el bienestar de los peces (Huntingford, 2006), y se han propuesto varios métodos para medir el estrés, métodos que generalmente son invasivos, aunque también existen métodos no-invasivos como la prueba de elección "two choices" o de selección entre dos opciones.

Este método es usado para diferenciar entre dos estilos o personalidades en animales para afrontar el estrés (Laursen et al., 2011). La prueba consiste en dar a elegir a los peces entre dos ambientes, a los que se denominarán A y B. Normalmente esto implica situaciones de estrés diferenciadas, entre A y B. La elección por una situación de estrés A o B, dependerá de una serie de factores.

Uno de estos factores es el estilo de afrontamiento al estrés. En este sentido Barreto et al. (2011) han propuesto que $O$. niloticus puede clasificarse en dos estilos opuestos, a saber: proactivo (dominante) o reactivo (pasivo). El desarrollo de un estilo depende de la composición genética del pez y de su experiencia previa (Sørensen et al., 2013). Pero se sabe menos acerca del posible efecto que el estado nutricional puede desempeñar a este respecto, y qué papel puede desempeñar la suplementación con A. platensis.

La prueba se basa en el hecho de que los peces prefieren la penumbra a la luz, donde se sienten más seguros. Por otro lado, los niveles de oxígeno bajos hacen que se sientan incómodos e intenten buscar alternativas a esa situación. Bajo estos preceptos, se parte de una situación inicial con dos tanques unidos por un canal. El Tanque A permanece en penumbra, mientras que el Tanque B permanece iluminado. De esta forma, todos los peces permanecen en el Tanque A (oscuro) y poco a poco se va disminuyendo los niveles de $\mathrm{O}_{2}$. De esta forma obligamos a los peces a tomar la decisión de quedarse o buscar una alternativa (Tanque B, iluminado), bajo la suposición de que los peces más débiles e inseguros serán los primeros en abandonar el tanque A y pasar al B.

Durante los ensayos para poner a puesta la técnica de "two-choices" (figura 3.20), se observó algunas consideraciones a tener en cuenta. La primera es que si la fuente de luz 
utilizada en el tanque B es muy directa e intensa los peces no salen del tanque pese a las bajadas de $\mathrm{O}_{2}$. Asimismo, la luz utilizada debe ser indirecta a un ángulo de entre $40^{\circ}-60^{\circ}$, con 2 bombillas de $100 \mathrm{~W}$, que son las que usamos durante la experimentación.

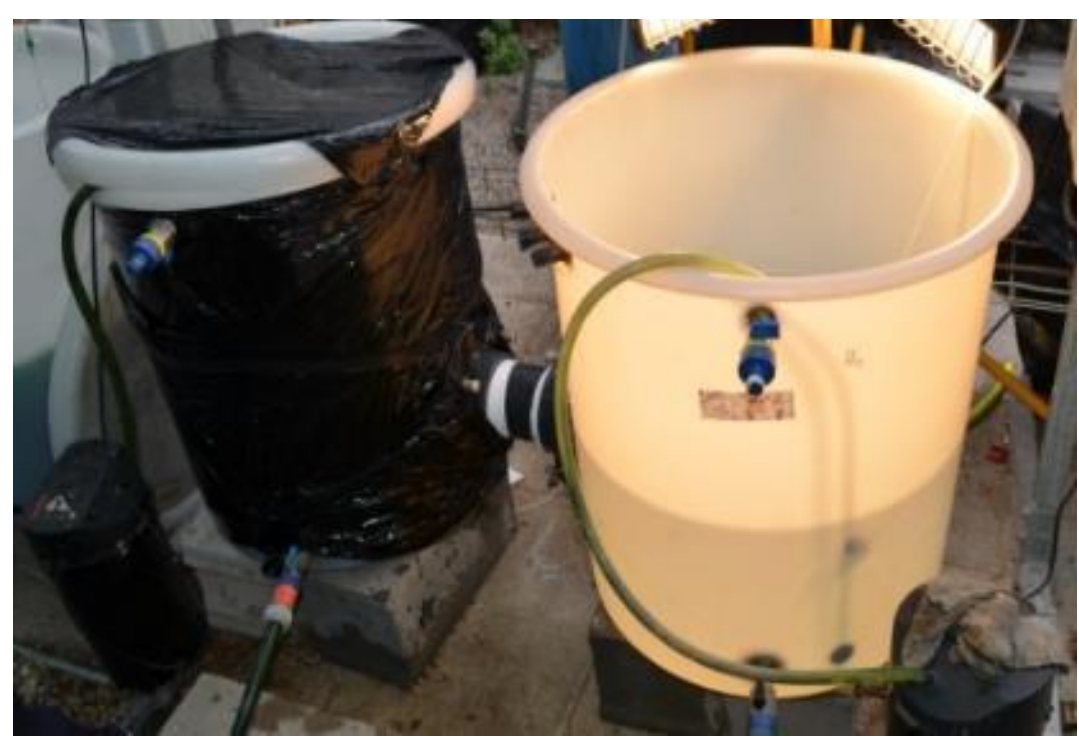

Figura 3.20 Fotografía de los tanques durante los ensayos del experimento "Two-Choices", en los invernaderos de los campos de prácticas de Agrónomos, UPM.

La segunda es que por debajo de $2 \mathrm{ppm}$ de $\mathrm{O}_{2}$, existe un punto de no retorno. A estos niveles de oxígeno los peces permanecen inmóviles y en estado de letargo. Tercero, la hora del día en que se realiza la prueba es clave, pues los peces son más activos a primeras horas de la mañana y ultimas de la tarde, y son menos activos al medio día y en la tarde, por lo que las pruebas se han de realizar dentro de una misma franja horaria y de la forma más simultánea posible. Y la cuarta consideración, el canal de unión de los dos tanques debe ser lo más estrecho posible pues es el lugar idóneo para afrontar esta prueba, y si un pez dominante ocupa esta posición no dejará cruzar el canal a ningún otro individuo, invalidando la prueba completamente.

\subsubsection{Tanques Two-Choices}

La prueba se llevó a cabo utilizando dos tanques circulares negros idénticos (120 L) de 0,64 m de altura y 0,54 $\mathrm{m}$ de diámetro que se unieron entre sí mediante una compuerta (Figura 3.21), con $16 \mathrm{~cm}$ de diámetro. El Tanque A estaba cubierto con plástico negro (sombreado) y el tanque B estaba iluminado. Se instaló un flujo de agua en contracorriente en cada tanque para evitar el flujo de agua entre los tanques A y B. 


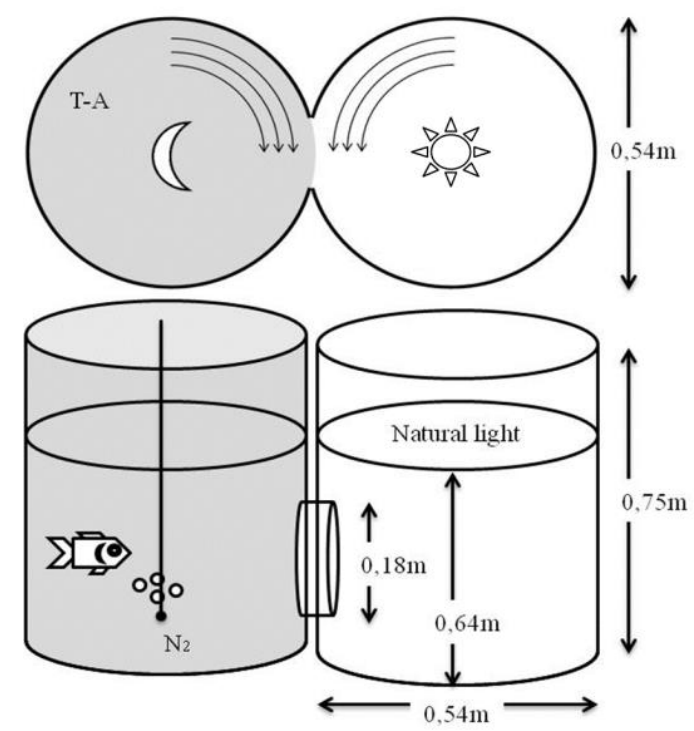

Figura 3.21 Esquema y medidas de los tanques utilizados para la realización de la prueba de "Two-Choices".

\subsubsection{Prueba 2. Parámetros biométricos}

En la prueba de pre-engorde se pesaron y se midieron de forma individual cada pez al introducirles en su jaula (-22 días), al comienzo de la prueba (0 días) y al final de la prueba (50 días), así como la alimentación utilizada en cada tanque (Figura 3.22). Como parámetros de crecimiento se tomaron la ganancia media diaria en \% (GMD), y el índice de conversión de alimentación del tanque (IC).

\subsubsection{Ganancia media diaria}

La ganancia media diaria mide habitualmente se expresa en gramos y se calcular de la manera siguiente:

GMD $\left(\frac{\mathrm{g}}{\mathrm{d}}\right)=\frac{\text { peso final }(g)-\text { peso inical }(g)}{(\text { dias transcurridos })}$

\subsubsection{2 Índice de conversión alimenticia}

El índice de conversión (IC) es un parámetro que evalúa la "calidad" del crecimiento. El IC depende de muchos factores. La manera de calcularlo es la siguiente (el parámetro no tiene unidades):

ICA $=\frac{\text { Alimento suministrasdo }(\mathrm{g})}{\text { peso final }(g)-\text { peso inical }(g)}$ 

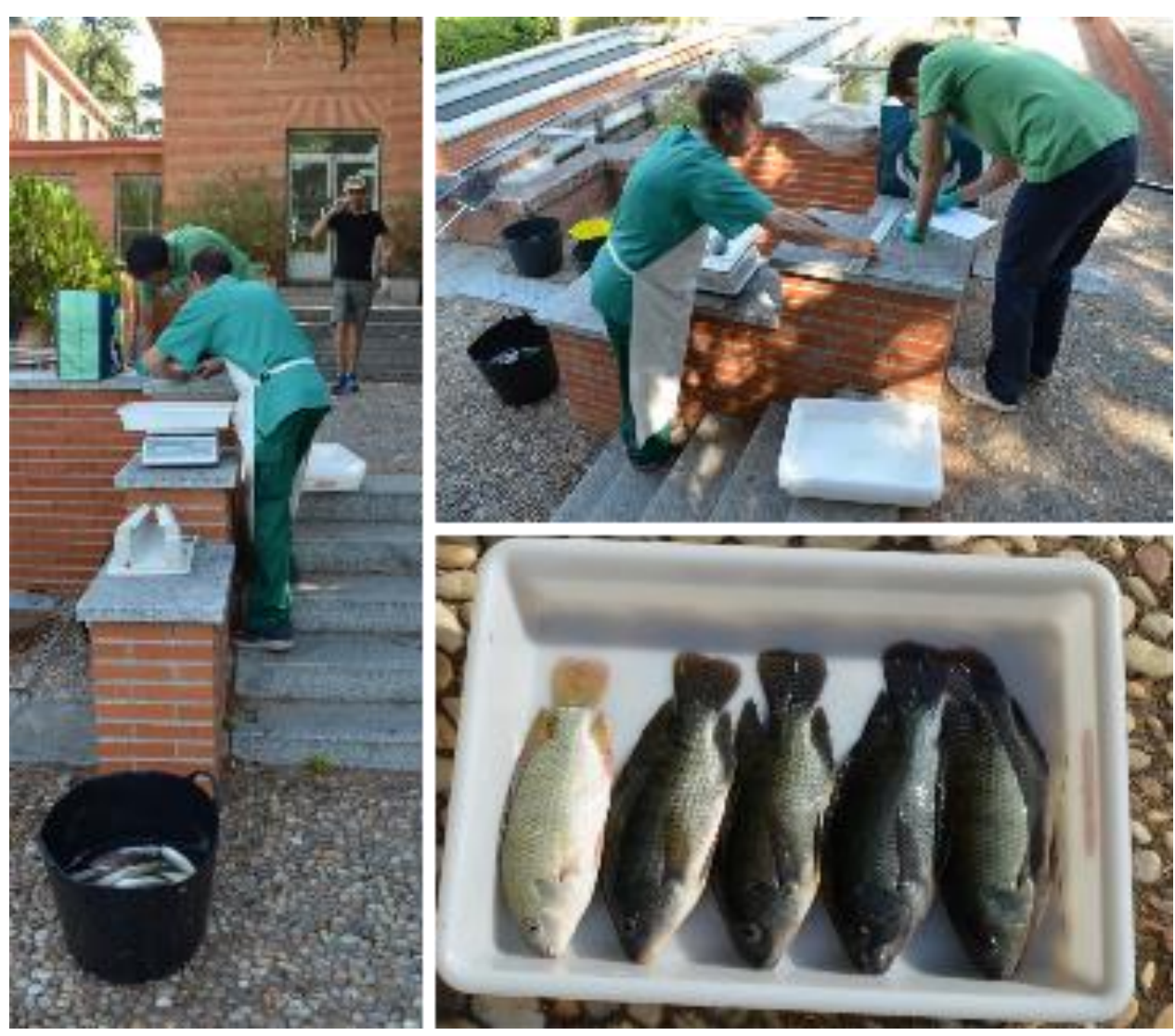

Figura 3.22 Trabajos de aturdimiento, pesado y medición en la prueba de pre-engorde.

\subsubsection{Parámetros de calidad de la carne}

\subsubsection{Rigor mortis}

Para evaluar la evolución del rigor mortis, este se midió a las 0 h, 6 h, 24 h, y 48 h post mortem utilizando el método Cuttinger (Korhenen et al., 1990). Este método consiste en colocar al pez sobre una superficie plana y dejar colgar la parte posterior desde el borde y sin ningún apoyo desdé el extremo posterior de la aleta dorsal. Se mide el "ángulo de rigor mortis" calculado como $\alpha=\tan ^{-1}(\mathrm{x} / \mathrm{y})$, donde " $\mathrm{x}$ " es la longitud (cm) del cateto horizontal del triángulo rectángulo formado e "y" es la longitud $(\mathrm{cm})$ del cateto vertical (Figura 3.23). 


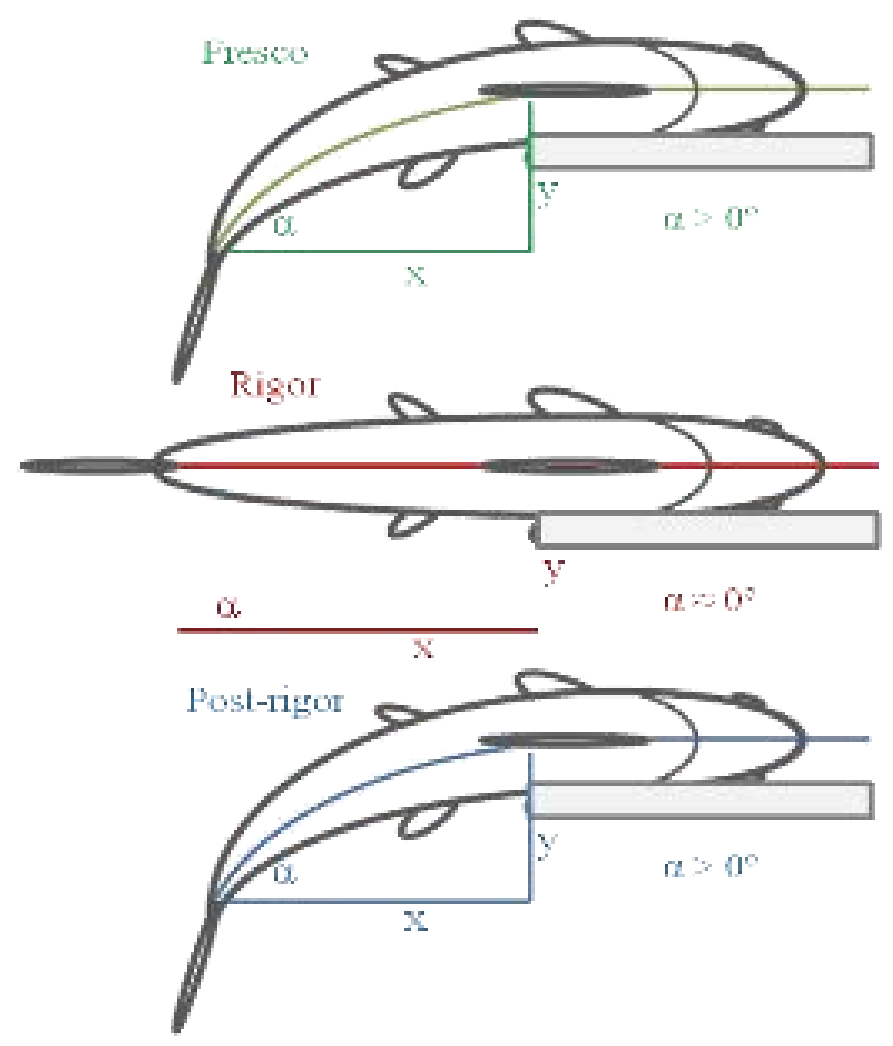

Figura 3. 23 Evolución y medición del rigor mortis. Método Cuttinger (Korhenen et al., 1990).

\subsubsection{2 pH muscular}

Se determinó la evolución del pH muscular con 20 peces por tratamiento usando el pH-metro de Hanna Instruments HI-9025 (Hanna Instruments, SL), introduciendo la sonda en el musculo dorsal derecho (Figura3.24). Las medidas se tomaron a las 0h, 6h, y 24h horas post-mortem, registrando a su vez la temperatura de la toma de muestras.

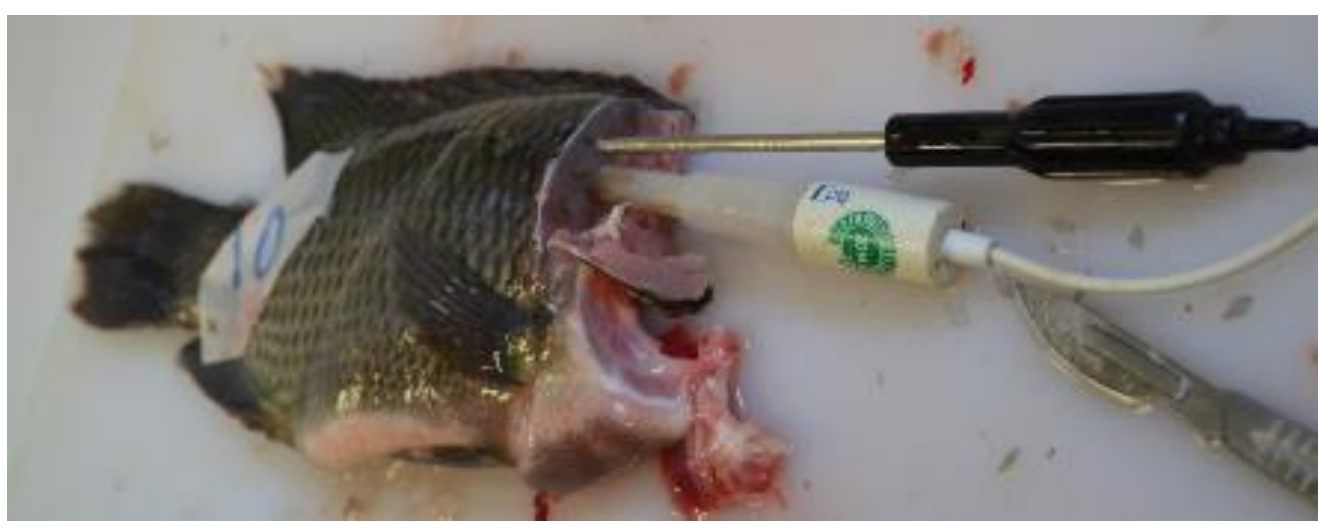

Figura 3.24 Fotografía de la medición de $\mathrm{pH}$ y la $\mathrm{T}^{\mathrm{a}}$ durante uno de los ensayos. 


\subsubsection{Color}

Para su determinación se midió el color de la carne en el lomo superior a 0 h y 24 h post mortem, utilizando el espectrofotómetro Minolta CM-2500c (Minolta, Osaka, Japón). Para su determinación, el CIE L * a * b fue utilizado (Intenacionale Comisión de l'Eclairage, CIE, 2004). Este sistema permite identificar un color con las coordenadas L* (luminosidad), a* (índice rojo) y b* (índice de amarillo) y calcular C* (chroma) y $\mathrm{h} *$ (hue). También se obtuvo el espectro visible del color de la carne de 360 a $740 \mathrm{~nm}$. Las medidas se tomaron por triplicado sobre 20 peces por tratamiento (Figura 3.25).
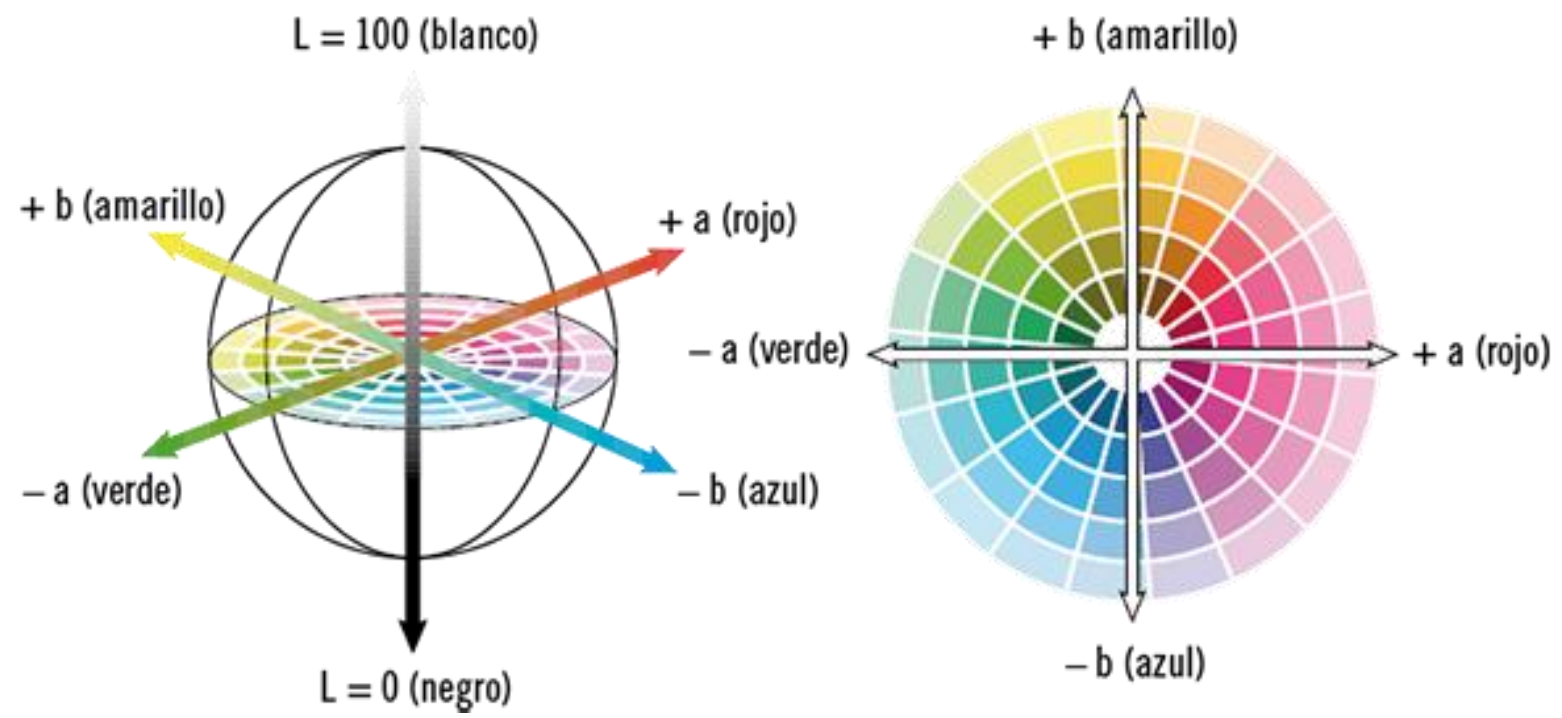

Figura 3.25 Modelo CIELAB.

\subsubsection{Parámetros hematológicos}

Se extrajeron muestras de sangre de la vena caudal de 20 ejemplares por tratamiento, usando jeringas de $2 \mathrm{ml}$ (BD, Franklin Lakes, New Jersey, EE.UU.). Se centrifugó $1 \mathrm{ml}$ de la muestra a $6000 \mathrm{rpm}$ durante 10 min y se extrajo el plasma para medir el cortisol, lactato y la glucosa (usando fluoruro como anticoagulante). Se utilizó $1 \mathrm{ml} \mathrm{de}$ sangre adicional para cuantificar leucocitos y establecer el hematocrito (con EDTA como anticoagulante) y se almacenaron inmediatamente a $4{ }^{\circ} \mathrm{C}$ hasta su análisis (López-Luna et al., 2016). 


\subsubsection{Cortisol}

El cortisol plasmático se determinó mediante ELISA competitivo. Primero, se pipetearon $10 \mu \mathrm{l}$ de cada muestra en los pocillos correspondientes, recubiertos con antisuero anti-cortisol de conejo. Seguidamente se añadieron $200 \mu 1$ de conjugado de enzima en todos los pocillos, excepto para el pocillo del blanco. Los pocillos se incubaron durante $60 \mathrm{~min}$ a $37^{\circ} \mathrm{C}$. Durante esta primera incubación, el cortisol muestra compite con el cortisol conjugado con la peroxidasa de rábano (HRPO) por los sitios específicos del antisuero de los pocillos. Después de la incubación, todo el material no unido se elimina mediante aspiración y se lava cuatro veces con $300 \mu 1$ de solución de lavado diluida (solución salina tamponada con fosfato, PBS). Se realizó una segunda incubación de los pocillos con $200 \mu 1$ de una solución de cromógeno (tetrametilbezidina, TMB) en un tampón citrato-fosfato durante 15 min a $37^{\circ} \mathrm{C}$. Finalmente, para finalizar la reacción se pipetearon $100 \mu 1$ de ácido sulfúrico $\left(\mathrm{H}_{2} \mathrm{SO}_{4}\right)$ en los pocillos. La lectura de color se hace mediante espectrofotómetro (Hitachi 717®) en dos longitudes de onda, $450 \mathrm{~nm}$ y $405 \mathrm{~nm}$. Se utiliza como blanco agua destilada para la referencia colorimétrica.

Para determinar la concentración de cortisol se realiza una curva de concentraciones patrón 0, 10, 30, 100, 300 y $900 \mathrm{ng} / \mathrm{ml}$. La lectura se debe realizar dentro de los siguientes $20 \mathrm{~min}$ tras la finalización de la prueba. Se utilizan dos longitudes de onda para mejorar la lectura. Los valores comprendidos entre $30-900 \mathrm{ng} / \mathrm{ml}$ se leen a $450 \mathrm{~nm}$, mientras que, para valores bajos, inferiores a $30 \mathrm{ng} / \mathrm{ml}$, se obtiene una mejor resolución a $405 \mathrm{~nm}$.

\subsubsection{Glucosa}

Para la medición de la concentración de glucosa en sangre se realizó formando complejos coloreados (Quinoaimina) siguiendo dos reacciones enzimáticas acopladas. La primera reacción se produce cuando la muestra se pone en contacto con oxígeno y agua con la acción de la enzima glucosa oxidasa (GOD, $250 \mathrm{UI} / \mathrm{ml})$, que forma ácido glucónico y peróxido de hidrogeno $\left(\mathrm{H}_{2} \mathrm{O}_{2}\right)$. En la segunda reacción el $\mathrm{H}_{2} \mathrm{O}_{2}$ reacciona en presencia de peroxidasa (POD, $20 \mathrm{UI} / \mathrm{ml})$, 4-aminoantipirina $(12.5 \mathrm{mmol} / \mathrm{l})$ y fenol $(5 \mathrm{mmol} / \mathrm{l})$ para formar el compuesto de color quinonaimina.

$$
\begin{aligned}
& \beta-D-\text { Glucosa }+\mathrm{O}_{2}+\mathrm{H}_{2} \mathrm{O} \stackrel{\text { GOD }}{\longrightarrow} \text { Acido Glucónico }+\mathrm{H}_{2} \mathrm{O}_{2} \\
& \mathrm{H}_{2} \mathrm{O}_{2}+\text { Fenol }+4-\text { Aminoantipirina } \stackrel{P O D}{\longrightarrow} \text { Quinonaimina }+\mathrm{H}_{2} \mathrm{O}
\end{aligned}
$$


Para realizar el ensayo se mezclan $10 \mu 1$ de suero de la muestra y $10 \mu 1$ de la solución patrón de glucosa $(100 \mathrm{mg} / \mathrm{dl})$ con $1 \mathrm{ml}$ de la solución reactiva. Se deja incubar $30 \mathrm{~min}$ a temperatura ambiente y se mide la absorbancia del patrón y de la muestra frente a un blanco de solución reactiva a $505 \mathrm{~nm}$ en un espectrofotómetro (Hitachi $717 \AA$ ). La intensidad del color producido es proporcional a la concentración de la glucosa en la muestra y es estable durante $2 \mathrm{~h}$. La concentración de glucosa ( $\mathrm{mg} / \mathrm{dl})$ se calcula aplicando la formula siguiente:

$$
\frac{\text { Abs.muestra }}{\text { Abs.patrón }} \text { Conc.patrón }
$$

\subsubsection{Lactato}

La concentración de lactato se mide por la transformación enzimática a un compuesto coloreado (Quinona) en dos fases. En la primera fase, el suero en presencia de oxígeno y agua por acción de la enzima lactato oxidasa (LO, $800 \mathrm{UI} / \mathrm{I}$ ) forma piruvato y $\mathrm{H}_{2} \mathrm{O}_{2}$. El $\mathrm{H}_{2} \mathrm{O}_{2}$ reacciona en presencia de la POD (2000 UI/I), 4-aminoantipirina $(0,4$ $\mathrm{mmol} / \mathrm{l}$ ) y 4-clorofenol (4 mmol/l) para formase un compuesto de color rosáceo, quinona.

$$
\begin{aligned}
& L-\text { Lactato }+\mathrm{O}_{2}+\mathrm{H}_{2} \mathrm{O} \stackrel{\text { LO }}{\rightarrow} \text { Piruvato }+\mathrm{H}_{2} \mathrm{O}_{2} \\
& 2 \mathrm{H}_{2} \mathrm{O}_{2}+4-\text { Clorofenol }+4-\text { Aminoantipirina } \stackrel{P O D}{\longrightarrow} \text { Quinona }+\mathrm{H}_{2} \mathrm{O}
\end{aligned}
$$

Los reactivos se tamponan en una disolución de fosfato a $\mathrm{pH}$ 7,5. Para realizar el ensayo se mezclan $10 \mu 1$ de suero de la muestra y $10 \mu 1$ de una solución de lactato patrón $(10 \mathrm{mg} / \mathrm{dl})$ con $1 \mathrm{ml}$ de disolución de reactivos, se dejan $10 \mathrm{~min}$ a temperatura ambiente y se lee la absorbancia en un espectrofotómetro (Hitachi 717 ®) a $505 \mathrm{~nm}$ de las dos mezclas utilizándose como blanco la disolución de los reactivos.

Para el cálculo de la concentración de lactato $(\mathrm{mmol} / \mathrm{l})$ se aplica la siguiente formula:

$$
\frac{\text { Abs.muestra }}{\text { Abs.patrón }} \times \text { Conc.patrón }
$$

\subsubsection{Lactato deshidrogenasa (LDH)}

Se determina la actividad enzimática mediante la reacción de hidrogenación del piruvato a L-lactato en presencia de NADH. Se valora la extinción por minuto de la reacción de la mezcla de 0,1 de la muestra (plasma en EDTA) con 2,5 ml de solución reactiva $(0,6 \mathrm{mmol} / 1$ de piruvato y $0,18 \mathrm{mmol} / 1$ de NADH con tampón fosfato $50 \mathrm{mmol} / \mathrm{l} \mathrm{a}$ $\mathrm{pH} 7,5)$, utilizando los tiempos 30”, 1'30”, 2'30” y 3'30”. La extinción por minuto se valora 
por la reducción de la absorbancia entre los tiempos dados, a una longitud de onda de 340 $\mathrm{nm}$. La temperatura de ensayo fue de $30^{\circ} \mathrm{C}$.

La actividad de la LDH (U/I) se calcula multiplicando la extinción por minuto media de las tres medidas multiplicada por 4921. Cuando la actividad enzimática es alta, el valor de la extinción por minuto a los 3 min de ser inferior a 0,1 , en estos casos se mide de nuevo la reacción diluyendo $1 / 10$ con una solución de $\mathrm{NaCl}$ al $0.9 \%$ y multiplicando la extinción por minuto media por 49210 .

\subsubsection{Creatina fosfoquinasa (CPK)}

Se valora la actividad enzimática de desfosforilación del fosfato de creatina a creatinina con la formación de ATP, asociado a dos reacciones: una desfosforilación de la glucosa por la enzima hexoquinasa con ATP y la deshidrogenación de la glucosa-6-fosfato por la enzima glucosa-6-fosfato deshidrogenasa, usando como coenzima NADP ${ }^{+}$. Se valora la extinción por minuto de la reacción en los tiempos $2^{\prime}, 3^{\prime}, 4^{\prime}$ y $5^{\prime}$ tras la mezcla de 0,1 $\mathrm{ml}$ de la muestra (plasma con EDTA) y $2,5 \mathrm{ml}$ de la solución reactiva $(30 \mathrm{mmol} / 1$ fosfato de creatina, $2 \mathrm{mmol} / 1$ de ADP, 20 mmol/1 de glucosa, 2 mmol/1 de NADP ${ }^{+}$). La extinción por minuto se valora por la reducción de la absorbancia entre los tiempos dados, a una longitud de onda de $340 \mathrm{~nm}$. La temperatura de ensayo fue de $30^{\circ} \mathrm{C}$

La actividad de la enzima CPK (U/I) se calcula multiplicando la extinción por minuto media de las tres medidas por 4127. Cuando la actividad enzimática es alta, el valor de la extinción por minuto a los 3 minutos es inferior a 0,25 , en estos casos se mide de nuevo la reacción diluyendo $1 / 10$ con una solución de $\mathrm{NaCl}$ al $0,9 \%$ y multiplicando la extinción por minuto media por 41270 .

\subsubsection{Metagenómica Análisis}

\subsubsection{Puesta a punto de la técnica}

Inicialmente se desconocía la metodología idónea para obtener adecuadamente el genoma del microbiota intestinal de la O. niloticus. Por ello, antes de realizar el experimento, se puso a punto la técnica (Figura 3.26). Esta metodología presenta varios problemas que hay que tener en cuenta. El primer problema que se presenta es que el intestino contiene una gran cantidad de enzimas que deterioran el material genético (ADN 
y ARN) así como inhibidores de la PCR. Para evitarlo se utilizaron las metodologías descritas por Zoetendal et al. (1998). Otro aspecto que hay que considerar es si se utilizan muestras frescas o congeladas, por eso se ensayaron los protocolos con muestras frescas y preservadas en RNAlater. Por otro lado, se ensayaron distintos protocolos de PCR, así como distintos cebadores (primers) de amplificación.

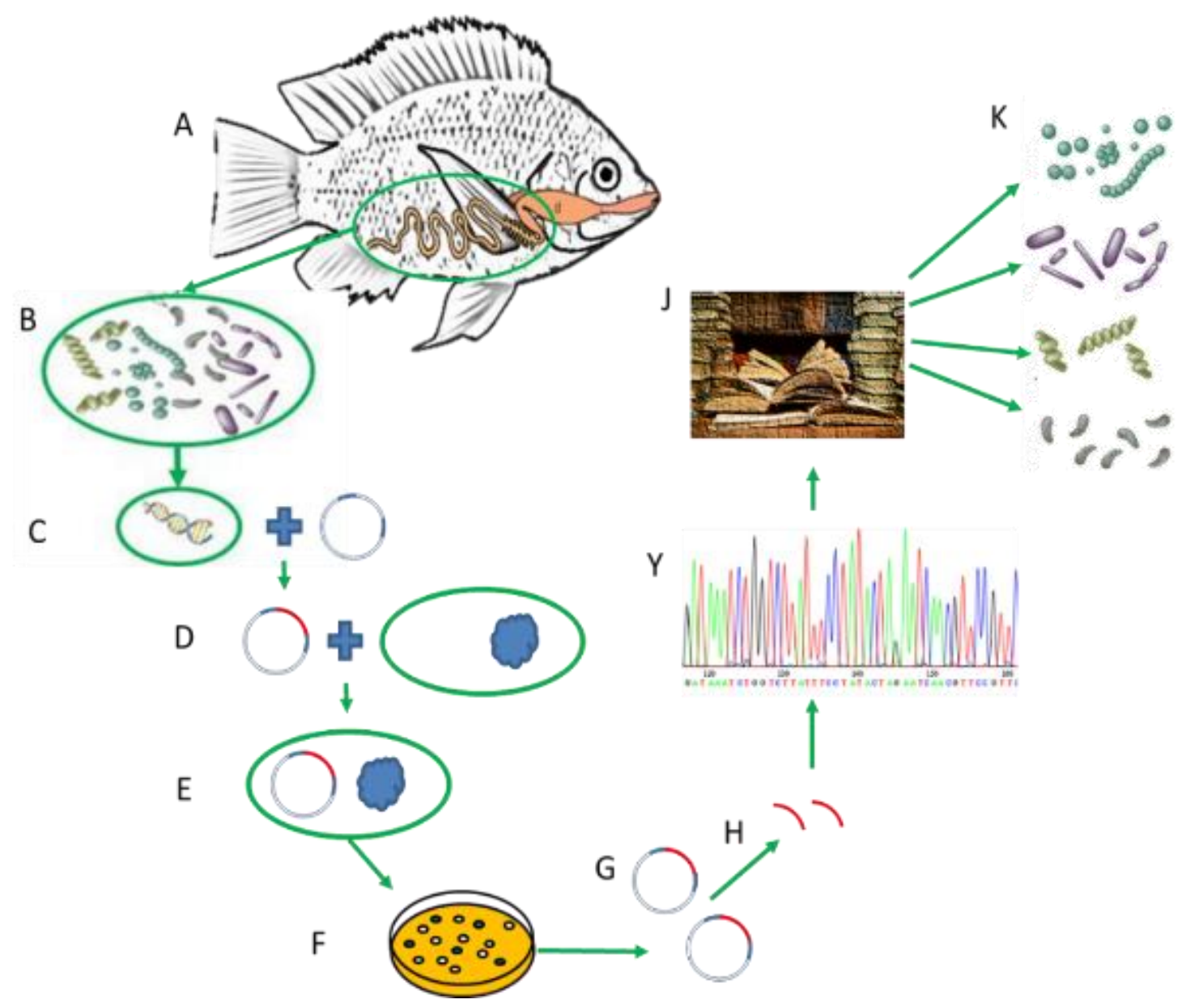

Figura 3. 26 Puesta a punto del protocolo de secuenciación de los genes marcadores del microbiota del intestino de $O$. niloticus. (A) Toma de muestras del intestino, (B) extracción, limpieza y extracción del contenido bacteriano del intestino, (C) lisis y extracción de ADN y amplificación del gen 16S-ARNr, (D) Ligación 16S-pGEM-T® Vector, (E) transformación E. coli, (F) cultivo de E. coli en LB+ampicilina y selección de colonias blancas (recombinantes), $(\mathrm{G}+\mathrm{H})$ extracción de plásmidos mediante el kit high pure plasmid isolation miniprep de Roche ${ }^{\circledR}$; (Y) secuenciación de los insertos con los 16S-ARNr clonados; (J) revisión de las secuencias en la biblioteca on-line (NCIB); (K) identificación de los genes encontrados.

En la primera fase y para tomar decisiones sobre cuál era el mejor protocolo que se podía utilizar y para comprobar la viabilidad de las extracciones se decidió utilizar una metodología de secuención convencional basada en la clonación previa de los fragmentos de 16S-ARNr amplificados. Esta consiste en obtener material genético de la muestra y 
amplificar por PCR el 16S-ARNr. Tras comprobar en gel de agarosa la amplificación se purifica el producto de PCR con el kit QIAquick PCR de QUIAGEN. Seguidamente, se utilizan células competentes de Escherichia coli (DH10B) para ser transformadas con una ligación del 16S-ARNr amplificado y purificado obtenido en el pGEM®-T Easy Vector. Este vector proporciona resistencia a ampicilina $\left(A m p^{R}\right)$ y permite seleccionar mayoritariamente las colonias que han incorporado el fragmento del gen 16S-RNAr dentro de la región de policlonaje (Figura 3.27). Estas células de E. coli transformadas se cultivaron en placas con medio LB con ampicilina $(0,1 \mathrm{mg} / \mathrm{ml})$, a las que se añade $50 \mu 1$ X-Gal como marcador de expresión. Transcurrido un día de cultivo en la placa se seleccionaron las colonias blancas. A partir de los cultivos de estas colonias blancas aisladas se extrajeron los plásmidos clonados mediante el kit High pure plasmid isolation miniprep de Roche. y se purificaron con kit QIAquick PCR de QUIAGEN. Finalmente, tras comprobar la presencia de los plásmidos en un gel de agarosa, estos se secuenciaron en Secugen S.L. y las secuencias obtenidas se compararon con la biblioteca online del NCIB.

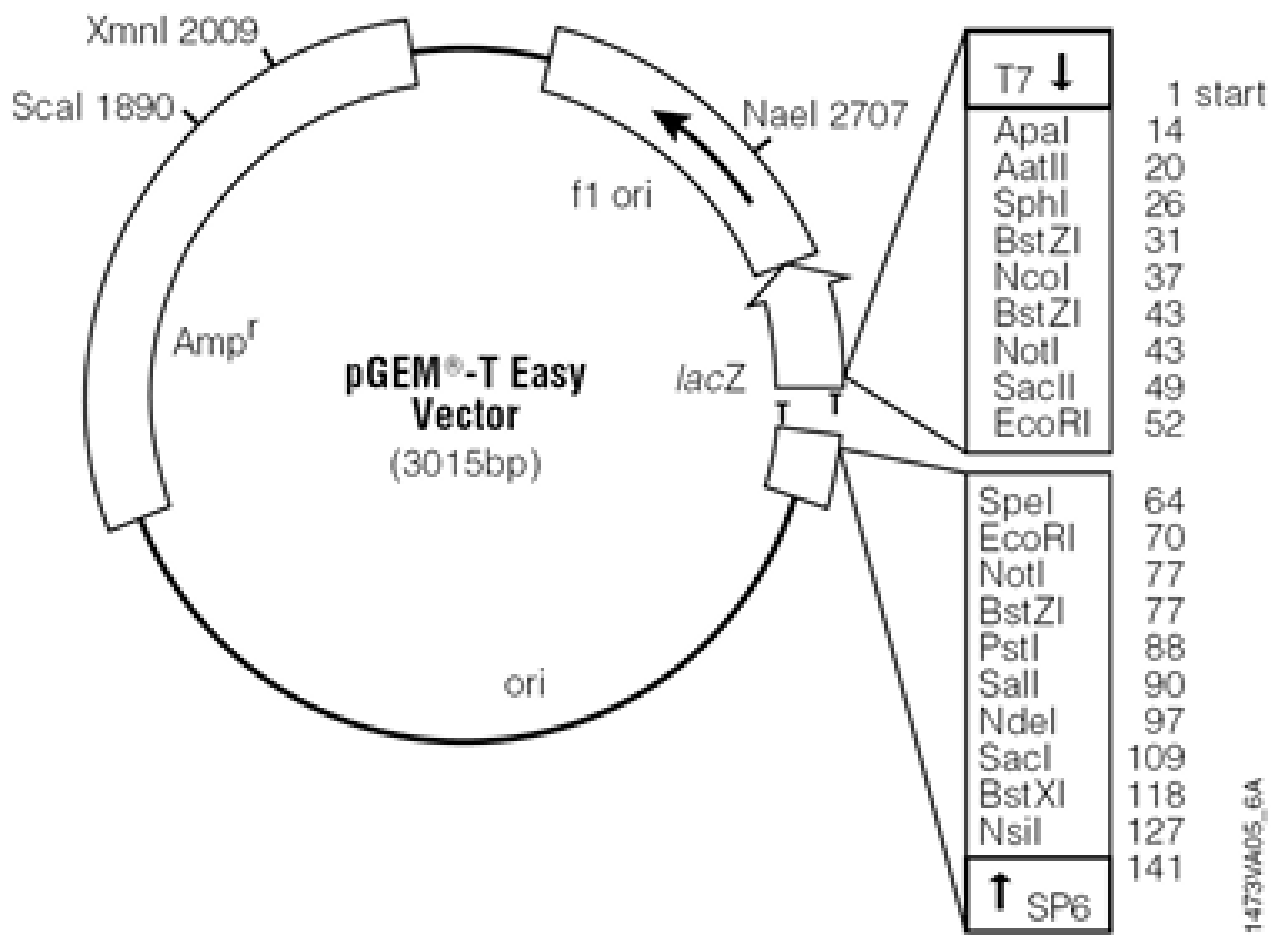

Figura 3.27 Mapa del plásmido p-GEM®-T Easy Vector. 


\subsubsection{Obtención de ADN bacteriano}

Tras la evaluación de los distintos protocolos de extracción del ADN bacteriano se decidió utilizar la metodología que se describe a continuación (Figura 3.28).

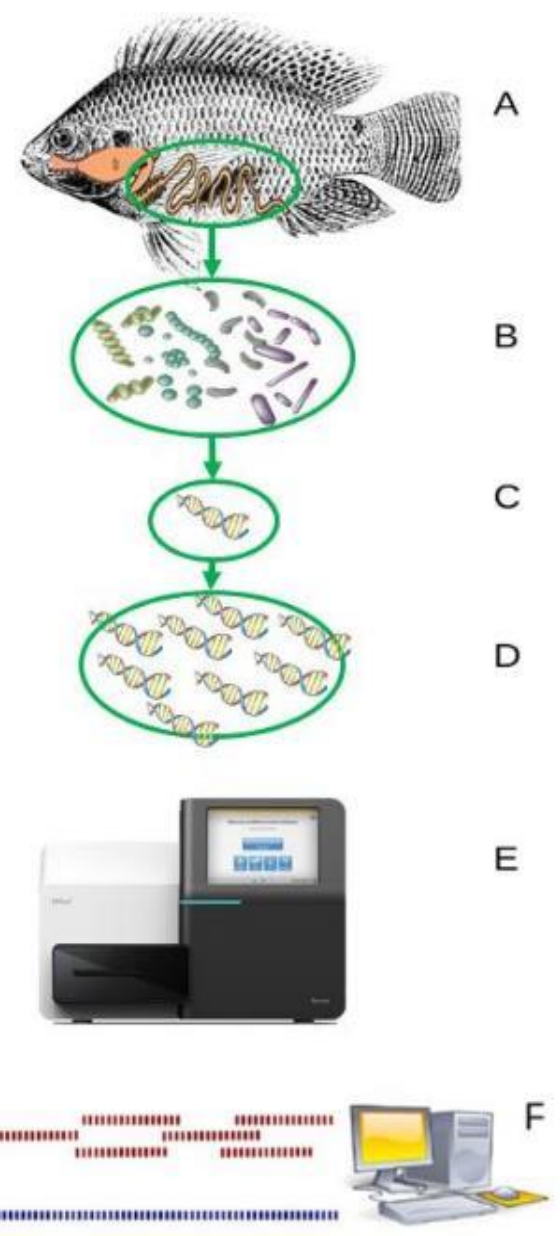

Figura 3.28 Esquema del protocolo de extracción del ADN de la microbiota intestinal de $O$. niloticus utilizado durante la tesis: (A) toma de muestras del intestino; (B) extracción, limpieza y extracción del contenido bacteriano del intestino; (C) lisis y extracción del ADN total; (D) amplificación del 16S-ARNr; (E) secuenciación en MiSeq de los amplicones 16S-ARNr; (F) ensamblaje de secuencias e identificación computacional con los programas Silva y QIIME.

\subsection{Toma de muestras intestinales}

Se seleccionaron 4 peces de cada tanque al azar ( 8 por tratamiento). Los intestinos se extrajeron asépticamente y las muestras de intestino se tomaron $1,0 \mathrm{~cm}$ de la parte distal del intestino a 1,0 cm de la cloaca. Este protocolo intenta evitar la heterogeneidad reportada al tomar muestras en diferentes áreas del intestino (Suzuki y Nachman, 2016). Las muestras se almacenaron en microtubos de $2 \mathrm{ml}$, marcados con el número de chip y procesados frescos, conservándolos a $4^{\circ} \mathrm{C}$ en hielo durante el proceso. 


\subsection{Aislamiento}

Uno de los grandes problemas al utilizar muestras de intestino es la presencia de gran variedad de inhibidores de la PCR, incluyendo sales biliares (Lanzt et al., 1997). Por ello y tras probar con diferentes técnicas y revisar a fondo la bibliografía, las muestras se procesaron en fresco usando el Stool minikit de QIAamp (Qiagen, Crawley, Unideted Kingdom) (Gajardo et al., 2016; Dehler et al., 2017; Gaikwad et al., 2017; Huyben et al., 2017; Torrecillas et al., 2017) de acuerdo con las instrucciones del fabricante (Figura 3.29) para muestras de gran volumen (utilizando $10 \mathrm{ml}$ de tampón ASL en lugar de $2 \mathrm{ml}$ ). Todas las muestras se dividieron en dos y se trataron por duplicado.

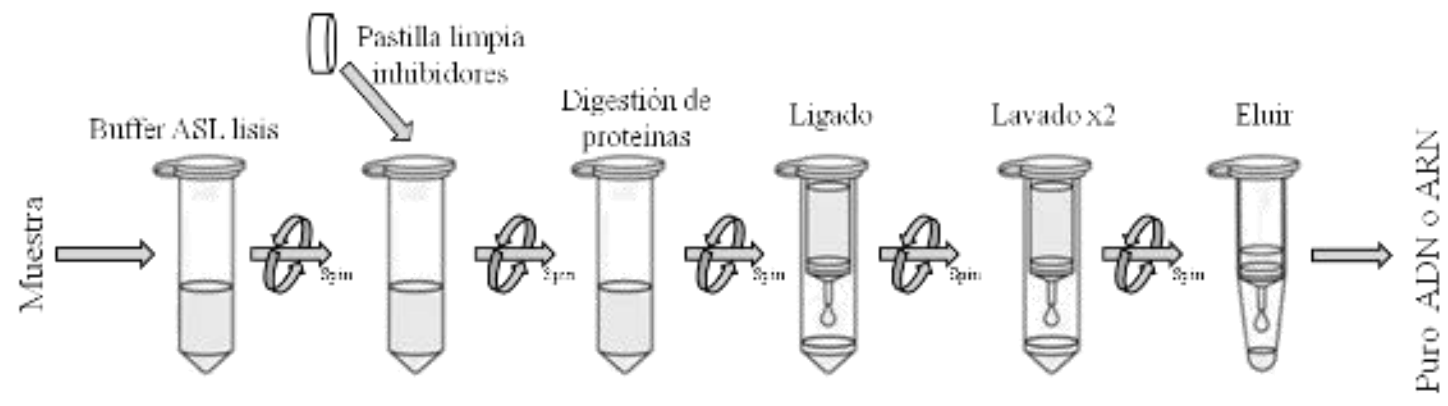

Figura 3.29 Esquema del procedimiento de extracción de ADN del Stool Mini Kit de QIAamp.

\subsection{PCR}

Los amplicones codificados en Bard de la región V1-V2 ( $310 \mathrm{pb})$ de los genes 16S-ARNr se generaron por PCR usando el cebador 27F-DegS (GAG TTT GAT CMT GGC TCA G) y una mezcla equimolar de dos cebadores 338RI (GCW GCC TCC CGT AGG AGT) y 388RII (GCW CGC ACC CGT AGG TGT) (Fan et al., 2013; Giatsis et al., 2015; Gajardo et al., 2016). El protocolo de PCR utilizó 100 ng de ADN total, 0,5 U de D N polimerasa Taq, tampón DMSO 2,5 mM, $5 \mu 1$ de dNTP, $10 \mu 1$ de Oligo 27F, $5 \mu 1$ de Oligo 33 R I, $5 \mu$ de Oligo 33 R I, en $50 \mu$ de volumen final. El ciclo de PCR fue de 1 min $95^{\circ} \mathrm{C}, 45 \mathrm{~s}$ a $57^{\circ} \mathrm{C}$ y $45 \mathrm{~s}$ a $72^{\circ} \mathrm{C}$ en un termociclador Eppendorf, seguido de 30 ciclos de 45 $\mathrm{s}$ a $95^{\circ} \mathrm{C}, 30 \mathrm{~s}$ a $56^{\circ} \mathrm{C}$ y $30 \mathrm{~s}$ a $72^{\circ} \mathrm{C}$ para cerrar el ciclo a $4^{\circ} \mathrm{C}$.

\subsection{MiSeq}

Las muestras fueron enviadas a Macrogen (República de Corea), dónde se usó el sistema MiSeq con la tecnología Illumina SBS para la secuenciación. 


\subsection{Estudio de los resultados}

El estudio de los resultados obtenidos por la secuenciación se llevó a cabo con los programas QIIME (Quantitative Insights Into Microbial Ecology) y Silva ngs (Ye et al., 2014; Giatsis et al., 2015; Gajardo et al., 2016; Dehler et al., 2017) y los índices de diversidad de la población se calcularon utilizando los métodos Simpson, Shannon y Chaos, utilizando el programa PAST (Hammer et al., 2017; Huyben et al., 2017, 2000).

Shannon's index $=\sum_{\mathrm{i}=1}^{\mathrm{s}}-\mathrm{p}_{\mathrm{i}} \log _{2}\left(\mathrm{p}_{\mathrm{i}}\right) \overline{\mathrm{I}}=\mathrm{H}^{\prime}$

Simpson's coefficiente $=\sum_{i=1}^{n} \frac{n_{1}\left(n_{1}-1\right)}{N(N-1)}$

Margalef ${ }^{\prime}$ s index $=\sum_{i=1}^{n} \frac{(s-1)}{\ln N}$

Chaos 1 coefficiente $=S+\frac{a^{2}}{2 b}$

S; Número de especies de la muestra.

$\mathrm{p}_{\mathrm{i}}$; Proporción de individuos de cada especie i en el total de la muestra $=\mathrm{ni} / \mathrm{N}$.

$\mathrm{n}_{\mathrm{i}}$; Número de individuos de la especie i.

$\mathrm{N}$; Total de individuos.

b; Especies que se representan con un solo individuo en la muestra ("singletons").

a; Número de especies que se representan por un par de individuos en la (“doubletons”). 


\subsection{Análisis estadístico}

Todas las pruebas estadísticas se llevaron a cabo utilizando R.commander (R Core Team, 2013). Según la prueba de Shapiro/Wilk, los datos sobre la calidad del agua, el crecimiento y la supervivencia se distribuyeron normalmente y se analizaron utilizando un N OV de un solo sentido. Los datos de las pruebas de "Two-Choices" no siguieron una distribución normal y se analizaron usando una prueba de Kruskal-Wallis. El nivel de significación fue $\mathrm{P}<0,05$ en ambos casos.

Para el análisis taxonómico se utilizó el programa QIIME (97\%) y se contrastaron con el programa Silva NGS. Se realizaron estudios de similitud de las muestras con el programa PAST (Hammer et al., 2001), utilizando grupos de coeficientes de similitud de Bray-Curtis. 


\section{RESULTADOS}




\section{RESULTADOS}

\subsection{Experimentos con alevines de tilapia "Two-Choices"}

\subsubsection{Crecimiento y supervivencia de peces}

Tanto el crecimiento como los índices de conversión durante el experimento realizado con los alevines de tilapia con dietas suplementadas y no suplementadas con Arthrospira fueron muy buenos, aunque no se encontraron diferencias significativas en el crecimiento entre los dos tratamientos ni a los 30 días ni a los 50 días de experimento. Tampoco, se encontraron diferencias en cuanto a la longitud corporal total entre los dos tratamientos (cm, media \pm DE, 4,13 $\pm 1,09$ CTR, 4,22 $\pm 0,97$ SPR), ni el coeficiente de variación en la longitud total (cm, media \pm DE: 0,26 $\pm 0,08$ CTR, 0,28 $\pm 0,08 \mathrm{SPR})$. Sin embargo, si se encontraron diferencias significativas con respecto a la mortalidad $(\mathrm{p}>0,05)$, que fue menor en alevines que recibieron una dieta con el 1\% de A. platensis (Tabla 4.1). Cabe destacar que no se encontró ninguna concentración de la mortalidad en ningún día, ni en ningún tanque en particular, durante las revisiones diarias realizadas durante el experimento. Y que los datos de mortalidad en ambos casos se encuentran por debajo de los normales en industria del 33\% según Meyer (2004).

Tabla 4.1 Resumen de las medias $( \pm$ S.E.) de los datos productivos de $O$. niloticus control y suplementado con A. platensis $1 \%$ para el peso inicial del tanque (PIT), la ganancia media del tanque (GMT), el índice de conversión (IC) y el \% de supervivencia.

\begin{tabular}{lrrr}
\hline TRT & Control (n ) & A. platensis $(\mathrm{n})$ & $\mathrm{p}$-Value \\
\hline PIT (d0) & $2,42 \pm 0,53$ & $2,6 \pm 0,76$ & 0,20 \\
GMT (d30) & $26,21 \pm 2,57$ & $26,07 \pm 2,61$ & 0,2 \\
GMT (d50) & $66,93 \pm 7,15$ & $70,55 \pm, 33$ & 0,32 \\
\hline IC (d30) & $0,73 \pm 0,07$ & $0,74 \pm 0,09$ & 0,9 \\
IC (d50) & $0,3 \pm 0,10$ & $0,79 \pm 0,07$ & 0,40 \\
\hline \% Srv (d30) & $4,5 \pm 7,23^{\text {a }}$ & $93,5 \pm, 0$ & 0,04 \\
\% Srv (d50) & $4,0 \pm 6,76^{\text {a }}$ & $93,0 \pm, 50$ b & 0,03 \\
\% Srv (d30-50) & $99,5 \pm 1,54$ & $99,5 \pm 1,41$ & 0,9 \\
\hline
\end{tabular}

Valores seguidos por la misma letra superíndice en la misma fila no presentaron diferencias significativas $(\mathrm{P}>0,05)$. 


\subsubsection{Prueba "Two-Choices"}

En los resultados obtenidos durante la prueba de "Two-Choices", se pudieron observar dos estilos de afrontamiento al estrés por hipoxia por parte de O. niloticus, con diferencias significativas entre los dos tratamientos $(\mathrm{p}>0,05)$. Un número mayor de alevines suplementados con $A$. platensis adoptaron un estilo de afrontamiento proactivo, tomando un tiempo significativamente más largo para abandonar el Tanque A, a pesar de la disminución de los niveles de $\mathrm{O}_{2}$ (Figura 4.1). Los peces control no solo abandonaron el Tanque A más rápidamente, sino que también mostraron mayor tendencia de hacerlo en grupos de dos o más peces. Mientras que los alevines suplementados con A. platensis que dejaron el Tanque A tendieron a hacerlo de forma individual ( $p>0,05$, ver Tabla 4.2).

Tabla 4.2 Tiempo medio de salida del Tanque A y nivel de $\mathrm{O}_{2}$ de los primeros cinco peces dividido por tratamiento, durante el desafío hipóxico en minutos, y él \% de abandono grupal del Tanque A.

$\begin{array}{llll}\text { TRT Tiempo medio de salida } & \text { Nivel } \mathrm{O}_{2} \text { medio de salida } & \text { Abandono grupal (\%) }\end{array}$

\begin{tabular}{lccc}
\hline Control (n6) & $17,35^{\mathrm{a}} \min$ & $4,01^{\mathrm{a}} \mathrm{ppm}$ & $7^{\mathrm{a}}$ \\
A. platensis (n6) & $30,20^{\mathrm{b}} \mathrm{min}$ & $2,3^{\mathrm{b}} \mathrm{ppm}$ & $40^{\mathrm{b}}$ \\
\hline p-value & 0,001 & 0,001 & 0,021
\end{tabular}

Valores seguidos por la misma letra superíndice en la misma columna no presentaron diferencias significativas $(\mathrm{P}>0,05)$.

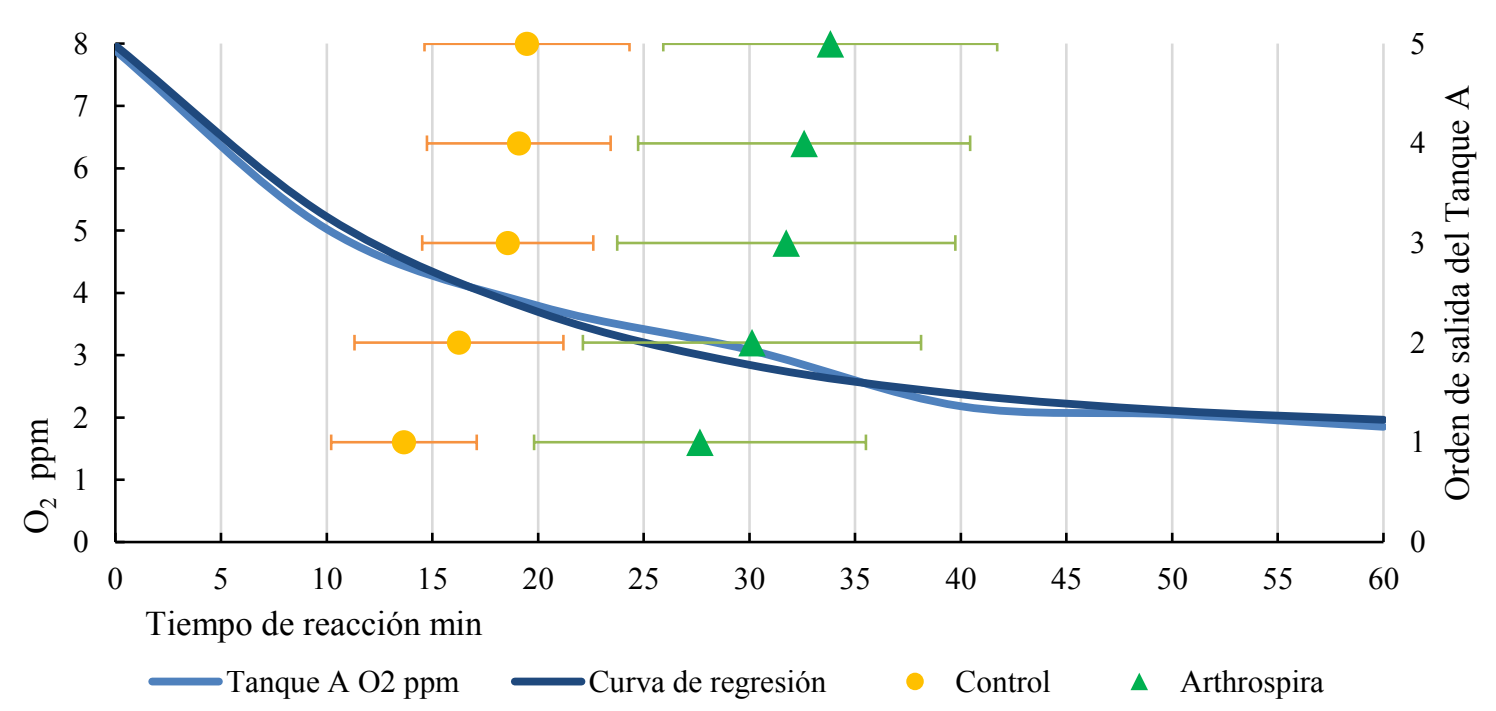

Figura 4.1 Tiempo de salida ( $\mathrm{min}$ ) de los primeros cinco peces por tratamiento, diferenciando entre los controles $(\bigcirc)$ y los suplementados con A. platensis $(\mathbf{\Delta})$. La línea azul claro es la concentración de $\mathrm{O}_{2}$ en ppm en el Tanque A. La línea azul oscuro es la curva de regresión obtenida con los datos de oxigeno medios durante la prueba, para conocer a qué nivel de $\mathrm{O}_{2}$ respondió cada pez, $\left(\mathrm{O}_{2}(\mathrm{ppm})\right.$ $\left.=1,78+6,19 \cdot 0,94^{\mathrm{t}(\mathrm{min})}\right)(\mathrm{r}=0,98)$. 


\subsection{Engorde y calidad de la carne de tilapia}

\subsubsection{Crecimiento y supervivencia}

No se encontraron diferencias en los parámetros de crecimiento durante la fase de adaptación (-22 a 0 días), cuando todos los peces fueron alimentados con dieta de control de mantenimiento ( $2 \%$ del peso vivo). Sin embargo, durante la fase de prueba ( 0 a 50 días) con un nivel de alimentación comercial a 3,5\% del peso vivo (Tabla 4.3), los peces duplicaron su peso vivo durante la fase experimental. Aunque el número de tanques es limitado, la suplementación con 3\% de A. platensis aumentó el crecimiento en un 10\% en comparación con los controles y una GMD con un porcentaje similar de mejora.

Tabla 4.3 Parámetros de crecimiento, dos tanques por tratamiento y 25 peces por tanque, -22 días de ingreso a los tanques, 0 días de inicio de la prueba y 50 días de finalización del experimento. Abreviaturas: control (CTR); suplementados con A. platensis (SPR); ganancia media diaria (GMD) e índice de conversión (IC). ANOVA de una vía con la prueba de comparación múltiple de Tukey.

\begin{tabular}{|c|c|c|c|c|}
\hline Dia & Parámetros de crecimiento & $\operatorname{CTR}(n=50)$ & $\operatorname{SPR}(n=50)$ & p-value \\
\hline \multirow{3}{*}{$\underset{\widetilde{T}}{\widetilde{\tau}}$} & Peso \pm ME (-22 d) (g) & $9,09 \pm 3,74$ & $90,5 \pm 3,74$ & 0,9 \\
\hline & Longitud \pm ME (-22 d) & $14,3 \pm 0,20$ & $14,51 \pm 0,21$ & 0,656 \\
\hline & Peso tanque $(-22 \mathrm{~d})(\mathrm{g})$ & 2310 & 2294,55 & \\
\hline \multirow{4}{*}{$\Xi$} & Peso \pm ME $(0 \mathrm{~d})(\mathrm{g})$ & $109,17 \pm 4,19$ & $109,06 \pm 4,23$ & 0,95 \\
\hline & $\operatorname{GMD}(0 \mathrm{~d})(\mathrm{g} / \mathrm{d})$ & $0, \pm 0,045$ & $0,4 \pm 0,05$ & 0,572 \\
\hline & IC tanque $(-22$ a $0 \mathrm{~d})$ & 2,41 & 2,47 & 0,537 \\
\hline & Peso tanque $(0 \mathrm{~d})(\mathrm{g})$ & 2793,00 & 2764,00 & \\
\hline \multirow{5}{*}{ in } & Peso \pm ME $(50$ d) $(g)$ & $236,65 \pm 9,73^{b}$ & $259,39 \pm 9,2^{a}$ & 0,046 \\
\hline & Longitud \pm ME (50d) & $1,61 \pm 0,23^{\mathrm{b}}$ & $19,41 \pm 0,23^{\mathrm{a}}$ & 0,015 \\
\hline & GMD (50d) (g/d) & $2,50 \pm 0,13^{b}$ & $2,95 \pm 0,13^{\mathrm{a}}$ & 0,020 \\
\hline & IC tanque ( 0 a $50 \mathrm{~d})$ & $1,37^{\mathrm{b}}$ & $1,14^{\mathrm{a}}$ & 0,007 \\
\hline & Peso tanque (50d) (g) & 600,25 & 657,57 & \\
\hline
\end{tabular}

$\overline{\text { Valores seguidos por la misma letra superíndice en la misma columna no presentaron diferencias significativas }(\mathrm{P}>0,05)}$. 


\subsubsection{Análisis de sangre}

No hubo diferencias significativas en los niveles de CPK, lactato y glucosa, ni en el conteo del hematocrito o de los leucocitos entre los dos tipos de peces alimentados con o sin Arthrospira. Sin embargo, los peces alimentados con A. platensis mostraron valores significativamente superiores de triglicéridos (TAG) y cortisol (Tabla 4.4). Los niveles de TAG en los peces suplementados con Arthrospira eran casi el doble de los niveles en peces control.

Tabla 4.4 Resumen de los parámetros hematológicos de O. niloticus (Media \pm SEM) y nivel de significancia en dos tratamientos diferentes de alimentación, control (CTR) y suplementado con Arthrospira (SPR). Los parámetros controlados fueron CPK (U /I), cortisol $(\mu \mathrm{g} / \mathrm{dl})$, glucosa $(\mathrm{mg} / 100 \mathrm{ml})$, hematocrito $(\%)$, triglicéridos $(\mathrm{mg} / 100 \mathrm{ml})$, leucocitos $(\mathrm{mil} / \mu \mathrm{l})$ y lactato $(\mathrm{mmol} / \mathrm{l})$. ANOVA de una vía con la prueba de comparación múltiple de Tukey.

\begin{tabular}{lrrr} 
& CTR $(\mathbf{n}=\mathbf{2 0})$ & SPR $(\mathbf{n}=\mathbf{2 0})$ & $\boldsymbol{p}$-value \\
\hline CPK & $3052,4 \pm 409,3$ & $3115,3 \pm 414,5$ & 0,839 \\
Cortisol & $10,10 \pm 1,20^{\mathrm{b}}$ & $15,46 \pm 1,50^{\mathrm{a}}$ & 0,019 \\
Glucosa & $89,23 \pm 3,50$ & $84,23 \pm 3,60$ & 0,571 \\
Hematocrito & $37,33 \pm 1,10$ & $37,39 \pm 1,10$ & 0,551 \\
Triacilglicéridos & $61,80 \pm 8,71^{\mathrm{b}}$ & $110,50 \pm 7,40^{\mathrm{a}}$ & 0,000 \\
Leucocitos & $8,68 \pm 0,60$ & $8,24 \pm 0,60$ & 0,296 \\
Lactato & $1,44 \pm 0,10$ & $1,43 \pm 0,10$ & 0,733 \\
\hline
\end{tabular}

Valores seguidos por la misma letra superíndice en la misma columna no presentaron diferencias significativas $(\mathrm{P}>0,05)$.

\subsubsection{Calidad de la carne}

Durante las primeras horas después del sacrificio ( 0 h y 6 h), no se encontraron diferencias entre los tratamientos en relación con el $\mathrm{pH}$ de la carne o el rigor mortis. Sin embargo, el ángulo de rigor mortis fue significativamente menor en los peces control a las $48 \mathrm{~h}$ post mortem (tabla 4.5).

Tabla 4.5 Media ( \pm SEM) del ángulo de rigor mortis, $\mathrm{pH}$ y temperatura $\left({ }^{\circ} \mathrm{C}\right)$, de $O$. niloticus para dos tratamientos, alimento control (CTR) y suplementado con A. platensis (SPR). ANOVA de una vía con la prueba de comparación múltiple de Tukey.

\begin{tabular}{lrrr} 
& CTR $(\mathbf{n}=\mathbf{2 0})$ & SPR $(\mathbf{n}=\mathbf{2 0})$ & $\boldsymbol{p}$-value \\
\hline Alpha 0h & $45,06 \pm 1,26$ & $42,08 \pm 1,26$ & 0,212 \\
Alpha 6h & $6,62 \pm 1,98$ & $8,32 \pm 1,53$ & 0,499 \\
Alpha 24h & $0,14 \pm 0,14$ & $0,12 \pm 0,12$ & 0,448 \\
Alpha 48h & $2,81 \pm 0,81^{\mathrm{b}}$ & $11,46 \pm 1,06^{\mathrm{a}}$ & 0,001 \\
\hline pH 0h & $6,81 \pm 0,04$ & $6,84 \pm 0,04$ & 0,691 \\
pH 6h & $6,79 \pm 0,02$ & $6,73 \pm 0,04$ & 0,149 \\
pH 24h & $6,43 \pm 0,02$ & $6,37 \pm 0,03$ & 0,093 \\
\hline
\end{tabular}




\begin{tabular}{lrrr}
\hline $\mathbf{T}^{\mathbf{a}} \mathbf{0 h}$ & $22,38 \pm 0,30$ & $20,41 \pm 0,79$ & 0,098 \\
$\mathbf{T}^{\mathbf{a}} \mathbf{6 h}$ & $5,16 \pm 0,61$ & $6,45 \pm 0,53$ & 0,122 \\
$\mathbf{T}^{\mathbf{a}} \mathbf{2 4 h}$ & $5,14 \pm 0,32$ & $5,43 \pm 0,35$ & 0,542 \\
\hline
\end{tabular}

Valores seguidos por la misma letra superíndice en la misma columna no presentaron diferencias significativas $(\mathrm{P}>0,05)$.

Aunque no se encontraron diferencias significativas $(\mathrm{P}<0.05)$ entre tratamientos a $0 \mathrm{~h}$, el parámetro L* fue algo mayor en los peces suplementados. Transcurridas 24 h, se revirtió el color de la carne, con diferencias significativas en ambos parámetros $a^{*}$ y b* con niveles más altos para los peces suplementado con A. platensis. Mientras que $\mathrm{C}^{*}$ fue mayor para los peces control. No hubo diferencias significativas se encontraron en el parámetro L* entre tratamientos.

Tabla 4.6Media $\left( \pm\right.$ SD) de los parámetros y color de la carne ( $\mathrm{L}^{*}, \mathrm{a}^{*}, \mathrm{~b}^{*}$, chroma $\mathrm{C}^{*}$ and hue $\left.\mathrm{h}^{*}\right)$ en $O$. niloticus control (CTR), y suplementados al $3 \%$ A. platensis (SPR).

\begin{tabular}{crrrr}
\multicolumn{2}{r}{ Parámetros de color } & CTR $(\mathbf{n}=\mathbf{2 0})$ & SPR $(\mathbf{n}=\mathbf{2 0})$ & $\boldsymbol{p}$-values \\
\hline $\mathbf{L}^{*}$ & $\mathbf{0 h}$ & $47.33 \pm 2.72$ & $49.30 \pm 3.60$ & 0.06 \\
& $\mathbf{2 4 h}$ & $48.95 \pm 1.65$ & $49.08 \pm 1.49$ & 0.79 \\
$\mathbf{a}^{*}$ & $\mathbf{0 h}$ & $-1.86 \pm 0.3$ & $1.84 \pm 0.29$ & 0.77 \\
& $\mathbf{2 4 h}$ & $-1.78 \pm 0.35^{\mathrm{b}}$ & $-1.42 \pm 0.42^{\mathrm{a}}$ & $<0.01$ \\
$\mathbf{b}^{*}$ & $\mathbf{0 h}$ & $-0.39 \pm 0.81$ & $-0.739 \pm 0.71$ & 0.16 \\
& $\mathbf{2 4 h}$ & $-4.74 \pm 0.87^{\mathrm{b}}$ & $-4.26 \pm 0.61^{\mathrm{a}}$ & 0.05 \\
$\mathbf{C}^{*}$ & $\mathbf{0 h}$ & $2.06 \pm 0.35$ & $2.09 \pm 0.32$ & 0.78 \\
& $\mathbf{2 4 h}$ & $5.09 \pm 0.75^{\mathrm{a}}$ & $4.51 \pm 0.57^{\mathrm{b}}$ & $<0.01$ \\
$\left.\mathbf{h}^{*} \mathbf{( 0}^{\mathbf{a}}\right)$ & $\mathbf{0 h}$ & $12.96 \pm 22.15$ & $21.40 \pm 18.86$ & 0.33 \\
& $\mathbf{2 4 h}$ & $68.70 \pm 6.30$ & $71.50 \pm 6.28$ & 0.17 \\
& &
\end{tabular}

Diferencias en la reflectancia fueron encontradas a diferentes longitudes de onda transcurridas $24 \mathrm{~h}$ post mortem. Los peces suplementados (SPR) presentaron una mayor reflectividad de la luz en los rangos de 470-500 nm y 620-670 nm (Figura 4.4 y tabla 4.7).

Tabla 4.7 Espectro de reflectancia diferencial de la carne de O. niloticus en \% a 24 h tras el sacrificio (Media). Para dos tratamientos distintos, control (CRT) y suplementada al $3 \%$ de $A$. platensis (SPR). ANOVA de una vía con la prueba de comparación múltiple de Tukey.

\begin{tabular}{cccc} 
Wavelength & CTR(n=20) & SPR(n=20) & p-value \\
\hline $\mathbf{3 6 0} \mathbf{~ n m}$ & $22,64 \pm 1,47$ & $23,14 \pm 1,22$ & 0,24 \\
$\mathbf{3 7 0} \mathbf{~ n m}$ & $22,64 \pm 1,47$ & $23,14 \pm 1,22$ & 0,24 \\
$\mathbf{3 8 0} \mathbf{~ n m}$ & $22,64 \pm 1,47$ & $23,14 \pm 1,22$ & 0,24 \\
$\mathbf{3 9 0} \mathbf{~ n m}$ & $22,64 \pm 1,47$ & $23,14 \pm 1,22$ & 0,24
\end{tabular}




\begin{tabular}{|c|c|c|c|}
\hline $400 \mathrm{~nm}$ & $22,64 \pm 1,47$ & $23,14 \pm 1,22$ & 0,24 \\
\hline $410 \mathrm{~nm}$ & $19,58 \pm 1,47$ & $20,03 \pm 1,14$ & 0,27 \\
\hline $420 \mathrm{~nm}$ & $17,69 \pm 1,45$ & $18,10 \pm 1,08$ & 0,32 \\
\hline $430 \mathrm{~nm}$ & $17,44 \pm 1,45$ & $17,84 \pm 1,15$ & 0,33 \\
\hline $440 \mathrm{~nm}$ & $18,14 \pm 1,30$ & $18,48 \pm 1,31$ & 0,43 \\
\hline $450 \mathrm{~nm}$ & $19,71 \pm 1,34$ & $20 \pm 10 \pm 1,47$ & 0,39 \\
\hline $460 \mathrm{~nm}$ & $21,06 \pm 1,19$ & $21,78 \pm 1,18$ & 0,10 \\
\hline $470 \mathrm{~nm}$ & $21,23 \pm 1,18^{b}$ & $22,14 \pm 1,51^{\mathrm{a}}$ & 0,04 \\
\hline $480 \mathrm{~nm}$ & $20,87 \pm 1,19^{b}$ & $21,84 \pm 1,53^{a}$ & 0,03 \\
\hline $490 \mathrm{~nm}$ & $20,22 \pm 1,18^{b}$ & $21,22 \pm 1,52^{a}$ & 0,03 \\
\hline $500 \mathrm{~nm}$ & $19,52 \pm 1,16^{b}$ & $20,45 \pm 1,50^{a}$ & 0,04 \\
\hline $510 \mathrm{~nm}$ & $18,86 \pm 1,15$ & $19,68 \pm 1,51$ & 0,06 \\
\hline $520 \mathrm{~nm}$ & $18,15 \pm 1,12$ & $18,90 \pm 1,50$ & 0,08 \\
\hline $530 \mathrm{~nm}$ & $17,47 \pm 1,08$ & $18,23 \pm 1,40$ & 0,07 \\
\hline $540 \mathrm{~nm}$ & $16,73 \pm 1,05$ & $17,46 \pm 1,41$ & 0,07 \\
\hline $550 \mathrm{~nm}$ & $16,09 \pm 1,06$ & $16,72 \pm 1,40$ & 0,11 \\
\hline $560 \mathrm{~nm}$ & $15,83 \pm 1,04$ & $16,48 \pm 1,40$ & 0,10 \\
\hline $570 \mathrm{~nm}$ & $15,75 \pm 1,02$ & $16,49 \pm 1,39$ & 0,06 \\
\hline $580 \mathrm{~nm}$ & $15,86 \pm 1,14$ & $16,65 \pm 1,43$ & 0,05 \\
\hline $590 \mathrm{~nm}$ & $16,05 \pm 1,14$ & $16,82 \pm 1,56$ & 0,08 \\
\hline $600 \mathrm{~nm}$ & $16,11 \pm 1,24$ & $16,85 \pm 1,66$ & 0,12 \\
\hline $610 \mathrm{~nm}$ & $16,40 \pm 1,33$ & $17,27 \pm 1,78$ & 0,09 \\
\hline $620 \mathrm{~nm}$ & $16,76 \pm 1,43^{b}$ & $17,88 \pm 1,93^{\mathrm{a}}$ & 0,04 \\
\hline $630 \mathrm{~nm}$ & $16,88 \pm 1,48^{b}$ & $18,11 \pm 2,03^{\mathrm{a}}$ & 0,04 \\
\hline $640 \mathrm{~nm}$ & $16,87 \pm 1,51^{b}$ & $18,11 \pm 2,06^{a}$ & 0,04 \\
\hline $650 \mathrm{~nm}$ & $16,93 \pm 1,55^{b}$ & $18,16 \pm 2,09^{a}$ & 0,03 \\
\hline $660 \mathrm{~nm}$ & $16,99 \pm 1,57^{b}$ & $18,21 \pm 2,10^{a}$ & 0,04 \\
\hline $670 \mathrm{~nm}$ & $17,11 \pm 1,58^{b}$ & $18,21 \pm 2,11^{\mathrm{a}}$ & $<0,05$ \\
\hline $680 \mathrm{~nm}$ & $17,28 \pm 1,60$ & $18,47 \pm 1,59$ & 0,06 \\
\hline $690 \mathrm{~nm}$ & $17,46 \pm 1,61$ & $18,64 \pm 2,10$ & 0,06 \\
\hline $700 \mathrm{~nm}$ & $17,69 \pm 2,11$ & $18,84 \pm 2,11$ & 0,06 \\
\hline $710 \mathrm{~nm}$ & $17,69 \pm 1,60$ & $18,84 \pm 2,12$ & 0,06 \\
\hline $720 \mathrm{~nm}$ & $17,69 \pm 1,60$ & $18,84 \pm 2,12$ & 0,06 \\
\hline $730 \mathrm{~nm}$ & $17,69 \pm 1,60$ & $18,84 \pm 2,12$ & 0,06 \\
\hline $740 \mathrm{~nm}$ & $17,69 \pm 1,60$ & $18,84 \pm 2,12$ & 0,06 \\
\hline
\end{tabular}

Valores seguidos por la misma letra superíndice en la misma columna no presentaron diferencias significativas $(\mathrm{P}>0,05)$. 


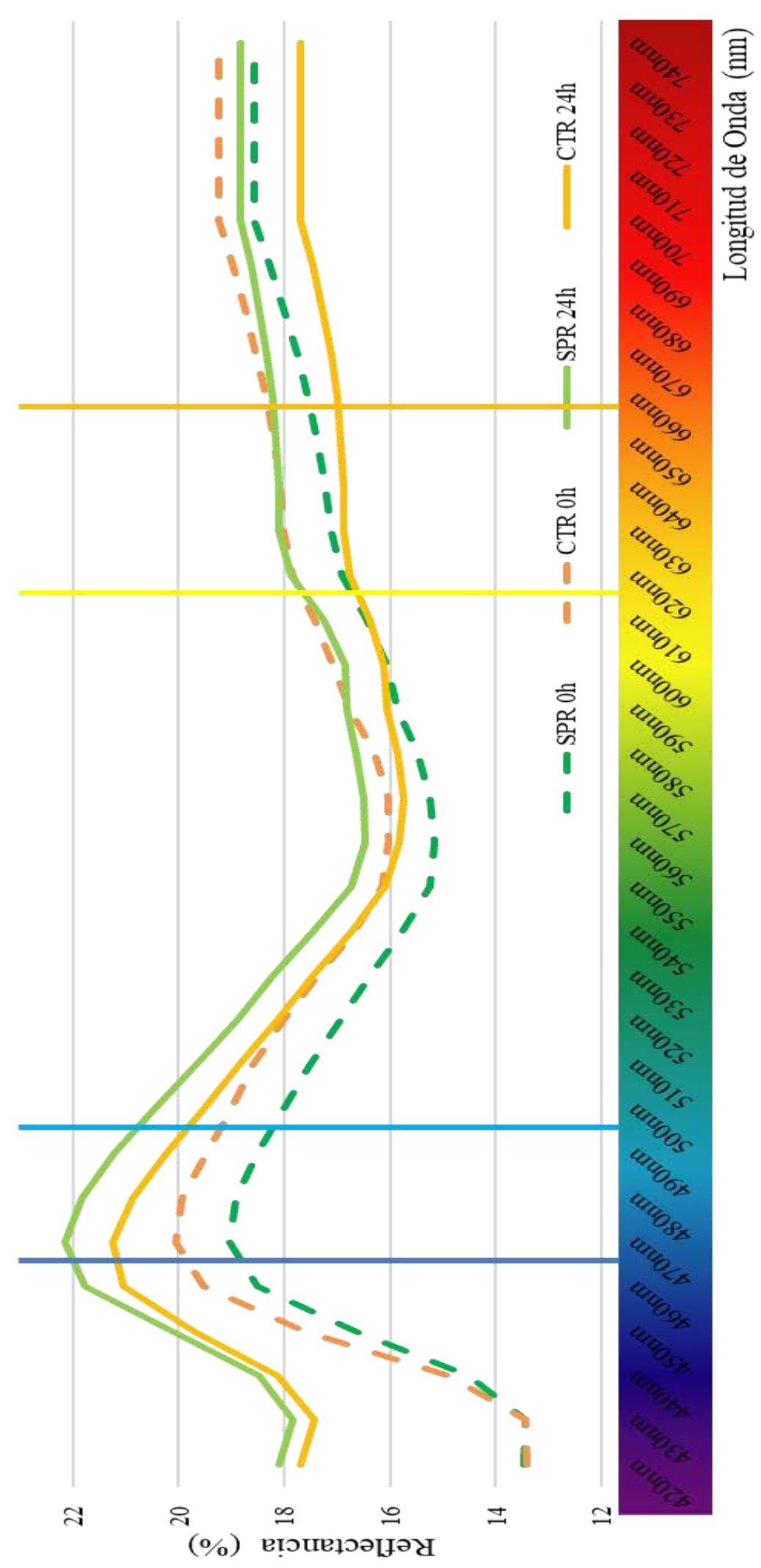

Figura 4.2 Curvas de espectro reflectancia de la carne de $O$. niloticus sp. a $0 \mathrm{~h}$ y $24 \mathrm{~h}$ tras el sacrificio. Para dos tratamientos distintos, control (CRT) y suplementada al 3\% de A. platensis (SPR). Las barras marcan los rangos donde se encontró diferencia significativa en la reflectancia (\%) entre tratamientos a las $24 \mathrm{~h}$. 


\subsubsection{Microbiota intestinal}

En el conjunto de los experimentos del microbiota intestinal se obtuvieron 5470272 lecturas de secuencia, correspondientes a 1563 especies, de las 16 muestras de intestino utilizadas (8 por tratamiento), obteniendo los datos Krona (Figura 4.4) de cada uno de los especímenes que se pude consultar en el anexo (Anexo 2).

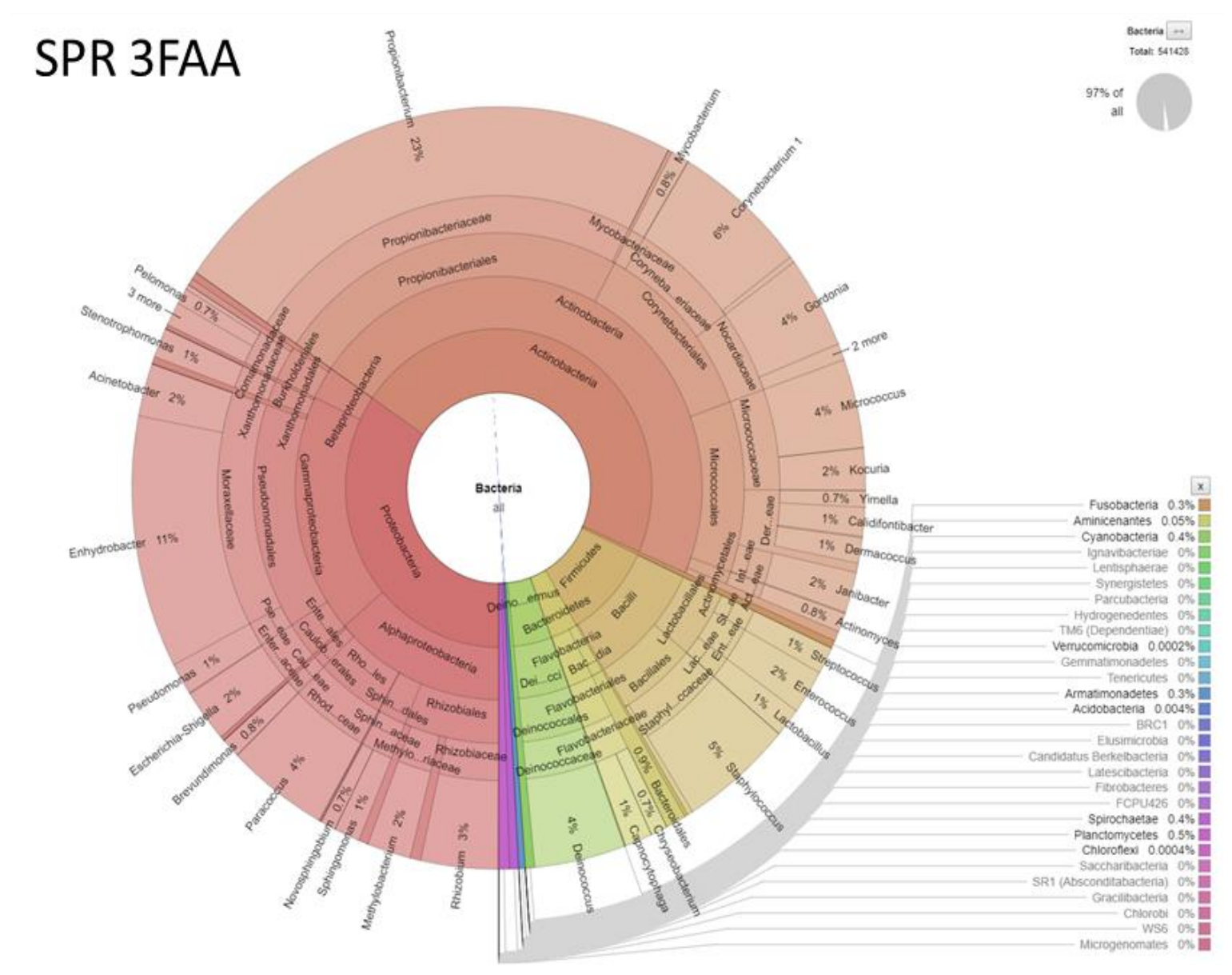

Figura 4.3 Grafica jerárquica en Krona, nivel de especie, de uno de los individuos de la prueba. Identificados con las siglas del tratamiento SPR (suplementados con A. platensis) y con los cuatro dígitos de su chip.

Para estimar la diversidad microbiana de cada muestra, se calculó el estimador de riqueza (Chao-1) y los índices de diversidad (Shannon, Margalef y Simpson), tomando como opción una cobertura del 97\% de similitud en el BAST (Tabla 4.8). A partir de estos análisis se pudo concluir que no se encontraron diferencias significativas del microbiota intestinal de los peces alimentados con o sin Arthrospira. 
Tabla 4.8 Índices de diversidad calculados por el software QIIME. Las unidades taxonómicas operativas (OTU) se definen al 97\% de similitud de secuencia. O. niloticus en dos tratamientos, control (CTR) y suplemento $3 \%$ con $A$. platensis (SPR). ANOVA de una vía con la prueba de comparación múltiple de Tukey.

\begin{tabular}{lcccccc} 
Tratamiento (chip) & Taxones & Lecturas & Simpson 1-D & Shannon H & Margalef & Chao-1 \\
\hline CTR (056A) & 71 & 209538 & 0,92 & 3,66 & 58,11 & 774,30 \\
CTR (13B6) & 431 & 441930 & 0,84 & 2,93 & 33,08 & 498,30 \\
CTR (CEE9) & 384 & 246371 & 0,60 & 1,73 & 30,85 & 500,20 \\
CTR (CEEB) & 469 & 307394 & 0,84 & 2,72 & 37,04 & 531,90 \\
CTR (E0BD) & 592 & 355241 & 0,78 & 2,68 & 46,24 & 679,10 \\
CTR (FF98) & 498 & 169468 & 0,76 & 2,47 & 41,28 & 588,40 \\
CTR (FF9B) & 429 & 387646 & 0,84 & 2,92 & 33,26 & 520,90 \\
CTR (FF9B) & 592 & 357727 & 0,81 & 2,57 & 46,22 & 664,90 \\
SPR (055B) & 412 & 365829 & 0,84 & 2,85 & 32,08 & 466,50 \\
SPR (3331) & 515 & 200177 & 0,80 & 2,44 & 42,11 & 606,70 \\
SPR (3E31) & 385 & 349497 & 0,75 & 2,52 & 30,08 & 431,50 \\
SPR (3FAA) & 558 & 423622 & 0,93 & 3,75 & 42,99 & 690,00 \\
SPR (CEEF) & 356 & 456785 & 0,79 & 2,55 & 27,24 & 406,40 \\
SPR (D415) & 607 & 437080 & 0,74 & 2,41 & 46,66 & 681,80 \\
SPR (FB22) & 332 & 286631 & 0,70 & 1,75 & 26,34 & 393,10 \\
SPR (FFDC) & 466 & 475336 & 0,85 & 2,91 & 35,57 & 541,10 \\
\hline CTR (media) & 513,50 & 309414 & 0,80 & 2,71 & 40,76 & 594,75 \\
SPR (media) & 453,88 & 374369 & 0,80 & 2,65 & 35,38 & 527,14 \\
\hline p-value & 0,766 & 0,188 & 0,977 & 0,825 & 0,225 & 0,246
\end{tabular}

Los resultados de la Figura 4.5, muestran la composición de la comunidad bacteriana encontrada en el intestino de los distintos especímenes de $O$. niloticus. Si se estudia a nivel global, está compuesta mayoritariamente por cuatro phylas. Estos phylas en término medio corresponden a Protobacterias que representa el 36,5\%, Fusobacterias el 32,8\%, con un $10,6 \%$ se encuentra Actinobacterias y un 5,9\% de Bacteriodetes. Estos porcentajes varían considerablemente entre individuos. Tres de las muestras control presentan un nivel alto de Actinobacterias, y dos de las muestras suplementadas con A. platensis contenían valores que superan el $35 \%$. Por otro lado, géneros como Spirochaetae, Euryarchaeota o Hydrogenedentes solo aparecen en peces suplementados con A. platensis, aunque su representación es menor de $0,05 \%$ de la población total. 


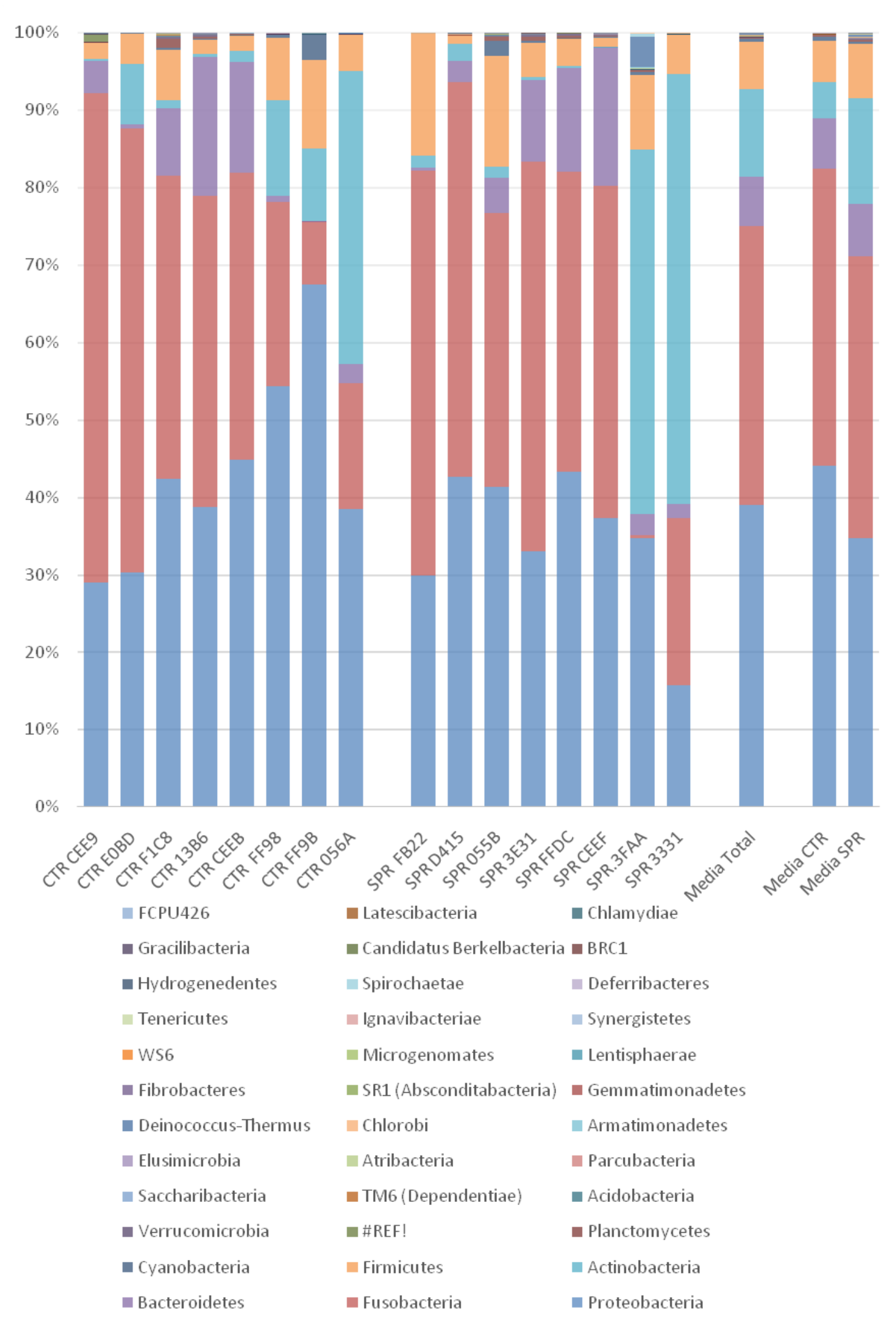

Figura 4.4 Abundancia relativa, nivel phyla, de bacterias encontradas en el intestino de 16 individuos $O$. niloticus en dos tratamientos alimentados diferentes, 8 individuos con dieta control (CTR) y 8 individuos suplementados con A. platensis (SPR), incluyendo medias por tratamiento y media total. 
Revisando los resultados en mayor profundidad, a nivel de género, encontramos una situación similar (Figura 4.5), donde 15 géneros representan más del 75\% del total encontrado. Los 4 géneros más representativos, bajo las condiciones experimentales, fueron Cetobacterium (32,8\%), seguido de Aeromonas (13,9\%), Echerichia/Shingella (6,7\%) y finalmente encontramos a Propionibacteirum (5,2\%). Sin embargo, encontramos divergencia en las muestras con patrones más altos en Actinobacteria. Propionibacteriumse encuentra por encima del 30\% en los individuos con el chip CTR056A y SPR3FAA. Así como en concentraciones de entorno al 10\% en los individuos CTRFF98 y CTRFF9B, donde hay una Actinobacteria dominante. Finalmente es Mycobacterium la bacteria dominante en el individuo SPR3331 con un 37,8\%, siendo estos géneros bacterianos los responsables de la diferencia de estas muestras.
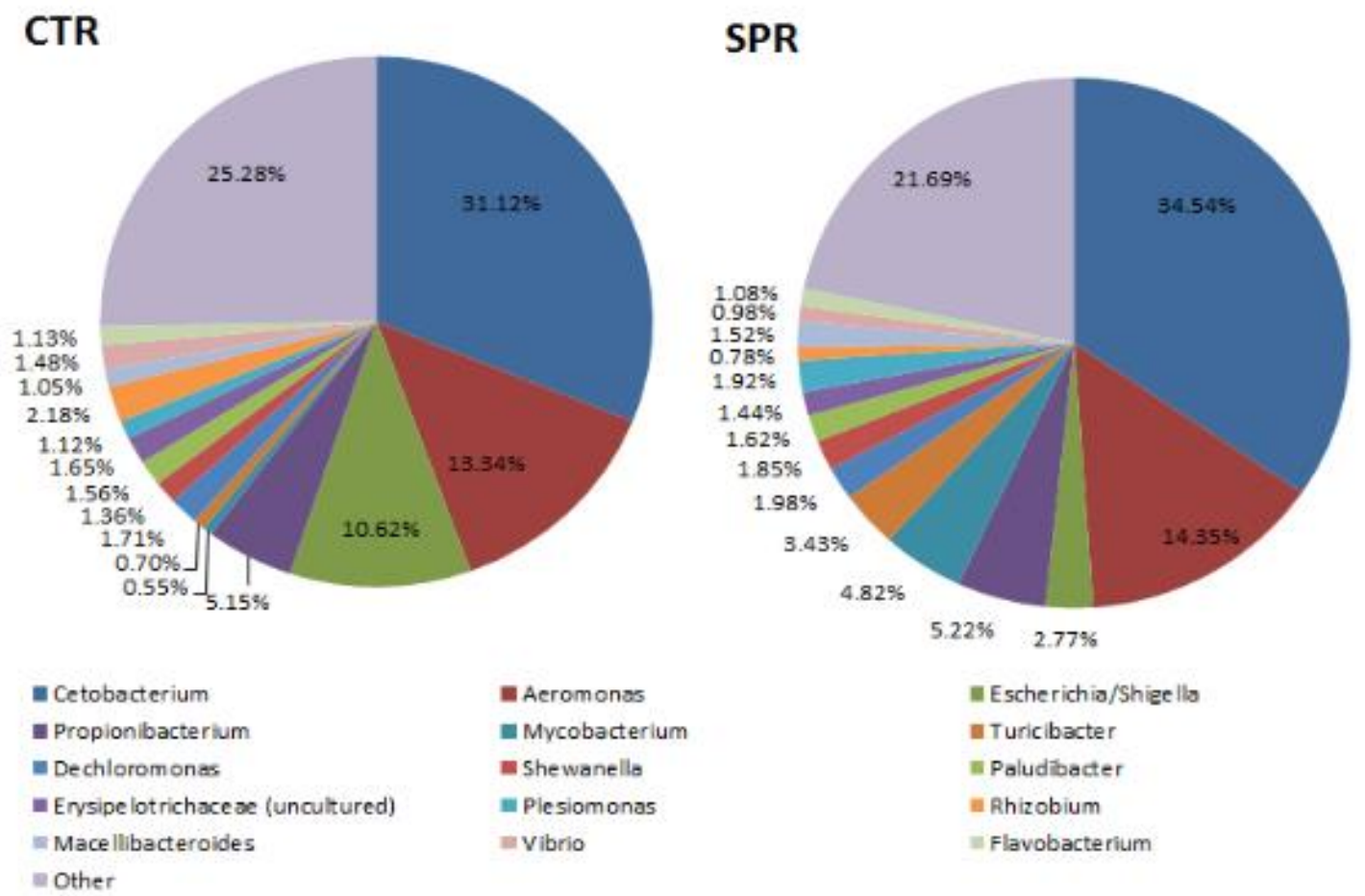

Figura 4.5 Abundancia media relativa, nivel género, de bacterias encontradas en el intestino de 16 individuos $O$. niloticus en dos tratamientos alimentados diferentes, 8 individuos con dieta control (CTR) y 8 individuos suplementados con A. platensis (SPR).

El estudio de la diversidad alfa (Tabla 4) mostró que no hubo diferencias significativas entre los tratamientos. También se realizó un agrupamiento (Figura 3) para analizar la diversidad $\beta$, pero no hubo diferencias en la diversidad bacteriana entre los tratamientos. 
Figura 4.1 Análisis de similitud por grupos de bacterias intestinales, a nivel de especie, de 8 individuos $O$. niloticus en dos tratamientos diferentes. Peces con alimento control (CTR) y con alimento suplemento con A. platensis (SPR) y número de chip, usando la prueba de Bray-Curtis (software PAST3, 2017.)

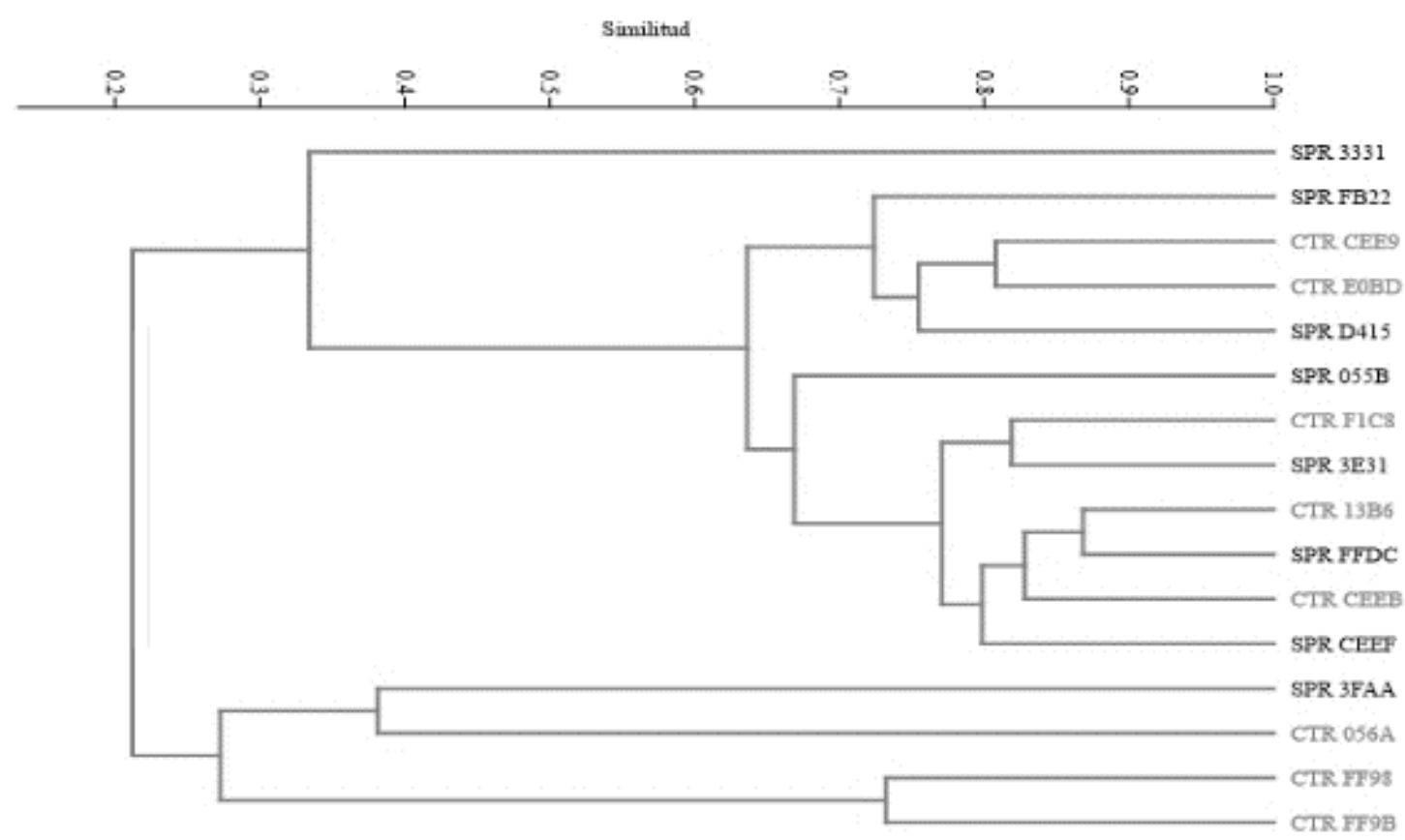




\section{DISCUSIÓN}




\section{DISCUSIÓN}

\subsection{Prueba 1 Alevinaje y Two-Choices}

\subsubsection{Crecimiento y supervivencia}

En la Prueba 1, agregar 1\% de A. platensis a la alimentación no afectó a los índices de producción (IC, GMD) en comparación con los controles. Esto contradice los estudios previos de James et al. (2006) usando X. helleri (8\% de suplementación), y de AbdelTawwab y Ahmed (2009) (0,5\% a 1\% de suplementación en tilapia), Kim et al. (2013) en Oplegnathus fasciatus (5-10\%), y lo observado en nuestro experimento con peces de preengorde ( $3 \%$ de suplementación) donde se observó una mejora del crecimiento.

Los resultados obtenidos en supervivencia, auqnue son mejores en ambos casos que los estimados por Meyer (2004) de un 33\% en producciones comerciales. Los resultados muestran una tasa de un $9 \%$ mayor en peces suplementados con A. platensis. Esto concuerda con otros estudios que encuentran un $6 \%$ de supervivencia más alta con $1 \%$ de suplementación de Arthrospira después de un desafío bacteriano (Ibrahem et al., 2013). En alevines de Cyprinus carpio (carpa común), alimentada con Arthrospira, Ramakrishnan et al. (2008) obtuvieron una mejora de un 3\% tanto en crecimiento como en supervivencia. Sin embargo, Boonyaratpalin y Unprasert (1989), Abdel-Tawwab y Ahmed (2009), y Ungsethaphand et al. (2010) no observaron diferencias en la supervivencia entre los peces alimentados con Arthrospira en comparación con los controles. En alevines de trucha arcoíris (O. mykiss) ni Pókniak (2007) ni Dallaire et al. (2007) tampoco encontraron diferencias significativas en cuanto a la supervivencia, así como Wang et al. (2006) en adultos de Hyphessobrycon callistus,

Los animales jóvenes a menudo tienen un sistema inmune deficiente durante las primeras semanas de vida (Belay et al., 1996). Un número significativo de las larvas de peces marinos, generalmente mueren debido a infecciones por patógenos oportunistas. El desarrollo temprano del sistema inmune puede ofrecer protección contra estos patógenos. Arthrospira o sus extractos pueden acelerar el desarrollo del sistema inmune de estos animales, especialmente durante las primeras etapas de sus vidas. 
Cuando comenzó el ensayo las tilapias se encontraban en la etapa de alevines (alrededor de 2-3 cm de longitud corporal). En esa etapa los peces son más sensibles a la mortalidad puesto que comienzan cambios en su dieta. Los alevines comienzan a cambiar de omnívoros a carnívoros, pues necesitan un mayor aporte proteico para su crecimiento. Más tarde, vuelven a cambiar a fitoplanctívoro, a unos 6-7 cm (Ibrahem et al., 2013). El cambio a carnívoro podría aumentar el canibalismo y el estrés jerárquico reduciendo la supervivencia de alevines más débiles (Berrios y Snow, 1983). En este escenario, el alto contenido de vitaminas y proteínas de $A$. platensis podría haber jugado un papel importante, ayudando a promover el crecimiento y a disminuir la mortalidad.

Los datos obtenidos en crecimiento y supervivencia, conducen a pensar que el suplemento con Arthrospira se comporta como un promotor del crecimiento cuando las condiciones del medio no son del todo adecuadas, siendo inocua en situaciones favorables.

\subsubsection{Two-choices}

Con respecto a la prueba de two-choices, los resultados sugieren que un mayor número de alevines suplementados con $A$. platensis adoptaron un estilo proactivo de afrontamiento al estrés por hipoxia. Muchos de ellos permanecieron en un ambiente estresante a pesar de la posibilidad de escape. Como sugieren Barreto et al. (2011), los peces que permanecen en el tanque "estresante" tienen una menor reacción al estrés y pueden clasificarse como proactivos. Algunos autores han demostrado que A platensis afecta los niveles plasmáticos de cortisol y de glucosa. En la trucha arco iris (O. mykiss), el cortisol y la glucosa disminuyeron significativamente con el aumento de la inclusión de A. platensis entre 0 y $10 \%$ en la dieta (Yeganeh et al., 2015), aunque los análisis realizados en esta tesis con $O$. niloticus en pre-engorde muestran un aumento en los niveles de cortisol en los peces suplementados con A. platensis. Aunque esos niveles no se salían de los rangos normales descritos para la especie en la bibliografía.

En el esturión (Huso huso), Adel et al. (2016) encontraron que la glucosa en sangre aumentó con una mayor inclusión de A. platensis (10\%). Además, según Delarue (2003), agregar ácidos grasos $\omega 3$ a las dietas de los peces puede inhibir la activación suprarrenal provocada por el estrés psicológico. Arthrospira tiene un alto nivel de ácidos grasos de cadena larga insaturados, como $\omega 3$ y $\omega 6$, que pueden haber proporcionado un efecto similar en $O$. niloticus. En los análisis hematológicos realizados en la prueba de pre-engorde 
encontramos un aumento en los niveles de triglicéridos en los peces suplementados con $A$. platensis.

En este sentido, Anzola (2013) encontró una disminución en el estrés psicológico con una mayor ingesta de triptófano en perros, y Shor-Posner (1994) encontró el mismo efecto en humanos con suplementos de triptófano y vitamina B6. A. platensis contiene triptófano (1,5\% de MS) y vitamina B6 (900 ppm de MS, Fernández-Cardenas et al., 2001)). Teniendo en cuenta que el requerimiento de triptófano de $O$. niloticus es el $1 \%$ de la dieta; con la inclusión de $1 \%$ de $A$. platenses (1.5\%), se aumenta hasta un $1.15 \%$. Los requerimientos de vitamina B6 en juveniles Oreochromis son de 15 a 16 ppm de la dieta (Shiau y Hsieh, 1997), pero se aumentó a 9 ppm (50\% más que los niveles de control estimados) mediante la adición de $1 \%$ de $A$. platensis.

Durante la prueba de two-choice se expuso a los peces a una situación que puede aparecer en una producción comercial, la falta de oxígeno. Debido a varios factores, como la rotura de una bomba, la sobrepoblación de peces o exceso de bacterias que reduzcan drásticamente y por periodos variables de tiempo la disponibilidad de $\mathrm{O}_{2}$. Que Arthrospira pueda paliar el estrés producido por estas situaciones, que puede resolverse en un alto número de bajas, puede hacer rentable su inclusión en los piensos.

En los peces, la longitud del cuerpo es un fuerte predictor de posiciones individuales en una jerarquía (Ward et al., 2006). Los peces grandes son presumiblemente más proactivos, dominantes. Pero durante la prueba, no encontramos ningún indicio de que el tamaño del pez esté involucrado en su respuesta.

\subsection{Prueba 2, Pre-engorde}

\subsubsection{Engorde}

La suplementación con $A$. platensis mejoró las tasas de crecimiento, GMD y IC en tilapia SPR. Esto está en sintonía con lo observado por otros autores y en diferentes especies. Adel et al. (2016) en H. huso (suplemento de 10\%), James et al. (2006) en X. helleri (8\%), Güroy et al. (2012) en ciclidos de cola amarilla (Pseudotropheus acei), y Abdel Tawwab et al. (2009) en O. niloticus (5\%). Sin embargo, Tukeuchi (2002) reportó lo opuesto, una menor tasa de crecimiento y eficacia de la alimentación más pobre en Oreochromis alimentado con Arthrospira. 
Estos resultados, son similares a los encontrados por varios investigadores en porcino. En ganado porcino la suplementación con Arthrospira con respecto a la respuesta al crecimiento es inconsistente. Hugh et al. (1985) encontraron que los cerdos destetados mestizos que recibían suplementos dietéticos de Arthrospira tenían tasas de crecimiento de hasta un 9\% más alta que sus pares no suplementados. Sin embargo, Grinstead et al. (1998) no encontraron diferencias de crecimiento entre los cerdos suplementados con Arthrospira y los no suplementados. Este hallazgo aparentemente contradictorio es atribuible a las diferencias en los procedimientos experimentales. Una explicación a esta inconsistencia es la salud de los cerdos, un resultado casual que puede afectar al resultado de los experimentos. Por otro lado, también puede ser causado por el alimento al que reemplaza Arthrospira en cada uno de los casos. Por ejemplo, se ha demostrado que la Arthrospira es un sustituto viable de la leche en polvo desnatada en raciones de alimento para cerdos (Grinstead et al., 1998).

En general nuestros resultados apoyan la idea que Arthrospira ayuda a promover el crecimiento animal. Como se demuestra en broilers (pollos de engorde), donde la investigación con Arthrospira en pienso ha sido más intensa, los resultados están más claros. Con la inclusión de entre 5-10\% conservan las tasas de crecimiento, pero sustituciones mayores del 20\% parecen empeorarlas (Ross y Dominy, 1990; Venkataraman et al., 1994; Saxena et al., 1983; Toyomizu et al., 2001). Venkataraman et al. (1994) encontraron que se pueden eliminar los complementos minerales y vitamínicos cuando se incluye Arthrospira en los piensos, disminuyendo así los costes de producción. Los pollos crecen más con $1 \%$ de suplemento de Arthrospira (Shanmugapriya et al., 2015).

El género Arthrospira sp. se presenta como un suplemento dietético que tiene muchos beneficios para la salud y un aditivo para animales con beneficios económicos (Kaoud 2012). A platensis es una cianobacteria filamentosa azul verdosa que no fija $\mathrm{N}_{2}$ que tiene un gran potencial para mejorar el suministro de alimentos y tiene varias características fisiológicas valiosas (Huili et al., 2013), debido a una cantidad importante en proteínas, aminoácidos esenciales, vitaminas y minerales, ácidos grasos vitales y polisacáridos. Recientemente, muchos autores concluyeron que la suplementación de SP mejoró la ganancia de peso corporal (GPC), el índice de conversión alimenticia (IC) y el aumento de la altura de las vellosidades (Shanmugapriya et al., 2015). 


\subsubsection{Análisis sanguíneo}

Dentro de los parámetros sanguíneos, las diferencias $(\mathrm{p}<0.05)$ obtenidas en los niveles de triglicéridos y cortisol fueron mayores en ambos casos en peces suplementados. Los triglicéridos en la sangre están relacionados con el metabolismo de las grasas y, a su vez, con el nivel de ejercicio y la dieta. Teniendo en cuenta que los peces han estado sujetos a condiciones idénticas, no parece el caso. Niveles más altos de triacilglicéridos plasmáticos también fueron encontrados por Velásquez (2016) en tilapias alimentadas con diferentes niveles de Arthrospira Esto parece mostrar que la suplementación con Arthrospira en tilapias aumenta el nivel plasmático de triglicéridos.

Los niveles de cortisol en los peces están comúnmente relacionados con sus niveles de estrés (Barton y Iwama., 1991; Pottinger y Carrick., 1999). Aunque los niveles eran mayores en los peces suplementados, están dentro de los rangos normales en la especie (sobre 10-20 ng/ml, Balm, 1994; Vijayan et al., 1997, Barcellos et al., 1999). En respuesta a la mayoría de los estresores, los peces exhibirán un aumento en las concentraciones plasmáticas de cortisol, que generalmente viene seguido de una elevación en los niveles de glucosa en plasma. Sin embargo, en el estudio actual, esto no sucedió. No se encontraron diferencias en los niveles de glucosa entre los diferentes tratamientos. Los estudios en trucha arco iris (O. mykiss), han encontrado una reducción de cortisol y glucosa con la suplementación con A. platensis (0 a $10 \%$; Yeganeh et al., 2015).

Por otro lado, el cortisol también está relacionado con el aumento de la lipólisis del sistema adiposo, que genera un aumento de triglicéridos en la sangre. Este aumento en los niveles plasmáticos de ácidos grasos durante la hipercortisolemia puede mejorar las reacciones metabólicas observadas para varias especies de peces (Mommsen et al., 1999). Este aumento en el metabolismo está relacionado con el crecimiento y puede ser una de las causas de las diferencias en el crecimiento entre los tratamientos. El cortisol no solo es un componente esencial de la respuesta al estrés en peces, sino que también desempeña un papel importante en la osmorregulación, el crecimiento y la reproducción (Mommsen et al., 1999).

Esto respalda lo encontrado también en otras especies. En conejos alimentados con Arthrospira (Peiretti y Meineri, 2011), encontraron un aumento significativo en el contenido de grasa de la canal. En peces de cola de espada roja (X. helleri) a los que se les administró $8 \%$ de $A$. platensis, aumento el peso de las gónadas y el número de crías (James 
et al., 2006). En porcino (Granaci 2007), y en rumiantes también se ha reportado una mejora de la eficiencia reproductiva en animales alimentados con esta bacteria.

\subsubsection{Calidad de la carne}

El pH de la carne analizada estuvo dentro de los valores normales para O. niloticus entre 6.4-7.0, según lo descrito por otros autores (Oliveira et al., 2015; Hsieh et al., 2011). No hubo efecto de la suplementación en el pH de la carne, pero el rigor mortis se resolvió antes en los peces suplementados, lo que podría implicar una vida útil más corta.

El color de la carne también fue diferente entre los tratamientos, con un croma más alto a las $24 \mathrm{~h}$ post-mortem en los peces control. A las $24 \mathrm{~h}$ post-mortem, hubo una mayor absorción de luz en los rangos de 470-500 nm, que se corresponde con el espectro de absorción del $\beta$-caroteno. El caroteno muestra dos picos de absorbancia entre $400 \mathrm{~nm}$ y $500 \mathrm{~nm}$ (que reflejan la luz roja-naranja-amarilla). Este cambio de color debido a los carotenos también ha sido descrito por otros autores en O. mykiss (Teimouri et al., 2013), C. carpio L. (Sun et al., 2012) y O. mossambicus (Gomes et al., 2012). James et al. (2006) también encontraron un mayor contenido de caroteno en $X$. helleri alimentado con $8 \%$ de Arthrospira. En Ciclidos de cola amarilla (P. acei), Güroy et al. (2012) también encontraron que los peces alimentados con esta bacteria presentaban mejor coloración en el amarillo de la cola.

El segundo rango $(620-670 \mathrm{~nm})$ podría corresponderse con la ficocianina que emite fluorescencia a aproximadamente $650 \mathrm{~nm}$. Karadal et al. (2017) encontraron un aumento en la coloración de la piel de los cíclidos de Kenyi (Maylandia lombardoi) alimentados con Arthrospira.

El estudio realizado por Regunathan y Wesley (2006) en camarones (Fenneropenaeus indicus). Confirma que la biodisponibilidad pigmentos y carotenoides de Arthrospira, y su inclusión regular en la dieta evita los problemas relacionados con síndrome de deficiencia de pigmentos en los reproductores. 


\subsubsection{Microbiota intestinal}

El microbiota intestinal se puede entender como un "órgano extra" debido a su papel clave en el desarrollo intestinal, la homeostasis y la protección. El microbiota intestinal influye en una amplia gama de procesos biológicos de su huésped, incluyendo digestión, inmunidad, crecimiento, acciones de barrera intestinal y el desarrollo en todos los vertebrados (O'Hara y Shanahan, 2006; Dhanasiri et al., 2011; Dehler et al., 2017; Backhed et al., 2004; Turnbaugh et al., 2006). Por todo esto, es un factor a tener en cuenta, para mejorar el bienestar de los individuos, así como la rentabilidad de las producciones.

Aunque en números estudios con Arthrospira (Belay et al., 1996; Lui et al., 2011; Nuhu, 2013) informan de actividades anticancerígenas y antimicrobianas (antibacterianas, antifúngicas y antivirales) a través de la producción de ficocianina, aloficocianina, y otros productos valiosos. En nuestro estudio la suplementación con A. platensis no modificó significativamente el microbiota intestinal en $O$. niloticus. El microbiota identificado en los peces de la prueba, fue similar a los controles y dentro del rango de otros estudios realizados en Oreochromis por otros autores (Fan et al., 2017; Ran et al., 2016; Giatsis et al. 2015).

A nivel de phyla, predominan las Proteobacteria y Fusobacteria (Fan et al., 2017; Ran et al., 2016), aunque en Giatsis et al. (2015), menciona que Acidobacteria ocupó el nicho de las Proteobacteria, dominando la población. Encontramos resultados similares en las muestras CTR-056A, CTR-FF98, CTR-FF9B, SPR-3331 y SPR-3FAA. Esto parece mostrar la existencia de dos ecotipos de microbiota intestinal (Figura 5.1). A nivel de género, casi todas las secuencias de $16 \mathrm{~S}$ ARNr de Fusobacteria en los dos tratamientos pertenecían al género Cetobacterium. Este resultado es similar a van Kessel et al. (2011) en C. carpio, y Ran et al. (2016) en O. niloticus, donde fue el grupo dominante para cada tratamiento, representando el 32\%. Las Cetobacterias son miembros conocidos del microbiota endógeno de los intestinos de los peces (Wu et al., 2010). 

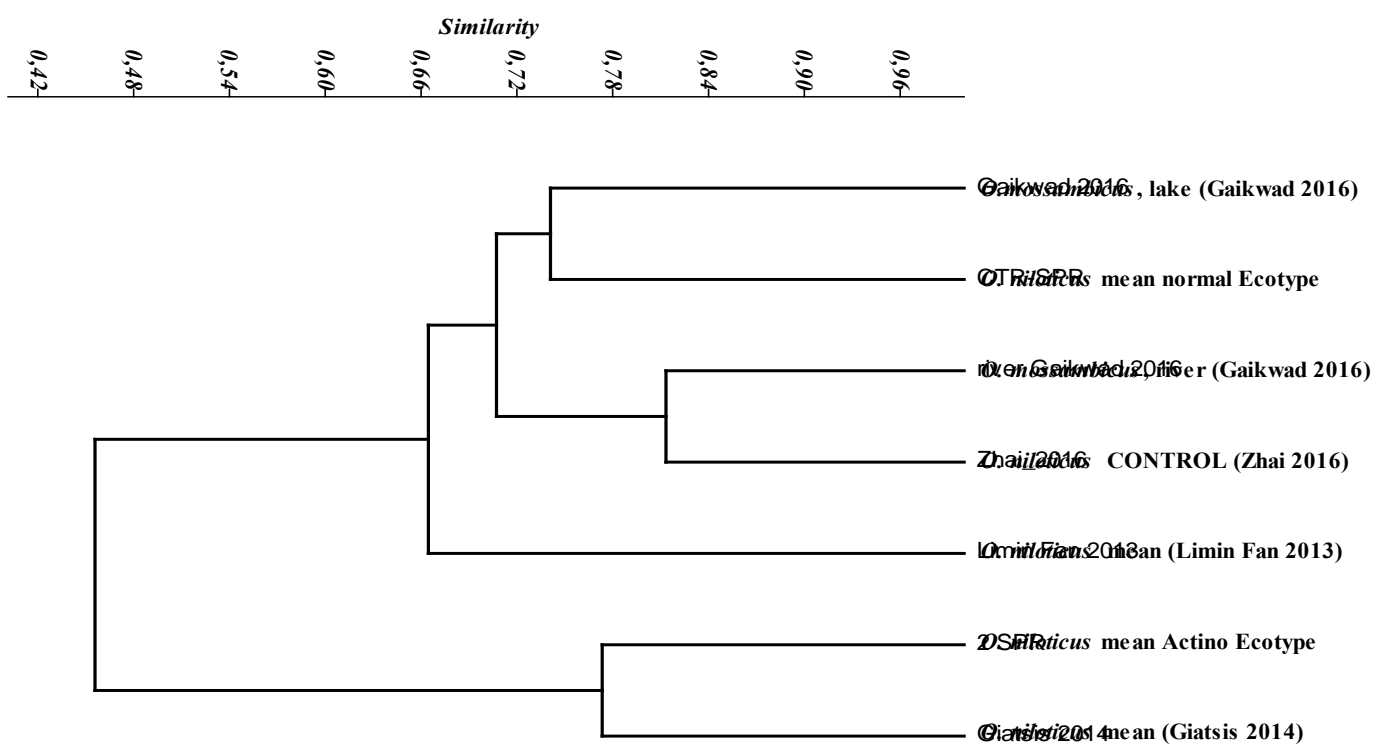

Figura 5.1 Análisis de similitud de grupos de bacterias intestinales de diferentes estudios en Oreochromis usando la prueba de Bray-Curtis. Utilizando los datos medios de los contribuidos por el control de peces de los diversos estudios realizados por los autores.

En este estudio, Fusobacteria representó el 36\%, mientras que otros autores como Fan et al. (2017) encontraron 26\%, Zhai et al. (2017) 56\%, Gaikwad et al. (2017) 45\% o Ran et al. (2016) 34\%. Aunque no todas las muestras del presente estudio respondieron a este patrón, los altos valores de Fusobacteria parecen característicos de Oreochromis, especialmente en comparación con otras especies como H. molitrix $<12 \%$ (Ye et al., 2014), S. salar <7\% (Gajardo et al., 2016; Dehler et al., 2017) u O. mykiss <1\% (Huyben et al., 2017). Merrifield y Ringo (2014) argumentaron que el contenido promedio de Fusobacteria en peces comerciales comunes es inferior al 7\%.

Sin embargo, las Proteobacterias fueron los phyla más numerosos, divididos en una gran cantidad de género, el más representativo fue Aeromonas $(13,8 \%)$, un miembro conocido de la microbiota endógena de peces de agua dulce, que ayuda a fermentar compuestos orgánicos y celulosa (Wu et al., 2010), seguido de Shigella (6,7\%), que puede ser un patógeno opcional como Aeromonas (Wu et al., 2010; Jiang et al., 2011; van Kessel et al., 2011; Wu et al., 2012).

Entre los géneros más representativos de Actinobacteria se encuentran Propionibacterium (5.2\%) y Mycobacterium (2.7\%), ambos miembros del orden de los Actinomycetales, ocupando el nicho principal del segundo ecotipo encontrado. 
Está claro que la alimentación suplementaria de Arthrospira ofrece algunos beneficios a los peces. Algunos de estos efectos, como la mayor tasa de crecimiento, la mejora del color y la calidad general del tejido, pueden ser efectos nutricionales. En este estudio demuestra que la aplicación de $1 \%$ A. platensisen la dieta de $O$. niloticus, no afecta a la composición del microbiota intestinal. Sin embargo, el hecho de que las tasas de crecimiento mejoren incluso con un $1 \%$ de suplemento. Lo que puede sugerir la presencia de sustancias que pueden imitar los efectos o estimular la producción de hormonas de crecimiento. Otros efectos como los efectos inmunomoduladores, los efectos antivirales y anticancerígenos se producen a concentraciones tan bajas que sus efectos pueden deberse a factores distintos de los meramente nutricionales. 


\section{CONCLUSIONES}

\subsection{Crecimiento}

A nivel general podemos concluir; que el género Arthrospira sp. se presenta como un suplemento dietético que tiene muchos beneficios para la salud. Y como aditivo puede presentar mejoras en aspectos que tienen interés económico.

Aunque, la suplementación, con Arthrospira al 1\%, no mejoró la ganancia de peso corporal (GPC), el índice de conversión alimenticia (IC), durante la fase de alevinaje. Si, mejoro considerablemente los índices de supervivencia de los alevines en un 9\%. Lo que se puede reflejar en una mayor producción final. Además, la suplementación con A. platensis mejoró la ganancia media diaria (GMD) en un 10\%, y el índice de conversión alimenticia (IC) en un porcentaje similar. A nivel comercial, y bajo nuestros parámetros de la tesis, en individuos en la fase de pre-engorde.

\subsection{Comportamiento y estrés}

Complementando alevines de $O$. niloticus con A. platensis aumentó la supervivencia y la proporción de individuos que adoptaron un estilo de afrontamiento proactivo, basado en los resultados de una prueba de dos opciones. Los resultados también sugieren que $A$. platensis aumentó la resistencia a la hipoxia, que es importante para la producción acuícola intensiva.

Por otro lado, la suplementación con A. platensis, no parece interferir en la mayoría de los parámetros sanguíneos. Aunque, bajo las condiciones de la tesis, Arthrospira parece generar una hipercortisolemia, relacionada con el aumento de la lipólisis del sistema adiposo, que genera un aumento de triglicéridos en la sangre. Este aumento en el metabolismo está relacionado con un mayor crecimiento y puede ser una de las causas de las diferencias en el crecimiento entre los tratamientos. 


\subsection{Calidad de la carne}

El estudio de colorimetría, parece sugerir que los pigmentos contenidos en Arthrospira (xantofila, $\beta$-caroteno, ficocianina y astaxantina, así como ficocianina), se fijan en la grasa y carne afectando su coloración, lo que aumenta el valor nutricional del producto. En cuanto al rigor mortis, la suplementación con Arthrospira, parece estar relacionada con un período de duración más corto, que puede estar relacionado con una reducción de la vida útil de la carne.

\subsection{Efecto del suplemento de espirulina sobre el microbiota intestinal de la tilapia.}

A nivel de microbiota intestinal, y sobre la base de los resultados de este estudio, concluimos que $A$. platensis puede mejorar el crecimiento en $O$. niloticus y podría ayudar a mejorar el color de la carne, sin modificar los parámetros generales del microbiota intestinal. Por otro lado, hemos observado diferentes configuraciones de microbiota intestinal en $O$. niloticus, que podemos categorizar en dos ecotipos. El predominante en nuestras muestras es el Ecotipo I (Fuso-Proteobacteria), con Cetobacterium como la bacteria dominante, y el Ecotipo II (Proteo-Actinobacteria) con las Proteobacterias dominantes Escherichia/Shigella y Aeromonas y la Actinobacteria Mycobacterium que ocupa el nicho principal. 


\section{BIBLIOGRAFÍA}




\section{BIBLIOGRAFÍA}

Abdel-Tawwab, M., Hagras, A. E., Elbaghdady, H. A. M., \& Monier, M. N. (2015). Effects of dissolved oxygen and fish size on Nile tilapia, Oreochromis niloticus (L.): growthperformance, whole-body composition, and innate immunity. Aquaculture international, 23(5), 1261-1274. (https://doi.org/10.1007/s10499-015-9882-y)

Abdel-Tawwab, M., \& Ahmad, M. H. (2009). Live Spirulina (Arthrospira platensis) as a growth and immunity promoter for Nile tilapia, Oreochromis niloticus (L.), challenged with pathogenic Aeromonas hydrophila. Aquaculture Research, 40(9), 1037-1046. (https://doi.org/10.1111/j.1365-2109.2009.02195.x)

Abdulqader, G., Barsanti, L., \& Tredici, M. R. (2000). Harvest of Arthrospira platensis from Lake Kossorom (Chad) and its household usage among the Kanembu. Journal of Applied Phycology, 12(3-5), 493-498. (https://doi.org/10.1023/A:1008177925799)

Adel, M., Yeganeh, S., Dadar, M., Sakai, M., \& Dawood, M. A. (2016). Effects of dietary Spirulina platensis on growth performance, humoral and mucosal immune responses and disease resistance in juvenile great sturgeon (Huso huso Linnaeus, 1754). Fish \& shellfish immunology, 56, 436-444.(https://doi.org/10.1016/j.fsi.2016.08.003)

Al-Batshan, H. A.; Al-Mufarrej, S. I.; Al-Homaidan, A. A.; Qureshi, M. A., 2001: Enhancement of chicken macrophage phagocytic function and nitrite production by dietary Spirulina platensis. Immunopharmacology and Immunotoxicology 23, 281-289. (https://doi.org/10.1081/IPH-100103866)

Anderson, D. W., Tang, C. S., \& Ross, E. (1991). The xanthophylls of Spirulina and their effect on egg yolk pigmentation. Poultry Science, 70(1), 115-119. (https://doi.org/10.3382/ps.0700115)

Anzola, B., Ibanez, M., Morillas, S., Benedetti, R., Perez, J., \& Farias, D. (2013). The Use of Tryptophan in Shelter Dogs to Treat Stress-related Anxiety Disorders. Revista cientificafacultad de ciencias veterinarias, 23(1), 26-32.

Bacha, F. (2015). Las algas en la alimentación animal rumiantes. NutriNews.No 2015. 119.

Bäckhed, F., Ding, H., Wang, T., Hooper, L. V., Koh, G. Y., Nagy, A., ...\& Gordon, J. I. (2004). The gut microbiota as an environmental factor that regulates fat storage. Proceedings of the National Academy of Sciences of the United States of America, 101(44), 15718-15723. (https://doi.org/10.1073/pnas.0407076101)

Baker, R. T. M., Pfeiffer, A. M., Schöner, F. J., \& Smith-Lemmon, L. (2002). Pigmenting efficacy of astaxanthin and canthaxanthin in fresh-water reared Atlantic salmon, Salmo salar. Animal Feed Science and Technology, 99(1-4), 97-106. (https://doi.org/10.1016/S03778401(02)00116-5)

Banaee, M., Sureda, A., Mirvaghefi, A. R., \& Ahmadi, K. (2011). Effects of diazinon on biochemical parameters of blood in rainbow trout (Oncorhynchus mykiss). Pesticide Biochemistry and Physiology, 99(1), 1-6. (https://doi.org/10.1016/j.pestbp.2010.09.001)

Barandica, C. L. M., \& Tort, L. (2008). Neuroendocrinología e inmunología de la respuesta al estrés en peces. Revista de la Academia Colombiana de Ciencias, 32(123), 267-284. 
Barcellos, L. J., Nicolaiewsky, S., De Souza, S. M., \& Lulhier, F. (1999). The effects of stocking density and social interaction on acute stress response in Nile tilapia Oreochromis niloticus (L.) fingerlings. Aquaculture Research, 30(11-12), 7 -892. (https://doi.org/10.1046/j.1365-2109.1999.00419.x)

Barreto, R. E., \& Volpato, G. L. (2011). Ventilation rates indicate stress-coping styles in Nile tilapia. Journal of Biosciences, 36(5), 851-855. (https://doi.org/10.1007/s12038-011-91114)

Barry, T. P., Lapp, A. F., Kayes, T. B., \& Malison, J. A. (1993). Validation of a microtitre plate ELISA for measuring cortisol in fish and comparison of stress responses of rainbow trout (Oncorhynchus mykiss) and lake trout (Salvelinus namaycush). Aquaculture, 117(3-4), 351-363. (https://doi.org/10.1016/0044-8486(93)90331-R)

Barton, B. A. (2011). Stress in finfish: Past, present and future-a historical perspective (pp. 1-34). Cambridge, UK: Cambridge University Press. (PMCid:PMC4781257) .

Barton, B. A., \& Iwama, G. K. (1991). Physiological changes in fish from stress in aquaculture with emphasis on the response and effects of corticosteroids. Annual Review of Fish Diseases, 1, 3-26. (https://doi.org/10.1016/0959-8030(91)90019-G)

Belal, E. B., \& El-Hais, A. M. A. (2012). Use of spirulina (Arthrospira fusiformis) for promoting growth of Nile Tilapia fingerlings. African Journal of Microbiology Research, 6(35), 64236431. (https://doi.org/10.5897/AJMR12.288)

Belay, A., \& Gershwin, M. E. (2007). Spirulina (Arthrospira). In Spirulina in Human Nutrition and Health (pp. 11-35). CRC Press. (https://doi.org/10.1201/9781420052572)

Bennett, P. M., Weber, L. P., \& Janz, D. M. (2007). Comparison of Chloroform-MethanolExtracted and Solvent-Free Triglyceride Determinations in Four Fish Species.Journal of aquatic animal health, 19(3), 179-185. (https://doi.org/10.1577/H06-044.1)

Bermejo-Poza, R., De la Fuente, J., Pérez, C., Lauzurica, S., González, E., Diaz, M. T., \& Villarroel, M. (2015). The effect of intermittent feeding on the pre-slaughter fasting response in rainbow trout. Aquaculture, 443, 24-30. (https://doi.org/10.1016/j.aquaculture.2015.03.007)

Berrios-Hernandez, J. M., \& Snow, J. R. (1983). Comparison of methods for reducing fry losses to cannibalism in Tilapia production [Freshwater food fishes, predation, Cichlidae]. The Progressive fish culturist-United States, Fish and Wildlife Service (USA). (https://doi.org/10.1577/1548-8659(1983)45[116:COMFRF]2.0.CO;2)

Beveridge, M. C. M., \& Baird, D. J. (2000). Diet, feeding and digestive physiology. In Tilapias: Biology and exploitation (pp. 59-87). Springer, Dordrecht. (https://doi.org/10.1007/97894-011-4008-9_3)

Bezerra, L. R., Silva, A. M. A., Azevedo, S. A., Mendes, R. S., Mangueira, J. M., \& Gomes, A. K. A. (2010). Performance of Santa Inês lambs submitted to the use of artificial milk enriched with Spirulina platensis. Ciência Animal Brasileira, 11(2), 258-263.

BOE (2013). Real Decreto 53/2013, de 1 de febrero, por el que se establecen las normas básicas aplicables para la protección de los animales utilizados en experimentación y otros fines científicos, incluyendo la docencia. BOE, 34, 11370-11421. 
Boeckaert, C., Vlaeminck, B., Dijkstra, J., Issa-Zacharia, A., Van Nespen, T., Van Straalen, W., \& Fievez, V. (2008). Effect of dietary starch or micro algae supplementation on rumen fermentation and milk fatty acid composition of dairy cows. Journal of Dairy Science, 91(12), 4714-4727. (https://doi.org/10.3168/jds.2008-1178)

Broom, D. M. (1986). Indicators of poor welfare. British veterinary journal, 142(6), 524-526. (https://doi.org/10.1016/0007-1935(86)90109-0)

Boonyaratpalin, M., \& Unprasert, N. (1989). Effects of pigments from different sources on colour changes and growth of red Oreochromis niloticus. Aquaculture, 79(1-4), 375-380.

Carvalho, T. B., Mendonça, F. Z., Costa-Ferreira, R. S., \& Gonçalves-de-Freitas, E. (2013). The effect of increased light intensity on the aggressive behavior of the Nile tilapia, Oreochromis niloticus (Teleostei: Cichlidae). Zoologia (Curitiba), 30(2), 125-129.

Cerezuela, R., Cuesta, A., Meseguer, J., \& Esteban, M. Á. (2008). Effects of inulin on gilthead seabream (Sparus aurata L.) innate immune parameters. Fish \& Shellfish Immunology, 24(5), 663-668. (https://doi.org/10.1016/j.fsi.2007.10.002)

Chamorro, G., \& Salazar-Jacobo, M. (1995). Toxicología de la Spirulina. Tecnología de alimentos, $30,13-14$.

Chamorro, G., Salazar, M., Gomes de Lima Araújo, K., Pereira dos Santos, C., Ceballos, G., \& Fabila Castillo, L. (2002). Actualización en la farmacología de Spirulina (Arthrospira), un alimento no convencional. Archivos Latinoamericanos de Nutrición, 52(3), 232-240.

Chao, A., \& Lee, S. M. (1992). Estimating the number of classes via sample coverage. Journal of the American statistical Association, 87(417), 210-217. (https://doi.org/10.1080/01621459.1992.10475194)

Christaki, E., Karatzia, M., Bonos, E., Florou-Paneri, P., \& Karatzias, C. (2012). Effect of dietary Spirulina platensis on milk fatty acid profile of dairy cows. Asian J. Anim. Vet. Adv, 7, 597-604. (https://doi.org/10.3923/ajava.2012.597.604)

Ciferri, O. (1983). Spirulina, the edible microorganism. Microbiological Reviews, 47(4), 551.

Cohen (2014). The chemicals of Spirulina.In Vonshak, A. (Ed.). (2014). Spirulina platensis arthrospira: physiology, cell-biology and biotechnology. CRC Press.

Conte, F. S. (2004). Stress and the welfare of cultured fish. Applied Animal Behaviour Science, 86(3), 205-223. (https://doi.org/10.1016/j.applanim.2004.02.003)

Curtis, S. E. (1985). What constitutes animal well-being? In Animal stress (pp. 1-14). Springer, New York, NY. (https://doi.org/10.1007/978-1-4614-7544-6_1)

Dale, N. M., Zumbado, M., Gernat, A. G., \& Romo, G. (2004). Nutrient value of tilapia meal. Journal of applied poultry research, 13(3), 370-372. (https://doi.org/10.1093/japr/13.3.370)

Dallaire, V., Lessard, P., Vandenberg, G., \& de la Noüe, J. (2007). Effect of algal incorporation on growth, survival and carcass composition of rainbow trout (Oncorhynchus mykiss) fry. Bioresource Technology, 98(7), 1433-1439.

Dantzer, R., \& Mormède, P. (1983). Stress in farm animals: a need for reevaluation. Journal of Animal Science, 57(1), 6-18. (https://doi.org/10.2527/jas1983.5716) 
Davis, M. W. (2010). Fish stress and mortality can be predicted using reflex impairment. Fish and Fisheries, 11(1), 1-11. (https://doi.org/10.1111/j.1467-2979.2009.00331.x)

de Jesus Raposo, M. F., de Morais, A. M. M. B., \& de Morais, R. M. S. C. (2016). Emergent sources of prebiotics: seaweeds and microalgae. Marine Drugs, 14(2), 27. (https://doi.org/10.3390/md14020027)

Dehler, C. E., Secombes, C. J., \& Martin, S. A. (2017). Environmental and physiological factors shape the gut microbiota of Atlantic salmon parr (Salmo salar L.). Aquaculture, 467, 149157. (https://doi.org/10.1016/j.aquaculture.2016.07.017)

Delarue, J. O. C. P., Matzinger, O., Binnert, C., Schneiter, P., Chiolero, R., \& Tappy, L. (2003). Fish oil prevents the adrenal activation elicited by mental stress in healthy men. Diabetes \& metabolism, 29(3), 289-295. (https://doi.org/10.1016/S1262-3636(07)70039-3)

Delbon, M. C. E., \& Paiva, M. J. T. R. (2012). Eugenol em juvenis de tilápia do Nilo: concentrações e administrações sucessivas. Boletim do Instituto de Pesca, 38(1), 43-52.

Dhaneshwar, S., Tewari, K., Joshi, S., Godbole, D., \& Ghosh, P. (2011). Diglyceride prodrug strategy for enhancing the bioavailability of norfloxacin. Chemistry and physics of lipids, 164(4), 307-313. (https://doi.org/10.1016/j.chemphyslip.2011.03.006)

EC, 2003.Regulation $N^{0} 1831 / 2003$ of the European Parliament and of the council of 22 September 2003 on additives for use in animal nutrient. Official Journal of the European Union, 43. [Lex - 32003R183]

El-Haroun, E. R., Goda, A. S., \& Chowdhury, K. (2006). Effect of dietary probiotic Biogen ${ }^{\circledR}$ supplementation as a growth promoter on growth performance and feed utilization of Nile tilapia Oreochromis niloticus (L.). Aquaculture Research, 37(14), 1473-1480. (https://doi.org/10.1111/j.1365-2109.2006.01584.x)

EL-Khaldi, A. T. (2010). Effect of different stress factors on some physiological parameters of Nile tilapia (Oreochromis niloticus). Saudi journal of biological sciences, 17(3), 241-246. (https://doi.org/10.1016/j.sjbs.2010.04.009)

Ellis, T., James, J. D., Stewart, C., \& Scott, . P. (2004). non-invasive stress assay based upon measurement of free cortisol released into the water by rainbow trout. Journal of Fish Biology, 65(5), 1233-1252. (https://doi.org/10.1111/j.0022-1112.2004.00499.x)

El-Sheekh, M., El-Shourbagy, I., Shalaby, S., \& Hosny, S. (2014). Effect of Feeding Arthrospira platensis (Spirulina) on Growth and Carcass Composition of Hybrid Red Tilapia (Oreochromis niloticus $x$ Oreochromis mossambicus). Turkish Journal of Fisheries and Aquatic Sciences, 14(2), 471-478. (https://doi.org/10.4194/1303-2712-v14_2_18)

Evans, F. D., \& Critchley, A. T. (2014). Seaweeds for animal production use. Journal of applied phycology, 26(2), 891-899. (https://doi.org/10.1007/s10811-013-0162-9)

Fan, L., Chen, J., Meng, S., Song, C., Qiu, L., Hu, G., \& Xu, P. (2017). Characterization of microbial communities in intensive GIFT tilapia (Oreochromis niloticus) pond systems during the peak period of breeding. Aquaculture Research, 48(2), 459-472. (https://doi.org/10.1111/are.12894)

FAO, 2016. El estado mundial de la pesca y la acuicultura. 2016. Contribución a la seguridad alimentaria y la nutrición para todos. Roma. 224 pp. 
Fernández-Cárdenas, T., González-San Miguel, H. V., \& Travieso, L. (2001). Determinación de vitaminas del Complejo B en Arthrospira maxima por cromatografía líquida de alta resolución.

Fitzsimmons, K. (1997). Introduction to tilapia nutrition. In Tilapia aquaculture. The International Symposium on Tilapia in aquaculture. ICLARM Conferences Proceedings, Florida (pp. 912).

Fletcher, T. C. (1997). Dietary effects on stress and health. Fish stress and health in aquaculture, 62, 223-246.

Fortes-Silva, R., Martínez, F. J., Villarroel, M., \& Sánchez-Vázquez, F. J. (2010). Daily rhythms of locomotor activity, feeding behavior and dietary selection in Nile tilapia (Oreochromis niloticus). Comparative Biochemistry and Physiology Part A: Molecular \& Integrative Physiology, 156(4), 445-450. (https://doi.org/10.1016/j.cbpa.2010.03.031)

Fraser, D., Weary, D. M., Pajor, E. A., \& Milligan, B. N. (1997). A scientific conception of animal welfare that reflects ethical concerns.

Gaggìa, F., Mattarelli, P., \& Biavati, B. (2010). Probiotics and prebiotics in animal feeding for safe food production. International journal of food microbiology, 141, S15-S28. (https://doi.org/10.1016/j.ijfoodmicro.2010.02.031)

Gaikwad, S. S., Shouche, Y. S., \& Gade, W. N. (2017). Deep Sequencing Reveals Highly Variable Gut Microbial Composition of Invasive Fish Mossambicus Tilapia (Oreochromis mossambicus) Collected from Two Different Habitats. Indian Journal of Microbiology, 57(2), 235-240. (https://doi.org/10.1007/s12088-017-0641-9)

Gajardo, K., Rodiles, A., Kortner, T. M., Krogdahl, Å., Bakke, A. M., Merrifield, D. L., \& Sørum, H. (2016). A high-resolution map of the gut microbiota in Atlantic salmon (Salmo salar): A basis for comparative gut microbial research. Scientific Reports, 6, 30893. (https://doi.org/10.1038/srep30893)

Garcia, A., Tume, J., \& Juárez, V. (2012). Determinación de los parámetros de crecimiento de la Tilapia Nilótica (Orechromis niloticus) en un estanque revestido con geomembrana y abastecido con agua de subsuelo. Ciencia y Desarrollo, 15(2), 47-55. (https://doi.org/10.21503/cyd.v15i2.1127)

Giatsis, C., Sipkema, D., Smidt, H., Heilig, H., Benvenuti, G., Verreth, J., \& Verdegem, M. (2015). The impact of rearing environment on the development of gut microbiota in tilapia larvae.Scientific reports, 5, 18206. (https://doi.org/10.1038/srep18206)

Giatsis, C., Sipkema, D., Smidt, H., Verreth, J., \& Verdegem, M. (2014). The colonization dynamics of the gut microbiota in tilapia larvae. PLoS One, 9(7), e103641. (https://doi.org/10.1371/journal.pone.0103641)

Gitelson, A., Qiuang, H., \& Richmond, A. (1996). Photic Volume in Photobioreactors Supporting Ultrahigh Population Densities of the Photoautotroph Spirulina platensis. Applied and Environmental Microbiology, 62(5), 1570-1573.

Gomes, I. G., Chaves, F. H., Barros, R. N., Moreira, R. L., Teixeira, E. G., Moreira, A. G., \& Farias, W. R. (2012). Dietary supplementation with Spirulina platensis increases growth and color of red tilapia. Revista Colombiana de Ciencias Pecuarias, 25(3), 462-471. 
Gouveia, L., Batista, A. P., Raymundo, A., \& Bandarra, N. M. (2008). Microalgae in novel food products. Food Chemistry Research Developments, 75-112.

Granaci, V. (2007). Achievements in the artificial insemination of swine. Bulletin of 360 University of Agricultural Sciences and Veterinary Medicine Cluj-Napoca. Animal 361 Science and Biotechnologies 63/64, 382-386.

Granados, A. I., Garduño, M., \& Muñoz, C. (2002). Comparación de crecimiento y evaluación económica entre el genotipo de tilapia gris (Oreochromis niloticus) y el híbrido rojo (Oreochromis mossambicus x O. niloticus). Recuperada de http://www. ecologia. edu. $\mathrm{mx} / \mathrm{sigolfo} /$ pagina_n2. htm.

Green Bartholomew, W. (1995). Polyculture of Tilapia with marine shrimp. Department of Fisheries and allied aquacultures. Alabama USA. In Acta del primer simposio centroamericano sobre cultivo de tilapia (pp. 117-127).

Grigorakis, K. (2007). Compositional and organoleptic quality of farmed and wild gilthead sea bream (Sparus aurata) and sea bass (Dicentrarchus labrax) and factors affecting it: A review. Aquaculture, 272(1-4), 55-75. (https://doi.org/10.1016/j.aquaculture.2007.04.062)

Grinstead, G. S., Tokach, M. D., Dritz, S. S., Goodband, R. D., \& Nelssen, J. L. (2000). Effects of Spirulina platensis on growth performance of weanling pigs. Animal Feed Science and Technology, 83(3-4), 237-247. (https://doi.org/10.1016/S0377-8401(99)00130-3)

Grisdale-Helland, B., Helland, S. J., \& Gatlin III, D. M. (2008). The effects of dietary supplementation with mannanoligosaccharide, fructooligosaccharide or galactooligosaccharide on the growth and feed utilization of Atlantic salmon (Salmo salar). Aquaculture, 283(1-4), 163-167. (https://doi.org/10.1016/j.aquaculture.2008.07.012)

G r oy, B., Şahin, İ., Mantoğlu, S., \& Kayalı, S. (2012). Spirulina as a natural carotenoid source on growth, pigmentation and reproductive performance of yellow tail cichlid Pseudotropheus acei. Aquaculture International, 20(5), 869-878.

Hammer, Ø., Harper, D. A. T., \& Ryan, P. D. (2001). Paleontological statistics software: package for education and data analysis. Palaeontologia Electronica, (4) 9.

Haygood, A. M., \& Jha, R. (2016). Strategies to modulate the intestinal microbiota of Tilapia (Oreochromis sp.) in aquaculture: a review. Reviews in Aquaculture. (https://doi.org/10.1111/raq.12162)

Henrikson, R. (1989). Earth food spirulina. Laguna Beach, CA: Ronore Enterprises, Inc, 187.

Henrique, M. M. F., Gomes, E. F., Gouillou-Coustans, M. F., Oliva-Teles, A., \& Davies, S. J. (1998). Influence of supplementation of practical diets with vitamin $C$ on growth and response to hypoxic stress of seabream, Sparus aurata. Aquaculture, 161(1-4), 415-426. (https://doi.org/10.1111/j.1095-8649.2002.tb00292.x)

Hsieh, C. W., Lai, C. H., Lee, C. H., \&Ko, W. C. (2011). Effects of High-Voltage Electrostatic Fields on the Quality of Tilapia Meat during Refrigeration. Journal of food science, 76(6). (https://doi.org/10.1111/j.1750-3841.2011.02218.x)

Hugh, W. I. (1985). Evaluation of dehydrated spirulina (Spirulina platensis) as a protein replacement in swine starter diets (No. 04; USDA, FOLLETO 3093.). 
Huntingford, F. A., Adams, C., Braithwaite, V. A., Kadri, S., Pottinger, T. G., Sandøe, P., \& Turnbull, J. F. (2006).Current issues in fish welfare.Journal of fish biology, 68(2), 332372.(https://doi.org/10.1111/j.0022-1112.2006.001046.x)

Hussain, M. G., Rao, G. P. S., Humayun, N. M., Randall, C. F., Penman, D. J., Kime, D., ...\& McAndrew, B. J. (1995). Comparative performance of growth, biochemical composition and endocrine profiles in diploid and triploid tilapia Oreochromis niloticus L. Aquaculture, 138(1-4), 87-97. (https://doi.org/10.1016/0044-8486(95)01079-3)

Huyben, D., Nyman, ., Vidaković, ., Passoth, V., Moccia, R., Kiessling, ., \& Lundh, T. (2017). Effects of dietary inclusion of the yeasts Saccharomyces cerevisiae and Wickerhamomyces anomalus on gut microbiota of rainbow trout. Aquaculture, 473, 528-537. (https://doi.org/10.1016/j.aquaculture.2017.03.024)

I.I.M.S.A.M. (2012). The Intergovernmental Institution for the Use of Micro-algae Spirulina sp. Against Malnutrition. Disponible en: http//www.iimsamSpirulina sp. pLEDge. org/isp/nutritionalbenefits.aspx\#

Ibrahem, M. D., Mohamed, M. F., \& Ibrahim, M. A. (2013).The role of Spirulina platensis (Arthrospira platensis) in growth and immunity of Nile tilapia (Oreochromis niloticus) and its resistance to bacterial infection. Journal of Agricultural Science, 5(6), 109. (https://doi.org/10.5539/jas.v5n6p109)

Iwata, K., Inayama, T., \& Kato, T. (1990). Effects of Spirulina platensis on plasma lipoprotein lipase activity in fructose-induced hyperlipidemic rats. Journal of Nutritional Science and Vitaminology, 36(2), 165-171. (https://doi.org/10.3177/jnsv.36.165)

James, R., Sampath, K., Thangarathinam, R., Vasudevan, I., (2006). Effects of dietary spirulina level on growth, fertility, coloration and leucocyte count in red swordtail, Xiphophorus helleri. Israeli Journal of Aquaculture-Bamidgeh 58 (2), 97-104.

Kaoud, H. A. (2015). Effect of Spirulina platensis as a dietary supplement on broiler performance in comparison with prebiotics Scientific Journal of Applied Research, 1: 44-48.

Karadal, O., Güroy, D., \& Türkmen, G. (2017). Effects of feeding frequency and Spirulina on growth performance, skin coloration and seed production on kenyi cichlids (Maylandia lombardoi). Aquaculture International, 25(1), 121-134. (https://doi.org/10.1007/s10499016-0017-x)

Khanzadeh, M., Fereidouni, A. E., \& Berenjestanaki, S. S. (2016). Effects of partial replacement of fish meal with Spirulina platensis meal in practical diets on growth, survival, body composition, and reproductive performance of three-spot gourami (Trichopodus trichopterus) (Pallas, 1770). Aquaculture International, 24(1), 69-84. (https://doi.org/10.1007/s10499-015-9909-4)

Kim, S. S., Rahimnejad, S., Kim, K. W., \& Lee, K. J. (2013). Partial replacement of fish meal with Spirulina pacifica in diets for parrot fish (Oplegnathus fasciatus). Turkish Journal of Fisheries and Aquatic Sciences, 13(2).

Koh, C. B., Romano, N., Zahrah, A. S., \& Ng, W. K. (2016). Effects of a dietary organic acids blend and oxytetracycline on the growth, nutrient utilization and total cultivable gut microbiota of the red hybrid tilapia, Oreochromis sp., and resistance to Streptococcus agalactiae. Aquaculture Research, 47(2), 357-369. (https://doi.org/10.1111/are.12492) 
Korhonen, R. W., Lanier, T. C., \& Giesbrecht, F. (1990). An evaluation of simple methods for following rigor development in fish. Journal of Food Science, 55(2), 346-348. (https://doi.org/10.1111/j.1365-2621.1990.tb06759.x)

Kulpys, J., Paulauskas, E., Pilipavicius, V., \& Stankevicius, R. (2009). Influence of cyanobacteria Arthrospira (Spirulina) platensis biomass additive towards the body condition of lactation cows and biochemical milk indexes. Agronomy Research, 7, 823-835.

Lantz, P. G., Matsson, M., Wadström, T., \& Rådström, P. (1997). Removal of PCR inhibitors from human faecal samples through the use of an aqueous two-phase system for sample preparation prior to PCR. Journal of Microbiological Methods, 28(3), 159-167. (https://doi.org/10.1016/S0167-7012(97)00979-2)

Laursen, D. C., Olsén, H. L., de Lourdes Ruiz-Gomez, M., Winberg, S., \& Höglund, E. (2011). Behavioural responses to hypoxia provide a non-invasive method for distinguishing between stress coping styles in fish. Applied Animal Behaviour Science, 132(3), 211-216. (https://doi.org/10.1016/j.applanim.2011.03.011)

Leal, B. E. S., Prado, M. R., Grzybowski, A., Tiboni, M., Koop, H. S., Scremin, L. B., ...\& Fontana, J. D. (2017). Potential prebiotic oligosaccharides from aqueous thermopressurized phosphoric acid hydrolysates of microalgae used in treatment of gaseous steakhouse waste. Algal Research, 24, 138-147. (https://doi.org/10.1016/j.algal.2017.03.020)

Liu, W., Yang, Y., Zhang, J., Gatlin, D. M., Ringø, E., \& Zhou, Z. (2014). Effects of dietary microencapsulated sodium butyrate on growth, intestinal mucosal morphology, immune response and adhesive bacteria in juvenile common carp (Cyprinus carpio) pre-fed with or without oxidised oil. British Journal of Nutrition, 112(1), 15-29.

(https://doi.org/10.1017/S0007114514000610)

López-Luna, J., Bermejo-Poza, R., Bravo, F. T., \& Villarroel, M. (2016). Effect of degree-days of fasting stress on rainbow trout, K. Aquaculture, 462, 109-114. (https://doi.org/10.1016/j.aquaculture.2016.05.017)

Lu, J., Takeuchi, T., \& Ogawa, H. (2003). Flesh quality of tilapia Oreochromis niloticus fed solely on raw Spirulina. Fisheries Science, 69(3), 529-534. (https://doi.org/10.1046/j.14442906.2003.00653.x)

Liu, J. G., Hou, C. W., Lee, S. Y., Chuang, Y., \& Lin, C. C. (2011). Antioxidant effects and UVB protective activity of Spirulina (Arthrospira platensis) products fermented with lactic acid bacteria. Process Biochemistry, 46(7), 1405-1410.

Lyons, P. P., Turnbull, J. F., Dawson, K. A., \& Crumlish, M. (2017). Effects of low-level dietary microalgae supplementation on the distal intestinal microbiome of farmed rainbow trout Oncorhynchus mykiss (Walbaum). Aquaculture Research, 48(5), 2438-2452. (https://doi.org/10.1111/are.13080)

Mancera, J. M., \& del Río, M. D. P. M. (2002). El sistema de estrés en peces teleósteos. Encuentros en la Biología, (78), 3.

Masser, M. P., Rakocy, J., \& Losordo, T. M. (2000). Recirculating aquaculture tank production systems. Southern Regional Aquaculture Center.

Maximino, C., Marques, T., Dias, F., Cortes, F. V., Taccolini, I. B., Pereira, P. M., ... \& Valéria, S. (2007). A comparative analysis of the preference for dark environments in five teleosts. International Journal of Comparative Psychology, 20(4). 
Maza, L. R., Guevara, M., Arredondo-Vega, B., Gómez, B., Licett, B., \& Freites, L. (2011). Contenido de lípidos, ácidos grasos, exopolisacáridos y minerales de Arthrospira maxima cultivada en fotobiorreactores1. Agronomía Tropical, 61(3-4), 231-240.

McCarty, M. F. (2007). Clinical potential of Spirulina as a source of phycocyanobilin. Journal of Medicinal Food, 10(4), 566-570. (https://doi.org/10.1089/jmf.2007.621)

Mendl, M. (2001). Animal husbandry: assessing the welfare state. Nature, 410(6824), 31. (https://doi.org/10.1038/35065194)

Merrifield, D. L., \&Ringo, E. (Eds.). (2014). Aquaculture nutrition: gut health, probiotics and prebiotics. John Wiley \& Sons. (https://doi.org/10.1002/9781118897263)

Meyer, D. (2004). Introducción a la Acuacultura. Mimeo. Zamorano, Honduras: Panamerican Agriculture School.

Meyer, J. L., Sale, M. J., Mulholland, P. J., \& Poff, N. L. (1999). Impacts of climate change on aquatic ecosystem functioning and health. JAWRA Journal of the American Water Resources Association, 35(6), 1373-1386. (https://doi.org/10.1111/j.17521688.1999.tb04222.x)

Michl, S. C., Ratten, J. M., Beyer, M., Hasler, M., LaRoche, J., \& Schulz, C. (2017). The malleable gut microbiome of juvenile rainbow trout (Oncorhynchus mykiss): Diet-dependent shifts of bacterial community structures. PloS One, 12(5), e0177735. (https://doi.org/10.1371/journal.pone.0177735)

Mommsen, T. P., Vijayan, M. M., \& Moon, T. W. (1999). Cortisol in teleosts: dynamics, mechanisms of action, and metabolic regulation. Reviews in Fish Biology and Fisheries, 9(3), 211-268. (https://doi.org/10.1023/A:1008924418720)

Montero, D., Robaina, L. E., Socorro, J., Vergara, J. M., Tort, L., \& Izquierdo, M. S. (2001). Alteration of liver and muscle fatty acid composition in gilthead seabream (Sparus aurata) juveniles held at high stocking density and fed an essential fatty acid deficient diet. Fish Physiology and Biochemistry, 24(1), 63-72. (https://doi.org/10.1023/A:1011145426543)

Moriarty, C. M., \& Moriarty, D. J. W. (1973). Quantitative estimation of the daily ingestion of phytoplankton by Tilapia nilotica and Halochromic nigripinnis in Lake George, Uganda. Journal of Zoology, 171(1), 15-23. (https://doi.org/10.1111/j.1469-7998.1973.tb07513.x)

Mosenthin, R., \& Bauer, E. (2000). The potential use of prebiotics in pig nutrition. AsianAustralasian Journal of Animal Sciences, 13(Special iss.), 315-325.

Nandeesha, M. C., Gangadhara, B., Manissery, J. K., \& Venkataraman, L. V. (2001). Growth performance of two Indian major carps, catla (Catla catla) and rohu (Labeo rohita) fed diets containing different levels of Spirulina platensis. Bioresource Technology, 80(2), 117-120. (https://doi.org/10.1016/S0960-8524(01)00085-2)

Nuhu, A. A. (2013). Spirulina (Arthrospira): An important source of nutritional and medicinal compounds. Journal of Marine Biology, 2013. (http://dx.doi.org/10.1155/2013/325636)

O’Sullivan, L., Murphy, B., McLoughlin, P., Duggan, P., Lawlor, P. G., Hughes, H., \& Gardiner, G. E. (2010). Prebiotics from marine macroalgae for human and animal health applications. Marine Drugs, 8(7), 2038-2064. (https://doi.org/10.3390/md8072038) 
O'Hara, A. M., \& Shanahan, F. (2006). The gut flora as a forgotten organ. EMBO reports, 7(7), 688-693. (https://doi.org/10.1038/sj.embor.7400731)

Oliveira Filho, P. R. C., Oliveira, C. A. F., Sobral, P. J. A., Balieiro, J. C. C., Natori, M. M., \& Viegas, E. M. M. (2015). How Stunning methods affect the quality of Nile tilapia meat. CyTA-Journal of Food, 13(1), 56-62. (https://doi.org/10.1080/19476337.2014.911211)

Ortuno, J., Esteban, M. A., \& Meseguer, J. (2003). The effect of dietary intake of vitamins C and $\mathrm{E}$ on the stress response of gilthead seabream (Sparus aurata L.). Fish \& Shellfish Immunology, 14(2), 145-156. (https://doi.org/10.1006/fsim.2002.0428)

Paniagua-Michael, J., Dujardin, E., \& Sironval, C. (2004). Crónica Azteca: El tecuitlatl, concentrado de algas espirulinas fuente de proteínas comestibles del pueblo de los Aztecas.

Panjaitan, T., Quigley, S. P., McLennan, S. R., \& Poppi, D. P. (2010). Effect of the concentration of Spirulina (Spirulina platensis) algae in the drinking water on water intake by cattle and the proportion of algae bypassing the rumen. Animal Production Science, 50(6), 405-409. (https://doi.org/10.1071/AN09194)

Patterson, J. A., \& Burkholder, K. M. (2003). Application of prebiotics and probiotics in poultry production. Poultry Science, 82(4), 627-631. (https://doi.org/10.1093/ps/82.4.627)

Pedrotti, F. S., Davies, S., Merrifield, D. L., Marques, M. R. F., Fraga, A. P. M., Mouriño, J. L. P., \&Fracalossi, D. M. (2015). The autochthonous microbiota of the freshwater omnivores jundiá (Rhamdia quelen) and tilapia (Oreochromis niloticus) and the effect of dietary carbohydrates. Aquaculture Research, 46(2), 472-481. (https://doi.org/10.1111/are.12195)

Peiretti, P. G., \& Meineri, G. (2008). Effects of diets with increasing levels of Spirulina platensis on the performance and apparent digestibility in growing rabbits. Livestock Science, 118(1), 173-177. (https://doi.org/10.1016/j.livsci.2008.04.017)

Peiretti, P. G., \& Meineri, G. (2011). Effects of diets with increasing levels of Spirulina platensis on the carcass characteristics, meat quality and fatty acid composition of growing rabbits. Livestock Science, 140(1), 218-224. (https://doi.org/10.1016/j.livsci.2011.03.031)

Penninks, A., Baert, K., Levorato, S., \& Binaglia, M. (2017). Dyes used in aquaculture. EFSA Journal, 15(7).

Phang, S. M., Miah, M. S., Yeoh, B. G., \& Hashim, M. A. (2000). Spirulina cultivation in digested sago starch factory wastewater. Journal of Applied Phycology, 12(3-5), 395-400. (https://doi.org/10.1023/A:1008157731731)

Pickering, A. D. (1998). Stress responses of farmed fish. Biology of Farmed Fish, 222-255.

Pickering, A. D., \& Christie, P. (1981). Changes in the concentrations of plasma cortisol and thyroxine during sexual maturation of the hatchery-reared brown trout, Salmo trutta L. General and Comparative Endocrinology, 44(4), 487-496. (https://doi.org/10.1016/S18730140(06)80043-3)

Pickering, A. D., \& Pottinger, T. G. (1995). Biochemical effects of stress. In Biochemistry and molecular biology of fishes (Vol. 5, pp. 349-379). Elsevier. (https://doi.org/10.1016/S1873-0140(06)80043-3) 
Pignolet, O., Jubeau, S., Vaca-Garcia, C., \& Michaud, P. (2013). Highly valuable microalgae: biochemical and topological aspects. Journal of Industrial Microbiology \& Biotechnology, 40(8), 781-796. (https://doi.org/10.1007/s10295-013-1281-7)

Pókniak, J. (2007). Incorporación de Espirulina (Spirulina Maxima) en dietas para alevines de truchas arco iris (Oncorhynchus Mykiss). Avances en Ciencias Veterinarias, 22(1-2). (Doi:10.5354/0719-5273.2010.911).

Poli, B. (2009). Farmed fish welfare-suffering assessment and impact on product quality. Italian Journal of Animal Science, 8(sup1), 139-160. (https://doi.org/10.4081/ijas.2009.s1.139)

Pottinger, T. G., \& Carrick, T. R. (1999). Modification of the plasma cortisol response to stress in rainbow trout by selective breeding. General and comparative endocrinology, 116(1), 122132. (https://doi.org/10.1006/gcen.1999.7355)

Powers, D. A. (1980). Molecular ecology of teleost fish hemoglobins: strategies for adapting to changing environments. American Zoologist, 139-162. (https://doi.org/10.1093/icb/20.1.139)

Quevedo, H. J. M., Quintana, M., Almares, A., \& Hernández, L. (1999). Composición bioquímica y evaluación de la calidad proteica de la biomasa autotrófica de la Chlorella vulgaris. Revista Cubana de Alimentación y Nutrición. 13, 123-128.

Quigley, S. P., Poppi, D. P., \& McLennan, S. R. (2009). Strategies to increase growth of weaned Bali calves. Australian Centre for International Agricultural Research, Canberra. 1-90

R Core Team, 2013. R: A language and environment for statistical computing. Vienna: R Foundation for Statistical Computing. Available at www.r-project.org. [21 September 2013].

Ramakrishnan, C. M., Haniffa, M. A., Manohar, M., Dhanaraj, M., Arockiaraj, A. J., \& Arunsingh, S. V. (2008). Effects of probiotics and spirulina on survival and growth of juvenile common carp (Cyprinus carpio). Israeli Journal of Aquaculture Bamidgeh (http://hdl.handle.net/10524/19247)

Ramírez, L., \& Olvera, R. (2006). Conocimiento acerca del alga Spirulina (Arthrospira). Interciencia, 31(9), 1-5.

Ran, C., Huang, L., Hu, J., Tacon, P., He, S., Li, Z., ...\& Zhou, Z. (2016). Effects of dietary live and heat-inactive baker's yeast on growth, gut health, and disease resistance of Nile tilapia under high rearing density. Fish \& Shellfish Immunology, 56, 263-271. (https://doi.org/10.1016/j.fsi.2016.07.001)

Raoof, B., Kaushik, B. D., \& Prasanna, R. (2006). Formulation of a low-cost medium for mass production of Spirulina. Biomass and Bioenergy, 30(6), 537-542. (https://doi.org/10.1016/j.biombioe.2005.09.006)

Regunathan, C., \& Wesley, S. G. (2006). Pigment deficiency correction in shrimp broodstock using Spirulina as a carotenoid source. Aquaculture Nutrition, 12(6), 425-432. (https://doi.org/10.1111/j.1365-2095.2006.00444.x)

Ringø, E., Olsen, R. E., Gifstad, T. Ø., Dalmo, R. A., Amlund, H., HEMRE, G. I., \& Bakke, A. M. (2010). Prebiotics in aquaculture: a review. Aquaculture Nutrition, 16(2), 117-136. (https://doi.org/10.1111/j.1365-2095.2009.00731.x) 
Ross, E., \&Dominy, W. (1990). The nutritional value of dehydrated, blue-green algae (Spirulina plantensis) for poultry. Poultry Science, 69(5), 794-800. (https://doi.org/10.3382/ps.0690794)

Ross, E., Puapong, D. P., Cepeda, F. P., \& Patterson, P. H. (1994). Comparison of freeze-dried and extruded Spirulina platensis as yolk pigmenting agents. Poultry Science, 73(8), 1282-1289. (https://doi.org/10.3382/ps.0731282)

Sandoval-Gío, J. J., Rosado-Vallado, M., \& Rodríguez-Canul, R. (2013). Efectos individuales de la ciclidogiriasis y estreptococosis inducidas en la bioquímica sanguínea de la tilapia Oreochromis niloticus. Hidrobiológica, 23(3), 328-339.

Saxena, P. N., Ahmad, M. R., Shyam, R., \& Amla, D. V. (1983). Cultivation ofSpirulina in sewage for poultry feed. Experientia, 39(10), 1077-1083. (https://doi.org/10.1007/BF01943117)

Shanmugapriya, B., Babu, S. S., Hariharan, T., Sivaneswaran, S., \& Anusha, M. B. (2015). Dietary administration of Spirulina platensis as probiotics on growth performance and histopathology in broiler chicks. International Journal of Recent Scientific Research, 6(2), 2650-3.

Sharma S, Charma S, Sharma KP: Protective role of Spirulina feed in freshwater fish (Poecilia reticulate Peters) exposed to an azo dye-methyl red. Indian Journal of Experimental Biology, 2005;3:1165-1169

Shiau, S. Y., \& Hsieh, H. L. (1997). Vitamin B6 requirements of tilapia Oreochromis niloticus $x$ O. aureus fed two dietary protein concentrations. Fisheries Science, 63(6), 1002-1007. (https://doi.org/10.2331/fishsci.63.1002)

Shimamatsu, H. (2004). Mass production of Spirulina, an edible microalga. Hydrobiologia, 512(13), 39-44. (https://doi.org/10.1023/B:HYDR.0000020364.23796.04)

Shimkiene, A., Bartkevichiute, Z., Chernauskiene, J., Shimkus, A., Chernauskas, A., Ostapchuk, A., \& Nevitov, M. (2010). The influence of Spirulina platensis and concentrates on lambs' growth. Zhivotnov'dni Nauki, 47(1), 9-14.

Shor-Posner, G., Feaster, D., Blaney, N. T., Rocca, H., Mantero-Atienza, E., Szapocznik, J., ...\& Baum, M. K. (1994). Impact of vitamin B6 status on psychological distress in a longitudinal study of HIV-1 infection. The International Journal of Psychiatry in Medicine, 24(3), 209222. (https://doi.org/10.2190/7VD8-DA67-8T9L-UCHL)

Šimkus, ., Oberauskas, V., Laugalis, J., Želvytè, R., Monkevičienè, I., Sederevičius, ., ...\& Pauliukas, K. (2007). The effect of weed Spirulina platensis on the milk production in cows. Vet. Zootech, 38, 74-77.

Šimkus, ., Oberauskas, V., Laugalis, J., Želvytė, R., Monkevičienė, I., Sederevičius, ., ...\& Pauliukas, K. (2007). The effect of weed Spirulina platensis on the milk production in cows. Veterinarija ir Zootechnika, 38, 74-77.

Sommer, T. R., D'Souza, F. M. L., \& Morrissy, N. M. (1992). Pigmentation of adult rainbow trout, Oncorhynchus mykiss, using the green alga Haematococcus pluvialis. Aquaculture, 106(1), 63-74.

Sommer, T. R., Potts, W. T., \& Morrissy, N. M. (1991). Utilization of microalgal astaxanthin by rainbow trout (Oncorhynchus mykiss). Aquaculture, 94(1), 79-88. (https://doi.org/10.1016/0044-8486(92)90250-O) 
Sørensen, C., Johansen, I. B., \& Øverli, Ø. (2013). Neural plasticity and stress coping in teleost fishes. General and comparative endocrinology, 181, 25-34. (https://doi.org/10.1016/00448486(91)90130-Y)

Sujatha, T., \& Narahari, D. (2011). Effect of designer diets on egg yolk composition of 'White Leghorn'hens.Journal of food science and technology, 4(4), 494-497. (https://doi.org/10.1016/j.ygcen.2012.12.003)

Sumpter, J. P. (1997). The endocrinology of stress. Fish stress and health in aquaculture, 819, 95118. (https://doi.org/10.1007/s13197-010-0132-z)

Sun, X., Chang, Y., Ye, Y., Ma, Z., Liang, Y., Li, T., ...\& Luo, L. (2012). The effect of dietary pigments on the coloration of Japanese ornamental carp (koi, Cyprinus carpio L.). Aquaculture, 342, 62-68. (https://doi.org/10.1016/j.aquaculture.2012.02.019)

Suzuki, T. A., \& Nachman, M. W. (2016). Spatial heterogeneity of gut microbial composition along the gastrointestinal tract in natural populations of house mice. PloS One, 11(9), e0163720. (https://doi.org/10.1371/journal.pone.0163720)

Takashi, S. (2003). Effect of administration of Spirulina on egg quality and egg components. Animal Husbandry, 57, 191-195.

Takeuchi, T., Lu, J., Yoshizaki, G., \& Satoh, S. (2002). Effect on the growth and body composition of juvenile tilapia Oreochromis niloticus fed raw Spirulina. Fisheries Science, 68(1), 3440. (https://doi.org/10.1046/j.1444-2906.2002.00386.x)

Teimouri, M., Amirkolaie, A. K., \& Yeganeh, S. (2013). The effects of Spirulina platensis meal as a feed supplement on growth performance and pigmentation of rainbow trout $\begin{array}{llll}\text { (Oncorhynchus mykiss). } & \text { Aquaculture, }\end{array}$ (https://doi.org/10.1016/j.aquaculture.2013.02.009)

Torrecillas, S., Mompel, D., Caballero, M. J., Montero, D., Merrifield, D., Rodiles, A., ...\& Izquierdo, M. (2017). Effect of fishmeal and fish oil replacement by vegetable meals and oils on gut health of European sea bass (Dicentrarchus labrax). Aquaculture, 468, 386398. (https://doi.org/10.1016/j.aquaculture.2016.11.005)

Toyomizu, M., Sato, K., Taroda, H., Kato, T., \& Akiba, Y. (2001). Effects of dietary Spirulina on meat colour in muscle of broiler chickens. British Poultry Science, 42(2), 197-202. (https://doi.org/10.1080/00071660120048447)

Trewavas, E. (1983). Tilapiine fishes of the genera Sarotherodon, Oreochromis and Danakilia. British Museum (Natural History). (https://doi.org/10.5962/bhl.title.123198)

Turnbaugh, P. J., Ley, R. E., Mahowald, M. A., Magrini, V., Mardis, E. R., \& Gordon, J. I. (2006). An obesity-associated gut microbiome with increased capacity for energy harvest. Nature, 444(7122), 1027. (https://doi.org/10.1038/nature05414)

Ungsethaphand, T., Peerapornpisal, Y., Whangchai, N., \& Sardsud, U. (2010). Effect of feeding Spirulina platensis on growth and carcass composition of hybrid red tilapia (Oreochromis mossambicus $\times$ O. niloticus). Maejo International Journal of Science and Technology, 4(2), 331-336.

USDA Food Composition Databases 2017 
Valenzuela, A., Alveal, K., \& Tarifeño, E. (2002). Respuestas hematologicas de truchas (oncorhynchus mykiss walbaum 1792) a estrés hipoxico agudo: serie roja. Gayana (Concepción), 66(2), 255-261. (https://doi.org/10.4067/S0717-65382002000200024)

Van Kessel, M. A., Dutilh, B. E., Neveling, K., Kwint, M. P., Veltman, J. A., Flik, G., ... \& den Camp, H. J. O. (2011). Pyrosequencing of $16 \mathrm{~S}$ rRNA gene amplicons to study the microbiota in the gastrointestinal tract of carp (Cyprinus carpio L.). AMB Express, 1(1), 41. (https://doi.org/10.1186/2191-0855-1-41)

Van Soest, P. V., Robertson, J. B., \& Lewis, B. A. (1991). Methods for dietary fiber, neutral detergent fiber, and nonstarch polysaccharides in relation to animal nutrition. Journal of Dairy Science, 74(10), 3583-3597. (https://doi.org/10.3168/jds.S0022-0302(91)78551-2)

Vatsos, I. N., \& Angelidis, P. (2010). Water quality and fish diseases. Journal of the Hellenic Veterinary Medical Society, 61(1), 40-48. (https://doi.org/10.12681/jhvms.14875)

Velasquez, S. F., Chan, M. A., Abisado, R. G., Traifalgar, R. F. M., Tayamen, M. M., Maliwat, G. C. F., \& Ragaza, J. A. (2016). Dietary Spirulina (Arthrospira platensis) replacement enhances performance of juvenile Nile tilapia (Oreochromis niloticus). Journal of Applied Phycology, 28(2), 1023-1030. (https://doi.org/10.1007/s10811-015-0661-y)

Venkataraman, L. V., Somasekaran, T., \& Becker, E. W. (1994). Replacement value of blue-green alga (Spirulina platensis) for fishmeal and a vitamin-mineral premix for broiler chicks. British Poultry Science, 35(3), 373-381. (https://doi.org/10.1080/00071669408417702)

Vijayan, M. M., Pereira, C., Grau, E. G., \& Iwama, G. K. (1997). Metabolic responses associated with confinement stress in tilapia: the role of cortisol. Comparative Biochemistry and Physiology Part C: Pharmacology, Toxicology and Endocrinology, 116(1), 89-95. (https://doi.org/10.1016/S0742-8413(96)00124-7)

Villarroel, M., Tupac-Yupanqui, I., Nicodemus, N., Rico, M., Cañón, J., Menoyo, D., ...\& Dunner, S. (2011). Expresión diferencial de genes en tilapia Oreochromis niloticus (L., 1758) bajo estrés alimentario. Boletín. Instituto Español de Oceanografía, 21(1-4), 261-270.

Volpato, G. L., \& Barreto, R. E. (2001). Environmental blue light prevents stress in the fish Nile tilapia. Brazilian Journal of Medical and Biological Research, 34(8), 1041-1045. (https://doi.org/10.1590/S0100-879X2001000800011)

Vonshak, A., \& Tomaselli, L. (2000). Arthrospira (Spirulina): systematics and ecophysiology. In The ecology of cyanobacteria (pp. 505-522). Springer, Dordrecht.

Wang, Y. J., Chien, Y. H., \& Pan, C. H. (2006). Effects of dietary supplementation of carotenoids on survival, growth, pigmentation, and antioxidant capacity of characins, Hyphessobrycon callistus. Aquaculture, 261(2), 641-648.

Ward, A. J., Webster, M. M., \& Hart, P. J. (2006). Intraspecific food competition in fishes. Fish and Fisheries, 7(4), 231-261. (https://doi.org/10.1111/j.1467-2979.2006.00224.x)

Watanuki, H., Ota, K., Tassakka, A. C. M. A., Kato, T., \& Sakai, M. (2006). Immunostimulant effects of dietary Spirulina platensis on carp, Cyprinus carpio. Aquaculture, 258(1-4), 157163. (https://doi.org/10.1016/j.aquaculture.2006.05.003)

Wedemeyer, G. (1996). Physiology of fish in intensive culture systems. Springer Science \& Business Media. (https://doi.org/10.1007/978-1-4615-6011-1) 
Wendelaar Bonga, S. E. (1997). The stress response in fish. Physiological Reviews, 77(3), 591625. (https://doi.org/10.1152/physrev.1997.77.3.591)

Whitton, B. A. (1992). Diversity, ecology, and taxonomy of the cyanobacteria. In Photosynthetic prokaryotes (pp. 1-51). Springer, Boston, MA. (https://doi.org/10.1007/978-1-4757-13329_1)

Xarxa Spirulina (2016). Manual práctico de cultivo de espirulina en casa. red internacional de cultivadores de espirulina por la soberanía alimentaria. http://www.xarxaespirulina.cat

Xie, J., Hu, L., Tang, J., Wu, X., Li, N., Yuan, Y., ...\& Chen, X. (2011). Ecological mechanisms underlying the sustainability of the agricultural heritage rice-fish coculture system. Proceedings of the National Academy of Sciences, 108(50), E1381-E1387. (https://doi.org/10.1073/pnas.1111043108)

Ye, L., Amberg, J., Chapman, D., Gaikowski, M., \& Liu, W. T. (2014). Fish gut microbiota analysis differentiates physiology and behavior of invasive Asian carp and indigenous American fish. The ISME Journal, 8(3), 541. (https://doi.org/10.1038/ismej.2013.181)

Yeganeh, S., Teimouri, M., \& Amirkolaie, A. K. (2015). Dietary effects of Spirulina platensis on hematological and serum biochemical parameters of rainbow trout (Oncorhynchus mykiss). Research in Veterinary Science, 101, 84-88. (https://doi.org/10.1016/j.rvsc.2015.06.002)

Zarrouk, C. (1966). Contribution a l'etude d'une Cyanophycee. Influence de Divers Facteurs Physiques et Chimiques sur la croissance et la photosynthese de Spirulina maxima. Thesis. University of Paris, France.

Zhai, Q., Yu, L., Li, T., Zhu, J., Zhang, C., Zhao, J., ...\& Chen, W. (2017). Effect of dietary probiotic supplementation on intestinal microbiota and physiological conditions of Nile tilapia (Oreochromis niloticus) under waterborne cadmium exposure. Antonie van Leeuwenhoek, 110(4), 501-513. (https://doi.org/10.1007/s10482-016-0819-x)

Zhang, J., Miao, S., Huang, S., \& Li, S. (2010). Effect different levels of Spirulina on ruminal internal environment and degradation of fibre in dairy cows. China Cattle Science, 36(6), 32-36.

Zheng, J., Inoguchi, T., Sasaki, S., Maeda, Y., McCarty, M. F., Fujii, M., \& Takayanagi, R. (2012). Phycocyanin and phycocyanobilin from Spirulina platensis protect against diabetic nephropathy by inhibiting oxidative stress. American Journal of Physiology-Regulatory, Integrative and Comparative Physiology, 304(2), R110-R120. (https://doi.org/10.1152/ajpregu.00648.2011)

Zhou, Z. G., He, S., Liu, Y., Shi, P., Huang, G., \& Yao, B. (2009). The Effects of Dietary Yeast Culture or Short-chain Fructo-oligosaccharides on the Intestinal Autochthonous Bacterial

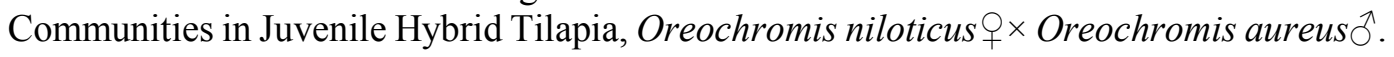
Journal of the World Aquaculture Society, 40(4), 450-459. (https://doi.org/10.1111/j.17497345.2009.00272.x) 


\title{
Effect of spirulina (Arthrospira platensis) supplementation on tilapia (Oreochromis niloticus) growth and stress responsiveness under hypoxia
}

\author{
Ignacio Plaza $^{1,2,}$ José L. García $^{2}$ and Morris Villarroel ${ }^{1}$ \\ ${ }^{1}$ Universidad Politécnica de Madrid, ETSIAAB, Dept. de Producción Agraria, Avda. Puerta de Hierro 2, 28040 Madrid, Spain. \\ ${ }^{2}$ CSIC, Centro de Investigaciones Biológicas, Biotecnología Medioambiental. C/ Ramiro de Maeztu 9, 28040 Madrid, Spain.
}

\begin{abstract}
Several recent studies have shown that Arthrospira sp. supplementation of feeds has a beneficial effect on fish health and growth, but less is known about its possible effects on stress responsiveness. The present study was designed to evaluate using Arthrospira platensis as a feed supplement for Oreochromis niloticus fry, reared in recirculating aquaculture systems (RAS). Two isocaloric and isonitrogenous (5.00/4.98 kcal/g DM and 44.6/44.8 CP\% DM, respectively) fishmeal-based diets were prepared with $0 \%$ and $1 \%$ A. platensis and fed to fry (approximately $10 \mathrm{mg}$ live weight, $\mathrm{n}=16$ tanks with 25 fry each, feeding rate $6 \%$ live weight, four meals a day for $50 \mathrm{~d}$ ). The weight gain per tank, specific growth rate and feed conversion ratio were similar among treatments, but A. platensis supplementation significantly increased survival $(p<0.05)$. Stress responsiveness was measured in all fish from 12 tanks using a non-invasive two-choice test. All fish from one home tank ( $\mathrm{n}=6$ per treatment), were placed into a shaded tank where oxygen levels were slowly reduced. A doorway was then opened to a second illuminated tank with normal oxygen levels and the number of fish who left the home tank were counted. Significantly more of the fish fed A. platensis stayed in the home tank compared to controls, suggesting a lower stress responsiveness and a higher tolerance to hypoxia.
\end{abstract}

Key words: tilapia; feed additives, stress test; behaviour; non-invasive

\section{Introduction}

qua culture provides more than half of the world's fish (F O , 2016) but better feeding strategies are need in order to keep it sustainable. One option is to use natural feed additives instead of artificial antibiotics, which cannot be used as growth promoters in the European Union (Regulation 1831; European Commission, 2003) since they promote microbial resistance. Arthrospira platensis is a natural product that can improve the quality of the fish production by providing a rich source of vitamin B12 and $\beta$-carotene 
(20 times more than carrots), essential amino acids, fatty acids ( $\omega 3$ and $\omega 6$ ), and minerals (James et al., 2006), protein (approximately 65\% dry weight; Phang et al., 2000), as well as anti-oxidant properties. For all of these reasons, it is commonly used as a natural supplement in animal feeds, including for fish (McCarty, 2007). Less is known about how A. platensis can improve the condition of weaker fish or their response to stress.

Several studies have considered the effects of $A$. platensis supplementation (less than $10 \%$ of diet) in fish. Red swordtail (Xiphophorus helleri) given \% A. platensis increase feed consumption, body weight, length, gonad weight and number of offspring (James et al., 2006). In three-spot gourami (Trichopodus trichopterus), Khanzadeh et al. (2016) found that $5 \% \mathrm{~A}$. platensis (replacing fishmeal) improves feed intake, feed conversion ratio (FCR) and the gonadosomatic index. Rainbow trout (Oncorhynchus mykiss) fed with $10 \%$ A. platensis (a natural pigment source) deposit more carotenoids in muscle tissue (Teimouri et al., 2013). $\operatorname{dding} A$. platensis to feed for guppies (Poecilia reticulata) improves their tolerance to a toxin (methyl red), manifested by a noticeable reduction in the cytotoxic effects on red blood cells (Sharma et al., 2005). In Oreochromis niloticus, adding 0.5-1-2\% A. platensis to feed improves its immune system ( bdel-Tawwab, 2009), has antioxidant effects and promotes growth (Takeuchi, 2002), but less is known about its possible effect on behaviour under stressful situations.

Regarding possible behavioural effects, A. platensis contains many different nutrients, including tryptophan and B6, which decrease psychological distress in humans (Shor-Posner, 1994). Fatty acids $\omega 3$, also present in A. platensis, can inhibit adrenal activation elicited by a mental stress in dogs (Delarue, 2003). Thus, supplementing O. niloticus diet with A. platensis could change their stress responsiveness. In their natural habitat, $O$. niloticus normally consumes algae (including cyanobacteria) and some invertebrates (Ibrahem et al., 2013).

In the past decade, there have been many studies on fish welfare (Huntingford, 2005), and several methods have been proposed to measure stress, including non-invasive behavioural methods to measure stress coping styles using a two-choice test (Laursen et al., 2011). Barreto et al. (2011) found that $O$. niloticus can be sorted into two opposing coping styles under stress, namely proactive (dominant) or reactive (passive). It is assumed that the development of a coping style depends on the genetic makeup of the fish and its previous experience (Sørensen et al., 2013), but less is known about possible effects of nutrition. In this study we set out to verify whether a $1 \%$ A. platensis supplementation affected growth and survival as well as behavioural response to stress using the two-choice test. 


\section{Material and methods}

Algae culture

We used the A. platensis strain PCC 9108 obtained from the Culture Collection at Spanish National Research Council (Consejo Superior de Investigaciones Científicas, CSIC). A platensis was grown in plastic bioreactors $(120 \times 12 \mathrm{~cm})$ in a greenhouse at the Universidad Politécnica de Madrid (40.446353 N, -3.738341 E), from July to August using the natural photoperiod. The cultivation media was composed of four solutions (Table 1) modified from Zarrouk (1966). A. platensis was harvested when the culture reached approximately $1 \mathrm{~g} / \mathrm{L}$ of dry weight. The harvest was performed from 9:30 to 10:30 am, when the protein content is higher (Jourdan 1999). Then the cells were dried on a horizontal sheet at $50^{\circ} \mathrm{C}$ for approximately 4-6 h and kept in an opaque container at $4^{\circ} \mathrm{C}$ to prevent oxidation before inclusion in the fish feed.

\section{Fish and feeds}

O. niloticus fry originally purchased from Valenciana de Acuicultura (Puçol, Valencia), were housed in 16 green fiberglass tanks $(120 \mathrm{~L}, 0.46 \mathrm{~m}$ high, and $0.64 \mathrm{~m}$ in diameter). Each tank was connected to a filter (EHEIM Classic; MOD. 2217, 6 L of capacity, $20 \mathrm{~W}$ and water flow $1000 \mathrm{~L} / \mathrm{h}$ ) and aerated with an air pump common to all tanks. This set up allowed us to maintain independent water conditions in each tank so as not to mix sediments and bacteria among treatments. The filters were prepared by inoculating nitrifying bacteria (EHEIM water care), using the supplier indications. We added 5 ppm of ammonia daily for 3 weeks, testing the evolution of nitrogen compounds, until microbial activity was satisfactory. The distribution of treatments among the tanks was random.

O. niloticus fry were introduced in the tanks randomly and given a two-week acclimatization period. After that, all the fish from each tank were weighed in groups and their length measured individually using a ruler (day 0). The initial average weight per tank was a $2.64 \pm 0.45 \mathrm{mg}$ (mean $\pm \mathrm{SD} ; \mathrm{n}=25)$ and initial fish length was $1.17 \pm 0.10 \mathrm{~cm}$, with no significant differences among treatments. Fish were counted and weighed in groups at $30 \mathrm{~d}$, and counted, weighed individually and measured at $50 \mathrm{~d}$. To quantify mortality during the fry phase tanks were checked every day. The number of dead fish 
were and eliminated. The incidence of mortality was not concentrated on any particular day nor in any particular tank.

To make the experimental diet, commercial feed (Skretting T3) was crushed and sifted to a crumb size of $0.5-1 \mathrm{~mm}$, mixed with $1 \%$ of $A$. platensis by weight and passed through the same sieve. The control diet was made in the same way but with no added algae. The samples of food were sent, for their analysis, to the laboratories of the department of animal production of the ETSIAAB (Higher Technical School of Agronomic Engineering, Food and Biosystems). We worked with $n=5$ per treatment, in each of the analyzes performed. The percentage of dry matter was obtained by oven drying at $105^{\circ} \mathrm{C}$, up to constant weight, and the ash content by incineration $550^{\circ} \mathrm{C}$. On the other hand, the protein content was carried out by the Kjeldahl (1883) method and the ethereal extract with previous hydrolysis. The fiber content was obtained by the Van Soest (1991) method and finally the energy was calculated by calorimetric bomb (Table 2). Both feeds were isocaloric (crude energy) and isoproteic (crude protein), 5.02/4.98 kcal/ g DM and 44.6/44.8 CP\% DM, respectively, and were kept at $4^{\circ} \mathrm{C}$ until used Fish were fed at $6 \%$ live weight using an auto-feeder (EHEIM 3581) that provided four meals a day (7:00 h, 12:00 $\mathrm{h}, 17: 00 \mathrm{~h}$ and 22:00 h), beginning the trial on 04/08/2015 until 24/09/2015, for a total of 50 days ( 7 weeks). The filters were turned off for 20 min after each meal to avoid feed loss.

\section{Water quality}

Water quality measurements were taken in all tanks twice a week on Monday and Thursday after the first meal $(9: 30$ to 10:00 h). The measurements included dissolved oxygen (DO2), electrical conductivity (EC), and levels of ammonia, nitrites and nitrates (Hanna HI83203). Water quality parameters were maintained within normal values for O. niloticus growth (mean \pm S.E.; temperature $27.3 \pm 0.25^{\circ} \mathrm{C}$; $\mathrm{pH} 7.36 \pm 0.33$; EC $0.60 \pm$ 0.07 dS; DO2 $7.19 \pm 0.17$ ppm; NH4 $0.01 \pm 0.02$ ppm; NO2 $0.01 \pm 0.02$ ppm; NO3 13.48 $\pm 5.78 \mathrm{ppm})$, and were not significantly different between treatments.

\section{Two-choice test}

At the end of the trial (50 d), we performed a two-choice test based on Laursen et al. (2011), built using two circular tanks that were identical to the grow-out tanks (120 L) and attached to one another via a closable floodgate, $16 \mathrm{~cm}$ in diameter (Figure 1). Tank 
A was tightly covered with black plastic (shaded) and Tank B was illuminated (natural light). Twelve two choice tests were carried out, using six tanks per treatment, discarding the tanks with less than 20 remaining fry (for A. platensis fry, where all tanks had over 20 fish, the six tanks were chosen randomly). For each test, all the fish in a tank were placed in Tank A at the same time and left to acclimate for $30 \mathrm{~min}$. Then the door to the second tank (Tank B) was opened, and Tank A was bubbled with nitrogen gas to decrease oxygen levels (at a rate of 1 ppm per $10 \mathrm{~min}$ ). Tank B was oxygenated to maintain normal oxygen levels (approx. 7 ppm) and a counter-current water flow was set up in each tank to avoid water flowing between tanks. Oxygen levels were monitored in both tanks every 5 min. Each test was recorded with a video camera to avoid the effects of any human disturbance. We noted the times when any fish left Tank A. The test ended when the first five fish had left Tank A or after one hour had passed.

\section{Statistical analysis}

All statistical tests were carried out using R.commander (R Core Team, 2013). According to a Shapiro/Wilk test, the data on water quality, growth and survival were normally distributed and were analyzed using a one-way ANOVA. The data from the two-choice tests did not follow a normal distribution and were analyzed using a KruskalWallis test. The level of significance was $p<0.05$ in both cases.

\section{Results}

Fish growth and survival

There were no significant growth differences among treatments at 30 or $50 \mathrm{~d}$. Total body length was not significantly different among treatments (cm; mean $\pm \mathrm{SD} ; 4.13$ $\pm 1.09 \mathrm{CTR}, 4.22 \pm 0.97 \mathrm{SPR}$ ) nor the coefficient of variation in total length (mean $\pm \mathrm{SD}$; $0.26 \pm 0.08$ CTR, $0.28 \pm 0.08$ SPR). However, there were significant differences regarding mortality $(\mathrm{p}>0.05)$, which was lower in fry that received $1 \%$ of A. platensis (Table 3).

Two-choice test

The coping styles of the tilapia were significantly differences between treatments $(\mathrm{p}>0.05)$. More $A$. platensis supplemented fry adopted a proactive coping style, taking a significantly longer time to leave Tank A, despite decreasing oxygen levels (Figure 1). 
Control fish tended to leave Tank A in groups of two or more fish, while A. platensis fry tended to leave one by one ( $p>0.05$; see Table 4$)$. Also, focusing on fish size, fry that left Tank A tended to be smaller, less than $3 \mathrm{~cm}$ long $(\mathrm{p}=0.148)$, in both treatments.

\section{Discussion}

The main goal of fish nutrition is to provide a balanced mixture of ingredients to support vital functions at an acceptable cost. Following this line of thought, at the moment it would not be cost-effective to use $A$. platensis $(\approx 40 € / \mathrm{kg})$ as a protein substitute, but it may be useful as a nutritional supplement, since it improves feed efficiency, carcass quality, and physiological response to stress in several species of fish (Takechi et al., 2002, Abdel-Tawwab et al., 2009, Velasquez et al., 2016). In the current study, adding $1 \%$ A. platensis to feed did not affect production indices (FCR, growth) compared to controls. This contradicts previous studies such as James et al. (2006), using Xiphophorus helleri (8\% supplementation) and Abdel-Tawwab and Ahmed (2009) (0.5\% to 1\% supplementation) who observed improved growth. However, Tukeuchi (2002) found that the specific growth rate and feed efficiency of Arthrospira sp.-fed Orechromis sp. were lower than controls. Our findings of a 9\% higher survival rate are in accordance with other studies that report $6 \%$ higher survival at 1\% Arthrospira sp. supplementation after a bacterial challenge (Ibrahem et al., 2013). However, Abdel-Tawwab and Ahmed (2009), and Ungsethaphand et al. (2010) did not observe differences in survival among fish fed with Arthrospira sp. compared to controls. Our study may be different, however, due to the size of the fish. When the trial began, tilapia were in the fry stage (around 2-3 cm body length), when their diet changes begins to change from more omnivorous to carnivorous. It then changes back again to phytoplanktivorous filter feeding at about 6-7 cm (Ibrahem et al., 2013). The change to carnivorous could increase hierarchical stress and cannibalism, reducing the survival of weaker fry (Berrios \& Snow, 1983). In this scenario, the high vitamin content of $A$. platensis could have played a role, helping to promote growth and decrease mortality.

\section{Two-choice test}

Regarding the two-choice test, our results suggest that more of the fry consuming A. platensis supplemented feed adopted a proactive coping style, since more of them remained in a stressful environment despite the possibility of escape. As suggested by Barreto et al. (2011) the fish that remain in the "stressful" tank have a lower reaction to 
stress and can be classified as proactive. Although several recent studies have assessed coping styles in fish (e.g., Ferrari et al., 2016), few have considered the effects of nutritional supplementation. Some authors have shown that $A$. platensis affects plasma cortisol and glucose levels. In rainbow trout (Oncorhynchus mykiss) cortisol and glucose significantly decreased with increasing of inclusion A. platensis at 0 to $10 \%$ (Yeganeh et al., 2015). In great sturgeon (Huso huso), Adel et al. (2016) found that blood glucose increased at higher inclusion of A. platensis (10\%). Furthermore, according to Delarue (2003), adding $\omega 3$ fatty acids to fish diets can inhibit adrenal activation elicited by psychological stress. Arthrospira sp. has a high level of unsaturated long chain fatty acids such as $\omega 3$ and $\omega 6$, which may have provided a similar effect in $O$. niloticus. In this sense, Anzola (2013) found a decrease in psychological stress with higher tryptophan intake in dogs, and Shor-Posner (1994) found the same effect in humans with tryptophan and vitamin B6 supplementation. A. platensis contains tryptophan (1.5\% DM) and vitamin B6 $(0.8 \% \mathrm{DM})$. Taking into account that the tryptophan requirement of $O$. niloticus is $1 \%$ of the diet; with the inclusion of $1 \%$ A. platensis, it is increased to $1.15 \%$. The vitamin B6 requirements in juvenile Oreochromis sp. are 15 to $16 \mathrm{ppm}$ of the diet (Shiau \& Hsieh, 1997), but that was increased to $80 \mathrm{ppm}$ (500\% more than estimated control levels) by adding $1 \%$ of $A$. platensis.

In fish, body length is a strong predictor of individual positions in a hierarchy (Ward et al., 2006). Large fish are presumably more proactive, dominating other individuals, taking prime feeding sites and aggressively excluding smaller subordinate competitors (Webster and Hixon 2000), In addition, the fish, which feel threatened, seek the safety of the group, as was the case with the control fish. Our results agree with that hypothesis since it was the smaller fish that tended to leave Tank A while larger fish did not. Finally, although it was not our aim to measure resistance to hypoxia, our results also suggest that the A. platensis fish were more tolerant to low oxygen levels. This is in accordance with other studies in humans, where Arthrospira sp. supplementation increases cardiovascular capacity (Kalafati et al., 2010). Moreover, it has been found to increase hematocrit levels of O. niloticus (Ibrahem et al., 2013), which improves the efficiency of oxygen consumption. This finding is important for the aquaculture industry since oxygen levels are often a limiting factor for production (Abdel-Tawwab et al., 2015).

Conclusions 
Supplementing O. niloticus fry with A. platensis strain PCC 9108 increased survival and the proportion of individuals that adopted a proactive coping style, based on the results from a two-choice test. The results also suggest that $A$. platensis increased resistance to hypoxia, which is important for intensive aquaculture production.

\section{Acknowledgments}

This work was performed within the project INSPIRA1 (Ref. S2013/ABI2783) funded by the Community of Madrid and co-financed by structural funds of the European Union FEDER

\section{Bibliography}

Abdel-Tawwab M, Ahmad MH, 2009. Spirulina (Arthrospira platensis) as a growth and immunity promoter for Nile tilapia, Oreochromis niloticus (L.), challenged with pathogenic Aeromonas hydrophila. Aquac Res 40 (9): 1037-1046.

Abdel-Tawwab M, Hagras AE, Elbaghdady HAM, Monier MN, 2015. Effects of dissolved oxygen and fish size on Nile tilapia, Oreochromis niloticus (L.): growth performance, whole-body composition, and innate immunity. Aquacult Int 23 (5): 1261-1274.

Anzola B, 2013. The use of tryptophan in shelter dogs to treat stress-related anxiety disorders. Rev Cient 23 (1): 26-32.

Barreto RE, Volpato GL, 2011. Ventilation rates indicate stress-coping styles in Nile tilapia. J Bioscience 36 (5): 851-855.

Berrios-Hernandez JM, Snow JR, 1983. Comparison of methods for reducing fry losses to cannibalism in tilapia production. Prog Fish Cult, 45 (2): 116-118.

Delarue JOCP, Matzinger O, Binnert C, Schneiter P, Chiolero R, Tappy L, 2003. Fish oil prevents the adrenal activation elicited by mental stress in healthy men. Diabetes and Metab 29 (3): 289-295.

EC, 2003. Regulation No 1831/2003 of the European Parliament and of the council of 22 September 2003 on additives for use in animal nutrient. Office Journal of the European Union, 43. [Lex 32003R183]

FAO, 2016. El estado mundial de la pesca y la acuicultura. 2016. Contribución a la seguridad alimentaria y la nutrición para todos. Roma. 224 pp.

Ferrari S, Horri K, Allal F, Vergnet A, Benhaim D, Vandeputte M, Chatain, B, Bégout ML, 2016. Heritability of boldness and hypoxia avoidance in European seabass, Dicentrarchus labrax. Plos One 11 (12): e0168506.

Huntingford FA, Adams C, Braithwaite VA, Kadri S, Pottinger TG, Sandøe P, Turnbull JF, 2006. Current issues in fish welfare. J Fish Biol 68 (2): 332-372.

Ibrahem MD, Mohamed MF, Ibrahim MA, 2013. The role of spirulina platensis (Arthrospira platensis) in growth and immunity of Nile tilapia (Oreochromis niloticus) and its resistance to bacterial infection. J Agr Sci 5 (6): 109-117.

James R, Sampath K, Thangarathinam R, Vasudevan I, 2006. Effect of dietary spirulina level on growth, fertility, coloration and leucocyte count in red swordtail, Xiphophorus helleri. The Israel J Aquaculture 58: 97-104. 
Jourdan JP, 1999. Cultivez votre spiruline, manuel de culture artisanale de la spiruline. Antenna Technology. París, Francia.

Kalafati M, Jamurtas AZ, Nikolaidis MG, Paschalis V, Theodorou AA, Sakellariou GK, Kouretas D, 2010. Ergogenic and antioxidant effects of spirulina supplementation in humans. Med Sci Sports Exerc 42 (1) $142-151$.

Khanzadeh M, Fereidouni AE, Berenjestanaki SS, 2016. Effects of partial replacement of fish meal with spirulina platensis meal in practical diets on growth, survival, body composition, and reproductive performance of three-spot gourami (Trichopodus trichopterus) (Pallas, 1770). Aquacult Int 24 (1), 69-84.

Kjeldahl J, 1883. A new method for the determination of nitrogen in organic matter. Z. Anal Chem 22(1), 366-382.

Laursen DC, Olsén HL, de Lourdes Ruiz-Gomez M, Winberg S, Höglund E, 2011. Behavioural responses to hypoxia provide a non-invasive method for distinguishing between stress coping styles in fish. Appl Anim Behav Sci 132 (2): 211-216.

McCarty MF, 2007. Clinical potential of spirulina as a source of phycocyanobilin. J Med Food 10 (4): 566570.

Phang SM, Miah MS, Yeoh BG, Hashim MA, 2000. Spirulina cultivation in digested sago starch factory wastewater. J Appl Phycol 12 (3): 395-400.

R Core Team, 2013. R: A language and environment for statistical computing. Vienna: R Foundation for Statistical Computing. Available at www.r-project.org. [21 September 2013].

Sharma S, Sharma S, Sharma KP, 2005. Protective role of spirulina feed in a freshwater fish (Poecilia reticulata Peters) exposed to an azo dye-methyl red. Indian J Expl Biol 43: 1165-1169.

Shiau SY, Hsieh HL, 1997. Vitamin B6 requirements of tilapia Oreochromis niloticus x O. aureus fed two dietary protein concentrations. Fish Sci 63 (6): 1002-1007.

Shor-Posner G, Feaster D, Blaney NT, Rocca H, Mantero-Atienza E, Szapocznik J, Baum MK, 1994. Impact of vitamin B6 status on psychological distress in a longitudinal study of HIV-1 infection. Int J Psychiat Med 24 (3): 209-222.

Sørensen C, Johansen IB, Øverli Ø, 2013. Neural plasticity and stress coping in teleost fishes.Gen Comp Endocr 181: 25-34.

Takeuchi T, Lu J, Yoshizaki G, Satoh S, 2002. Effect on the growth and body composition of juvenile tilapia (Oreochromis niloticus) fed raw spirulina. Fisheries Sci 68 (1): 34-40.

Teimouri M, Amirkolaie AK, Yeganeh S, 2013. The effects of spirulina platensis meal as a feed supplement on growth performance and pigmentation of rainbow trout (Oncorhynchus mykiss). Aquaculture 396: 14-19.

Ungsethaphand T, Peerapornpisal Y, Whangchai N, Sardsud U, 2010. Effect of feeding spirulina platensis on growth and carcass composition of hybrid red tilapia (Oreochromis mossambicus $\times O$. niloticus). Maejo Int J Sci Technol 4 (2): 331-336.

Van Soest PV, Robertson JB, Lewis BA. (1991). Methods for dietary fiber, neutral detergent fiber, and nonstarch polysaccharides in relation to animal nutrition. J Anim Sci 74(10), 3583-3597.

Velasquez SF, Chan MA, Abisado RG, Traifalgar RFM, Tayamen MM, Maliwat GCF, Ragaza JA, 2016. Dietary spirulina (Arthrospira platensis) replacement enhances performance of juvenile Nile tilapia (Oreochromis niloticus). J Appl Phycol 28 (2): 1023-1030.

Ward AJ, Webster MM, Hart PJ, 2006. Intraspecific food competition in fishes. Fish Fish 7 (4): 231-261.

Webster MS, Hixon MA, 2000. Mechanisms and individual consequences of intraspecific competition in a coral-reef fish. Mar Ecol Prog Ser 196: 187-194. 
Yeganeh S, Teimouri M, Amirkolaie AK, 2015. Dietary effects of Spirulina platensis on hematological and serum biochemical parameters of rainbow trout (Oncorhynchus mykiss). Res Vet Sci 101: 84-88.

\section{TABLES}

Table 1. Arthrospira sp. culture medium composition. Culture medium consists of four different solutions. The first solution is the Macroelements, which will form the base solution, to which added the other three. Solutions and $\mathrm{B}$ adds at the rate of $1 \mathrm{~mL} / \mathrm{L}$, and the trace solution to $100 \mathrm{~mL} / \mathrm{L}$.

\begin{tabular}{|c|c|}
\hline Macroelements & Base $\mathrm{g} / \mathrm{L}$ \\
\hline $\mathrm{NaHCO}_{3}$ & $16.50 \mathrm{~g} / \mathrm{L}$ \\
\hline $\mathrm{NaCl}$ & $1.00 \mathrm{~g} / \mathrm{L}$ \\
\hline $\mathrm{K}_{2} \mathrm{HPO}_{4}$ & $0.55 \mathrm{~g} / \mathrm{L}$ \\
\hline $\mathrm{NaNO}_{3}$ & $2.50 \mathrm{~g} / \mathrm{L}$ \\
\hline $\mathrm{K}_{2} \mathrm{SO}_{4}$ & $1.00 \mathrm{~g} / \mathrm{L}$ \\
\hline Solution A & $1 \mathrm{ml} / \mathrm{L}$ \\
\hline $\mathrm{H}_{3} \mathrm{BO}_{3}$ & $0.2 \mathrm{~g} / \mathrm{L}$ \\
\hline $\mathrm{MnCl}_{2} 4 \cdot \mathrm{H}_{2} \mathrm{O}$ & 1. $1 \mathrm{~g} / \mathrm{L}$ \\
\hline $\mathrm{CuSO}_{4} 5 \cdot \mathrm{H}_{2} \mathrm{O}$ & $0.0 \mathrm{~g} / \mathrm{L}$ \\
\hline $\mathrm{ZnSO}_{4} 7 \cdot \mathrm{H}_{2} \mathrm{O}$ & $0.22 \mathrm{~g} / \mathrm{L}$ \\
\hline $\mathrm{MoO}_{3}$ & $0.02 \mathrm{~g} / \mathrm{L}$ \\
\hline Solution B & $1 \mathrm{ml} / \mathrm{L}$ \\
\hline $\mathrm{CoN}_{2} \mathrm{O}_{6} 6 \cdot \mathrm{H}_{2} \mathrm{O}$ & $0.44 \mathrm{~g} / \mathrm{L}$ \\
\hline $\mathrm{NiSO}_{4} 7 \cdot \mathrm{H}_{2} \mathrm{O}$ & $0.4 \mathrm{~g} / \mathrm{L}$ \\
\hline $\mathrm{TiSO}_{4}$ & $0.20 \mathrm{~g} / \mathrm{L}$ \\
\hline Trace Solution & $100 \mathrm{ml} / \mathrm{L}$ \\
\hline $\mathrm{C}_{10} \mathrm{H}_{12} \mathrm{~N}_{2} \mathrm{O}$ FeNa $3 \cdot \mathrm{H}_{2} \mathrm{O}$ & $0.0 \mathrm{~g} / \mathrm{L}$ \\
\hline $\mathrm{CaCl}_{2}$ & $0.04 \mathrm{~g} / \mathrm{L}$ \\
\hline $\mathrm{MgSO}_{4} 7 \cdot \mathrm{H}_{2} \mathrm{O}$ & $2.00 \mathrm{~g} / \mathrm{L}$ \\
\hline $\mathrm{FeSO}_{4} 7 \cdot \mathrm{H}_{2} \mathrm{O}$ & $0.01 \mathrm{~g} / \mathrm{L}$ \\
\hline
\end{tabular}


Table 2. Proximate composition of experimental diets (DM dry matter, ash, CP crude protein; EE ether extract, NDF neutral detergent fiber, DF acid detergent fiber, DL acid detergent lignin and CE crude energy).

\begin{tabular}{lrr}
\hline & Control & A. platensis \\
\hline DM (\%) & 92.60 & 92.60 \\
sh $(\%)$ & 7.39 & 7.37 \\
CP (\%/DM) & 44.59 & 44.3 \\
EE (\%/DM) & 6.39 & 6.44 \\
NDF (\%/DM) & 26.4 & 26.23 \\
DF (\%/DM) & 4.9 & 5.05 \\
DL (\%/DM) & 0.6 & 0.7 \\
CE (Kcal /gr MS) & 5.00 & 4.9 \\
\hline
\end{tabular}

Table 3: Mean ( \pm S.E.) initial bulk weight (IBW), weight bulk gain (WBG grams), feed conversion ratio (FCR) and \% survival (\% Srv) of Oreochromis niloticus control and fed Arthrospira platensis.

\begin{tabular}{lccr}
\hline TRT & Control (n $)$ & A. platensis $(\mathrm{n})$ & p-Value \\
\hline IBW (d0) & $2.42 \pm 0.53^{\mathrm{a}}$ & $2.6 \pm 0.76^{\mathrm{a}}$ & 0.20 \\
WBG (d30) & $26.21 \pm 2.57^{\mathrm{a}}$ & $26.07 \pm 2.61^{\mathrm{a}}$ & 0.2 \\
WBG (d50) & $66.93 \pm 7.15^{\mathrm{a}}$ & $70.55 \pm .33^{\mathrm{a}}$ & 0.32 \\
\hline FCR (d30) & $0.73 \pm 0.07^{\mathrm{a}}$ & $0.74 \pm 0.09^{\mathrm{a}}$ & 0.9 \\
FCR (d50) & $0.3 \pm 0.10^{\mathrm{a}}$ & $0.79 \pm 0.07^{\mathrm{a}}$ & 0.40 \\
\hline$\%$ Srv (d30) & $4.5 \pm 7.23^{\mathrm{a}}$ & $93.5 \pm .0^{\mathrm{b}}$ & 0.04 \\
\% Srv (d50) & $4.0 \pm 6.76^{\mathrm{a}}$ & $93.0 \pm .50^{\mathrm{b}}$ & 0.03 \\
\% Srv (d30-50) & $99.5 \pm 1.54^{\mathrm{a}}$ & $99.5 \pm 1.41^{\mathrm{a}}$ & 0.9
\end{tabular}

Values followed by the same superscript letters in the same row are not significantly different $(\mathrm{P}>0.05)$.

Table 4: Time output means of the first five fish, during hypoxic challenge in minutes, and \% of fish leave the Tank A on group or alone.

TRT Mean output time Mean output $\mathrm{O}_{2}$ level Group Leavers (\%) Individual Leavers (\%)

\begin{tabular}{lcccc}
\hline Control (n6) & $17.35^{\mathrm{a}} \min$ & $4.01^{\mathrm{a}} \mathrm{ppm}$ & $7^{\mathrm{a}}$ & $13^{\mathrm{a}}$ \\
A. platensis (n6) & $30.20^{\mathrm{b}} \mathrm{min}$ & $2.3^{\mathrm{b}} \mathrm{ppm}$ & $40^{\mathrm{b}}$ & $60^{\mathrm{b}}$ \\
\hline p-value & 0.001 & 0.001 & 0.021 & 0.021
\end{tabular}

Values followed by the same superscript letters in the same row are not significantly different $(\mathrm{P}>0.05)$. 


\section{FIGURES}

Fig 1. Two-choice scheme. Two tanks attached via a floodgate (closable door). Tank was in darkness and water was infused with nitrogen to decrease oxygen levels. Tank B was under natural light and had normal oxygen levels. Water was rotated in both tanks in the same direction to avoid water moving from one tank to another, through the floodgate.

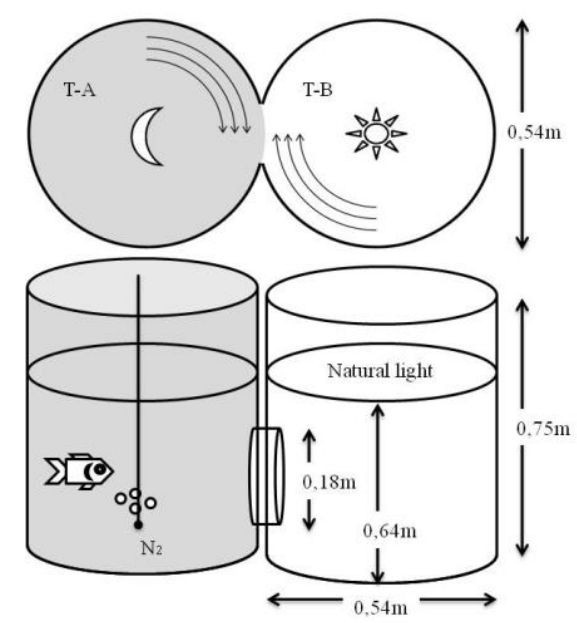

Fig 2. Departure times of the first five fish per treatment. Differentiating between controls (O), and $A$. platensis $(\mathbf{A})$. The continuous line is the $\mathrm{O}_{2}$ concentration in ppm in Tank A (TA), and the regression curve (---) to know at what level $\mathrm{O}_{2}$ of the fish responded, $\left(1.78+6.19 \times 0.94^{\mathrm{min}}\right)(\mathrm{r}=0.98)$.

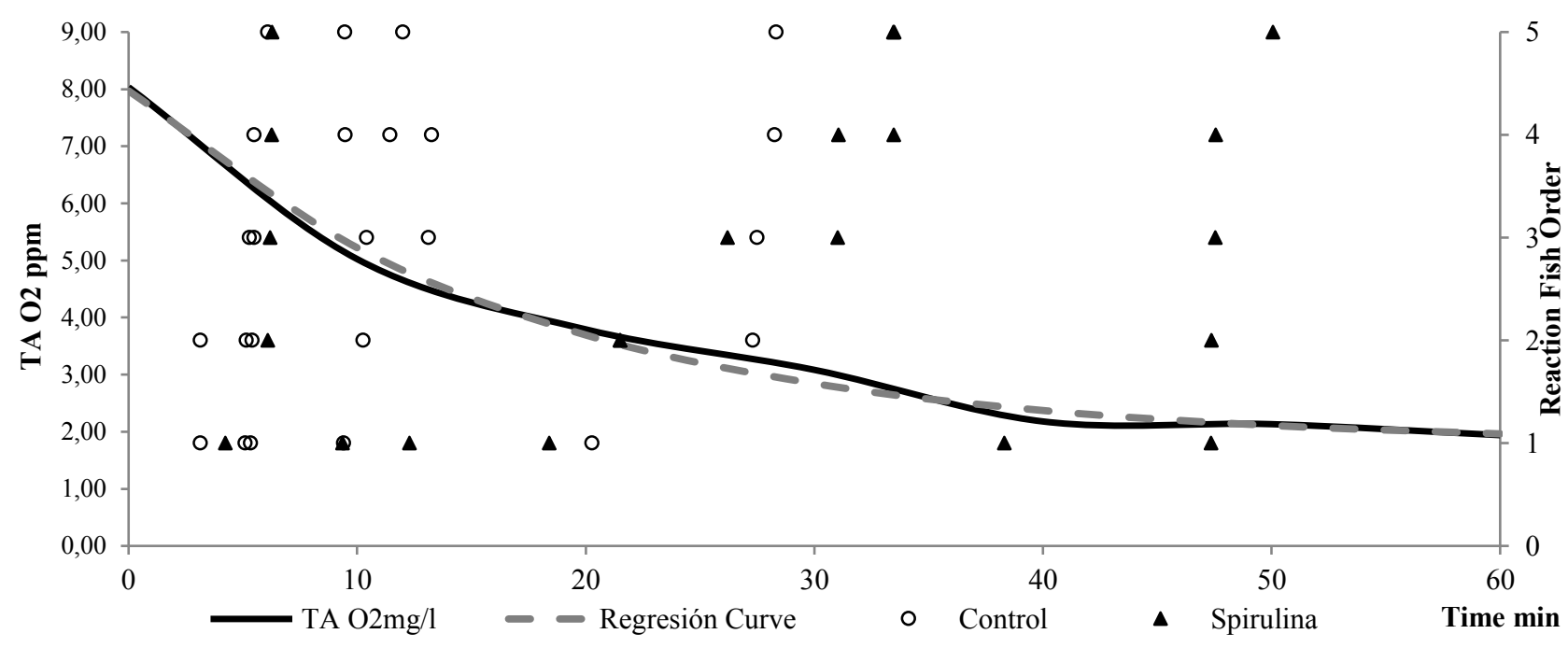




\title{
Effect of Arthrospira supplementation on Oreochromis niloticus gut microbiota and flesh quality \\ Ignacio Plaza ${ }^{1,2}$ | José Luis García ${ }^{2}$ | Beatriz Galán ${ }^{2}$ | Jesús de la Fuente ${ }^{3}$ | Rubén Bermejo-Poza ${ }^{3}$ | Morris Villarroel ${ }^{1}$ \\ 1Departamento de Producción Agraria, ETSIAAB, Universidad Politécnica de Madrid, Avenida Puerta de Hierro s/n, 28040, Madrid, Spain. \\ 2Centro de Investigaciones Biológicas. CSIC. Calle Ramiro de Maeztu, 9, 28040, Madrid, Spain. 3Departamento de Producción Animal, Facultad de Veterinaria, Universidad Complutense, Avenida Puerta de Hierro s/n, 28040, Madrid, Spain.
}

\section{Correspondence}

Ignacio Plaza, Departamento de Producción g raria, ETSI B, Universidad Politécnica de Madrid, venida Puerta de Hierro s/n, 2 040, Madrid, Spain. Email: i.plazagordo@gmail.com

\begin{abstract}
Supplementing fish feed with Arthrospira platensis has several beneficial effects, such as improved growth, survival and feed conversion, but little is known about how it affects gut microbiota or flesh quality. In this trial, feed with $3 \%$ A. platensis was given to Oreochromis niloticus (SPR, spirulina supplemented) over a period of 50 days and their gut microbiota and flesh quality were compared with controls (CTR, no supplementation). verage daily growth was higher in SPR fish $(\mathrm{P}<0.05)$. Regarding microbiota, a total of 5,470,272 readings (individuals) were obtained from 16 gut samples $(n=$ CTR, $n=$ SPR), with a gamma diversity of 1,563 species. 1though, no significant differences were found between treatments, two gut microbiota ecotypes were observed, comparing the results of this study with those of the literature. Main one dominated by Proteobacteria (36.6\%) and Fusobacteria (32.9\%), and secondary one dominated by ctinobacteria (37\%). Regarding flesh quality, significant differences were observed in flesh colour post mortem ( $\mathrm{a}^{*}, \mathrm{~b}^{*}$ and chroma). These changes corresponded with higher reflectance in the range of 470-500 $\mathrm{nm}$ and 620-670 $\mathrm{nm}$ in SPR tilapia, which corresponds with the reflectance range of $\beta$-carotene and phycocyanin. However, rigor mortis was resolved earlier in SPR fish $(\mathrm{P}<0.05)$.
\end{abstract}

\section{KEYWORDS}

Arthrospira platensis, Oreochromis niloticus, gut microbiota, flesh quality 


\section{1 | INTRODUCTION}

In an effort to reduce the use of antibiotics in intensive animal production, researchers have been looking for alternatives (El-Haroun et al., 2006; He et al, 2017; Fečkaninová et al., 2017), including prebiotics (Mosenthin \& Bauer, 2000; Patterson \& Burkholder, 2003; Gaggìa et al., 2010), which stimulate the activity of beneficial microbiota in the intestine while improving health and growth. Prebiotics are more commonly used in terrestrial animals than in fish and shellfish, but a number of studies have shown the beneficial effects of using prebiotics in aquaculture (Ringø et al., 2010, Ringø et al., 2016; Wang et al., 2017). The prebiotics used in fish include short chain fatty acids (Manzano et al., 2012; Liu et al., 2014), non-digestible oligosaccharides (fructose, galactose, xylose and glucose; Zhou et al., 2007; Ly et al., 2007; Grisdale-Helland et al., 2008, Zhou et al., 2009; Ringø et al., 2016), and dietary fibre (inulin, oligofructose or cellulose; Cerezuela et al., 2008; Ringø et al., 2008; Zhou et al., 2003; Ringø et al., 2016). All of these compounds can be found in microalgae and cyanobacteria (O'Sullivan et al., 2010; Evans \& Critchley, 2014; De Jesus Raposo et al., 2016; Leal et al., 2017; Lyons et al., 2017), which has increased interest in their use as dietary supplements.

One cyanobacteria used as a natural nutritional supplement is Arthrospira sp., which promotes health and growth in fish (McCarty, 2007) and has been shown to have prebiotic effects in vitro (Parada et al., 1998). In Oreochromis niloticus, Arthrospira sp. supplementation improves the immune system (Abdel \& Ahmad, 2009) and growth (Belal et al., 2012), probably due to its high content in xylose, fructose, galacturonic and glucuronic acids (all of which are considered prebiotics) and other compounds such as $\omega 3$ and $\omega 6$ fatty acids, $\beta$-carotene or phycocyanin (Pingnolet et al., 2012), which have antiviral activity (Chamorro et al., 2002). Different strategies have been used to modify intestinal microbiota using prebiotics in Oreochromis sp. (Haygood \& Jha, 2016), but the effect of Arthrospira sp. on microbiota and flesh quality is not well understood.

Gut microbiota affects growth, immune function and gut barrier actions (Backhed et al., 2004; Turnbaugh et al., 2006 O'Hara \& Shanahan, 2006). In fish, several metagenomic-based studies have found that different treatments affect gut microbiota, but the results are quite variable. Recently, Lyon et al. (2016) found that Oncorhynchus mykiss supplemented with 5\% microalgae had more diverse gut microbiota than controls. In Oreochromis sp., Koh et al. (2014) found that fish fed with organic acids had significantly lower colony forming units of adherent gut bacteria compared to the control or oxytetracycline feed. Pedrotti et al. (2015) studied the effect of dietary 
carbohydrate on microbiota in $O$. niloticus and showed that cassava bagasse and ground corn increase significantly $(\mathrm{P}<0.05)$ the population of amylolytic bacteria in tilapia.

Improvements in technology used to characterize microbiota, such as the Illumina technique, have facilitated the study of gut microbiota in general. Table 1 summarizes the techniques and primers used by different authors to identify gut microbiota in different fish species. Gajardo et al. (2016) built a high-resolution map of the gut microbiota in Salmo salar (Atlantic salmon) using Fluorometria Qubit 2.0. Dehler et al. (2017) studied environmental and physiological factors in $S$. salar parr gut microbiota. In O. niloticus Giatsis et al. (2015), using 454 pyrosequencing, studied the impact of rearing environment on the development of gut microbiota, but less has been analysed regarding the effect of $A$. platensis on $O$. niloticus gut microbiota.

Besides its effect on microbiota, microalgae and their pigments have been used extensively in aquaculture as colouring agents in feeds for O. mykiss and $S$. salar to modify flesh colour (Sommer et al., 1991, 1992; Baker et al., 2002). Since concerns have been raised about the safety of certain artificial pigments (Penninks et al., 2017), algae can be a viable natural alternative for several species. Microalgae and their components can also help to improve the biochemical composition of fish flesh. In Oreochromis sp., several studies have analysed how supplementing with Arthrospira sp. (less than $10 \%$ of diet) can change flesh texture, protein and fatty acid composition (Lu et al., 2003; James et al., 2006; Ungsethaphand et al., 2010; El-Sheekh et al., 2014; Khanzadeh et al., 2016). In O. niloticus, adding 0.5-1-2\% A. platensis to feed improves its immune system ( bdel-Tawwab \& hmad, 2009), has antioxidant effects and promotes growth (Takeuchi et al., 2002). However, less is known about the effect of this cyanobacterium on the evolution of rigor mortis and flesh pigmentation over time. In this study we analysed how $A$. platensis affected intestinal microbiota and flesh quality in $O$. niloticus grown in raceways.

\section{2| MATERIALS AND METHODS}

\section{1 | Fish and installations}

The trial was carried out at the aquaculture facilities of the College of Forestry Engineering, Technical University of Madrid (Madrid, Spain; 40.4508 N, -3.7210 W). The fish farm is located on a slope divided into terraces with raceways. The terrace arrangement allows the downward water flow to be distributed among the different raceways by means of channels and water falls. For the trial we used one raceway (total volume $5.16 \mathrm{~m}^{3}$ ), filled with water from an underground well and recirculated. $O$. niloticus fry, originally purchased from Valenciana de Acuicultura (Puçol, Spain), were 
placed into one raceway until they reached $90.2 \pm 2.6 \mathrm{~g}($ mean $\pm \mathrm{SD})$. After that fish were anesthetized, weighed and tagged individually by placing a PIT-tag (i-Tag 162,2x12 mm) under the dorsal fin. Then fish were placed into one of four divisions in the same raceway ( $1.5 \times 0.8 \times 0.4 \mathrm{~m}$; length $\times$ width $\times$ height $)$, with $\mathrm{n}=25$ fish per division, and were left to acclimate for 22 days, during which they were fed commercial feed (T3 Skretting, Stavanger, Norway) at $2 \%$ live weight.

The experimental feed was made by grounding up the commercial control feed (T3 Skretting) and adding $10 \mathrm{~g}$ of A. platensis strain PCC 910 (SPR) per kg of feed. Both control (CTR) and experimental (SPR) diets were isocaloric and isoproteic (see Table 2), 5.02/4.9 kcal.g-1 dry matter (DM), and 44.6/44. PB \% DM respectively, and were kept at $4^{\circ} \mathrm{C}$ until used. Fish were fed at 3,5\% live weight during the trial ( 0 to $50 \mathrm{~d}$ ). To ad ust the feed to the growth of the fish, it was started with $5 \mathrm{~g}$ of feed per tank. Every two weeks, it was increasing by $5 \mathrm{~g}$, until reaching $105 \mathrm{~g}$ in the last week.

\section{2 | Algae Culture}

We used the A. platensis strain PCC 910 obtained from the Culture Collection at the Spanish National Research Council (Consejo Superior de Investigaciones Cientificas, CSIC. Madrid, Spain). A. platensis was grown in plastic bioreactors $(120 \times 12 \mathrm{~cm})$ in a greenhouse at the Universidad Politécnica de Madrid, Spain (40.446353 N -3.73 341 E) from July to ugust (2016), using Zarrouk medium (Zarrouk, 1966) composed of four solutions. SPR was harvested when the culture reached approximately $1 \mathrm{~g} \cdot 1^{-1}$ of dry weight. The harvest was performed from 9:30 to 10:30 am when the protein content is higher (Jourdan, 1999). Then cells were dried on a horizontal sheet at $50^{\circ} \mathrm{C}$ for approximately $4-6 \mathrm{~h}$ and kept in an opaque container at $4{ }^{\circ} \mathrm{C}$ to prevent oxidation before inclusion in the fish feed.

\section{3 | Water quality}

Water quality measurements were taken in each compartment twice a week (on Monday and Thursday) after the first meal (between 9:30 - 10:00 h). The measurements included dissolved oxygen $\left(\mathrm{DO}_{2}\right)$, electrical conductivity (EC), and levels of ammonia, nitrites and nitrates (Hanna HI 3203, Hanna Instruments, Woonsocket, US ). The water temperature was recorded once every 5 min throughout the trial using an underwater temperature sensor (Hobo-U11, ONSET, Bourne, Massachusetts, US ). 11 water quality parameters were within normal ranges ( zaza et al., 200 ; Ebeling et al., 2012; Boyd \& Tucker, 2012) for tilapia (mean $\pm \mathrm{SD}$, temperature $27.3 \pm$ $0.3{ }^{\circ} \mathrm{C} ; \mathrm{pH} .3 \pm 0.15$; EC $\left.0.50 \pm 0.01 \mathrm{dSm} ; \mathrm{O}_{2} 7.12 \pm 0.05 \mathrm{ppm} ; \mathrm{NH}_{4} 0.43 \pm 0.29 \mathrm{ppm}\right)$ and were not significantly different between treatments. 


\section{4 | Sampling}

Fish were weighed and measured individually at the beginning of the adaptation period $(-22 \mathrm{~d})$ and when the trial began $(0 \mathrm{~d})$. We noted the amount of feed provided to each compartment throughout the trial. At the end of the trial (day 50) with $24 \mathrm{~h}$ of fasting, fish were caught and euthanized with an overdose of eugenol $(100 \mathrm{mg} / \mathrm{L})$, and then weighed and measured individually. 40 SPR fish and 40 CTR fish (20 per division) were blood sampled to evaluate hematological variables. Blood samples were taken from the caudal vein using $2 \mathrm{ml}$ syringes, $1 \mathrm{ml}$ was centrifuged at $6000 \times \mathrm{g}$ for $10 \mathrm{~min}$ and the plasma was extracted to measure cortisol glucose and lactate (using sodium fluoride as the anticoagulant). Another $1 \mathrm{ml}$ of blood was used to measure creatine phosphokinase (CPK), triglycerides, leucocytes and hematocrit (with ethylenediaminetetraacetic acid, EDTA, as anticoagulant) and immediately stored at $4{ }^{\circ} \mathrm{C}$ until analysis.

After blood sampling, half of the fish $(\mathrm{n}=20)$ were used to measure flesh $\mathrm{pH}$ and colour and the other half to measure rigor mortis. Flesh $\mathrm{pH}$ was measured at 0,6 and 24 $\mathrm{h}$ in the same front-dorsal region using a $\mathrm{pH}$-meter with temperature compensation (HI9025, Hanna Instruments, Woonsocket, USA). Flesh colour was measured on 20 fish per treatment on the upper front-dorsal region at 0 and $24 \mathrm{~h}$ post-mortem, using a Minolta Spectrophotomer CM-2500c (Minolta, Osaka, Japan). For its determination, the CIE L* $a * b *$ colour space was used (Commision Intenacionale de l'Eclairage, CIE, 2004). This system allows to identify a colour with the coordinates $L^{*}$ (luminosity), a* (index of red) and $b^{*}$ (index of yellow). With $\mathrm{a}^{*}$ and $\mathrm{b}^{*}$ indices, parameters $\mathrm{C}^{*}$ (chroma) and $\mathrm{h}^{*}$ (hue) were calculated.

$C^{*}=\left(a^{* 2}+b^{* 2}\right)^{1 / 2}$

$h^{*}\left(^{\circ}\right)=\arctan \left(b^{*} / a^{*}\right)$

Rigor mortis was measured at 0, 6, 24 and $48 \mathrm{~h}$ post-mortem using Cuttinger's method (Korhenen et al., 1990). We also calculated average daily gain in percentage (ADG) and division feed conversion ratio (T.FCR) as:

$$
\begin{aligned}
& \text { ADG (\%) = final weight }(g) \text { - initial weight }(g) / \text { day } \times 100 \\
& \text { D. FCR }=\text { feed supplied }(\mathrm{g}) / \text { final weight }(g)-\text { initial weight }(g)
\end{aligned}
$$




\section{5 | Isolation of DNA}

Among the fish used to measure flesh $\mathrm{pH}$, samples of intestinal microbiota were taken from four fish per division, eight per treatment. The microbiota samples were taken 1.0 $\mathrm{cm}$ from the distal part of the intestine in order to avoid the heterogeneity reported by taking samples from different areas of the intestine (Suzuki \& Nachman, 2016). They were then stored in $2 \mathrm{ml}$ tubes labelled with the chip number and processed fresh and maintained at $4{ }^{\circ} \mathrm{C}$ on ice during the process. Duplicate samples were processed immediately using the QIAamp Stool minikit (Qiagen, Crawley, United Kingdom) according to the manufacturer's instructions for large volume samples (using $10 \mathrm{ml}$ buffer ASL instead of $2 \mathrm{ml})$.

\section{6 | PCR and MiSeq}

According to Chakravorty et al. (2007), V2 and V3 are the most adequate regions to distinguish among bacterial species at the genus level, except for the closely related Enterobacteriaceae. V2 is best to distinguish between mycobacterial species and V3 among Haemophilus species. Other authors working with tilapia have also used the V1V2 region, such as Fan et al. (2003), Giatsis et al. (2015) and Gajardo et al. (2017), so we thought it best to use the same regions in order to facilitate comparisons. Barcoded amplicons from the V1-V2 ( $310 \mathrm{pb})$ region of 16S rRNA genes were generated by PCR using the 27F-DegS primer (GAG TTT GAT CMT GGC TCA G), as a reverse primer, and equimolar mix of two primers 338RI (GCW GCC TCC CGT AGG AGT) and 388RII (GCW GCC ACC CGT AGG TGT). The PCR protocol used $100 \mathrm{ng}$ of total DNA, $0.5 \mathrm{U}$ of Taq DNA polymerase, $2.5 \mathrm{mM}$ DMSO buffer, $5 \mu \mathrm{l}$ dNTPs, $10 \mu$ l Oligo 27F, $5 \mu 1$ Oligo 338RI, $5 \mu$ l Oligo 338RI, in $50 \mu \mathrm{l}$ final volume. The PCR cycle was $1 \mathrm{~min}$ at $95^{\circ} \mathrm{C}, 45 \mathrm{~s}$ at $57^{\circ} \mathrm{C}$, and $45 \mathrm{~s}$ at $72{ }^{\circ} \mathrm{C}$ in an Eppendorf thermocycler, followed by 30 cycles of $45 \mathrm{~s}$ at $95{ }^{\circ} \mathrm{C}, 30 \mathrm{~s}$ at $56{ }^{\circ} \mathrm{C}$, and $30 \mathrm{~s}$ at $72{ }^{\circ} \mathrm{C}$, to close the cycle at $4{ }^{\circ} \mathrm{C}$. Finally, the samples were shipped to Macrogen Inc.C (Republic of Korea) to perform its sequencing. The MiSeq system Illumina SBS technology uses a proprietary reversible terminator-based method that detects single bases as they are incorporated into DNA template strands. As all 4 reversible, terminator-bound dNTPs are present during each sequencing cycle, natural competition minimizes incorporation bias and greatly reduces raw error rates compared to other technologies. 
The data from sequencing were analysed using Quantitative Insights Into Microbial Ecology (QIIME). Population diversity indices were calculated using the Shannon, Simpson, Margalef and Chaos methods using the PAST program (Hammer et al., 2000) where:

Shannon's index: $\mathrm{H}^{\prime}=-\sum_{\mathrm{i}=1}^{\mathrm{s}} \mathrm{p}_{\mathrm{i}} \log _{2}\left(\mathrm{p}_{\mathrm{i}}\right)$ (Magurran, 2013).

Simpson's index diversity: $1-D ; D=\sum_{i=1}^{n} n_{i}\left(n_{i}-1\right) / N(N-1)($ Magurran, 2013).

Margalef's Richness index : $\mathrm{d}=(S-1) / \ln N($ Gamito, 2010).

Chaos 1 coefficiente $=\mathrm{S}+a^{2} / 2 b($ Chao, 1984; Smith \& van Belle, $1984 \&$ Chao \& Lee, 1992)

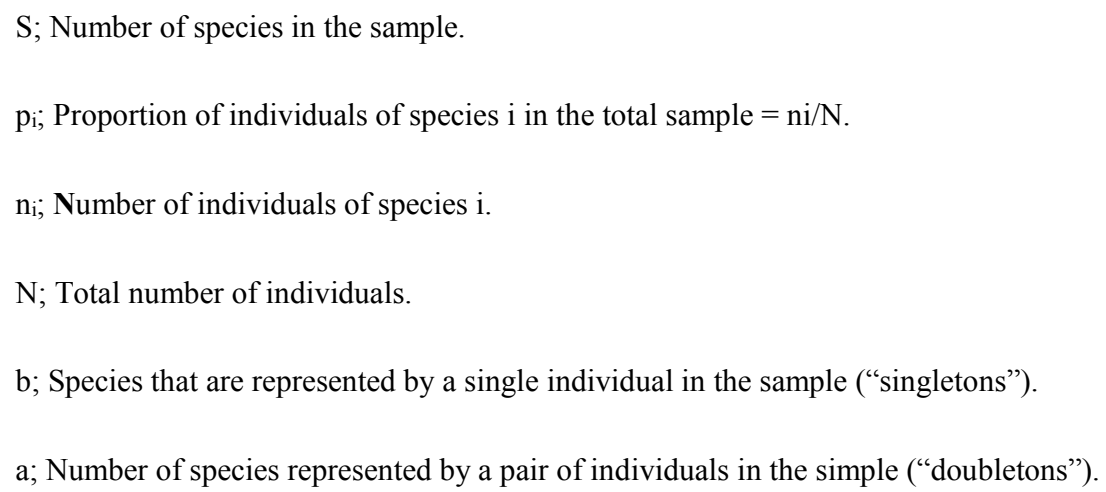

\section{7 | Statistical analysis}

All statistical tests were carried out using R.software (R Core Team, 2015). The data following a normal distribution were analysed with a one-way ANOVA and Turkey's multiple-comparison test. The level of significance for all analyses was set at $\mathrm{P}<0.05$. For the taxonomic analysis the QIIME program was used (97\%). Similarity studies of samples were performed with the PAST program (Hammer et al; 2000), Bray-Curtis test (PAST software, 2017).

\section{3 | RESULTS}

\section{1 | Growth and survival}

During the experiment there were no mortality. No differences were found in growth parameters during the adaptation phase ( -22 to 0 day). However, during the trial phase ( 0 to 50 days), individual weight and length, average daily gain and race-way division 
weight were higher in SPR fish (Table 3). Supplementation with 3\% A. platensis increased growth by $10 \%$ compared with controls and better FCR.

\section{2 | Blood analysis}

There were no significant differences in glucose, lactate and CPK levels, nor in haematocrit or leucocyte count. However, SRP-fish had significantly higher values of triglycerides (TGC) and cortisol (Table 4). Levels of TGC in SPR-fish were almost double the levels in control fish.

\section{3 | Flesh quality}

During the first hours after slaughter ( $0 \mathrm{~h}$ and $6 \mathrm{~h}$ ), no differences were found between treatments regarding flesh $\mathrm{pH}$ or rigor mortis. However, rigor mortis angle was significantly lower in CTRfish at $4 \mathrm{~h}$ post-mortem (Table 5). No significant differences $(\mathrm{P}<0.05)$ were found between treatments at $0 \mathrm{~h}$ but $\mathrm{L}^{*}$ was somewhat higher in SPR fish. fter $24 \mathrm{~h}$, the flesh colour was reversed, with significant differences in both parameters $a *$ and $b *$ with higher levels in SPR fish, while $\mathrm{C}^{*}$ value was higher for CTR. No significant differences were found in $\mathrm{L}^{*}$ parameter between treatments.

Differences in reflectance were found at different wavelengths after $24 \mathrm{~h}$ post-mortem, when SPR fish presented a greater reflectance of light in the ranges of $470 \mathrm{~nm}-500 \mathrm{~nm}$ and $620 \mathrm{~nm}-670 \mathrm{~nm}$ (Figure 4 and Table 6).

\section{4 | Intestinal microbiota}

We obtained 5,470,272 readings, corresponding to 1,563 species from the 16 gut samples. No significant differences were found between treatments regarding the measures of microbial diversity (Shannon, Simpson, Margalef and Chao-1). Confidence level coverage was at the $97 \%$ similarity level (Table 7).

On average, the composition of gut microbiota at the phylum level was composed of $36.6 \%$ Proteobacteria, 32. \% Fusobacteria, and 9.24\% ctinobacteria (Figure 1), although, these percentages varied considerably among individuals. Three of the control samples presented high levels of ctinobacteria, and two of the SPR samples had high values of ctinobacteria (37\%). On the other hand, while genera such as Spirochaetae, Euryarchaeota or Hydrogenedentes only appeared in SPR fish, they represented less than $0.05 \%$ of the population.

$\mathrm{t}$ the genus level, we find a similar situation (Figure 2), where the top 15 represented more than $75 \%$ of the genera found. The most representative genus was Cetobacterium (32. \% ), followed by Aeromonas (13.9\%), Escherichia/Shigella (6.7\%) and Propionibacterium (5.2\%). However, we found some divergence in samples, with higher patterns in actinobacteria. Propionibacterium (above 30\%) in two individuals (CTR-056 and SPR-3F ) and around 10\% in two controls 
(CTR-FF9 and CTR-FF9B), where the predominant proteobacteria was Escherichia/Shigella (above 45\%). Finally, Mycobacterium was the dominant actinobacteria in SPR-3331, at 37. \%.

The alpha-diversity study (Table 6) showed that there were no significant differences between treatments. cluster was also performed (Figure 3) to analyse $\beta$ diversity, but there were no significant differences in bacterial diversity among treatments.

\section{4 | DISCUSSION}

Supplementation with $A$. platensis improved growth rates and FCR in SPR tilapia, as found in other species of fish, such as Adel et al. (2016) in Huso huso (10\% supplementation), James et al. (2006) in Xiphophorus helleri (8\%) and Abdel-Tawwab et al. (2009) in O. niloticus (5\%). However, Tukeuchi (2002) reported the opposite, a lower specific growth rate and poorer feed efficiency in Oreochromis sp. fed Arthrospira sp. Overall, our results support the idea that Arthrospira sp. helps promote animal growth, a noted in other vertebrates as well (e.g., broilers grow more with 1\% Arthrospira sp. supplement; Shanmugapriya, et al., 2015).

SPR tilapia had higher levels of TCG, which was also reported by Belal et al. (2012) and Velasquez et al. (2016) in Oreochromis sp. fed different levels of Arthrospira $\mathrm{sp}$, although some authors have found the opposite effect in fatty fish, such an O. mykiss (Teimouri et al., 2013) or Huso huso (Adel et al., 2016). Adel et al. (2016) also observed more lipase activity in the intestines of tilapia fed Arthrospira sp., which may also reflect increased lipid digestion and TCG in plasma. In addition, carotenoids in A. platensis can facilitate absorption of dietary lipids (Iwata et al., 1990; Teimouri et al., 2013).

SPR fish had higher levels of cortisol in plasma (15.46 \pm 1.5$)$ which could imply a higher stress response (Barton \& Iwama, 1991; Pottinger \& Carrick, 1999) but cortisol levels were well within the normal range for this species (around 10-20 ng/ml, Balm, 1994; Vi ayan et al., 1997; Barcellos et al., 1999). In response to most stressors fish will exhibit an increase in plasma cortisol concentrations, which is generally followed by an elevation in plasma glucose levels. However, in the current study, no differences were found in glucose levels between the different treatments. Studies in rainbow trout (O. mykiss), have found a reduction of both cortisol and glucose with $A$. platensis supplementation (0 to 10\%; Yeganeh et al., 2015).

Increased levels of cortisol will also increase lipolysis, which raises plasma TCG and the general metabolic rate (Mommsen et al., 1999). Within the relatively low ranges 
of cortisol found in the current study, slightly higher levels of cortisol could favor growth and may be one of the causes for the differences in growth between treatments. Cortisol is not only an essential component of the stress response in fish, but also plays an important role in osmoregulation, growth and reproduction (Mommsen et al., 1999).

Flesh $\mathrm{pH}$ was within normal values for tilapia between 6.4-7.0, as described by other authors (Olivera et al., 2015; Hsieh et al., 2011). There was no effect of supplementation on flesh $\mathrm{pH}$ but rigor mortis was resolved earlier in SPR fish, which could imply a shorter shelf life. Flesh colour was also different among treatments, with a higher chroma at $24 \mathrm{~h}$ post-mortem in CTR fish. $\mathrm{t} 24 \mathrm{~h}$ post-mortem, there was a greater absorption of light in the ranges of $470 \mathrm{~nm}-500 \mathrm{~nm}$, which corresponds with the absorption spectrum of $\beta$-carotene. Carotene shows two peaks of absorbance between $400 \mathrm{~nm}$ and $500 \mathrm{~nm}$ (reflecting red-orange-yellow light). This colour change due to carotenes has also been described by other authors in O. mykiss (Teimouri et al., 2013), Cyprinus carpio L. (Sun et al., 2012) and O. mossambicus (Gomes et al., 2012). James et al. (2006) also found a higher carotene content in Xiphophorus helleri fed \% Arthrospira sp. The second range $(620 \mathrm{~nm}-670 \mathrm{~nm})$ could correspond with phycocyanin which emits fluorescence at about $650 \mathrm{~nm} . \mathrm{n}$ increase in blue-derived phycocyanin was mentioned by Karadal et al. (2017) in the colouration of the skin of Kenyi cichlids (Maylandia lombardoi) fed with Arthrospira sp.

A. platensis supplementation did not significantly modify the intestinal microbiota of SPR tilapia. The microbiota identified were similar to controls and within the range of other studies performed in Oreochromis sp. $\mathrm{t}$ the phylum level, Proteobacteria and Fusobacteria (Fan et al., 2013; Ran et al., 2016) predominate, although in Giatsis et al. (2016), cidobacteria occupied the niche of Proteobacteria, dominating the population. We found similar results in CTR-056 ,CTRFF9, CTR-FF9B, SPR-3331 and SPR-3F samples. This seems to show the existence of two ecotypes of intestinal microbiota (Figure 5). $\mathrm{t}$ the genus level, almost all Fusobacterial 16S rRN sequences in the two treatments belonged to genus Cetobacterium. This result is similar than Van Kessel et al. (2011) in Cyprinus carpio, and Ran et al. (2016) in O. niloticus, where it was the dominant group for each treatment, representing 32\%. Cetobacterium are known members of the endogenous microbiota of fish intestines (Wu et al., 2010).

In this study, Fusobacteria represented 36\%, while others authors such as Fan et al. (2013) reported 26\%, Zhai et al. (2016) 56\%, Gaikwad et al. (2016) 45\% or Ran et al. (2016) 34\%. lthough not all samples of the present study responded to this pattern, high values of Fusobacteria seem characteristic of Oreochromis sp., especially compared to other species like $H$. molitrix $<12 \%$ (Ye et al., 2014), S. salar < 7\% (Ga ardo et al., 2016, Dehler et al., 2017) or $O$. mykiss $<1 \%$ (Huyben et al., 2017). Merrifield \& Ringo (2014) argued that the average content of Fusobacteria in common commercial fish is below $7 \%$. 
However, Proteobacteria were the most numerous phyla, divided into a diverse amount of genus, the most representative of which was Aeromonas (13. \%), a known member of the endogenous microbiota of freshwater fish, which helps to ferment organic compounds and cellulose (Wu et al., 2010), followed by Shigella (6.7\%), which can be optional pathogen like Aeromonas (Wu et al., 2010; Jiang et al., 2011; Van Kessel et al. 2011; Wu et al., 2012).

mong the most representative genus of ctinobacteria was Propionibacterium (5.2\%) and Mycobacterium (2.7\%), both members of the order of Actinomycetales, occupying the main niche of the second ecotype found.

Based on the results of this study, we conclude that Arthrospira platensis can improve growth in $O$. niloticus and could help to improve flesh colour, without modifying the general parameters of intestinal microbiota. On the other hand, we have observed different configurations of intestinal microbiota in O. niloticus, which we can categorize into two ecotypes. The predominant in our samples is Ecotype I (Fuso-Proteobacteria), with Cetobacterium as the dominant bacterium, and also an Ecotype II (Proteo- ctinobacteria) with proteobacteria's Escherichia/Shigella, Aeromonas, and the actinobacteria Mycobacterium occupying the main niche. We can find these ecotypes by reviewing the data of other intestinal microbiota studies in Oreochromis. Zhai et al (2016) found a microbiota with type I distribution (Fuso-Proteobateria), dominated by Fusobacteria at 56\%, Proteobacteria at 31\%, Bacterioidetes at $12 \%$ and Firmicutes at $0.5 \%$, in its control population. Fan et al (2013) found the same ecotype I, formed by Fusobacteria at 26\%, Proteobacteria at $25 \%$ and Firmicutes at $19 \%$. However, Giatsis et al. (2016) found a population similar to ecotype II (Proteo- ctinobacteria), dominated by ctinobacteria above $40 \%$, followed by Proteobacteria at $20 \%$.

\section{CKNOLEDGEMENTS}

This work is part of the pro ect Cofounded by the Community of Madrid with structural funds from the European Union FEDER (INSPIR 1, Ref. S2013/ B I27 3).

\section{REFERENCES}

Abdel-Tawwab, M., \& Ahmad, M. H. (2009). Live Spirulina (Arthrospira platensis) as a growth and immunity promoter for Nile tilapia, Oreochromis niloticus (L.), challenged with pathogenic Aeromonas hydrophila. Aquaculture Research, 40(9), 1037-1046. Retrieved from: https://doi.org/10.1016/j.fsi.2016.08.003

Adel, M., Yeganeh, S., Dadar, M., Sakai, M., \& Dawood, M. A. (2016). Effects of dietary Spirulina platensis on growth performance, humoral and mucosal immune responses and disease resistance in juvenile great sturgeon (Huso huso Linnaeus, 1754). Fish \& Shellfish Immunology, 56, 436444. Retrieved from: https://doi.org/10.1111/j.1365-2109.2009.02195.x 
Azaza, M. S., Dhraief, M. N., \& Kraiem, M. M. (2008). Effects of water temperature on growth and sex ratio of juvenile Nile tilapia Oreochromis niloticus (Linnaeus) reared in geothermal waters in southern Tunisia. Journal of Thermal Biology, 33(2), 98-105. Retrieved from: https://doi.org/10.1111/j.1365-2109.2009.02195.x

Bäckhed, F. et al. (2004). The gut microbiota as an environmental factor that regulates fat storage. Proceedings of the National Academy of Sciences of the United States of America, 101(44), 1571815723. Retrieved from: https://doi.org/10.1111/j.1365-2109.2009.02195.x

Baker, R. T. M., Pfeiffer, A. M., Schöner, F. J., \& Smith-Lemmon, L. (2002). Pigmenting efficacy of astaxanthin and canthaxanthin in fresh-water reared Atlantic salmon, Salmo salar. Animal Feed Science and Technology, 99(1-4), 97-106. Retrieved from: https://doi.org/10.1111/j.13652109.2009.02195.x

Balm, P. H. M., Pepels, P. P. L. M., Helfrich, S., Hovens, M. L. M., \& Bonga, S. W. (1994). Adrenocorticotropic hormone in relation to interrenal function during stress in tilapia (Oreochromis mossambicus). General and Comparative Endocrinology, 96(3), 347-360. Retrieved from: https://doi.org/10.1006/gcen.1994.1190

Barcellos, L. J., Nicolaiewsky, S., De Souza, S. M., \& Lulhier, F. (1999). The effects of stocking density and social interaction on acute stress response in Nile tilapia Oreochromis niloticus (L.) fingerlings. Aquaculture Research, 30(11-12), 887-892. Retrieved from: https://doi.org/10.1046/j.1365-2109.1999.00419.x

Belal, E. B., \& El-Hais, A. M. A. (2012). Use of spirulina (Arthrospira fusiformis) for promoting growth of Nile Tilapia fingerlings. African Journal of Microbiology Research, 6(35), 6423-6431. Retrieved from: https://doi.org/10.5897/AJMR12.288

Barton, B. A., \& Iwama, G. K. (1991). Physiological changes in fish from stress in aquaculture with emphasis on the response and effects of corticosteroids. Annual Review of Fish Diseases, 1, 3-26. Retrieved from: https://doi.org/10.1016/0959-8030(91)90019-G

Boyd, C. E., \& Tucker, C. S. (2012). Pond aquaculture water quality management. Springer Science \& Business Media.

Cerezuela, R., Cuesta, A., Meseguer, J., \& Esteban, M. Á. (2008). Effects of inulin on gilthead seabream (Sparus aurata L.) innate immune parameters. Fish and Shellfish Immunology, 24(5), 663-668. Retrieved from: https://doi.org/10.1016/j.fsi.2007.10.002

Chamorro, G., Salazar, M., Gomes de Lima Araújo, K., Pereira dos Santos, C., Ceballos, G., \& Fabila Castillo, L. (2002). Actualización en la farmacología de Spirulina (Arthrospira), un alimento no convencional. Archivos Latinoamericanos de Nutricion, 52(3), 232-240.

Chao, A. (1984). Nonparametric estimation of the number of classes in a population. Scandinavian Journal of Statistics, 11(4), 265-270.

Chao, A., \& Lee, S. M. (1992). Estimating the number of classes via sample coverage. Journal of the American Statistical Association, 87(417), 210-217. Retrieved from: https://doi.org/10.1080/01621459.1992.10475194

De Jesus Raposo, M. F., de Morais, A. M. M. B., \& de Morais, R. M. S. C. (2016). Emergent sources of prebiotics: seaweeds and microalgae. Marine Drugs, 14(2), 27. Retrieved from: https://doi.org/10.3390/md14020027

Dehler, C. E., Secombes, C. J., \& Martin, S. A. (2017). Environmental and physiological factors shape the gut microbiota of Atlantic salmon parr (Salmo salar L.). Aquaculture, 467, 149-157. Retrieved from: https://doi.org/10.1016/j.aquaculture.2016.07.017

Ebeling, J. M., \& Timmons, M. B. (2012). Recirculating aquaculture systems. Aquaculture Production Systems, 245-277. Retrieved from: https://doi.org/10.1002/9781118250105.ch11 
El-Haroun, E. R., Goda, . S., \& Chowdhury, K. (2006). Effect of dietary probiotic Biogen ${ }^{\circledR}$ supplementation as a growth promoter on growth performance and feed utilization of Nile tilapia Oreochromis niloticus (L.). Aquaculture Research, 37(14), 1473-1480. Retrieved from: https://doi.org/10.1111/j.1365-2109.2006.01584.x

El-Sheekh, M., El-Shourbagy, I., Shalaby, S., \& Hosny, S. (2014). Effect of feeding Arthrospira platensis (Spirulina) on growth and carcass composition of hybrid red Tilapia (Oreochromis niloticus $x$ Oreochromis mossambicus). Turkish Journal of Fisheries and Aquatic Sciences, 14(2), 471-478. Retrieved from: https://doi.org/10.4194/1303-2712-v14_2_18

Evans, F. D., \& Critchley, A. T. (2014). Seaweeds for animal production use. Journal of Applied phycology, 26(2), 891-899. Retrieved from: https://doi.org/10.1007/s10811-013-0162-9

Fan, L., et al. (2017). Characterization of microbial communities in intensive GIFT tilapia (Oreochromis niloticus) pond systems during the peak period of breeding. Aquaculture Research, 48(2), 459472. Retrieved from: https://doi.org/10.1111/are.12894

Fečkaninová, ., Koščová, J., Mudroňová, D., Popelka, P., \& Toropilova, J. (2017). The use of probiotic bacteria against Aeromonas infections in salmonid aquaculture. Aquaculture, 469, 1-8. Retrieved from: https://doi.org/10.1016/j.aquaculture.2016.11.042

Gaggìa, F., Mattarelli, P., \& Biavati, B. (2010). Probiotics and prebiotics in animal feeding for safe food production. International Journal of Food Microbiology, 141, S15-S28. Retrieved from: https://doi.org/10.1016/j.ijfoodmicro.2010.02.031

Gaikwad, S. S., Shouche, Y. S., \& Gade, W. N. (2017). Deep sequencing reveals highly variable gut microbial composition of invasive fish Mossambicus Tilapia (Oreochromis mossambicus) Collected from two different habitats. Indian Journal of Microbiology, 57(2), 235-240. Retrieved from: https://doi.org/10.1007/s12088-017-0641-9

Gajardo, K., et al. (2016). A high-resolution map of the gut microbiota in Atlantic salmon (Salmo salar): A basis for comparative gut microbial research. Scientific Reports, 6, 30893. Retrieved from: https://doi.org/10.1038/srep30893

Gamito, S. (2010). Caution is needed when applying Margalef diversity index. Ecological Indicators, 10(2), 550-551. Retrieved from: https://doi.org/10.1016/j.ecolind.2009.07.006

Giatsis, C., et al. (2015). The impact of rearing environment on the development of gut microbiota in tilapia larvae. Scientific Reports, 5, 18206. Retrieved from: https://doi.org/10.1038/srep18206

Gomes, I. G., et al. (2012). Dietary supplementation with Spirulina platensis increases growth and colour of red tilapia. Revista Colombiana de Ciencias Pecuarias, 25(3), 462-471.

Grisdale-Helland, B., Helland, S. J., \& Gatlin III, D. M. (2008). The effects of dietary supplementation with mannanoligosaccharide, fructooligosaccharide or galactooligosaccharide on the growth and feed utilization of Atlantic salmon (Salmo salar). Aquaculture, 283(1-4), 163-167. Retrieved from: https://doi.org/10.1016/j.aquaculture.2008.07.012

Hammer, Ø., Harper, D. A. T. \& Paul, D. R. (2001). Past: Paleontological statistics software package for education and data analysis. Palaeontología Electrónica, 4(1), 9. Retrieved from: http://palaeoelectronica.org/2001_1/past/issue1_01.htm

Haygood, A. M., \& Jha, R. (2016). Strategies to modulate the intestinal microbiota of Tilapia (Oreochromis sp.) in aquaculture: a review. Reviews in Aquaculture (0), 1-14. Retrieved from: https://doi.org/10.1111/raq.12162

He, S., et al. (2017). Antibiotic growth promoter olaquindox increases pathogen susceptibility in fish by inducing gut microbiota dysbiosis. Science China Life Sciences, 60(11), 1260-1270. Retrieved from: https://doi.org/10.1007/s11427-016-9072-6 
Hsieh, C. W., Lai, C. H., Lee, C. H., \& Ko, W. C. (2011). Effects of high-voltage electrostatic fields on the quality of Tilapia meat during refrigeration. Journal of Food Science, 76(6), M312-7. Retrieved from: https://doi.org/10.1111/j.1750-3841.2011.02218.x

Huyben, D., et al. (2017). Effects of dietary inclusion of the yeasts Saccharomyces cerevisiae and Wickerhamomyces anomalus on gut microbiota of rainbow trout. Aquaculture, 473, 528-537. Retrieved from: https://doi.org/10.1016/j.aquaculture.2017.03.024

Iwata, K., Inayama, T., \& Kato, T. (1990). Effects of Spirulina platensis on plasma lipoprotein lipase activity in fructose-induced hyperlipidemic rats. Journal of Nutritional Science and Vitaminology, 36(2), 165-171. Retrieved from: https://doi.org/10.3177/jnsv.36.165

James, R., Sampath, K., Thangarathinam, R., \& Vasudevan, I. (2006). Effect of dietary spirulina level on growth, fertility, colouration and leucocyte count in red swordtail, Xiphophorus helleri. Retrieved from http://hdl.handle.net/10524/19166.

Jiang, Y., et al. (2011). Cellulase-producing bacteria of Aeromonas are dominant and indigenous in the gut of Ctenopharyngodon idellus (Valenciennes). Aquaculture Research, 42(4), 499-505. Retrieved from: https://doi.org/10.1111/j.1365-2109.2010.02645.x

Jourdan, J. P. (1999). Cultivez votre spiruline, manuel de culture artisanale de la spiruline. Antenna Technology. París, Francia.

Karadal, O., Güroy, D., \& Türkmen, G. (2017). Effects of feeding frequency and Spirulina on growth performance, skin colouration and seed production on kenyi cichlids (Maylandia lombardoi). Aquaculture International, 25(1), 121-134. Retrieved from: https://doi.org/10.1007/s10499-0160017-x

Khanzadeh, M., Fereidouni, A. E., \& Berenjestanaki, S. S. (2016). Effects of partial replacement of fish meal with Spirulina platensis meal in practical diets on growth, survival, body composition, and reproductive performance of three-spot gourami (Trichopodus trichopterus) (Pallas, 1770). Aquaculture International, 24(1), 69-84. Retrieved from: https://doi.org/10.1007/s10499-0159909-4

Koh, C. B., Romano, N., Zahrah, A. S., \& Ng, W. K. (2016). Effects of a dietary organic acids blend and oxytetracycline on the growth, nutrient utilization and total cultivable gut microbiota of the red hybrid tilapia, Oreochromis sp., and resistance to Streptococcus agalactiae. Aquaculture research, 47(2), 357-369. Retrieved from: https://doi.org/10.1111/are.12492

Korhonen, R. W., Lanier, T. C., \& Giesbrecht, F. (1990). An evaluation of simple methods for following rigor development in fish. Journal of Food Science, 55(2), 346-348. Retrieved from: ttps://doi.org/10.1111/j.1365-2621.1990.tb06759.x

Leal, B. E. S., et al. (2017). Potential prebiotic oligosaccharides from aqueous thermopressurized phosphoric acid hydrolysates of microalgae used in treatment of gaseous steakhouse waste. Algal Research, 24, 138-147. Retrieved from: https://doi.org/10.1016/j.algal.2017.03.020

Liu, W., et al. (2014). Effects of dietary microencapsulated sodium butyrate on growth, intestinal mucosal morphology, immune response and adhesive bacteria in juvenile common carp (Cyprinus carpio) pre-fed with or without oxidised oil. British Journal of Nutrition, 112(1), 15-29. Retrieved from: https://doi.org/10.1017/S0007114514000610

López-Luna, J., Bermejo-Poza, R., Bravo, F. T., \& Villarroel, M. (2016). Effect of degree-days of fasting stress on rainbow trout, Oncorhynchus mykiss. Aquaculture, 462, 109-114. Retrieved from: https://doi.org/10.1016/j.aquaculture.2016.05.017

Lu, J., Takeuchi, T., \& Ogawa, H. (2003). Flesh quality of tilapia Oreochromis niloticus fed solely on raw Spirulina. Fisheries Science, 69(3), 529-534. Retrieved from: https://doi.org/10.1046/j.14442906.2003.00653.x

Lyons, P. P., Turnbull, J. F., Dawson, K. A., \& Crumlish, M. (2017). Effects of low-level dietary microalgae supplementation on the distal intestinal microbiome of farmed rainbow trout Oncorhynchus mykiss 
(Walbaum). Aquaculture Research, 48(5), 2438-2452. Retrieved from: https://doi.org/10.1111/are.13080

Lv, H. Y., Zhou, Z. G., Rudeaux, F., \& Respondek, F. (2007). Effects of dietary short chain fructooligosaccharides on intestinal microflora, mortality and growth performance of Oreochromis aureus $\widehat{\partial} \times$ O. niloticus +. Chinese Journal of Animal Nutrition, 19(6), 691-697.

Magurran, A. E. (2013). Measuring biological diversity. John Wiley \& Sons.

Manzano, M., Iacumin, L., Giusto, C., Cecchini, F., Patthey, C. (2012). Utilization of denaturing gradient gel electrophoresis (DGGE) to evaluate the intestinal microbiota of brown trout Salmo trutta fario. Journal of Veterinary Science \& Medical Diagnosis, 1, 2. Retrieved from: https://doi.org/10.4172/2325-9590.1000105

Merrifield, D. L., \& Ringo, E. (Eds.). (2014). Aquaculture nutrition: gut health, probiotics and prebiotics. John Wiley \& Sons. Retrieved from: https://doi.org/10.1002/9781118897263

McCarty, M. F. (2007). Clinical potential of Spirulina as a source of phycocyanobilin. Journal of Medicinal Food, 10(4), 566-570. Retrieved from: https://doi.org/10.1089/jmf.2007.621

Michl, S. C., et al. (2017). The malleable gut microbiome of juvenile rainbow trout (Oncorhynchus mykiss): Diet-dependent shifts of bacterial community structures. PloS One, 12(5), e0177735. Retrieved from: https://doi.org/10.1371/journal.pone.0177735

Mommsen, T. P., Vijayan, M. M., \& Moon, T. W. (1999). Cortisol in teleosts: dynamics, mechanisms of action, and metabolic regulation. Reviews in Fish Biology and Fisheries, 9(3), 211-268. Retrieved from: https://doi.org/10.1023/A:1008924418720

Mosenthin, R., \& Bauer, E. (2000). The potential use of prebiotics in pig nutrition. Asian-Australasian Journal of Animal Sciences, 13 (Special iss.), 315-325.

O’Sullivan, L., et al. (2010). Prebiotics from marine macroalgae for human and animal health applications. Marine Drugs, 8(7), 2038-2064. Retrieved from: https://doi.org/10.3390/md8072038

O'Hara, A. M., \& Shanahan, F. (2006). The gut flora as a forgotten organ. EMBO Reports, 7(7), 688-693. Retrieved from: https://doi.org/10.1038/sj.embor.7400731

Oliveira Filho, P. R. C., et al (2015). How Stunning methods affect the quality of Nile tilapia meat. CyTAJournal of Food, 13(1), 56-62. Retrieved from: https://doi.org/10.1080/19476337.2014.911211

Parada, J. L., de Caire, G. Z., de Mule, M. C. Z., \& de Cano, M. M. S. (1998). Lactic acid bacteria growth promoters from Spirulina platensis. International Journal of Food Microbiology, 45(3), 225-228. Retrieved from: https://doi.org/10.1016/S0168-1605(98)00151-2

Patterson, J. A., \& Burkholder, K. M. (2003). Application of prebiotics and probiotics in poultry production. Poultry Science, 82(4), 627-631. Retrieved from: https://doi.org/10.1093/ps/82.4.627

Pedrotti, F. S., et al. (2015). The autochthonous microbiota of the freshwater omnivores jundiá (Rhamdia quelen) and tilapia (Oreochromis niloticus) and the effect of dietary carbohydrates. Aquaculture Research, 46(2), 472-481. Retrieved from: https://doi.org/10.1111/are.12195

Penninks, A., Baert, K., Levorato, S., \& Binaglia, M. (2017). Dyes used in aquaculture. EFSA Journal, 15(7). Retraived from: https://doi.org/10.2903/j.efsa.2017.4920

Pignolet, O., Jubeau, S., Vaca-Garcia, C., \& Michaud, P. (2013). Highly valuable microalgae: biochemical and topological aspects. Journal of Industrial Microbiology and Biotechnology, 40(8), 781. Retrieved from: https://doi.org/10.1007/s10295-013-1281-7

Pottinger, T. G., \& Carrick, T. R. (1999). Modification of the plasma cortisol response to stress in rainbow trout by selective breeding. General and Comparative Endocrinology, 116(1), 122-132. Retrieved from: https://doi.org/10.1006/gcen.1999.7355 
R.Team, T. R. D. C. (2008). The R project for statistical computing. Retrieved from: http://www.r-project. org.

Ran, C., et al. (2016). Effects of dietary live and heat-inactive baker's yeast on growth, gut health, and disease resistance of Nile tilapia under high rearing density. Fish and Shellfish Immunology, 56, 263-271. Retrieved from: https://doi.org/10.1016/j.fsi.2016.07.001

Ringø, E., Sperstad, S., Kraugerud, O. F., \& Krogdahl, Å. (2008). Use of 16S rRNA gene sequencing analysis to characterize culturable intestinal bacteria in Atlantic salmon (Salmo salar) fed diets with cellulose or non-starch polysaccharides from soy. Aquaculture Research, 39(10), 1087-1100. Retrieved from: https://doi.org/10.1111/j.1365-2109.2008.01972.x

Ringø, E., et al. (2010). Prebiotics in aquaculture: a review. Aquaculture Nutrition, 16(2), 117-136. Retrieved from: https://doi.org/10.1111/j.1365-2095.2009.00731.x

Ringø, E., et al., (2016). Effect of dietary components on the gut microbiota of aquatic animals. A neverending story? Aquaculture Nutrition, 22(2), 219-282. Retrieved from: https://doi.org/10.1111/anu.12346

Shanmugapriya, B., Babu, S. S., Hariharan, T., Sivaneswaran, S., \& Anusha, M. B. (2015). Dietary administration of Spirulina platensis as probiotics on growth performance and histopathology in broiler chicks. International Journal of Recent Scientific Research, 6(2), 2650-3.

Smith, E. P., \& van Belle, G. (1984). Nonparametric estimation of species richness. Biometrics, 119-129. Retrieved from: https://doi.org/10.2307/2530750

Sommer, T. R., D'Souza, F. M. L., \& Morrissy, N. M. (1992). Pigmentation of adult rainbow trout, Oncorhynchus mykiss, using the green alga Haematococcus pluvialis. Aquaculture, 106(1), 63-74. Retrieved from: https://doi.org/10.1016/0044-8486(92)90

Sommer, T. R., Potts, W. T., \& Morrissy, N. M. (1991). Utilization of microalgal astaxanthin by rainbow trout (Oncorhynchus mykiss). Aquaculture, 94(1), 79-88. Retrieved from: https://doi.org/10.1016/0044-8486(91)90130-Y

Sun, X., et al. (2012). The effect of dietary pigments on the colouration of Japanese ornamental carp (koi, Cyprinus carpio L.). Aquaculture, 342, 62-68. Retrieved from: https://doi.org/10.1016/j.aquaculture.2012.02.019

Suzuki, T. A., \& Nachman, M. W. (2016). Spatial heterogeneity of gut microbial composition along the gastrointestinal tract in natural populations of house mice. PloS One, 11(9). Retrieved from: https://doi.org/10.1371/journal.pone.0163720

Takeuchi, T., Lu, J. U. N., Yoshizaki, G., \& Satoh, S. (2002). Effect on the growth and body composition of juvenile tilapia Oreochromis niloticus fed raw Spirulina. Fisheries Science, 68(1), 34-40. Retrieved from: https://doi.org/10.1046/j.1444-2906.2002.00386.x

Torrecillas, S., et al. (2017). Effect of fishmeal and fish oil replacement by vegetable meals and oils on gut health of European sea bass (Dicentrarchus labrax). Aquaculture, 468, 386-398. Retrieved from: https://doi.org/10.1016/j.aquaculture.2016.11.005

Turnbaugh, P. J., et al. (2006). An obesity-associated gut microbiome with increased capacity for energy harvest. Nature, 444(7122), 1027. Retrieved from: https://doi.org/10.1038/nature05414

Ungsethaphand, T., Peerapornpisal, Y., Whangchai, N., \& Sardsud, U. (2010). Effect of feeding Spirulina platensis on growth and carcass composition of hybrid red tilapia (Oreochromis mossambicus $\times$ O. niloticus). Maejo International Journal of Science and Technology, 4(2), 331-336

van Kessel, M. A., et al. (2011). Pyrosequencing of 16S rRNA gene amplicons to study the microbiota in the gastrointestinal tract of carp (Cyprinus carpio L.). AMB Express, 1(1), 41. Retrieved from: https://doi.org/10.1186/2191-0855-1-41 
Velasquez, S. F., et al. (2016). Dietary Spirulina (Arthrospira platensis) replacement enhances performance of juvenile Nile tilapia (Oreochromis niloticus). Journal of Applied Phycology, 8(2), 1023-1030. Retrieved from: https://doi.org/10.1007/s10811-015-0661-y

Vijayan, M. M., Pereira, C., Grau, E. G., \& Iwama, G. K. (1997). Metabolic responses associated with confinement stress in tilapia: the role of cortisol. Comparative Biochemistry and Physiology Part C: Pharmacology, Toxicology and Endocrinology, 116(1), 89-95. Retrieved from: https://doi.org/10.1016/S0742-8413(96)00124-7

Wang, A. R., Ran, C., Ringø, E., \& Zhou, Z. G. (2017). Progress in fish gastrointestinal microbiota research. Reviews in Aquaculture Retrieved from: https://doi.org/10.1111/raq.12191.

Wu, S., et al. (2010). Microbial diversity of intestinal contents and mucus in yellow catfish (Pelteobagrus fulvidraco). Aquaculture, 303(1-4), 1-7. Retrieved from: https://doi.org/10.1016/j.aquaculture.2009.12.025

Wu, S., Tian, J., Wang, G., Li, W., \& Zou, H. (2012). Characterization of bacterial community in the stomach of yellow catfish (Pelteobagrus fulvidraco). World Journal of Microbiology and Biotechnology, 28(5), 2165-2174. Retrieved from: https://doi.org/10.1007/s11274-012-1022-5

Ye, L., Amberg, J., Chapman, D., Gaikowski, M., \& Liu, W. T. (2014). Fish gut microbiota analysis differentiates physiology and behavior of invasive Asian carp and indigenous American fish. The ISME Journal, 8(3), 541. Retrieved from: https://doi.org/10.1038/ismej.2013.181

Yeganeh, S., Teimouri, M., \& Amirkolaie, A. K. (2015). Dietary effects of Spirulina platensis on hematological and serum biochemical parameters of rainbow trout (Oncorhynchus mykiss) Research in Veterinary Science, 101, 84-88. Retrieved from: https://doi.org/10.1016/j.rvsc.2015.06.002

Zarrouk, C. (1966). Contribution a l'etude d'une Cyanophycee. Influence de Divers Facteurs Physiques et Chimiques sur la croissance et la photosynthese de Spirulina maxima. Thesis. University of Paris, France.

Zhai, Q., et al. (2017). Effect of dietary probiotic supplementation on intestinal microbiota and physiological conditions of Nile tilapia (Oreochromis niloticus) under waterborne cadmium exposure. Antonie van Leeuwenhoek, 110(4), 501-513. Retrieved from: https://doi.org/10.1007/s10482-016-0819-x

Zhou, Z., Ding, Z., \& Huiyuan, L. V. (2007). Effects of dietary short-chain fructooligosaccharides on intestinal microflora, survival, and growth performance of juvenile white shrimp, Litopenaeus vannamei. Journal of the World Aquaculture Society, 38(2), 296-301. Retrieved from: https://doi.org/10.1111/j.1749-7345.2007.00099.x.

Zhou, Z., et al. (2009). The effects of dietary yeast culture or short-chain fructo-oligosaccharides on the intestinal autochthonous bacterial communities in juvenile hybrid tilapia, Oreochromis

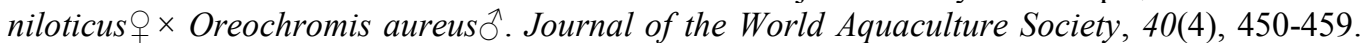
Retrieved from: https://doi.org/10.1111/j.1749-7345.2009.00272.x

Zhou, Z., et al. (2013). Enhancement of growth and intestinal flora in grass carp: the effect of exogenous cellulase. Aquaculture, 416, 1-7. Retrieved from: https://doi.org/10.1016/j.aquaculture.2013.08.023. 
BIBLIOGRAFÍA

TABLE 1 Summary of publications that have studied analysed microbiota in Oreochromis species.

\begin{tabular}{|c|c|c|c|c|c|c|c|c|c|}
\hline Reference & Species & $\begin{array}{l}\text { Country } \\
\text { /System } \\
\end{array}$ & Kit Isolation & Primer & $\left.5^{\prime}-3^{\prime}\right)$ & Amplification & Tax. Program & $\begin{array}{l}\text { Principal } \\
\text { Bacteria } \\
\end{array}$ & $\pm \%$ \\
\hline $\begin{array}{l}\text { Fan et al., } \\
2013\end{array}$ & $\begin{array}{l}\text { Orechromis } \\
\text { niloticus }\end{array}$ & $\begin{array}{l}\text { Wuxi, China } \\
\text { /Ponds }\end{array}$ & $\begin{array}{l}\text { PowerSoil DNA Kit } \\
\text { (MO BIO, Carlsbad, } \\
\text { CA, USA) }\end{array}$ & $\begin{array}{l}27 \mathrm{~F} \\
338 \mathrm{RI} \\
388 \mathrm{RII}\end{array}$ & $\begin{array}{l}\text { 5'-GAG TTT GAT CMT GGC TCA G-3' } \\
\text { 5'-GCW GCC TCC CGT AGG AGT-3' } \\
\text { 5'-GCW GCC ACC CGT AGG TGT-3' }\end{array}$ & $\begin{array}{l}\text { QuantiFluor TM-ST } \\
\text { fluorometer }\end{array}$ & QIIME & $\begin{array}{l}\text { Fusobacteria } \\
\text { Protobacteria } \\
\text { Firmicutes }\end{array}$ & $\begin{array}{l}26.0 \\
25.6 \\
19.4\end{array}$ \\
\hline $\begin{array}{l}\text { Zhai et al., } \\
2016\end{array}$ & $\begin{array}{l}\text { Orechromis } \\
\text { niloticus }\end{array}$ & $\begin{array}{l}\text { Wuxi, China } \\
\text { /Tanks }\end{array}$ & $\begin{array}{l}\text { E.Z.N.A DNA kit } \\
\text { (Omega Bio-tek, } \\
\text { Norcross, GA, US) }\end{array}$ & $\begin{array}{l}515 \mathrm{~F} \\
907 \mathrm{R}\end{array}$ & $\begin{array}{l}\text { 5'-BCode-GTG CCA GCM GC CGC GG-3' } \\
\text { 5'-CCG TCA ATT CMT TTR AGT TT-3' }\end{array}$ & Illumina MiSeq & QIIME & $\begin{array}{l}\text { Fusobacteria } \\
\text { Potobacteria } \\
\text { Bacterioidetes }\end{array}$ & $\begin{array}{l}57.9 \\
30.7 \\
11.8\end{array}$ \\
\hline $\begin{array}{l}\text { Giatsis et } \\
\text { al., } 2015\end{array}$ & $\begin{array}{l}\text { Orechromis } \\
\text { niloticus }\end{array}$ & $\begin{array}{l}\text { Velden, Netherlands } \\
\text { /Recirculation } \\
\text { aquaculture system \& } \\
\text { active suspension }\end{array}$ & $\begin{array}{l}\text { DNeasy Blood \& Tissue Kit } \\
\text { (Qiagen, } \\
\text { Netherlands) }\end{array}$ & $\begin{array}{l}27 \mathrm{~F} \\
338 \mathrm{RI} \\
388 \mathrm{RII}\end{array}$ & $\begin{array}{l}\text { 5'-GAG TTT GAT CMT GGC TCA G-3' } \\
\text { 5'-GCW GCC TCC CGT AGG AGT-3' } \\
\text { 5'-GCW GCC ACC CGT AGG TGT-3' }\end{array}$ & 454 pyrosequencing & QIIME & $\begin{array}{l}\text { Actinobacteria } \\
\text { Protobacteria } \\
\text { Planctomycetes }\end{array}$ & $\begin{array}{l}43.2 \\
21.7 \\
16.6\end{array}$ \\
\hline $\begin{array}{l}\text { Ran et al., } \\
2015\end{array}$ & $\begin{array}{l}\text { Orechromis } \\
\text { niloticus }\end{array}$ & $\begin{array}{l}\text { Beijing, China } \\
\text { /Tanks }\end{array}$ & NGS toolkits & $\begin{array}{l}349 \mathrm{~F} \\
806 \mathrm{R}\end{array}$ & $\begin{array}{l}\text { 5'-GYG CAS CAG KCG MGA AW-3' } \\
\text { 5'-GGA CTA CHV HHH TWT CTA AT-3' }\end{array}$ & Illumina Hiseq2500 & $\begin{array}{l}\text { UCLUST } \\
\text { v1.2.22 }\end{array}$ & $\begin{array}{l}\text { Fusobacteria } \\
\text { Potobacteria }\end{array}$ & $\begin{array}{l}54.0 \\
34.0\end{array}$ \\
\hline $\begin{array}{l}\text { Gaikwad } \\
\text { et al., } 2017\end{array}$ & $\begin{array}{l}\text { Orechromis } \\
\text { mossambicus }\end{array}$ & $\begin{array}{l}\text { Maharashtra, India } \\
\text { River, Mula }\end{array}$ & $\begin{array}{l}\text { Stool Mini Kit } \\
\text { (Qiagen, Venlo, } \\
\text { Netherlands) } \\
\end{array}$ & $\begin{array}{l}27 \mathrm{~F} \\
519 \mathrm{R}\end{array}$ & $\begin{array}{l}\text { 5'-AGR GTT TGA TCM TGG CTC AG-3' } \\
\text { 5'-GWA TTA CCG CGG CKG CTG-3' }\end{array}$ & Illumina Miseq & QIIME & $\begin{array}{l}\text { Fusobacteria } \\
\text { Protobacteria } \\
\text { Firmicutes } \\
\end{array}$ & $\begin{array}{l}53.2 \\
26.8 \\
6.9 \\
\end{array}$ \\
\hline $\begin{array}{l}\text { Gaikwad } \\
\text { et al., } 2017\end{array}$ & $\begin{array}{l}\text { Orechromis } \\
\text { mossambicus }\end{array}$ & $\begin{array}{l}\text { Maharashtra, India } \\
\text { Lake, Talegaon } \\
\text { Dabhade }\end{array}$ & $\begin{array}{l}\text { Stool Mini Kit } \\
\text { (Qiagen, Venlo, } \\
\text { Netherlands) }\end{array}$ & $\begin{array}{l}27 \mathrm{~F} \\
519 \mathrm{R}\end{array}$ & $\begin{array}{l}\text { 5'-AGR GTT TGA TCM TGG CTC AG-3' } \\
\text { 5'-GWA TTA CCG CGG CKG CTG-3' }\end{array}$ & Illumina Miseq & QIIME & $\begin{array}{l}\text { Fusobacteria } \\
\text { Protobacteria } \\
\text { Actinobacteria }\end{array}$ & $\begin{array}{l}36.8 \\
23.6 \\
15.0\end{array}$ \\
\hline
\end{tabular}


TABLE 2 Proximate composition of experimental diets Control (CTR) and A. platensis (SPR) (DM dry matter; CP crude protein; EE ether extract, NDF neutral detergent fibre, DF acid detergent fibre, DL acid detergent lignin and CE crude energy).

\begin{tabular}{lrr} 
& CTR & SPR \\
\hline Fish meal (\%) & 35 & 35 \\
Soybean meal (\%) & 23.5 & 23.5 \\
Wheat meal (\%) & 6,5 & 6.5 \\
Mix mineral-vitamin \% (\%) & 1 & 1 \\
Arthrospira platensis (\%) & 0 & 3 \\
\hline DM (\%) & 92.60 & 92.60 \\
Ash (\%) & 7.39 & 7.37 \\
CP (\%/DM) & 44.59 & 44.3 \\
EE (\%/DM) & 6.39 & 6.44 \\
NDF (\%/DM) & 26.4 & 26.23 \\
ADF (\%/DM) & 4.9 & 5.05 \\
ADL (\%/DM) & 0.6 & 0.7 \\
CE (kcal/g MS) & 5.00 & 4.9
\end{tabular}

* Vitamin-mineral mixture: vitamin A, 500IU; vitamin D, 100IU; vitamin E, 75,000 mg; vitamin K, 20,000 mg; vitamin B1, 10,000 mg; vitamin B3, 30,000 mg; vitamin B6, 20,000 mg; b12 vitamin, 100 $\mathrm{mg}$; vitamin D, 60,000 mg; niacin, 200,000 mg; folic acid, $500 \mathrm{mg}$; biotin, $0.235 \mathrm{mg}$; selenium, 0.2 g, iron, $80 \mathrm{~g}$; manganese, $100 \mathrm{~g}$; zinc, $80 \mathrm{~g}$; copper, $15 \mathrm{~g}$; potassium chloride, $4 \mathrm{~g}$; manganese oxide, $0.6 \mathrm{~g}$; sodium bicarbonate, $1.5 \mathrm{~g}$; iodine, $1.0 \mathrm{~g}$; cobalt, $0.25 \mathrm{~g}$

TABLE 3 Means \pm SD of growth parameters of tilapia fed control feed (CTR) or 3\% A. platensis (SPR) at the initial day 0 (start of experiment) and on finial day 50 (end of experiment).

\begin{tabular}{lrrc} 
& CTR $(\mathbf{n}=\mathbf{5 0})$ & SPR $(\mathbf{n}=\mathbf{5 0})$ & p-values \\
\hline Initial body weight $(\mathbf{g})$ & $109.17 \pm 4.19$ & $109.06 \pm 4.23$ & 0.9 \\
Final body weight $(\mathbf{g})$ & $236.65 \pm 9.73^{\mathrm{b}}$ & $259.39 \pm 9.2^{\mathrm{a}}$ & 0.04 \\
ADG fish (g/d) & $2.50 \pm 0.13^{\mathrm{b}}$ & $2.95 \pm 0.13^{\mathrm{a}}$ & 0.02 \\
& $\mathbf{C T R}(\mathbf{n}=\mathbf{2})$ & $\mathbf{S P R}(\mathbf{n}=\mathbf{2})$ & $\mathbf{p}$-values \\
\hline Division FCR & $1.37^{\mathrm{a}}$ & $1.14^{\mathrm{b}}$ & 0.01 \\
Division TFI (g) & 430 & 430 & 1 \\
Division Survival (\%) & 100 & 100 & 1 \\
\hline
\end{tabular}

*average daily gain (ADG), feed conversion rate (FCR) and total feed intake (TFI). 
TABLE 4 Means \pm SEM of haematological parameters of $O$. niloticus fed control feed (CTR) or $3 \% A$. platensis (SPR).

\begin{tabular}{lrrr} 
& CTR $(\mathbf{n}=\mathbf{2 0})$ & SPR $(\mathbf{n}=\mathbf{2 0})$ & p-value \\
\hline Cortisol (ng/ml) & $10.10 \pm 1.2^{\mathrm{b}}$ & $15.46 \pm 1.5^{\mathrm{a}}$ & 0.02 \\
Glucose (mg//00 ml) & $89.23 \pm 3.5$ & $84.23 \pm 3.6$ & 0.57 \\
Lactate (mmol/L) & $1.44 \pm 0.1$ & $1.43 \pm 0.1$ & 0.73 \\
CPK (U/I) & $3052.4 \pm 409.3$ & $3115.3 \pm 414.5$ & 0.84 \\
Triglycerides (mg/100 $\mathbf{~ m l )}$ & $61.8 \pm 8.7^{\mathrm{b}}$ & $110.5 \pm 7.4^{\mathrm{a}}$ & $<0.001$ \\
Leucocyte (ml/Ul) & $8.68 \pm 0.6$ & $8.24 \pm 0.6$ & 0.30 \\
Haematocrit (\%) & $37.33 \pm 1.1$ & $37.39 \pm 1.1$ & 0.55
\end{tabular}

TABLE 5 Mean $( \pm \mathrm{SD})$ rigor angle, $\mathrm{pH}$, and flesh colour parameters ( $\mathrm{L}^{*}, \mathrm{a}^{*}, \mathrm{~b}^{*}$, chroma $\mathrm{C}^{*}$ and hue $\left.\mathrm{h}^{*}\right)$ of O. niloticus fed control feed (CTR) or 3\% A. platensis (SPR).

\begin{tabular}{crrrr} 
& & $\mathbf{C T R}(\mathbf{n}=\mathbf{2 0})$ & $\mathbf{S P R}(\mathbf{n}=\mathbf{2 0})$ & p-values \\
\hline Rigor angle $\left.\mathbf{~}^{\circ}\right)$ & $\mathbf{0 h}$ & $45.06 \pm 1.26$ & $42.08 \pm 1.26$ & 0.21 \\
& $\mathbf{6 h}$ & $6.62 \pm 1.98$ & $8.32 \pm 1.53$ & 0.50 \\
& $\mathbf{2 4 h}$ & $0.14 \pm 0.14$ & $0.12 \pm 0.12$ & 0.45 \\
& $\mathbf{4 8 h}$ & $2.81 \pm 0.81^{\mathrm{b}}$ & $11.46 \pm 1.06^{\mathrm{a}}$ & $<0.001$ \\
Flesh $\mathbf{p H}$ & $\mathbf{0 h}$ & $6.81 \pm 0.04$ & $6.84 \pm 0.04$ & 0.69 \\
& $\mathbf{6 h}$ & $6.79 \pm 0.02$ & $6.73 \pm 0.04$ & 0.15 \\
& $\mathbf{2 4 h}$ & $6.43 \pm 0.02$ & $6.37 \pm 0.03$ & 0.09 \\
Flesh colour & & & & \\
$\mathbf{L}^{*}$ & $\mathbf{0 h}$ & $47.33 \pm 2.72$ & $49.30 \pm 3.60$ & 0.06 \\
& $\mathbf{2 4 h}$ & $48.95 \pm 1.65$ & $49.08 \pm 1.49$ & 0.79 \\
$\mathbf{a}^{*}$ & $\mathbf{0 h}$ & $-1.86 \pm 0.3$ & $1.84 \pm 0.29$ & 0.77 \\
& $\mathbf{2 4 h}$ & $-1.78 \pm 0.35^{\mathrm{b}}$ & $-1.42 \pm 0.42^{\mathrm{a}}$ & $<0.01$ \\
$\mathbf{b}^{*}$ & $\mathbf{0 h}$ & $-0.39 \pm 0.81$ & $-0.739 \pm 0.71$ & 0.16 \\
& $\mathbf{2 4 h}$ & $-4.74 \pm 0.87^{\mathrm{b}}$ & $-4.26 \pm 0.61^{\mathrm{a}}$ & 0.05 \\
$\mathbf{C}^{*}$ & $\mathbf{0 h}$ & $2.06 \pm 0.35$ & $2.09 \pm 0.32$ & 0.78 \\
& $\mathbf{2 4 h}$ & $5.09 \pm 0.75^{\mathrm{a}}$ & $4.51 \pm 0.57^{\mathrm{b}}$ & $<0.01$ \\
$\left.\mathbf{h}^{*}{ }^{*}{ }^{\circ}\right)$ & $\mathbf{0 h}$ & $12.96 \pm 22.15$ & $21.40 \pm 18.86$ & 0.33 \\
& $\mathbf{2 4 h}$ & $68.70 \pm 6.30$ & $71.50 \pm 6.28$ & 0.17
\end{tabular}


TABLE 6 Mean $( \pm$ SEM) Significant differences in spectral reflectance of $O$. niloticus meat at 24 h, on two different fed treatments, control fed (CTR) and A. platensis supplement fed (SPR)

\begin{tabular}{|c|c|c|c|c|}
\hline wavelength & & $\operatorname{CTR}(n=20)$ & $\operatorname{SPR}(n=20)$ & p-value \\
\hline & $470 \mathrm{~nm}$ & $21.23 \pm 1.18^{b}$ & $22.14 \pm 1.51^{\mathrm{a}}$ & 0.04 \\
\hline & $480 \mathrm{~nm}$ & $20.87 \pm 1.19^{\mathrm{b}}$ & $21.84 \pm 1.53^{\mathrm{a}}$ & 0.03 \\
\hline & $490 \mathrm{~nm}$ & $20.22 \pm 1.18^{\mathrm{b}}$ & $21.22 \pm 1.52^{\mathrm{a}}$ & 0.03 \\
\hline & $500 \mathrm{~nm}$ & $19.52 \pm 1.16^{\mathrm{b}}$ & $20.45 \pm 1.50^{\mathrm{a}}$ & 0.04 \\
\hline & $620 \mathrm{~nm}$ & $16.76 \pm 1.43^{\mathrm{b}}$ & $17.88 \pm 1.93^{\mathrm{a}}$ & 0.04 \\
\hline & $630 \mathrm{~nm}$ & $16.88 \pm 1.48^{\mathrm{b}}$ & $18.11 \pm 2.03^{\mathrm{a}}$ & 0.04 \\
\hline & $640 \mathrm{~nm}$ & $16.87 \pm 1.51^{\mathrm{b}}$ & $18.11 \pm 2.06^{\mathrm{a}}$ & 0.04 \\
\hline & $650 \mathrm{~nm}$ & $16.93 \pm 1.55^{\mathrm{b}}$ & $18.16 \pm 2.09^{\mathrm{a}}$ & 0.03 \\
\hline & $660 \mathrm{~nm}$ & $16.99 \pm 1.57^{b}$ & $18.21 \pm 2.10^{\mathrm{a}}$ & 0.04 \\
\hline & $670 \mathrm{~nm}$ & $17.11 \pm 1.58^{b}$ & $18.21 \pm 2.11^{\mathrm{a}}$ & $<0.05$ \\
\hline
\end{tabular}

TABLE 7 Diversity indices calculated by QIIME software comparing the gut microbiome of $O$. niloticus fed control feed (CTR) or 3\% A. platensis (SPR). Operational taxonomic units (OTUs) are defined at 97\% sequence similarity.

\begin{tabular}{lrrrrrr} 
& Taxa S & Individuals & Shannon H & Simpson 1-D & Margalef & Chao-1 \\
\hline CTR_056A & 71 & 209538 & 3.66 & 0.92 & 58.11 & 774.30 \\
CTR_13B6 & 431 & 441930 & 2.93 & 0.84 & 33.08 & 498.30 \\
CTR_CEE9 & 384 & 246371 & 1.73 & 0.60 & 30.85 & 500.20 \\
CTR_CEEB & 469 & 307394 & 2.72 & 0.84 & 37.04 & 531.90 \\
CTR_E0BD & 592 & 355241 & 2.68 & 0.78 & 46.24 & 679.10 \\
CTR_FF98 & 498 & 169468 & 2.47 & 0.76 & 41.28 & 588.40 \\
CTR_FF9B & 429 & 387646 & 2.92 & 0.84 & 33.26 & 520.90 \\
CTR_FF9B & 592 & 357727 & 2.57 & 0.81 & 46.22 & 664.90 \\
SPR_055B & 412 & 365829 & 2.85 & 0.84 & 32.08 & 466.50 \\
SPR_3331 & 515 & 200177 & 2.44 & 0.80 & 42.11 & 606.70 \\
SPR_3E31 & 385 & 349497 & 2.52 & 0.75 & 30.08 & 431.50 \\
SPR_3FAA & 558 & 423622 & 3.75 & 0.93 & 42.99 & 690.00 \\
SPR_CEEF & 356 & 456785 & 2.55 & 0.79 & 27.24 & 406.40 \\
SPR_D415 & 607 & 437080 & 2.41 & 0.74 & 46.66 & 681.80 \\
SPR_FB22 & 332 & 286631 & 1.75 & 0.70 & 26.34 & 393.10 \\
SPR_FFDC & 466 & 475336 & 2.91 & 0.85 & 35.57 & 541.10 \\
\hline CTR_(Mean \pm SEM) & $513.50 \pm 164$ & $309414 \pm 93849$ & $2.71 \pm 0.54$ & $0.80 \pm 0.1$ & $40.76 \pm 9.2$ & $594.75 \pm 101.4$ \\
SPR_(Mean \pm SEM) & $453.88 \pm 99$ & $374369 \pm 94171$ & $2.65 \pm 0.57$ & $0.80 \pm 0.1$ & $35.38 \pm 7.7$ & $527.14 \pm 120.9$ \\
\hline p-value & 0.766 & 0.188 & 0.8246 & 0.977 & 0.225 & 0.246 \\
& & & 176 & & & \\
\end{tabular}


FIGURES

FIGURE 1 Relative abundance of bacteria phyla in the intestines of eight individual $O$. niloticus fed control feed (CTR) or 3\% A. platensis (SPR) including treatment means and total means.

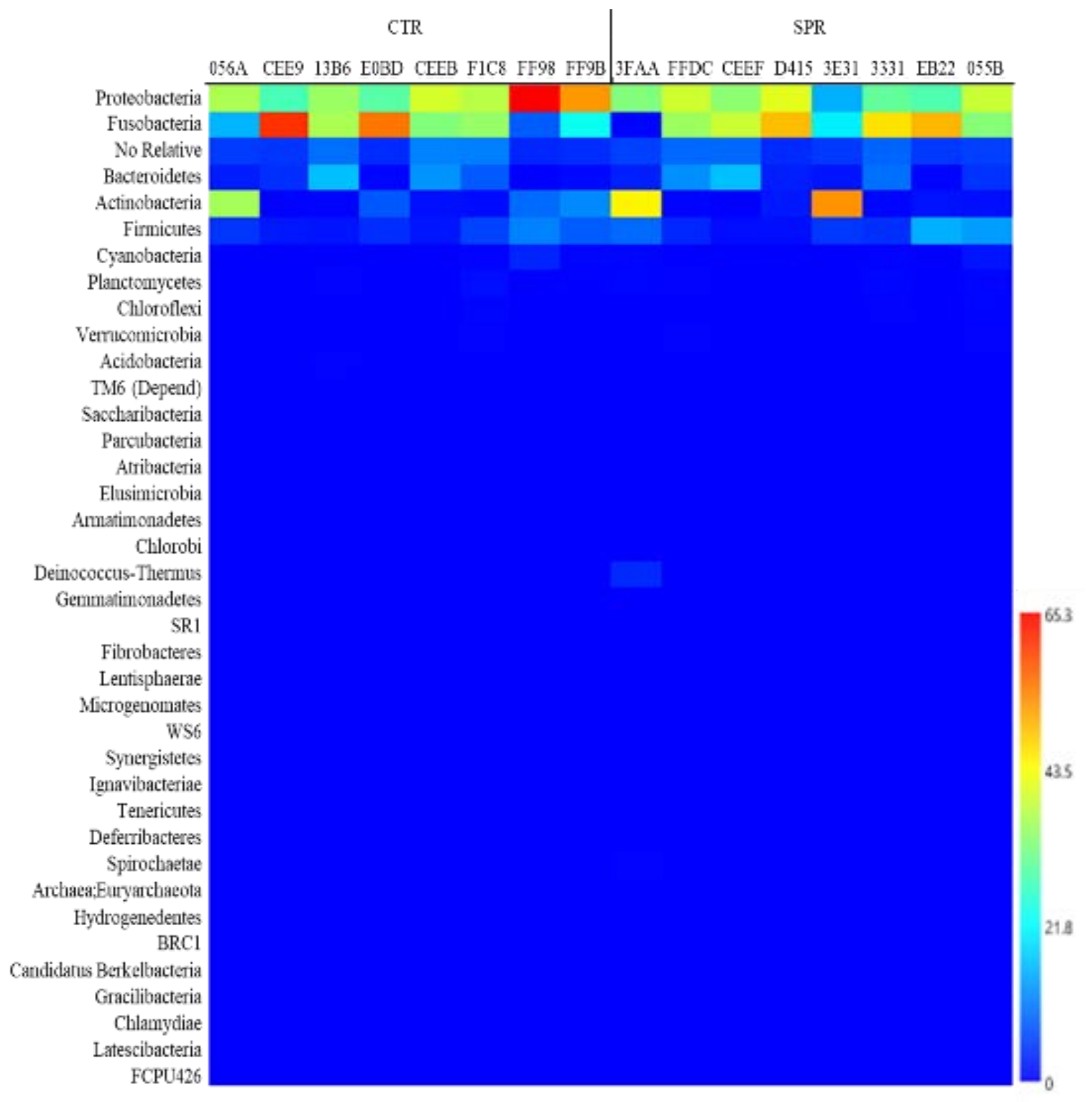


FIGURE 2 Relative abundance of bacteria genus in the intestine of $O$. niloticus fed control feed (CTR) or $3 \%$ A. platensis (SPR).

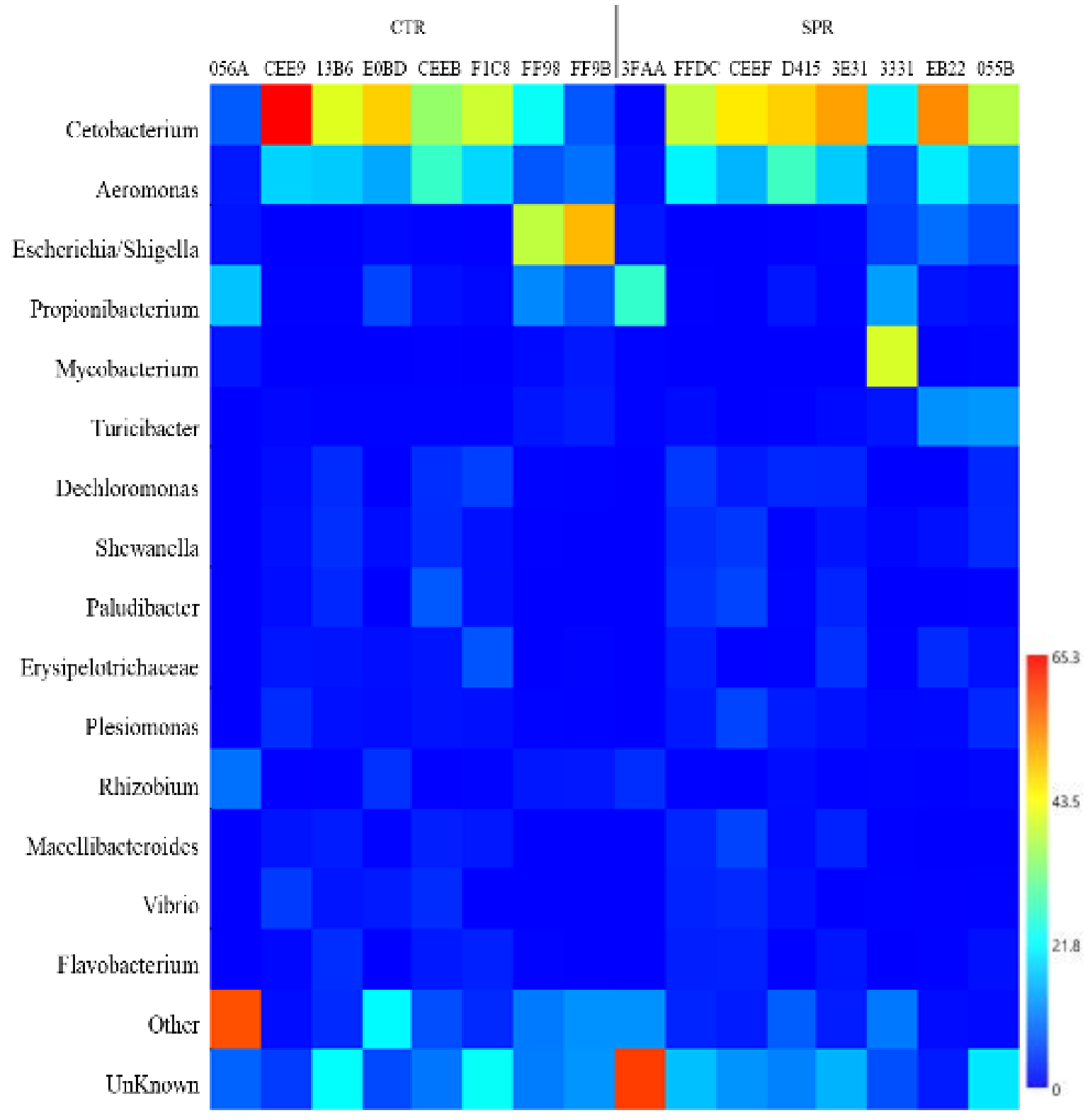


FIGURE 3 Cluster similitude analysis of gut bacteria from eight individual $O$. niloticus fed control feed (CTR) or 3\% A. platensis (SPR) using Bray-Curtis test (PAST software, 2017).

mykiss (Michl et al.,2017) s, lake (Gaikwad et al.,2016) s, river (Gaikwad et al., 2016)

mykiss (Huyben et al., 2017)

\begin{tabular}{|c|c|c|c|c|c|c|c|c|c|}
\hline \multicolumn{10}{|c|}{ Similarity } \\
\hline & 8 & $\therefore$ & 8 & $\therefore$ & 8 & $\therefore$ & 8 & 8 & $\therefore$ \\
\hline & $\infty$ & 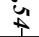 & ธิ & aे & N & कै & $\infty$ & 8 & 8 \\
\hline
\end{tabular}

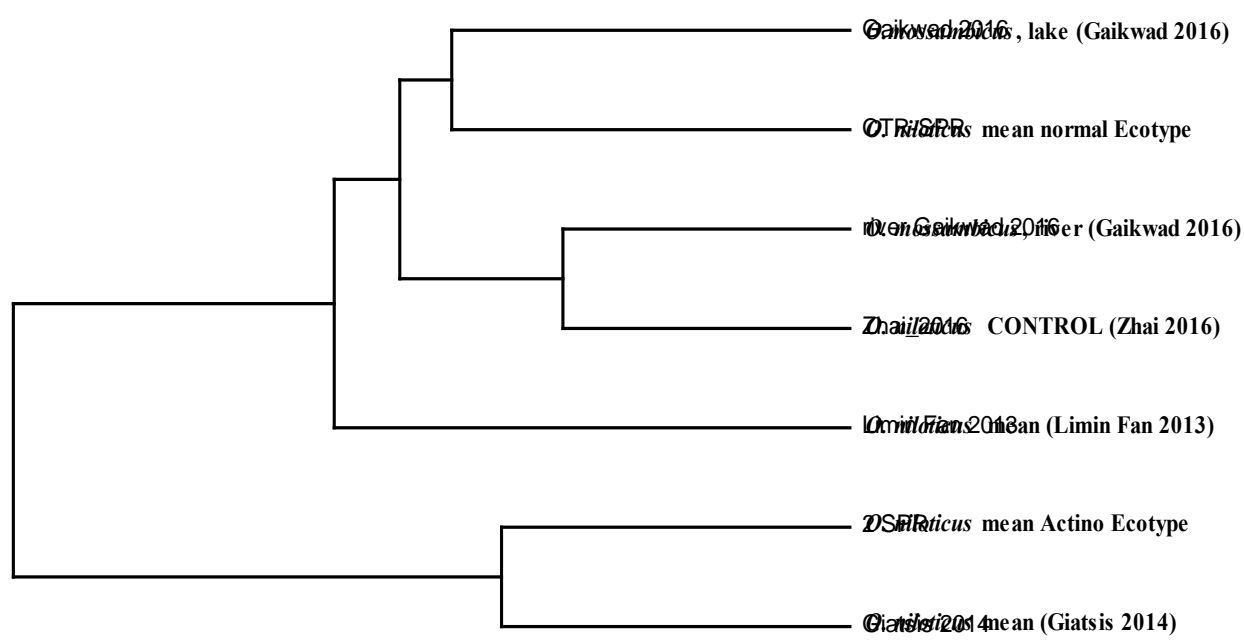


FIGURE 4 Spectral reflectance curves of $O$. niloticus. flesh at $0 \mathrm{~h}$ and $24 \mathrm{~h}$ post-mortem, on two different fed treatments, control fed (CTR) in orange and A. platensis supplement fed (SPR) in green.

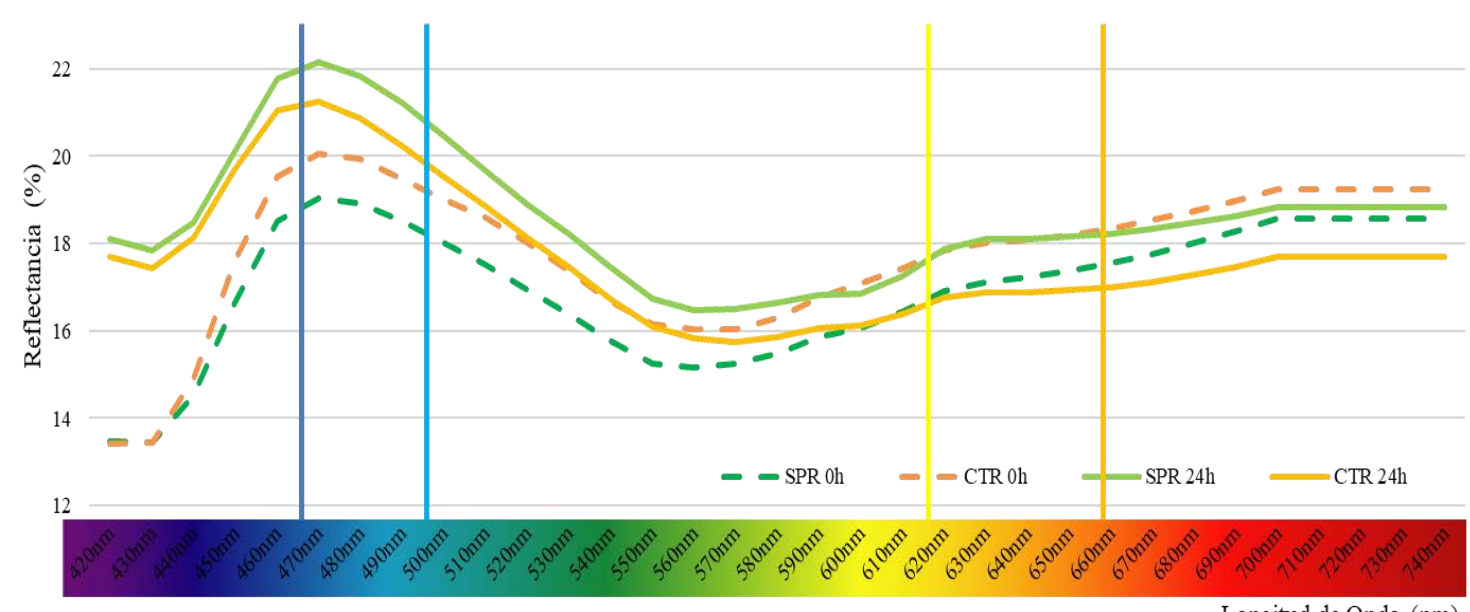

Longitud de Onda (nm)

*space between blue and orange bars mark p-value ranges

FIGURE 5 Cluster similitude analysis of gut bacteria of different Oreochromis sp. studies; Using BrayCurtis test. Using mean data from those contributed by the fish control of the various studies performed by the authors.

\begin{tabular}{|c|c|c|c|c|c|c|c|c|c|}
\hline \multicolumn{10}{|c|}{ Similarity } \\
\hline $\begin{array}{l}\underbrace{}_{N} \\
\text { N }\end{array}$ & $\stackrel{D}{\phi}$ & $\dot{i}_{t}$ & $\ddot{\vec{q}}$ & $\ddot{a}$ & $\underset{N}{N}$ & $\stackrel{\oplus}{\phi}$ & $\dot{\infty}$ & $\stackrel{8}{8}$ & $\stackrel{8}{\circ}$ \\
\hline
\end{tabular}

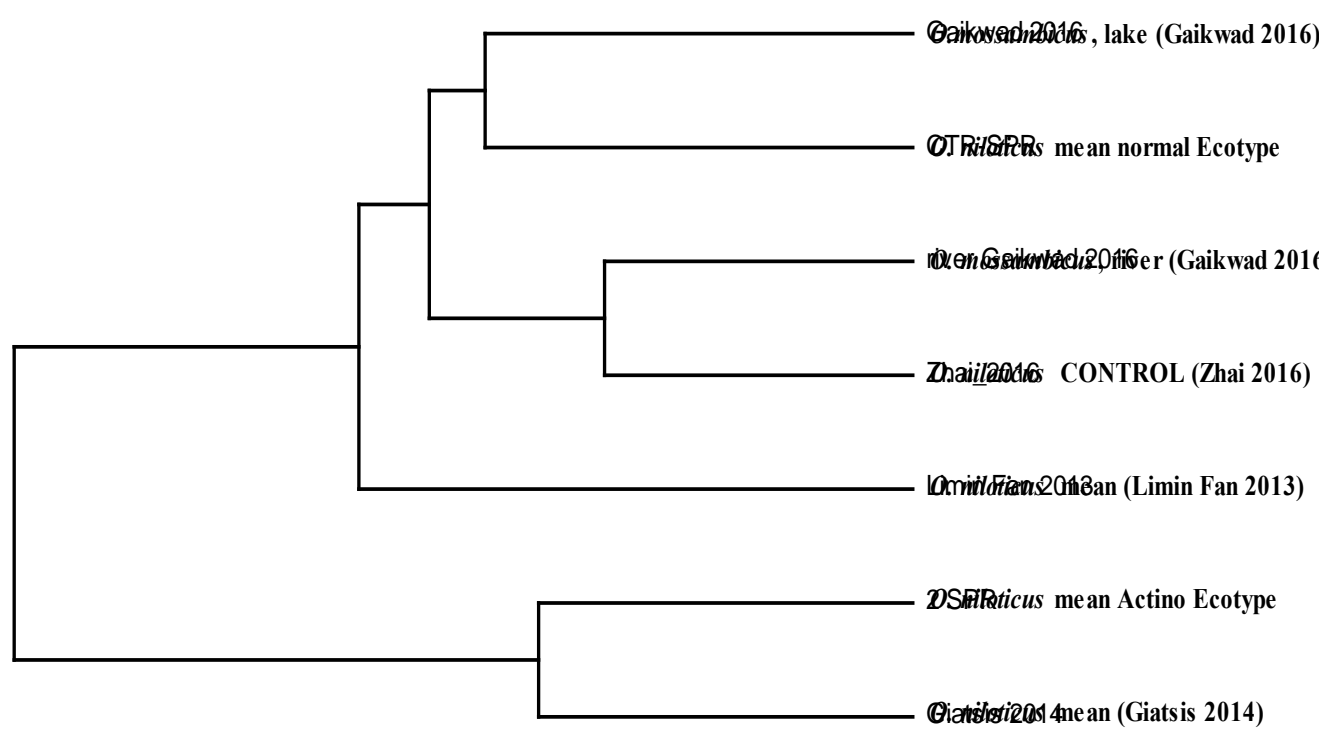

${ }^{3}$ Dep. de Producción Animal, Facultad de Veterinaria, Universidad Complutense, Av. Puerta de Hierro s/n, 28040, Madrid, Spain. 


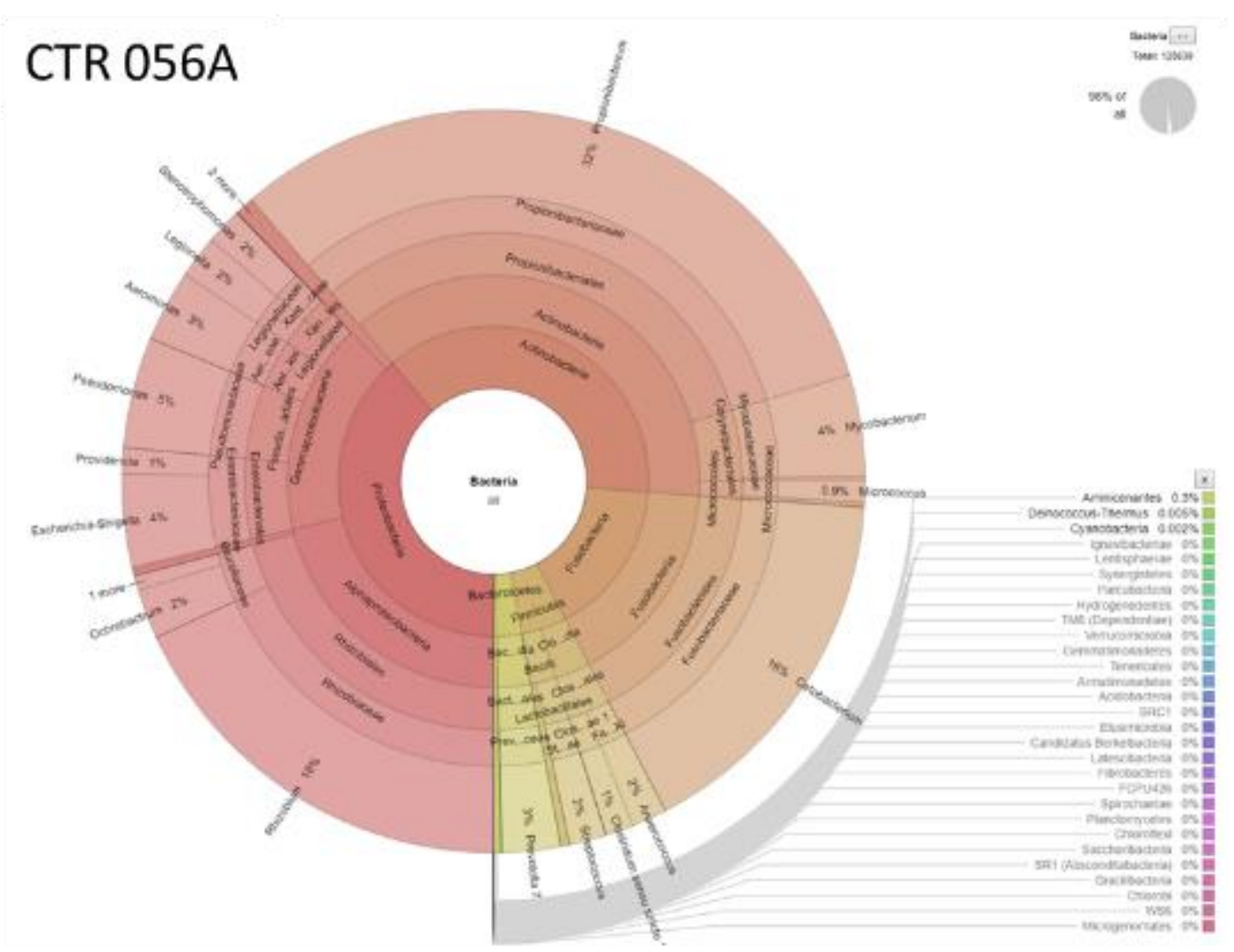

\section{CTR CEE9}

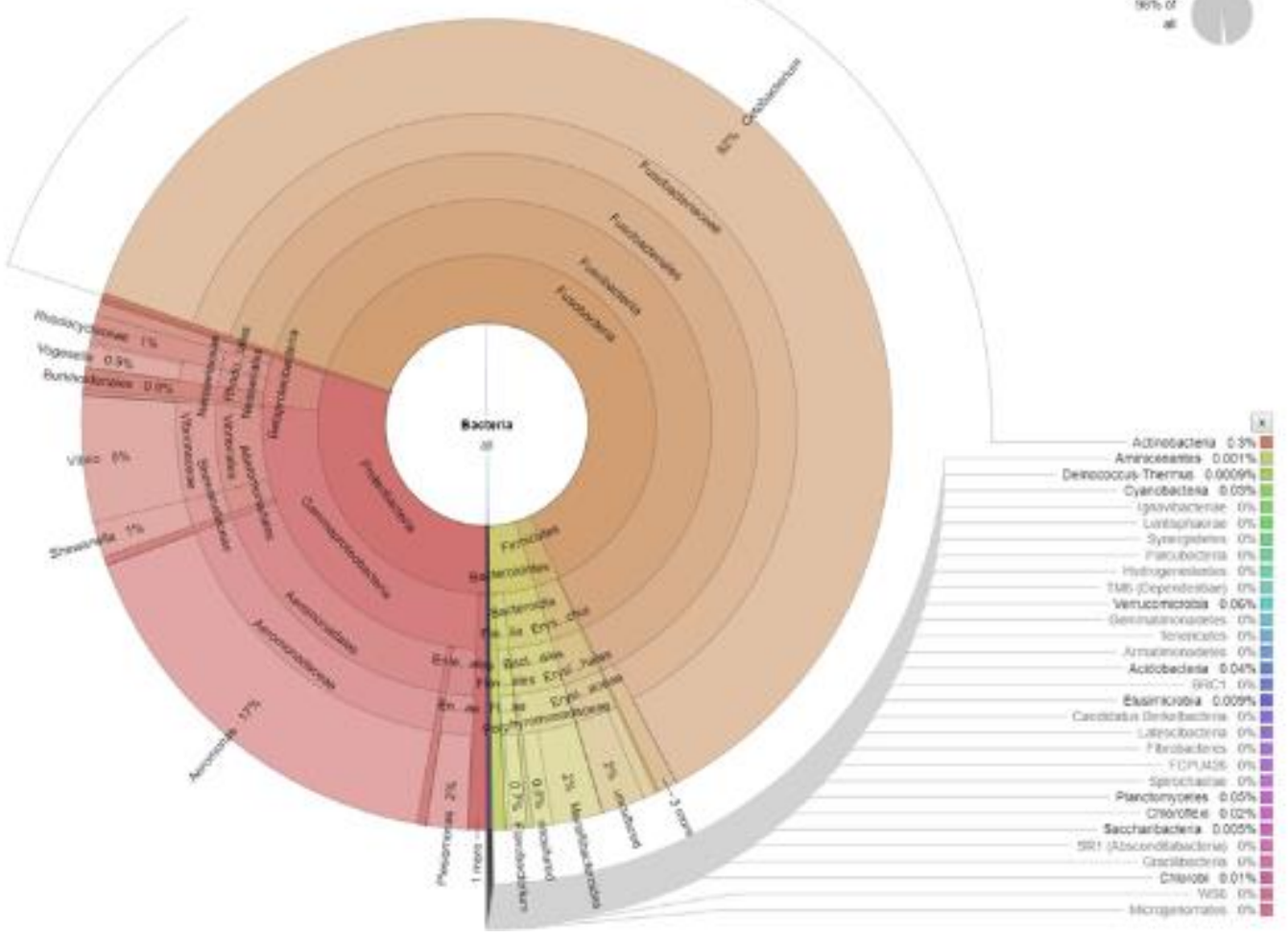



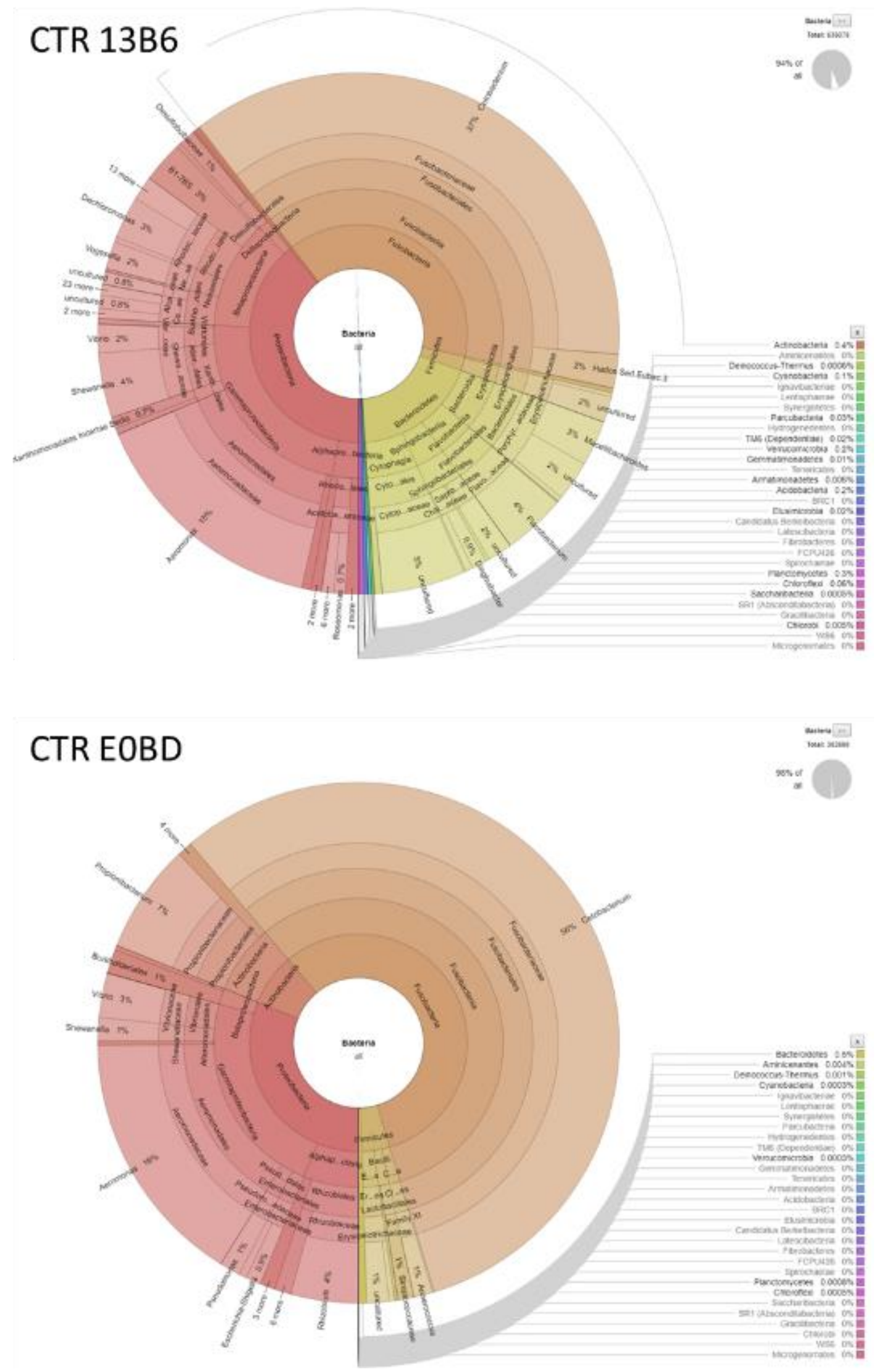

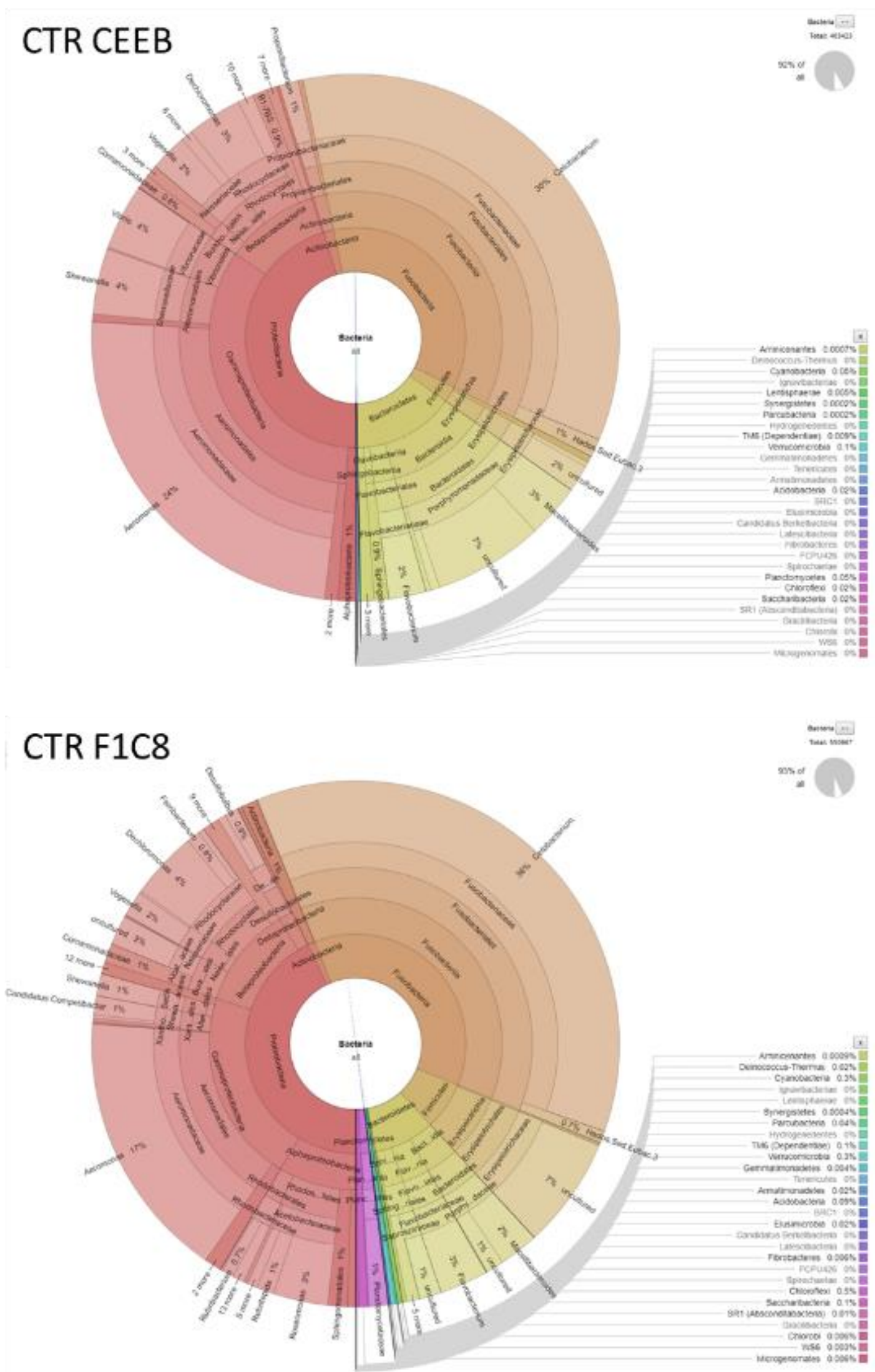

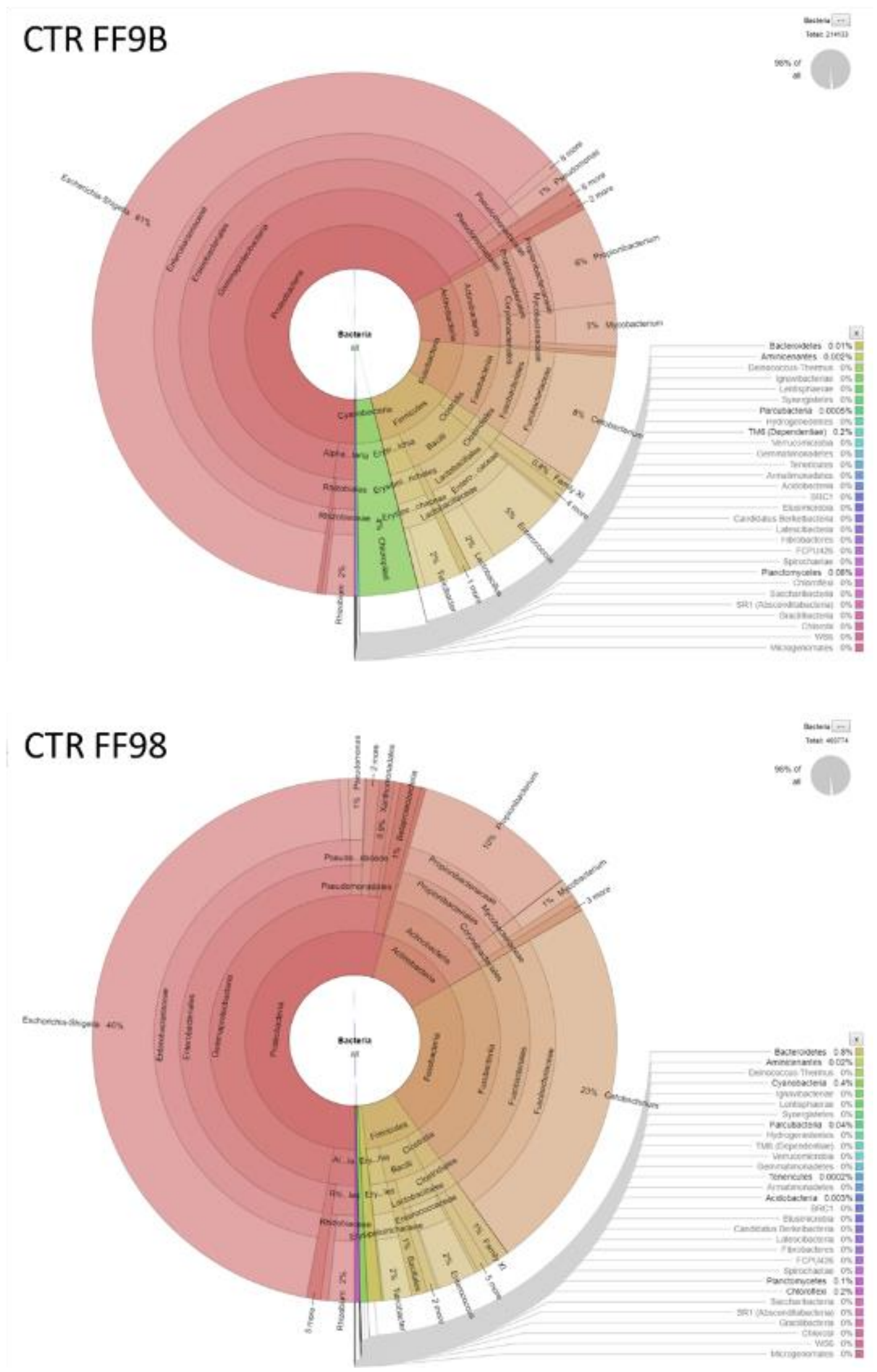

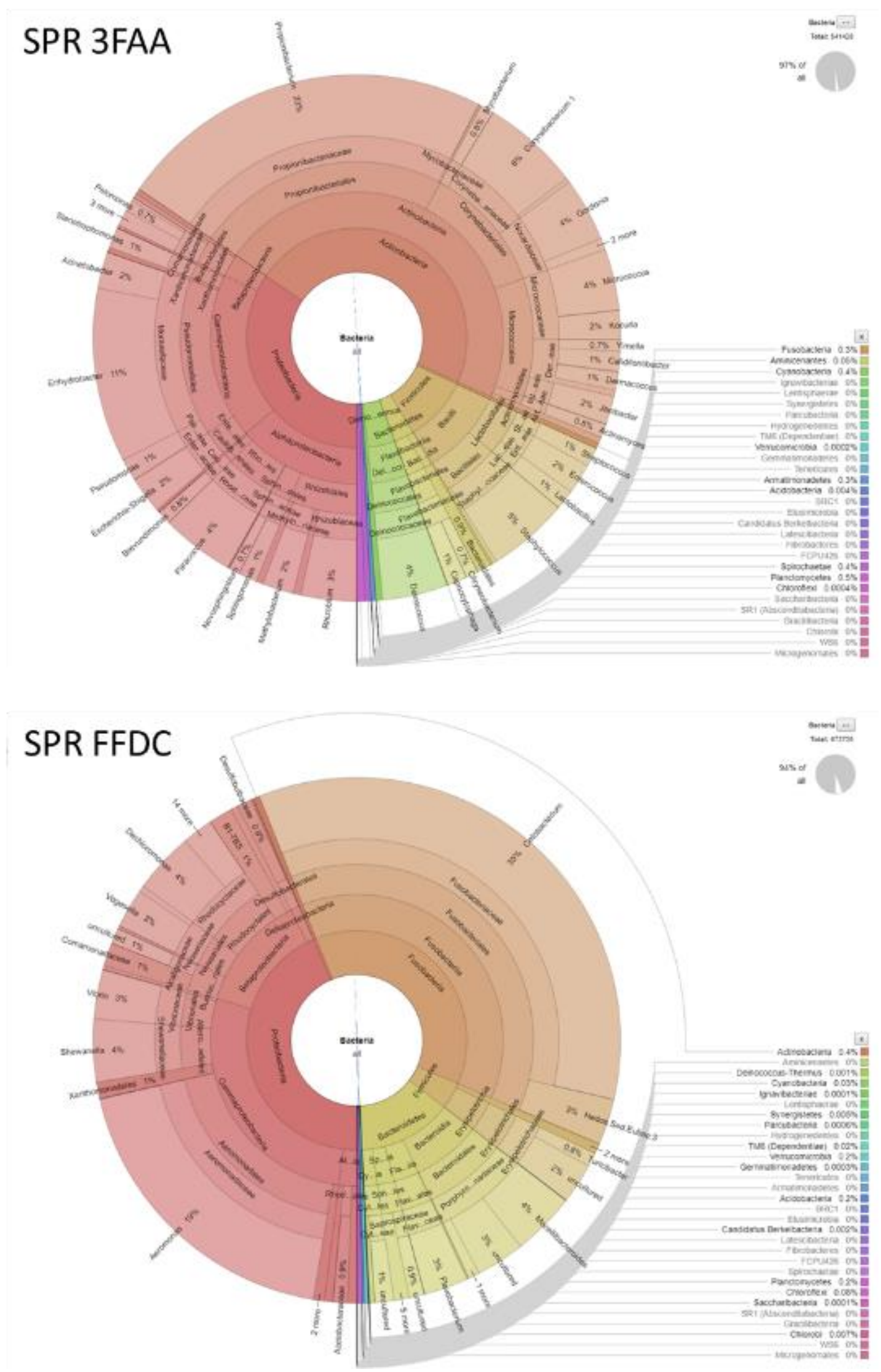

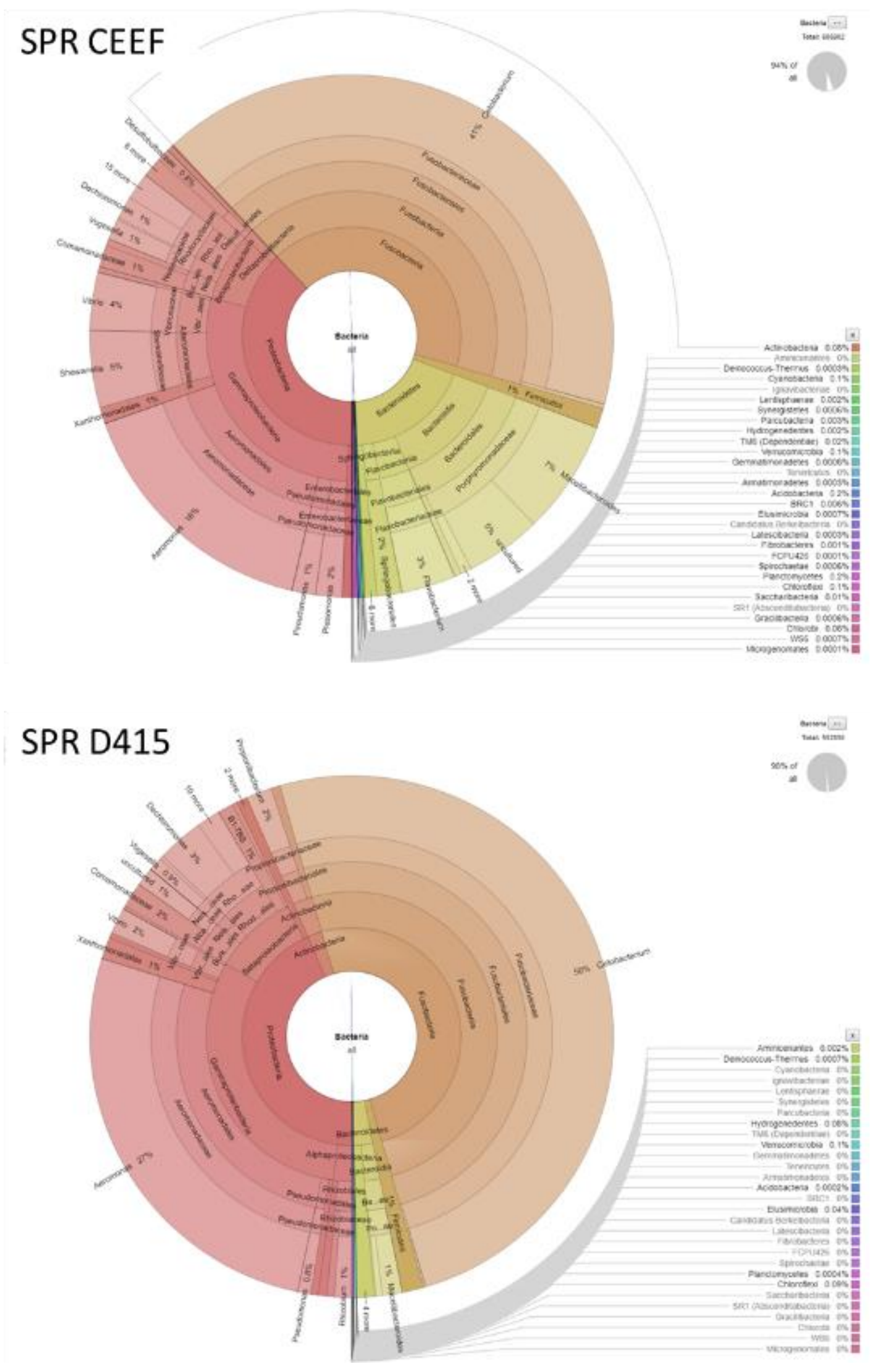

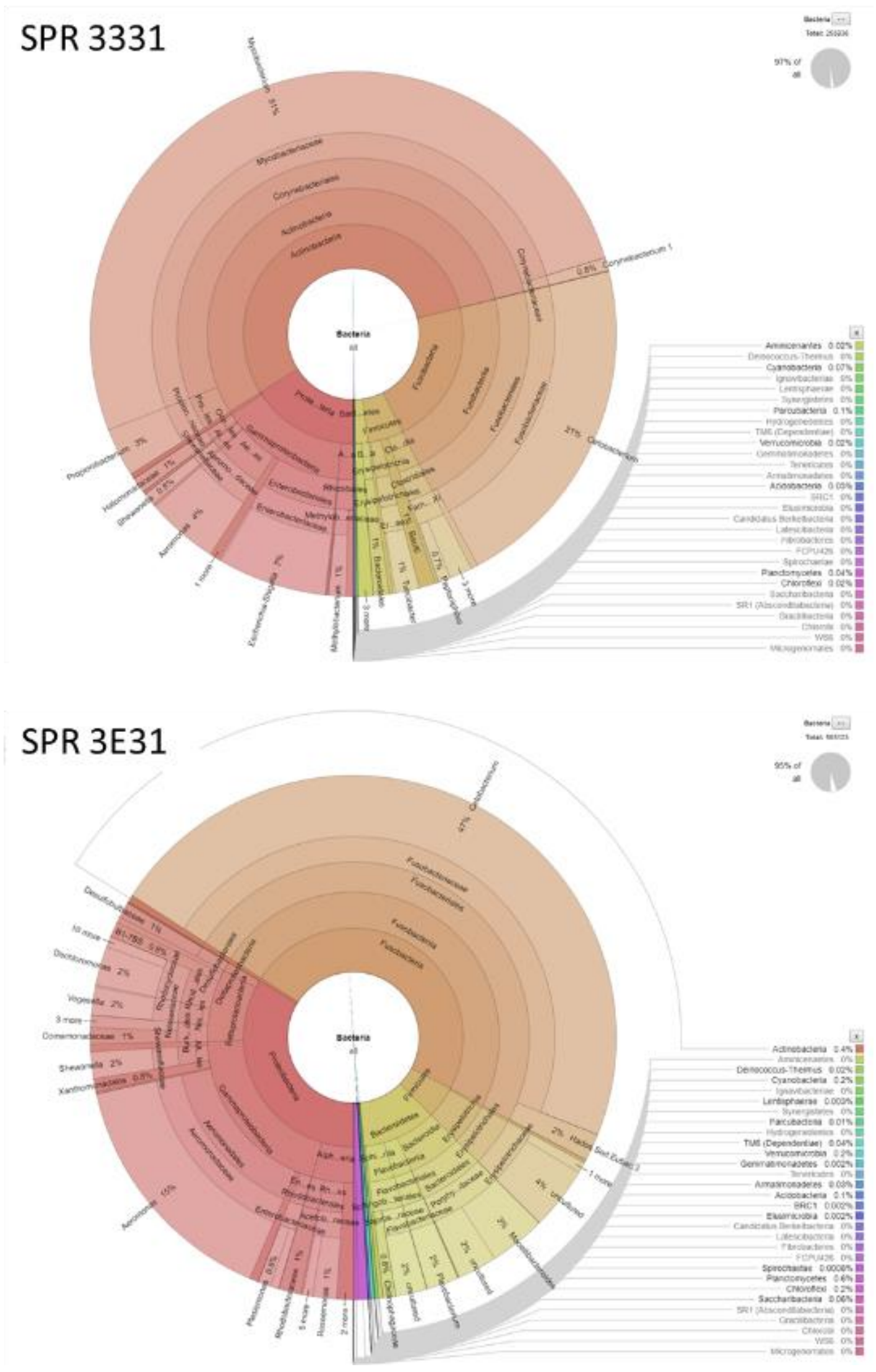

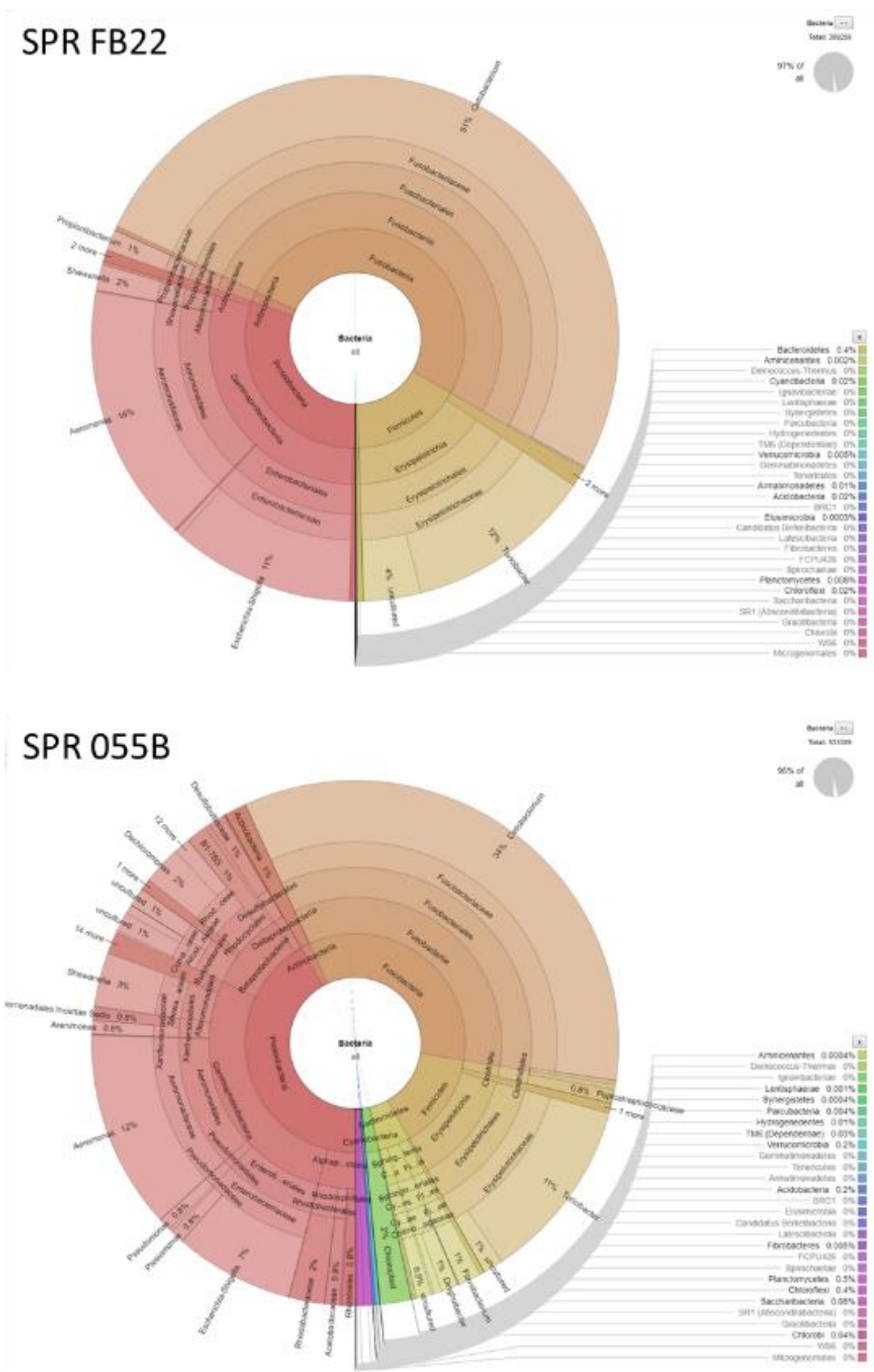


\section{SOFTWARE}

//Sample using LiquidCrystal library

\#include < LiquidCrystal.h>

//select the pins used on the LCD panel

LiquidCrystal $\quad \operatorname{lcd}(8,9,4,5,6,7)$;

// define some values used by the panel and buttons

int lcd_key $\quad=0$;

int adc_key_in $\quad=0$;

\#define btnRIGHT 0

\#define btnUP 1

\#define btnDOWN 2

\#define btnLEFT 3

\#define btnSELECT 4

\#define btnNONE 5

//LEDs pins

int red $\quad=2 ; \quad$ // Pin de conexión del carro de leds rojos.

intGreen $\quad=12 ; \quad$ // Pin de conexión del carro de leds azules.

int $\mathrm{i} \quad=0 ; \quad / /$ pin de conexión del calentador.

int blue $\quad=11 ; \quad$ // Pin de conexión del carro de leds azules.

int laser $\quad=3$; $\quad$ // Termometro pins

int analogtemp $=3 ; \quad$ // Pin de Conexión analogico del sensor de temperatura LM35

int tempmx $=35 ; \quad / /$ Selector de temperatura maxima.

int tempmn $=25 ; \quad / /$ Selector de temperatura minima.

float temp $=0$;

float turb $=0$;

float tempr;

float tempg;

float tempb; // termometro read

int temperatura () \{

temp $=$ analogRead(analogtemp); // lee el valor de tensión del pin returntemp;

\}

// Lectura de los botones del shield LCD

intread_LCD_buttons ()\{

adc_key_in $=$ analogRead(0);

$/ /$ read the value from the sensor

// my buttons when read are centered at these valies: 0, 144, 329, 504, 741 
// we add approx 50 to those values and check to see if we are close

if(adc_key_in > 1000) return btnNONE;

// We make this the 1st option for speed reasons since it will be the most

likely result

// For V1.1 us this threshold

$\begin{array}{lll}\text { if (adc_key_in < 50) } & \text { return } & \text { btnRIGHT; } \\ \text { if }(\text { adc_key_in }<250) & \text { return } & \text { btnUP; } \\ \text { if (adc_key_in }<400) & \text { return } & \text { btnDOWN; } \\ \text { if (adc_key_in }<450) & \text { return } & \text { btnLEFT; } \\ \text { if (adc_key_in }<1050) & \text { return } & \text { btnSELECT; } \\ * \text { / } & & \end{array}$

// For V1.0 comment the other threshold and use the one below:

$\begin{array}{lll}\text { if }(\text { adc_key_in }<50) & \text { return } & \text { btnRIGHT; } \\ \text { if }(\text { adc_key_in }<195) & \text { return } & \text { btnUP; } \\ \text { if }(\text { adc_key_in }<380) & \text { return } & \text { btnDOWN; } \\ \text { if }(\text { adc_key_in }<555) & \text { return } & \text { btnLEFT; } \\ \text { if }(\text { adc_key_in }<790) & \text { return } & \text { btnSELECT; }\end{array}$

$* /$

// when all others fail, return this...

return btnNONE;

\}

voidsetup()\{

\begin{tabular}{|c|c|c|}
\hline lcd.begin & $(16,2)$ & // start the library \\
\hline lcd.setCursor & $(0,0)$ & \\
\hline lcd.print & ("TURBIDEZ"); & // print a simple message \\
\hline Serial.begin & $(960)$ & \\
\hline PinMode & (3, OUTPUT); & //laser \\
\hline pinMode & (11, OUTPUT); & //LEDs Azule \\
\hline pinMode & (12, OUTPUT); & //LEDs Verde \\
\hline pinMode & (2, OUTPUT);/ & /LEDS Rojo \\
\hline
\end{tabular}

\}

voidloop()\{

lcd_key =read_LCD_buttons(); // read the buttons

switch (lcd_key) \{

// depending on which button was pushed, we perform an action

case btnRIGHT: \{

digitalWrite(red, HIGH); // enciende el led rojo

digitalWrite(green, LOW); // enciendo el led verde

digitalWrite(blue, LOW); // enciendo el led azul

digitalWrite (laser,LOW); // encendido laser

delay(500); 


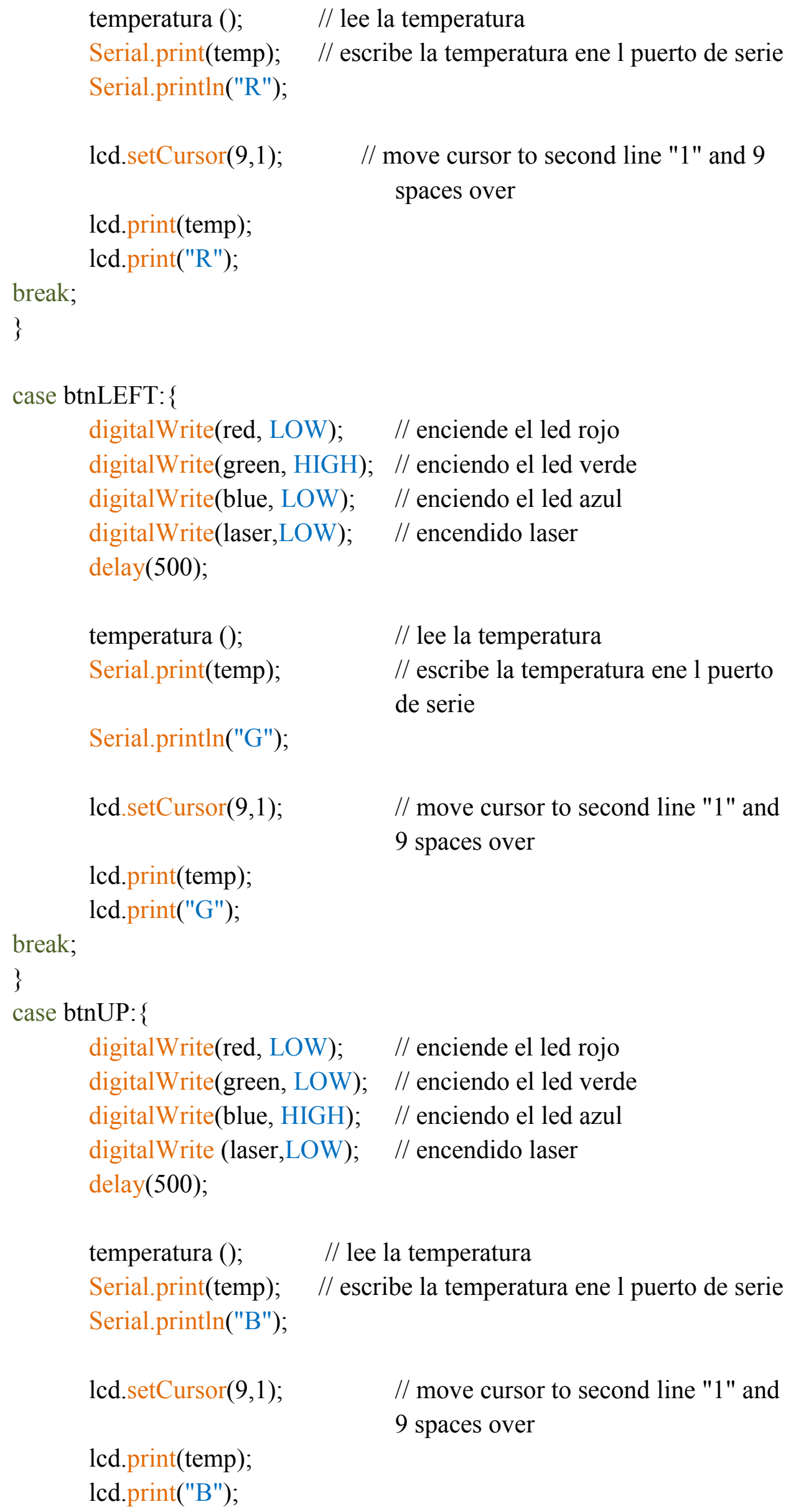


break;

\}

case btnDOWN: \{

digitalWrite(red, HIGH); // enciende el led rojo

digitalWrite(green, HIGH); // enciendo el led verde

digitalWrite(blue, HIGH) ;// enciendo el led azul

digitalWrite (laser,LOW); // encendido laser

delay(500);

temperatura (); / / lee la temperatura

Serial.print(temp); // escribe la temperatura ene l puerto de serie Serial.println("W");

lcd.setCursor $(9,1) ; \quad$ // move cursor to second line "1" and 9 spaces over

lcd.print(temp);

lcd.print("W");

break;

\}

case btnSELECT: \{

digitalWrite(red, LOW); // enciende el led rojo

digitalWrite(green, LOW);// enciendo el led verde

digitalWrite(blue, LOW);// enciendo el led azul

digitalWrite (laser,HIGH);// encendido laser

delay(500);

temperatura (); / le la temperatura

Serial.print(temp); // escribe la temperatura ene l puerto de serie Serial.println("L");

lcd.setCursor $(9,1)$; $\quad$ // move cursor to second line "1" and

9 spaces over

lcd.print(temp);

lcd.print("L");

break;

\}

\} 
